\title{
Unveiling the determinants of scientific productivity in middle-income countries
}

Citation for published version (APA):

Rivera Léon, L. (2021). Unveiling the determinants of scientific productivity in middle-income countries: an economics of science perspective. [Doctoral Thesis, Maastricht University]. ProefschriftMaken. https://doi.org/10.26481/dis.20210610lr

Document status and date:

Published: 01/01/2021

DOI:

10.26481/dis.20210610lr

Document Version:

Publisher's PDF, also known as Version of record

\section{Please check the document version of this publication:}

- A submitted manuscript is the version of the article upon submission and before peer-review. There can be important differences between the submitted version and the official published version of record.

People interested in the research are advised to contact the author for the final version of the publication, or visit the DOI to the publisher's website.

- The final author version and the galley proof are versions of the publication after peer review.

- The final published version features the final layout of the paper including the volume, issue and page numbers.

Link to publication

\footnotetext{
General rights rights.

- You may freely distribute the URL identifying the publication in the public portal. please follow below link for the End User Agreement:

www.umlib.nl/taverne-license

Take down policy

If you believe that this document breaches copyright please contact us at:

repository@maastrichtuniversity.nl

providing details and we will investigate your claim.
}

Copyright and moral rights for the publications made accessible in the public portal are retained by the authors and/or other copyright owners and it is a condition of accessing publications that users recognise and abide by the legal requirements associated with these

- Users may download and print one copy of any publication from the public portal for the purpose of private study or research.

- You may not further distribute the material or use it for any profit-making activity or commercial gain

If the publication is distributed under the terms of Article $25 \mathrm{fa}$ of the Dutch Copyright Act, indicated by the "Taverne" license above, 


\title{
Unveiling the Determinants of Scientific Productivity in Middle-Income Countries
}

\author{
An Economics \\ of Science Perspective
}


C copyright Lorena Rivera Leon, Maastricht 2021

Printing: ProefschriftMaken || www.proefschriftmaken.nl

ISBN 9789464232080

All rights reserved. No part of this publication may be reproduced, stored in a retrieval system or transmitted, in any form or by any means, electronic, mechanical, photocopying, recording or otherwise, without prior permission of the author or the copyright-owning journals for previous published chapters. 


\title{
Unveiling the Determinants of Scientific Productivity in Middle-Income Countries
}

\author{
An Economics \\ of Science Perspective
}

DISSERTATION

To obtain the degree of Doctor at Maastricht University,

on the authority of Prof. Dr. Rianne M. Letschert, rector magnificus,

in accordance with the decision of the Board of Deans,

to be defended in public on

Thursday 10 June 2021, at 16.00 hours

by

Lorena Rivera León 



\section{Supervisors}

Prof. Dr. Robin Cowan

Prof. Dr. Jacques Mairesse

Dr. Moritz Müller

\section{Assessment Committee}

Prof. Pierre Mohnen (Chair)

Prof. Claudia González Brambila (Instituto Tecnológico Autónomo de México)

Prof. Johann Mouton (Stellenbosch University)

Dr. Fabiana Visentin 



\section{Summary}

Science is an important contributor to innovation and economic growth. While the production of scientific knowledge is a complex process, there is a lack of economic research concerning the organization of scientific activities and a need to expand the empirical evidence in the economics of science field to better understand the different forces at play in the production of scientific knowledge as well as its impact.

This thesis aims to understand the role of scientists and scientific communities in the process of knowledge creation by looking at scientific productivity, its determinants and effects at the individual level, and the macro level, in the context of Middle-Income Countries (MICs). It uses a quantitative econometric approach anchored in the economics of science literature and is conceptually largely informed by social network theory.

The thesis investigates the role and effects of different determinants on scientific productivity: cognitive proximity - notably gender and ethnicity, status homophily, organizational proximity, social and community structure, and access to foreign knowledge and international collaboration networks. We use four empirical chapters to understand the role and effect of these determinants on scientific productivity in-depth. For doing so, we use two-novel datasets of researchers of the National Research Foundation (NRF) of South Africa and the National System of Researchers (SNI) of Mexico and their scientific production.

Chapter 2 investigates the determinants of scientific productivity using a network theory perspective and focuses on South Africa as a particular case. The chapter looks at the different factors associated with tie formation (the first collaboration between co-authors) and tie persistence (second and subsequent collaborations) affecting collaborative scientific research. Four different sets of factors are analyzed in detail: cognitive proximity (1); status homophily (2); organizational proximity (3); and social and community structure (4). The results show that different factors are associated with each type of collaboration. Collaborations happen for the first time among researchers that are well connected and close to each other, have high cognitive and organizational proximity, and are part of the same social communities. In contrast, little seems to matter apart from social structure and organizational proximity to make a collaboration persist over time. We also find that researchers are more likely to collaborate for the first time with others of the same ethnicity and are more likely to make the collaboration persist over time with others of the same gender.

Chapters 3 and 4 aim to understand the role that gender plays on researchers' scientific productivity and shed light on the reasons and consequences of existing inequalities in scientific 
performance at the individual and aggregate academic system levels in Mexico (Chapter 3) and South Africa (Chapter 4). We show that collaboration characteristics, probabilities of promotion, selectivity, and initial productivity account for differences in scientific productivity. Other factors, such as the quality of the research and institutional affiliation (Chapter 3), also explain the different magnitudes of gender productivity gaps. Chapter 4 shows that race plays a more important role than gender in explaining productivity gaps in South Africa and suggests the existence of a race productivity gap.

The results of both empirical applications in Mexico and South Africa show that women are marginally less productive than men or as productive as men, particularly when the research output is weighted by the quality of the outputs (Chapter 3). Moreover, female researchers are underrepresented in the highest seniority levels and have fewer chances than men to be promoted in their academic careers. However, once we control for other factors, notably promotion, we find that the gender productivity gap favors women. We also show that significant individual and system-wide productivity increases for both females and males (but notably females) could be achieved by controlling for selectivity and promotion. Eliminating promotion biases would result in the largest increase in aggregate scientific productivity.

Chapter 5 analyzes how access to foreign/international knowledge through education and training affects scientific productivity. Firstly, we look at how foreign training affects the career of the researcher itself (impact-on-self). Secondly, we look at the 'outward' effects of foreign training by analyzing how it influences the researchers' position in international collaboration networks and facilitates the diffusion of knowledge nationally and internationally (impact-on-others). We find that foreign-educated researchers play an important role as conduits of knowledge to the scientific community at large and have a central role in the domestic upgrading of their academic fields. However, we also find that the degree's origin becomes irrelevant at higher seniority levels as locallytrained researchers are equally well connected internationally. Moreover, this increased connectedness comes with a cost. We find that foreign-educated researchers have fewer probabilities of promotion to higher academic ranks relative to their nationally-trained peers when controlling for endogenous sample selection. 
To mom, Filip, Frida, and Felix 



\section{Acknowledgements}

I write this about nine years after I started my PhD journey at UNU-MERIT in 2011. I will not lie. This journey has been a mix of ups and downs, successes and failures. I have felt at the top high academically and in a dark hole all at the same time. I believe that all of what I have grown and learned over the past nine years are the bricks and walls that hold me academically and professionally nowadays.

There are so many people I should acknowledge.

First of all, I want to thank the Mexican National Council for Science and Technology (CONACYT) for their financial support during the first years of my research journey.

My most extensive gratitude goes to my supervisors and co-supervisor: Prof. Dr. Robin Cowan, Prof. Dr. Jacques Mairesse, and Dr. Moritz Müller.

I still remember the day Jacques came to see me in the PhD students' office at UNU-MERIT. In perspective, that day truly changed my academic life. He introduced me to gender economics, which has shaped my personal and research interests over the past years. I was fortunate to travel with him to South Africa and Mexico to present and discuss our research. He also introduced me to so many outstanding academics and researchers around the world. I admire you so much, Jacques. Not only for your contribution to science but also for your simplicity, flexibility, and openness to share ideas.

One could best characterize my relationship with Robin as a roller-coaster ride. He pushed me always to deliver excellence and challenged me theoretically, methodologically, and personally all these years. He was patient with me but also pushy. Persistence, perseverance, and quality are skills I learned from you, and that, without a doubt, makes me different from my peers. I will be forever grateful that you pushed me to surpass what I thought were my limits. Thanks for everything Robin.

Thanks also to my co-supervisor, Dr. Moritz Müller, who patiently listened to me, dug into my work, and then showed me how to do things ten times better. Thanks a lot for your time, and constructive comments.

My gratitude also goes to Prof. Pierre Mohnen, Prof. Johann Mouton, Prof. Claudia González Brambila, and Dr. Fabiana Visentin for accepting to be part of the reading committee and for your insightful comments. Thank you for your time. Your research has been a source of inspiration, and I feel honored to have you as my reviewers.

I also want to thank Michele Pezzoni, whom I met through Jacques. Thanks for the research sessions we had in Paris and at EPFL in Switzerland. I enjoyed your openness, your pragmatism, and your humor. I hope we can continue working together in the future. 
My time at Maastricht was brief but sweet. At UNU-MERIT, I want to thank first and foremost Eveline for all her help and emotional support. I am also grateful to all the staff for their assistance and help, notably to Ad, Howard, and Mourik-Jan.

To my paranymphs and dearest friends Charlotte and Simone, for all the laughs, sleepless nights, trips, parties, phone calls, and memories. Thanks for being there for me. Just for meeting you, this whole experience is priceless and worth it. Thanks, Simone, for co-authoring Chapter 5 with me. It is great to see what we managed to do together out of those initial ideas we had years ago. Thank you also, Andi, Julieta, Josy, Fernando, Andrés, and Tashmia, for your friendship and for making Maastricht much more exciting and fun.

I wrote a good part of this thesis in Brussels. I want to thank my former boss and friend Alasdair Reid for his unconditional support during the first years of my research and to my friends Christine, Helen, Miriam, and Griet for your emotional support. In Geneva, my thanks go to my colleagues at the World Intellectual Property Organization (WIPO), notably Intan and Alica, for constantly checking up and pushing me to get this done. I finished this thesis thanks to Alica's great advice of doing at least 30 minutes of research a day when my workload at WIPO was keeping me distracted. You were right. I got this done in a bunch of 30 minutes altogether.

I also want to say thank you to Vero, who held my hand in my lowest moments, when I felt burnout, unable to write anymore and when I almost quit. In her very unique way, she managed to get me back on track to the point of no return. Thanks, my dear friend, for inspiring me since the very first day $I$ met you.

Filip, my husband, is, without doubt, the one that has carried most of the weight in the past years. Working full-time, always on the side, raising our young children -Frida and Felix, while doing my thesis put so many strains on our relationship and family life. I often felt I was failing on all fronts, family-wise, professionally, and academically. With his usual sense of humor and joy for life, Filip has always been there for me. He never questioned my choices, but rather, he provided all his support and took over large shares of responsibility towards our children during these years. People say that women marry their glass ceilings. I am fortunate to have Filip by my side. Filip is responsible for all the emotional effort that kept our family and me going over all these years. I will be forever grateful for your unconditional support.

And finally, to my mom: María del Carmen. She has been my inspiration all my life. She raised my brother and me as a single mom. In a family with limited financial resources, she did not have access to higher education herself. My mom had to work hard all her life. She gave all her energy and resources to provide my brother and me with the best education. I am proud to be the first (woman) in my family with a Doctoral degree. She is responsible for allowing me to push the glass ceiling in the family a bit higher 
up. I hope to be able to show my daughter, just as my mom did, that there are no limits to a woman's dreams. That she can become anything, she dreams. Gracias, mamá, for making us a priority throughout your life.

Geneva, Switzerland, May 2021 



\section{Table of Contents}

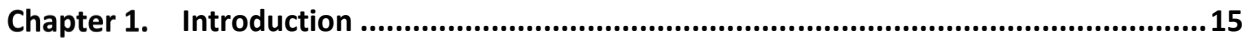

1.1. The determinants of scientific productivity in Middle-Income Countries............................. 17

1.2. An economics of science perspective to understand the determinants

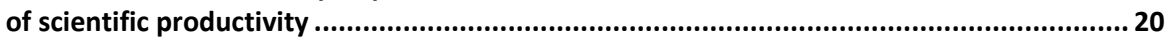

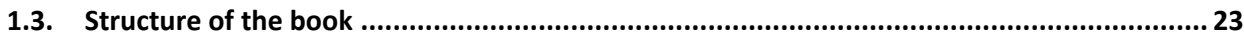

Chapter 2. Unveiling the determinants of scientific collaboration and persistence - a network analysis perspective ................................................................2 27

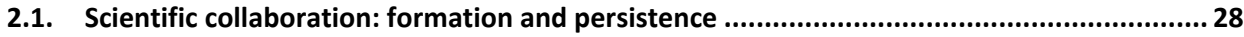

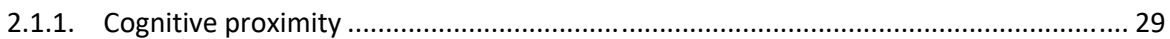

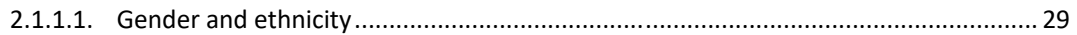

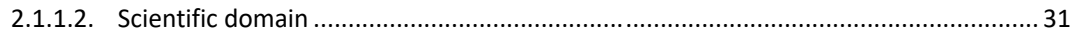

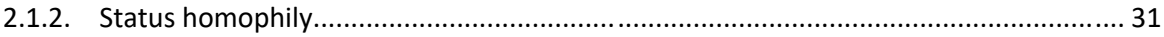

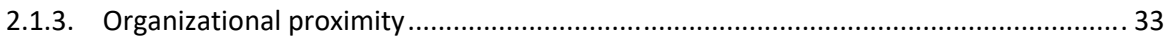

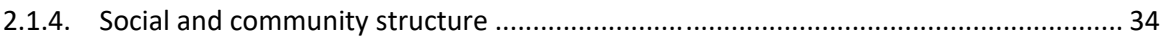

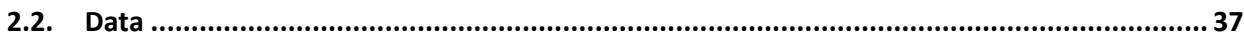

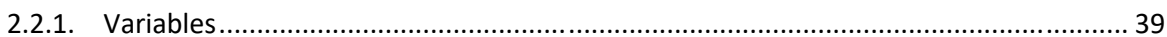

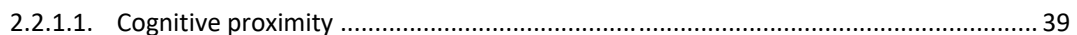

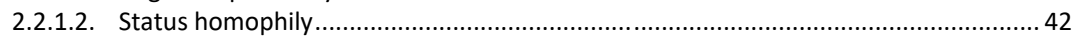

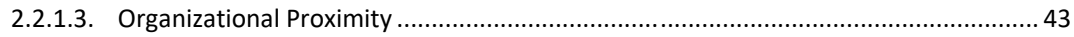

2.2.1.4. Social and community structure.......................................................................... 45

2.2.1.4.1. Membership to Network communities ........................................ 46

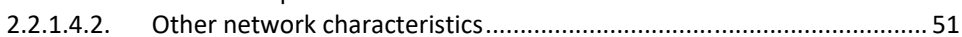

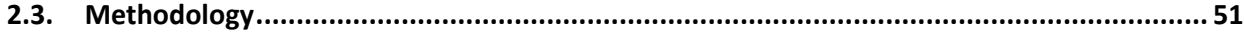

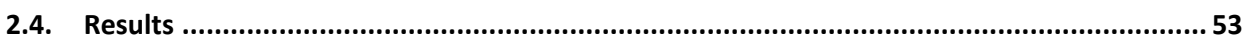

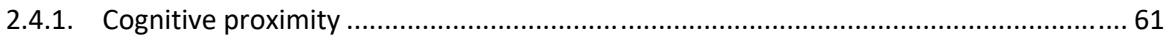

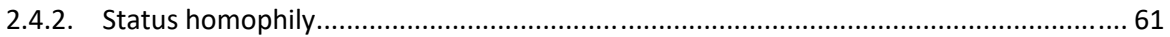

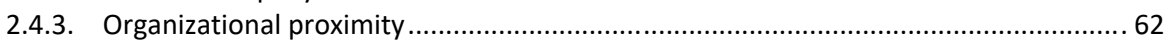

2.4.4. Network structure and social communities ................................................................ 62

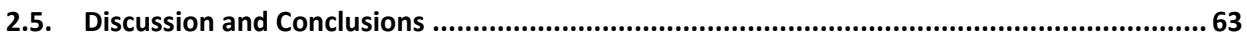

Chapter 3. Micro and Macro effects of Gender Publication Productivity Gaps in Middle-Income Countries: an illustration for Mexico ..................................67

3.1. Understanding the determinants of the gender productivity gap.........................................68

3.2. The Mexican Science and Research context and the National

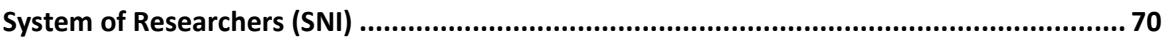

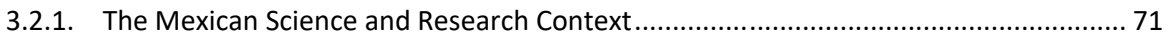

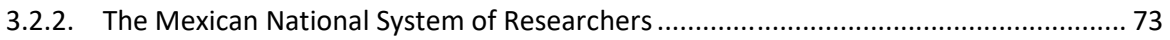

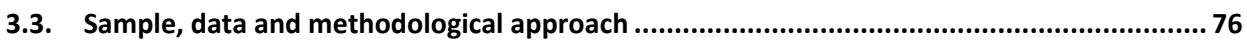

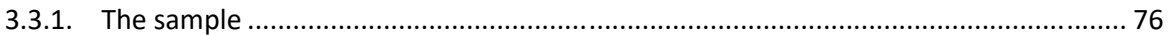

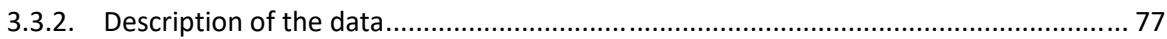

3.3.3. Methodological approach: econometric panel data analysis at

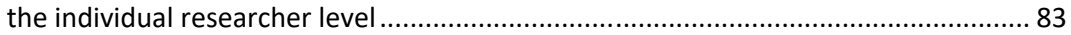

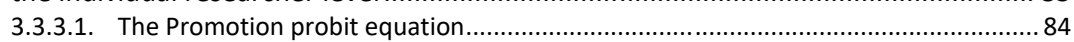

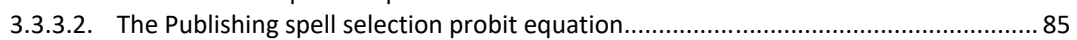

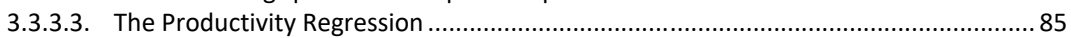




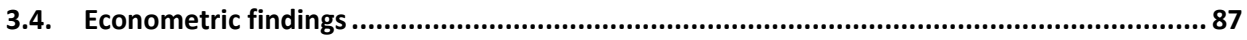

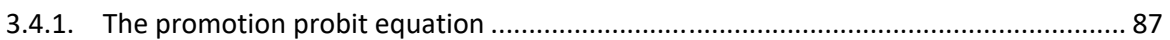

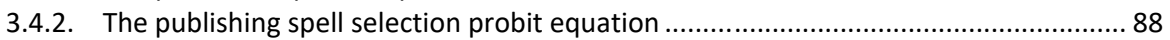

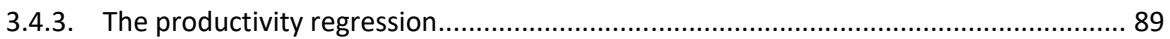

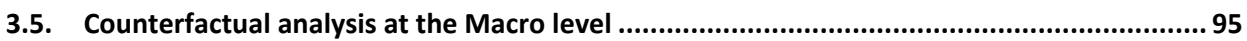

3.5.1. Policies and initiatives focusing on decreasing gender gaps in the

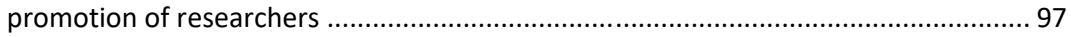

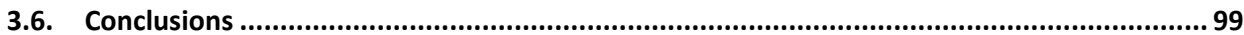

Chapter 4. A continuation for South Africa: Micro and Macro Effects of gender productivity gaps and their interaction with ethnicity ...................103

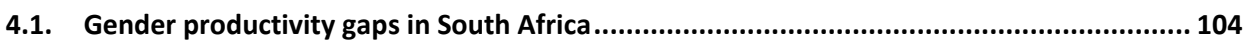

4.2. Understanding the National Rating system of Researchers of the

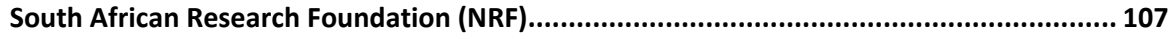

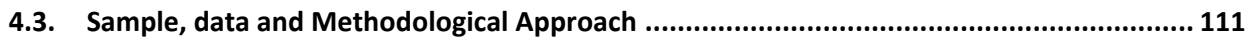

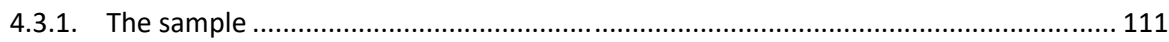

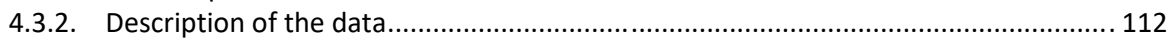

4.3.2.1. Descriptive statistics of publication productivity by gender ................................... 114

4.3.2.2. Descriptive statistics of promotion of NRF researchers .......................................... 116

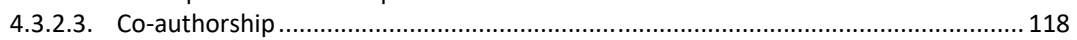

4.3.3. Methodological Approach - A continuation for South Africa ................................... 120

4.3.3.1. Micro-Level Analysis ........................................................................................... 120

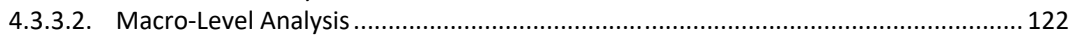

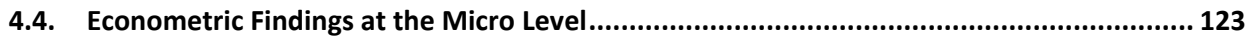

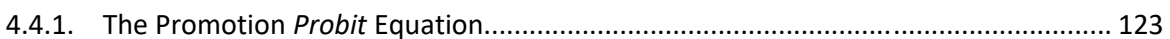

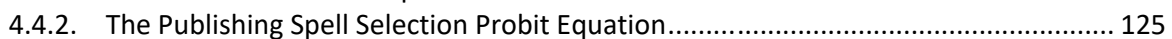

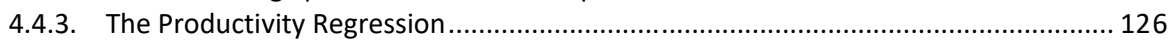

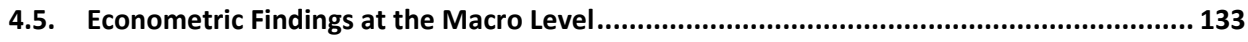

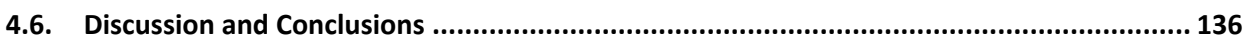

Chapter 5. Access to international knowledge and its impact on academic upgrading in Mexico ............................................................ 141

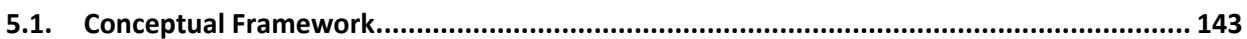

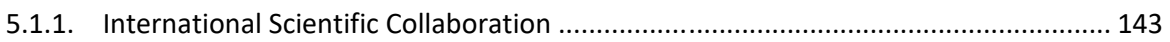

5.1.2. Access to foreign knowledge and scientific upgrading in

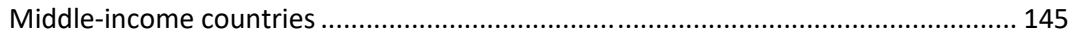

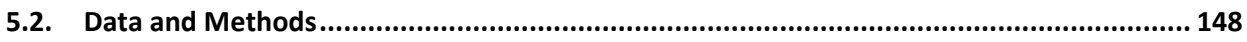

5.2.1. The gatekeeping function of foreign-educated researchers...................................... 150

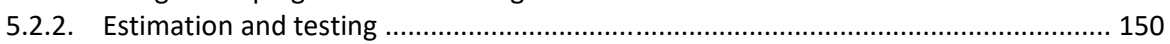

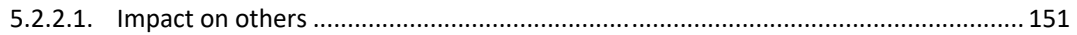

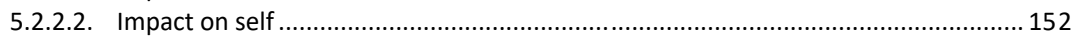

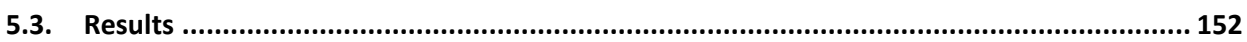

5.3.1. The role of foreign training and education in the Mexican science system ............... 152

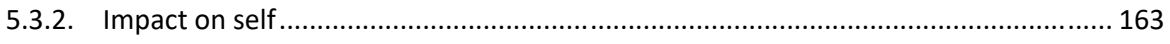

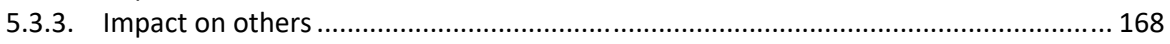

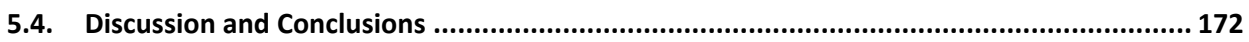




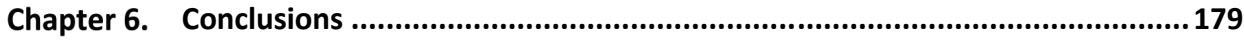

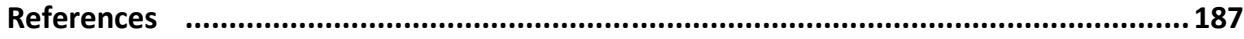

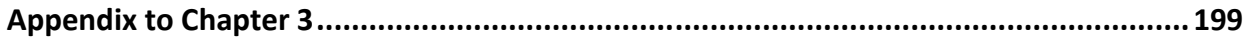

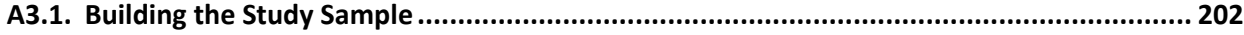

A3.2. Detailed Analysis of the Contribution of the Selectivity and Endogeneity

Correction in Accounting for the Gender Productivity Gap............................................. 205

Impact

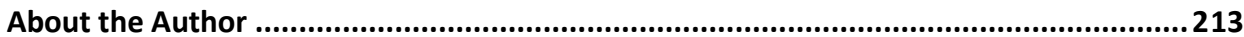




\section{Figures}

Figure 2.1 Number of publications of the co-authors (sum of $i$ and $j$ ):

Tie formation vs. Tie persistence

Figure 2.2 Boxplots of the average number of co-authors by partition (size larger than 20 members) obtained using the Fastgreedy algorithm on the 2010 co-authorship network.

Figure 3.1 Distribution of Observed Weighted Log-productivity for Female and Male SNI Researchers Affiliated with Public Universities and Public Research Centers

Figure 3.2 Distribution of Weighted Predicted Log-productivity for Representative Female and Male SNI Researchers Affiliated with Public Universities and Public Research Centers

Figure 3.3 Change with Age of Estimated Log-productivity for Representative Female and Male SNI Researchers Affiliated with Public Universities and Public Research Centers

Figure 4.1 Distribution of Observed Log-Productivity for Female and Male, NRF researchers by ethnicity.

Figure 4.2 Distribution of predicted log-productivity for the representative female and male, white and non-white NRF researcher, with the corrections for endogeneity and selectivity

Figure 4.3 Change with Age of Predicted productivity for representative Female and Male NRF Researchers by Ethnicity

Figure 5.1 SNI level shares (2013) by latest academic degree received and origin of training

Figure 5.2 Boxplot of the share of foreign co-authors among all co-authors. 156

Figure 5.3 Network graph of SNI co-authors 160

Figure 5.4 Simplified network of co-authorships by SNI level and degree origin 161

Figure 5.5 Estimated density of QAP replications, correlation between same degree origin and research collaboration 


\section{Tables}

Table 2.1 Tie Formation and Persistence by scientific field of co-authorships.

Table 2.2 Tie Formation and Persistence among co-authors of main institutional affiliations of NRF rated researchers

Table 2.3 Basic statistics on community algorithm results applied on the year 2010 network (2000-2009).

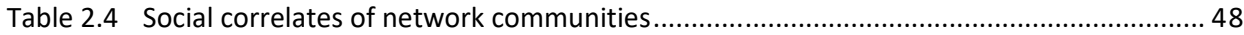

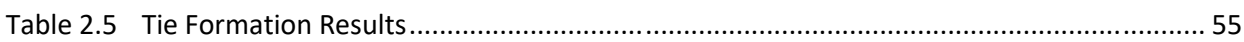

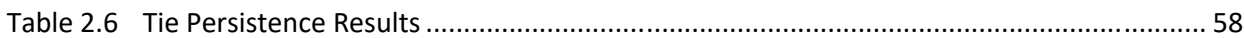

Table 3.1 Number and Proportion of Female and Male Researchers in Public Universities and Research Centers in Two Age Groups and Low and High Ranks in 2013.

Table 3.2 Descriptive Statistics on Average Unweighted Publication Productivity for Female and Male Researchers in Public Universities and Research Centers, Including and Excluding Non-publishing Years.

Table 3.3 Descriptive Statistics on Average Unweighted Log Publication Productivity for Female and Male Researchers in Public Universities and Research Centers, for Different Average Impact Factor Levels

Table 3.4 Proportion of Non-publishing Years for Female and Male SNI Researchers in Universities and Research Centers, in Two Age Groups and Low and High Ranks

Table 3.5 Promotion from Low Ranks to High Ranks by Affiliation and Gender

Table 3.6 Gender and Affiliation of SNI Co-authors, Share of Total (multiple choice allowed).

Table 3.7 Promotion Probit Equation for SNI Researchers Affiliated with Public Universities and Public Research Centers, with and without Age*Gender Interactions

Table 3.8 Publishing Yearly Selection Probit Equation for SNI Researchers Affiliated with Public Universities and Public Research Centers, with and without Age*Gender Interactions

Table 3.9 Productivity Equation for SNI Researchers Affiliated with Public Universities and Public Research Centers, with and without Gender Interactions

Table 3.10 Observed and Predicted (Weighted and Unweighted) Publication Productivity, Individual and System Gains.

Table 3.11 Summary Results of Individual and System Gains Based on Simulation of Different Scenarios

Table 3.12 Number of Male and Female Members on the SNI Disciplinary Committees, 2015-2016.

Table 4.1 Definitions of NRF research ratings.

Table 4.2 Number and proportion of female and male, white and non-white researchers in two age groups and Low and High ranks in 2011.

Table 4.3 Descriptive statistics on average publications per year for female and male, white and non-white researchers, including and excluding non-publishing years 
Table 4.4 Proportion of Non-publishing years for Female and Male NRF researchers, White and Non-white researchers, in Two Age Groups and Low and High Ranks........... 116

Table 4.5 Promotion from Low Ranks to High Ranks by Ethnicity and Gender .............................. 117

Table 4.6 Changes from No Ranks to Low Ranks and High Ranks by Ethnicity and Gender............ 118

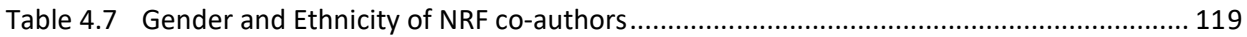

Table 4.8 Promtion Probit Equation for NRF Researchers by ethnicity, with and without Age * Gender Interactions.....

Table 4.9 Publishing Yearly Selection Probit Equation for NRF researchers by ethnicity, with and without Age*Gender Interactions.

Table 4.10 Productivity Equation for NRF Researchers by Ethnicity, with and without

Gender-Age Interactions

Table 4.11 Productivity Equation for NRF White Researchers, without and with corrections

Table 4.12 Productivity Equation for NRF Non-White Researchers, without and with corrections

Table 4.13 Summary results of individual and systems gains based on simulation of different scenarios

Table 5.1 Average number of WoS publications and weighted average 5-year Impact Factor by SNI level and origin of academic degree, 2008-2013.

Table 5.2 Average number and standard deviation of WoS publications by scientific discipline and origin of academic degree, 2008-2012.

Table 5.3 Number of publications and number of (foreign, unique foreign) listed co-affiliations within the five-year period before the rating (2008-2012), mean.

Table 5.4 Average number of co-authors by SNI level and origin of academic degree.

Table 5.5 Average number of co-authors by the origin of co-author and SNI level, discipline, and origin of the latest academic degree.

Table 5.6 Gatekeeping and External Weight scores by SNI level, mean and standard deviation, 2008-2012.

Table 5.7 Gatekeeping and External Weight scores by origin of latest academic degree, mean and standard deviation, 2008-2012.

Table 5.8 Average distance among researchers with Mexican and foreign degrees, reachable pairs

Table 5.9 Impact on self. Ordered probit regressions of SNI level with and without the predicted probability of foreign academic degree.

Table 5.10 Average marginal effects on the probability of being in a certain SNI level in 2013 ....... 167

Table 5.11 Impact on others, Average Treatment Effect. Regressions with endogenous treatment effects.

Table 5.12 Impact on others, Average Treatment Effect of Average Reach, and External Weight. Regressions with endogenous treatment effects on the separate components of the gatekeeping index.

Table A3.1 SNI's Managing Authorities, Composition, and Main Responsibilities 
Table A3.2 Definitions of SNI Levels

Table A3.3 List of Mexican Public Universities Covered in the Analysis ............................................ 200

Table A3.4 List of Mexican Public Research Centers Covered in the Analysis ................................... 201

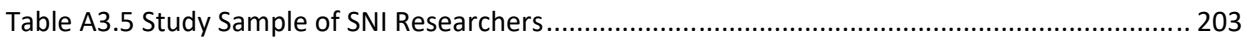

Table A3.6 Population of SNI Researchers in 2013 by Discipline and Corresponding Sample Obtained through Publication Matching with Web of Science (WoS) Data...... 204

Table A3.7 Productivity Equation for SNI Researchers in Public Universities, without and with Corrections

Table A3.8 Productivity Equation for SNI Researchers in Public Research Centers, without and with Corrections 



\section{Chapter 1. Introduction}

In The Economics of Science, Paula Stephan reminds us why economists give much attention to science. First and foremost, science is a source of economic growth. Second, there is a need to understand better scientific labor markets and the human capital within scientists in such labor market. Third, the current scientific reward system (e.g. one that gives recognition for the priority of discovery and provides compensation and financial remuneration for the contribution to science) has largely solved the appropriability problem that knowledge carries from being a public good, which also merits attention.

Science is an important contributor to innovation and economic growth (Stephan, 1996). This relationship is however, complex, with technology often bridging innovation and growth. Many theories have tried to explain what drives knowledge creation in the context of innovation and technical change.

What is the link between scientific research and economic growth? This relationship was first articulated by Adam Smith (1776). Smith's main contribution to economic growth theory was his emphasis on capital accumulation and the division of labor as the factors that determine countries' economic growth. In his fourth definition of capital, he refers to the acquisition of talents, education, study, or apprenticeship, as capital in (a) person, and that these talents are part of a person's fortune and that of society (Smith, 1776).

In the 1950s, the work of Robert Solow on economic growth resulted in the formulation of growth accounting and the uncovering of the "residual" (Solow, 1957). Solow demonstrated that the residual is the share of economic growth that cannot be explained by increasing physical production factors, such as capital, labor, etc. Something else, in addition to physical capital accumulation was responsible for a large share of growth. Human capital was this "something else" responsible for explaining much of the residual -or knowledge creation and increasing the labor input through education and training (Goldin, 2016).

Endogenous growth models later considered knowledge and creating knowledge as important parts of the production process. Research and development (R\&D) was then included as a variable affecting endogenous technological change in the extended endogenous growth models of Romer (1986, 
Romer, 1987, Romer, 1994). Romer's new growth theory hypothesizes that knowledge spillovers are a source of long-term growth and that these spillovers are set in motion endogenously through market operations. This is where Romer's idea of the 'research enterprise' comes in place. In the market, firms engage in $R \& D$ intending to make profits. This $R \& D$, in turn, is appropriated by other firms, creating increasing returns to scale and long-term growth (Stephan, 1996).

Stephan (1996) argues that the extent to which one can argue that research in the academic sector is an important component of long-term growth depends on whether scientific research in the academic sector is endogenous and set in motion by profit-seeking behavior. She argues that there are at least five aspects that make academic research have an endogenous element (Stephan, 1996):

1. Academic research is supported by private sector firms seeking profits, and this support is growing;

2. Academic research often answers questions to industry problems;

3. Markets drive technology development, and conversely, technology affects science directly;

4. The public sector funds large parts of academic research, and the levels of funding are often linked to the wealth of the economies in question; and

5. Salaries and the employability in the different academic fields largely determine the number and quality of scientists and human capital available in science.

Nevertheless, what is the link then between academic research and economic development and upgrading? New growth theory also emphasizes the importance of investments in human capital and the potential gains of technology transfer from developed to developing countries (Ucak, 2015). Knowledge transfer and spillovers are central to how science relates to economic development, especially given the characteristics of academic systems in Middle-Income Economies (MICs).

Interest in the economics of science has grown recently, as Higher Education Institutions (HEIs)' role in stimulating innovation and growth has attracted more policymakers worldwide. Academic research activity plays a central role in the production of scientific knowledge. Scientific publications are a necessary step in establishing the scientific priority of discovery (Stephan, 1996). They are probably the most important measure of research productivity within the existing reward structure of science.

In the last decades, there have been important changes in academic knowledge production, particularly regarding the organizational structure of higher education institutions and public research centers, and in the financing and development of scientific knowledge. In line with these changes, there is increasing importance attached to collaboration in the process of knowledge creation: knowledge production no longer depends on isolated interests of inventors and scientists (if it ever did), but it depends on and is a result of the exchange and free circulation of knowledge among different actors. This 
has implications for the spatial diffusion of knowledge, both locally and globally. Thus, it is central to understand the characteristics of knowledge creation patterns, and the rigidity of the interactions at micro, meso, and macro levels that hinder or facilitate the creation and diffusion of knowledge.

There is also more and more interest in understanding the determinants of collaboration and research outputs at individual and collective levels (i.e., departments, universities, and countries). Understanding these determinants can help design research policies focusing on boosting the quality and quantity of publication outputs.

The production of scientific knowledge is a complex process. Economists have argued for the need to rethink the ways we study the careers of scientists. As Carayol and Matt (2006) contend, there seems to be a lack of economic research concerning the organization of scientific activities, especially compared to the amount of economic literature available that aims to understand innovation processes. ${ }^{1}$

Stephan (1996) suggests that scientists could benefit if economic models drew more inspiration from empirical work in industrial organization. Attainment of a critical mass within a given time frame and past success are essential in determining the productivity and continuous success of researchers, in a very similar way as firms manage to survive and grow in markets.

Thus, there is a need to expand the empirical evidence in the economics of science to better understand the different forces at play in the scientific knowledge production and its impact.

\subsection{The determinants of scientific productivity in Middle-Income Countries}

So, what is particular about science and science systems in MICs? Typical science systems in MICs have scarce resources for research; governments are the main funders of the research system, access to knowledge is limited, publication policies are different than in the developed world, there is limited scientific infrastructure, the local research priorities may differ from global concerns, and so on.

MICs usually have an underdeveloped local capacity base, and they rely largely on external sources of knowledge and technology for productivity growth. However, Bell and Pavitt (1993) argue that economic upgrading is not guaranteed by the simple diffusion of knowledge involving the acquisition of capital and the processing of know-how. In the context of developing countries, they distinguish two stocks of resources: technological capabilities, or the skills, knowledge, and institutions that allow a country to generate change in the technologies and knowledge it uses; and the country's production

\footnotetext{
${ }^{1}$ The authors argue that the research questions addressed in the innovation economics literature could be to some extent adapted to the organization of science (e.g., the importance of interaction and interactivity in science, the role that size plays in academic performance, etc.). They contend that a better understanding of science could help revisit the rationales for science policies (Carayol and Matt, 2006).
} 
capacity, or the capital, knowledge, and skills that are needed for production with the 'given' technologies and knowledge. Thus, they argue that technical change is needed by which external knowledge is adapted to fit the conditions and specific situations of developing countries -or "technology adoption"; and by further improving the technologies to attain higher standards than the originally achieved - or 'incremental innovation' (Bell and Pavitt, 1993).

Thus, in developing countries, knowledge and capabilities need to be first accumulated before diffusion can happen. R\&D -and science are central for developing technological capabilities, creating new knowledge, and assimilating it. Bell and Pavitt (1993) argue that technology imports and local technological accumulation are complementary. A large amount of R\&D is needed to assimilate and modify technological developments of other countries and firms. Technological accumulation heavily depends on knowledge and skills that emerge from science and academic research and how it is transferred and used in the private sector. Thus, if successfully managed, science and technology constitute an important driver of economic upgrading.

Research resources (financial, infrastructure, human capital) are vital in the research process, and in many fields, notably the hard sciences, research infrastructures (labs, machinery, etc.) are a precondition for doing research (Stephan, 1996). ${ }^{2}$ Access to sophisticated forms of technology, such as specialized scientific instrumentation, is often costly and not widely available in MICs (Barnard et al., 2012). To enable researchers in developing countries to conduct world frontier research, their home institutions must invest in research infrastructure, which, given the resource constraints, demands significant prioritization. Moreover, funding constraints and prioritization are exogenous to the scientist and often change over time, requiring significant adaptation and resilience from the scientist's perspective. These constraints can be further enhanced by the underdeveloped academic structures and the lack of regulation for science and technology.

More importantly, researchers in MICs can face a tension between creating knowledge relevant to their local communities and achieving global excellence (e.g., what is a priority at the local level, might not be relevant globally). If researchers in developing countries minimize their engagements in local issues and priorities, this could limit world-class research (Barnard et al., 2012). Although inequality between researchers exists in developed countries, researchers in developing countries have a greater tolerance for unequal work arrangements. World-leading researchers in the developing world might also have a leading position nationally, concentrating most of the limited financial resources at the expense

\footnotetext{
2 Stephan (1996) argues that researchers working in the hard sciences hold many entrepreneurs' characteristics. They have to secure research grants and funding, time at research facilities, manage their research assistants, etc.
} 
of non-leading researchers and leaving non-leading researchers marginalized and with fewer incentives to remain in academia.

Moreover, there are growing concerns that the benefits of science-led growth are only touching a few countries. Global inequalities in science and infrastructure investment remain between developed and developing countries. Scientific production is very much concentrated among a few developed countries. According to the Web of Science database, in the period 2014-2018, 10 countries accounted for more than $80 \%$ of all scientific articles (Clarivate Analytics, 2018). Only two middle-income countries were among the most productive: China, accounting for $18.8 \%$ of all publications in the period; and India, representing $5.1 \%$ of all. This concentration has remained broadly unchanged if we look at the period 2000-2004. The only important shift observed is the extraordinary growth in the number of Chinese publications, representing only $5.2 \%$ of all scientific articles produced between 2000 and 2004. India has also continued to increase its output and share of global science activity, which back in 2000-2004 represented only $2.7 \%$ of the total.

Human capital in the form of researchers is also very much concentrated. About $64 \%$ of all researchers in 2013 were concentrated in high-income economies, while upper and lower-middleincome economies only accounted for $34 \%$ of the total number of researchers in the world (UNESCO, 2015). The share of middle-income economies has, however, grown in the past years. In 2007, these countries accounted for $29 \%$ of all researchers in the world.

Indeed, Burlamaqui (2020) argues that China did not "catch-up" with the developed world. Instead, it leapfrogged, and its speed and ability to surpass other MICs is explained largely by its Entrepreneurial State. This orchestrated action in forging science and innovation with strategic longer-term plans is a good characterization of a "Schumpeterian- or innovation-oriented State" (Burlamaqui, 2020), where collective entrepreneurship and learning (Lundvall, 2010) and institutions supporting innovation act as main drivers (Nelson, 1993).

The relative success of some middle-income countries, notably China and India, has demonstrated the value of scientific diffusion and knowledge transfer and the importance of building learning capabilities. There is no doubt that some middle-income economies can play an increasingly central role in transforming the global landscape of science. This transformation deserves investigation. 


\subsection{An economics of science perspective to understand the determinants of scientific productivity}

This thesis investigates the role of scientists and scientific communities in knowledge creation by looking at scientific productivity, its determinants, and effects at individual and collective levels and the macro level.

The research is anchored and framed in the economics of science literature. Most work in the field of economics of science concerns developed countries. However, the characteristics of science, technology, and research communities differ largely between developed and developing countries (Gonzalez-Brambila and Veloso, 2007). Clearly, the process of knowledge creation is different in MICs when compared to developed countries. However, what determines knowledge creation in MICs? This thesis aims to understand and characterize the determinants of knowledge creation in MICs using South Africa and Mexico as particular cases.

Three strands of literature in the economics of science are reviewed and used to guide this research.

First, research on the collective determinants of scientific productivity got great attention when authors observed that focusing on the individual researcher ignored the collective nature of research and had difficulty explaining individual productivity (Stephan, 1996). Studies at the collective level consider the age and the position of colleagues, the quality of institutions of affiliation and colleagues (productivity externalities), availability of non-permanent researchers ('supportive' knowledge), the size of the academic institution of affiliation, funding availability, social status, patenting, and the historical conditions of the academic labor market at the time of their recruitment or promotion (Carayol and Matt, 2006, Lissoni et al., 2011). The objective of these studies is to build an industrial organization theory of academic research production. Our proposed methodological approach for the study of scientists is influenced largely by the concept of cumulative advantage (Chapter 2) and path dependence (Arthur, 1990). These concepts are used and referred to throughout this thesis, but with particular prominence in Chapter 2, which introduces the main determinants further studied in Chapters 3, 4, and 5.

Second, studies on research productivity generally reveal that women publish less than men (Mairesse and Pezzoni, 2015, Prozesky and Boshoff, 2012, Lissoni et al., 2011), although the gender gap has been decreasing over time. To understand these gender differences, many researchers have focused on family-related factors affecting productivity. Most of the existing literature focuses on variables such as being married, the number of children in the household, and having a spouse who is an academic (Sax et al., 2002). Studies have found mixed results, with some concluding that being married and having children has a negative effect on women's productivity, and others finding no influence at all. 
More recent studies show no gender differences in inventors' technological outcome, but that there are in terms of income (Hoisl and Mariani, 2012), particularly in women with children. These differences are explained in terms of women's bargaining power in job-negotiations due to the higher allocation of tasks at home. The interest in this strand of literature remains high in light of the large number of young, predominately female professors who choose to postpone decisions about marriage and having children until they had received tenure.

Evidence in the context of MICs is very limited, however highly relevant, because of the small number of research positions with good and competitive work conditions (thus, arguably, competition for these positions is higher in MICs). Chapters 3 and 4 deal in detail with the study of gender productivity gaps in science. These chapters also discuss the literature and the most recent findings in the field.

The study of gender gaps and inequalities in science has witnessed a particularly increasing interest since this thesis was initially designed and started back in 2012. The number of economists studying the reasons behind the under-representation of women in science has exploded in the past years (Keynes, 2017). Research such as the effects of the network of collaborators on the productivity of women; how more female presence in academic departments increases the awareness of gender biases; and how exposure to gender bias workshops and campaigns among hiring faculty increases the share of women among new hires; are among the most common topics studied by economists in most recent years. Keynes (2019) briefly discusses the latest research trends in the field, as presented at the 2019 meeting of the American Economic Association.

Measuring gender productivity gaps is a real challenge for economists. It is often contested whether the measures of productivity and quality available for analysis are biased, and most importantly, if scientific performance is endogenous to expectations. Among many other empirical examples, Ginther and Kahn (2004) show that a significant portion of the gender promotion gap remains unexplained by the scientists' observable characteristics. Gender differences in productivity and the effect of having children on promotion only partly explain how women have fewer chances to be promoted and receive tenure in economics. $^{3}$

The study of the obstacles to women's promotion in science is among the most prominent in recent years. There also seems to be a lack of progress on tackling this problem across all academic fields, and

\footnotetext{
${ }^{3}$ Even though Ginther and Kahn (2004) focus on economics, the gender productivity gap is present in all fields of science. However, economics is particular because, differently from the hard sciences, women in economics do not seem to "catch-up" with men with age in their academic productivity and the achievement of tenure. More on the gender problem in economics is discussed in detail in the webcasts series of the American Economics Association (AEA, 2019).
} 
stagnation in this regard is a constant both in developed and developing countries. Our chapters 3 and 4 contribute to the increasing empirical evidence in this area.

Third, the economics of science has also been concerned with the phenomenon of 'brain drain/brain gain', particularly concerning the access to foreign knowledge and its effects on research collaboration and productivity. This phenomenon is of special relevance for MICs. An important part of the 'brain drain/brain gain' phenomenon is a result of government initiatives of leading developing countries that were actively encouraging their most promising graduate students to spend time abroad to undertake education and training and gain international experience in R\&D.

Jonkers and Tijssen (2008) argue that the chances of returning PhD graduates to be successful, in terms of research performance, increase when they are part of international professional networks in their home country, or when they retain professional linkages with their co-workers and supervisors in the former host country. Nevertheless, how does access to foreign knowledge and participation in international research networks influence scientific productivity? What are the gains for researchers in MICs of taking part in these international networks? It is often questioned whether scientists in developing countries can fully benefit from these connections in the long-term. It is also not clear if these researchers can transfer this tacit knowledge to their national networks.

Evidence in developing countries shows that researchers' productivity having received their PhDs abroad differs largely by discipline (Gonzalez-Brambila and Veloso, 2007). This lack of systemic higher productivity of researchers trained abroad has been explained by 'brain drain' or that locally trained PhDs tend to find partners more easily locally or have a better knowledge of how to obtain research resources.

Chapter 5 contributes to this last strand of the economics of science literature in which this thesis is anchored.

Finally, even though the economics of science guides the theoretical framework of the research, we make large use of network theory concepts, notably in Chapter 2 and Chapter 5. We started this chapter with the argument that one of the main reasons to study the economics of science is to understand better scientific labor markets and scientists' behavior as main contributors to human capital accumulation. Network analysis, adding a relational perspective, is an appropriate research tool to understand these phenomena.

Granovetter's influential work in the 1980s gave rise to an interest in the network approach in economics. He argued that all economic actions are embedded in social networks. Many market situations that are difficult to understand and explain would benefit if one considers the social structures in which these actions are embedded (Granovetter, 1985). Granovetter argues for a theoretical approach 
in economics that combines rational action and an account of agents' social relations. Similarly, Coleman introduced the function of social capital to incorporate social structure into the paradigm of rational action (Coleman, 1988). Since the 1990s, interest in networks has gradually increased, leading to new economic models of network formation and network interaction (van der Leij, 2006).

We recognize that scientific knowledge production is a complex process and that network structure influences scientists' decision-making and behavior. Moreover, network effects and network position also affect the behavior of researchers. Better network position often results in greater payoffs to individuals, and as a consequence, individuals will rationally try to influence their network position. This unveils the fact that social networks are not static and that their structure is shaped by individual strategies that deserve further investigation.

We thus aim to contribute to the economics of science literature by proposing research methods and econometric models that acknowledge these complexities and the embeddedness of social structure in rational behavior. We believe our findings contribute to the ongoing formation and shape of the network science field as well.

Overall, the research presented in this thesis provides tools for informing policy discussions on how best to implement science policies in MICs. It contributes theoretically, provides empirical evidence, and informs on the formulation of more evidence-based policies affecting the funding and conduct of scientific research in MICs.

\subsection{Structure of the book}

This thesis is structured into four main Chapters and a final chapter with conclusions.

Chapter 2 investigates the determinants of scientific productivity using a network theory perspective and focuses on South Africa as a particular case. The chapter looks at the different factors associated with tie formation (the first collaboration between co-authors) and tie persistence (second and subsequent collaborations) affecting collaborative scientific research. While some authors argue that the factors determining the formation of ties are similar to those of the persistence of the relationships (McPherson et al., 2001), other research on inter-organizational networks suggests that the two mechanisms are structurally different (Seabright et al., 1992).

Four different sets of factors affecting tie formation and persistence are analyzed in detail: cognitive proximity (1); status homophily (2); organizational proximity (3); and social and community structure (4).

This chapter gives an important place to investigate the effects of social structure as a determinant of scientific collaboration. A network approach to analyze the determinants of scientific collaboration 
allows understanding the formal and informal relationships between people and contributes to a better understanding of the factors affecting and promoting it. Empirically, we test various novel methods for analyzing social structure through Social Network Analysis techniques, contributing to community detection methods' empirical use to partition social networks and uncover scientific communities' effects on collaborations.

As such, Chapter 2 serves to frame the remainder of the thesis. Chapters 3,4 , and 5 focus on two of the most significantly important factors that affect scientific productivity: gender in Chapter 3 , gender and ethnicity in Chapter 4, and access to international research networks, or access to international knowledge (Chapter 5).

Chapter 3 and Chapter 4 focus on what Cole and Zuckerman (1984) first referred to as the "productivity puzzle". We try to understand whether women in science are less productive than men and explain the possible causes of gender productivity gaps. For doing so, we apply an adapted version of an econometric approach developed by (Mairesse and Pezzoni, 2015) to understand gender gaps in scientific publication productivity and apply this framework to Mexico (Chapter 3 ) and South Africa (Chapter 4) as empirical applications.

Among other measurable or approximate factors that help explain gender productivity gaps, special emphasis is given to two corrections included in the proposed econometric framework: selectivity or publishing occurrence and promotion to higher academic ranks. Selectivity refers to the fact that during an academic career, all researchers have periods when they do not publish (or publish in low visibility journals) and that these periods do not occur at random but are rather due to a set of determinants that can be explained to some extent. Further, the econometric framework also considers promotion to higher academic ranks as a source of endogeneity in any model that includes seniority or rank to explain individual productivity. As such, we characterize it and correct for it.

Chapter 3 adds to the original econometric framework of Mairesse and Pezzoni (2015). ${ }^{4}$ This chapter's main methodological contribution is a series of counterfactual macro simulations we propose with the dual objective of assessing the magnitude of the macro-impacts of gender gaps and illustrating the potential impacts of a range of policy scenarios aimed at reducing such gaps. To our understanding, no other studies focus on the macro-effects of reducing gender gaps in scientific production and productivity in the context of MICs.

\footnotetext{
${ }^{4}$ Chapter 3 benefited from the financial support of the Inter-American Development Bank (IADB) and its Gender and Diversity Fund.
} 
In Chapter 4, we expand the micro and macro effects econometric model to the case of South Africa. One of the initial findings of this chapter was the realization that history and path dependence matter in any empirical study. Even if our choice of case studies was oriented to analyze structurally similar countries concerning their knowledge base, research capabilities, and research infrastructure, South Africa is a rather particular case regarding the role race and ethnicity play in any of the country's social and economic area.

Race consciousness is a central element of South African modern society. The education system inherited from the apartheid era was highly unequal, along with race and gender lines (Afeti et al., 2008). However, in the post-apartheid era, a large-scale effort towards system-wide transformation has been undertaken. One of the main goals has been to end inequalities regarding race, gender, and locality generated by the apartheid, concerning institutional disparities and stark disparities in the number of students, graduation rates, staff qualifications, rank, and research outputs.

The results of Chapter 4 show that race plays a more important role than gender in explaining productivity gaps. We believe that our findings contribute to a better understanding of the interplay that race and gender have on scientific productivity in the South African context and add to the limited empirical evidence of the determinants of race productivity gaps in MICs.

Finally, chapter 5 focuses on a topic that is of special relevance to MICs given their generally underdeveloped science systems: access to a 'foreign', usually more advanced, knowledge base. The analysis focuses on young researchers that receive their training abroad, using the Mexican academic system as an empirical application. There is a general belief that policy instruments supporting graduates and researchers in developing countries to study and undertake research abroad give foreign-educated students new knowledge and capabilities that can be carried to their country of origin as well as facilitate contacts with other foreign scientists and institutions (Scellato et al., 2015).

Chapter 5 investigates the effects of foreign education on Mexican researchers at the individual and collective levels. As mentioned before, our analytical approach is largely informed by network theory. We implement an adapted version of a model developed by Barnard et al. (2012) to measure foreigntrained PhDs' role in scientific catch-up in developing countries. At the individual level, we look at the impact that foreign education and training have on research productivity and career development. At the collective level, we look at whether access to international research networks benefits the local scientific community in the researcher's country of origin.

Chapter 5 contributes to a better understanding of the benefits of policy schemes targeting the creation of national and international research networks and the benefits of the diffusion of knowledge between advanced and less-advanced science systems. Methodologically, we propose an innovative 
Chapter 1

bibliometric indicator to measure the societal impact of researchers' mobility that goes beyond traditional productivity measures. The Chapter suggests that the benefits of international collaboration in science with world-class researchers for developing countries are large. The local, often developing, scientific community can also benefit largely from these interactions.

Finally, Chapter 6 presents a final discussion about the thesis's main findings and the most important lessons derived from the research. It makes suggestions on further research avenues in the economics of science in general and MICs in particular. 


\section{Chapter 2. Unveiling the determinants of scientific collaboration and persistence - a network analysis perspective*}

The purpose of this chapter is to understand the different factors associated with tie formation and tie persistence affecting collaborative scientific research and whether these factors are similar or different. We focus on research networks in South Africa, using a rich database of researchers rated from the National Research Foundation (NRF). We focus on four sets of determinants: cognitive proximity, status homophily, organizational proximity, and social and community structure.

Understanding the dynamics and determinants of network formation is a major research concern of the study of innovation and research networks. However, most research's dominant concern is how collaboration happens (i.e., the determinants of tie formation) (Snijders, 2001, Levi-Martin and Yeung, 2006, Baldassari and Diani, 2007, Coleman, 1974). However, there is relatively less research focusing on how collaboration persists over time. While some authors argue that the factors determining the formation of ties are similar to those of the persistence of the relationships (McPherson et al., 2001), other research on inter-organizational networks suggests that the two mechanisms are structurally different (Seabright et al., 1992).

Social network analysis (SNA) is a tool that can contribute theoretically and empirically to the understanding of these determinants. The chapter gives an important place in understanding the effects

\footnotetext{
* This Chapter is based on joint work with Dr. Moritz Müller and Prof. Dr. Robin Cowan. A previous version of this Chapter is available as Rivera León et al., 2015.
} 
of social structure on scientific collaborations. A researcher's place in the network of collaborations may affect his or her ability or propensity to form or maintain collaborative ties.

Empirically, we propose new ways to measure the relational determinants of scientific collaborations through the concept of social network communities, making use of community detection algorithms in networks, and going beyond the more traditional network measures of closure and bridging ties. With this, we aim to investigate the meso-level effects of social structure on scientific collaboration.

Given the existence of relatively small scientific communities in Middle-Income Countries (MICS) and the tight relationships among researchers - beyond institutional and formal structures and social and community structure- it is further important to understand what makes researchers collaborate. This chapter aims at this gap and thus plays a central role in this thesis overall, as it guides the subsequent chapters' focus.

The Chapter is organized as follows. In Section 1, we discuss the literature, focusing on the four sets of determinants we analyze. Data and methodology are presented in Sections 2 and 3, and the results of the estimations in Section 4. In the final section, we discuss our findings and present conclusions.

\subsection{Scientific collaboration: formation and persistence}

Research collaboration is a voluntary process in which each researcher decides to team up with a colleague or a team when they think they are better-off collaborating than working alone. Generally, people would prefer to collaborate with those that provide returns to the partnership and a minimum amount of costs. Many scholars have found that scientists tend to collaborate with people similar to them and with those that share the same personal characteristics such as gender, ethnicity, and age. In fact, research (and to some extent common sense) has shown that people's personal networks are homogenous about several sociodemographic and behavioral variables as well as interpersonal characteristics (McPherson et al., 2001); and highly similar pairs show greater than average propensity to form new ties (Kossinets and Watts, 2009). The sociological explanation for this is that people with different characteristics tend to have different personal qualities. This enforces the creation of localized networks that follow the homophily principle.

Differences in sociodemographic characteristics -or relationships that do not comply with the homophily principle, exhibit higher network distance, making them difficult to create and maintain. Social structures that are homophilous also make communication and cognitive processes more likely.

Homophily can follow two distinct mechanisms: choice homophily and induced homophily (McPherson and Smith-Lovin, 1987). Choice homophily arises thanks to individual or psychological preferences. In contrast, induced homophily is the consequence of homogeneity of structural 
opportunities for interactions (e.g., neighborhoods, schools, workplaces, friendship circles, voluntary organizations, etc.) (Feld, 1980). There is empirical evidence that shows that both mechanisms play an important but partial self-reinforcing role in explaining homophily in large academic communities (Kossinets and Watts, 2009) and social communities (McPherson and Smith-Lovin, 1987). Both mechanisms appear to act as substitutes.

This chapter aims to understand what makes researchers collaborate, only once or many times. Even though we do not aim to disentangle the contributions of choice and induced homophily, our overarching hypothesis is that South African researchers will tend to collaborate with others similar to them, thus respecting the homophily principle.

In the following sub-sections, we expand on the four-different set of factors we investigate.

\subsubsection{Cognitive proximity}

In the innovation literature, actors with the same knowledge base or technology are said to have cognitive proximity. Cognitive proximity makes communication and knowledge sharing easier, given the shared knowledge base and the shared capacity to successfully absorb and process new information (Boschma, 2005).

We argue that researchers will be more likely to collaborate when their cognitive proximity is high, when they share sociodemographic characteristics (such as ethnicity, gender, and citizenship) and research in the same scientific domain.

\subsubsection{Gender and ethnicity}

There is large evidence in the literature that shows that social, organizational, and research networks tend to follow the homophily principle regarding gender and ethnicity.

Using a model of team formation of agents who have gender as a preference, Boschini and Sjögren (2007) showed that team formation for authorship of academic economists is not gender-neutral: the female-male gap in the propensity to co-author with a woman increases with the presence of women in the field of research, and women are significantly more single authors in research than men. On average, in economics, women are twice as likely as men to co-author with women. Also, collaboration teams that are only composed of females are more likely to be long-distance collaborations in contrast to gendermixed teams suggesting that the latter are less prone to take over the extra coordination costs associated with the relationship.

Evidence on small organizational communities shows that men are more likely to collaborate with other men and women with other women. In a study that explores how women are integrated into men's 
networks and vice versa at a newspaper publishing company, Brass (1985) found that even when a woman is highly central within an all-female organizational network, and even if she is as central as a male counterpart in the entire organization, neither the man nor the woman would interact with each other or those of the other gender. However, additional factors interact with gender that determine network position and degree of influence, such as tenure or performance, membership to a particularly powerful department, differences in job function, or simply stereotypes or perceptions that women are less influential than men.

Race and ethnicity have been found to create the strongest divides concerning personal and social networks (McPherson et al., 2001). Concerning ethnic minorities in organizations, and based on distinctiveness theory, studies have predicted and proved that people of numerically underrepresented groups (relative to the majority) would tend to identify within their own groups (Mehra et al., 1998).

Race consciousness is a central element of South African modern society. The education system inherited from the apartheid era was highly unequal, along with race and gender lines (Afeti et al., 2008). However, in the post-apartheid era, a large-scale effort towards system-wide transformation has been undertaken. One of the main goals has been to end inequalities regarding race, gender, and locality generated by apartheid, particularly concerning institutional disparities and stark disparities in the number of students, graduation rates, and staff qualifications, rank, and research outputs.

Despite the efforts, there are still clear challenges ahead. In 2015, out of the 28 researchers that received the highest excellence distinction (an A-rating) by the National Research Foundation of South Africa ${ }^{5}$, only 4 were black researchers, and 5 were female. By 2020, female and colored researchers' representation in the highest ranks of the NRF did not improve. Out of the 21 researchers that received an A-rating, only 2 were female and both white. ${ }^{6}$

Chapter 4 of this thesis shows that mixing gender, ethnicity, age, and disciplinary dimensions of inequalities in publication and career development, the South African science system is gender-biased concerning the promotion of female researchers to higher ranks, whether the researchers are white or black, but particularly among black females.

People are likely to belong to multiple groups, which would constitute similarity and social identification that work as determinants of tie formation and persistence. The tendency towards gender and ethnicity homophily is likely to lead to marginality and exclusion. Underrepresented researchers in

\footnotetext{
${ }^{5}$ This chapter uses data from the South African National Research Foundation (NRF). More details on the NRF's rating system of researchers is available in Chapter 4 of this thesis.

${ }^{6}$ See: https://www.nrf.ac.za/nrf-awards/a-rated-researchers
} 
the collaboration network will tend to select collaborators from the distinctive groups. This usually leads to limited network access, restricted knowledge, difficulties forming alliances, limited mobility, and "glass ceiling" effects (Ibarra, 1993). Given the South African context, we expect researchers within ethnic minorities (black, Indian, and colored) to collaborate and use ethnicity for social identification.

\subsubsection{Scientific domain}

In academic research collaboration, we argue that cognitive similarity is more likely to be present within academic domains and disciplines or between academic domains and disciplines that are 'close' to each other, have common epistemological frameworks, or are intellectually similar.

Authors have used reference similarity of the co-authors' research outputs to measure value homophily among researchers (Dahlander and McFarland, 2013). Studies that have focused on collaboration patterns in research projects have concluded that science does not operate in a single community. However, it is rather organized in many overlapping networks that cross the formal boundaries regarding domains, discipline, economic sectors, and geographies. These networks are continuously growing, declining, and in dissolution (Mali et al., 2012). This has given rise to a large amount of research investigating collaborations across academic disciplines, and concepts such as modes of interdisciplinary research, multidisciplinary and transdisciplinary research have emerged (Bellotti et al., 2016).

Put differently; we aim to understand if inter-disciplinarity, or within scientific domains research, leads to the formation and persistence of ties. Ultimately, inter-disciplinary research is a source of epistemic change and a sign of a dynamic research system. Recent evidence shows that interdisciplinary research receives more funding than research within the same disciplinary boundaries. However, interdisciplinary research diminishes with time, probably reflecting the contraction of public funding available for research (Bellotti et al., 2016).

\subsubsection{Status homophily}

In their choice of collaborators, researchers pay attention to whether or not the potential collaborator brings valuable resources, most typically in the form of human capital, to the research project. This is typically expected in the formation of self-selected teams or pairs of individuals pursuing a common goal. Research collaboration is associated with costs in terms of time and money, and thus researchers will tend to be selective concerning their collaboration partners. Consequently, researchers look for the "best" possible partners, where "best" may have a very broad definition. Lazega (2001) defined this fundamental process in collaboration networks as status competition or the process in which actors seek to accumulate status, which in Lazega's view is derived from control of production-related 
resources (in our case, this refers to knowledge or human capital). This process is said to be beneficial for the individual and an organization as a whole in knowledge sharing and competent work.

From a regional perspective, Hoekman et al. (2009), using a gravity framework to analyze interregional collaboration based on scientific publications and patents in Europe, found that elite researchers are more likely to collaborate and network with other elite researchers located in 'excellence regions' since the learning benefits of collaboration are higher to the researchers. Elite researchers also have better access to resources that favors collaboration, including funding. This has resulted in the emergence of regional academic hierarchies.

Following this line of thought, on the one hand, we can expect to see an assortative pairing process among researchers, in which the best researchers partner with each other, as do less good ones. Indeed, researchers have found that friends are more similar on status dimensions than chance (McPherson and Smith-Lovin, 1987) and that individuals dislike working with colleagues whose education is superior to their own (Voelker et al., 2013). Arguably, this assortative pairing is more important for tie formation than to tie persistence, as rank status is a visible 'quality' of every researcher.

On the other hand, collaborative research is frequently done in teams that have specialized contribution 'assets', and thus one could also expect that collaboration happens across different ranks, in which more senior researchers provide the strategic research lines and guidance while more junior researchers undertake data collection, processing and analysis, and thus conforming an 'advice network' that exhibits an efficient division of labor. Indeed, older and younger researchers have different skillsets and interpersonal relationships that can contribute differently to the partnership. Working in teams across different ranks does not necessarily mean moving away from the assortative pairing process. Senior ranked people will still select the best junior co-authors who have complementary knowledge assets to their own.

Age and experience are also, to a large extent, linked and correlated to status. However, the extent to which age homophily is a determinant of network formation and persistence depends largely on the type of studied ties. For example, age homophily is frequently found in close friendship networks and marriage. In academic teams, complementarity has been explained by the age differentials of the team members. Krapf (2015) finds that co-authors' pairs are most productive when their age difference is about 10 years. In this case, age differentials can be accounted for as a proxy for different sets of skills. We aim to understand how rank status interacts with age in the formation and persistence of collaboration teams; and if rank and age homophily (or complementarity) account as determinants of research collaboration. 


\subsubsection{Organizational proximity}

Geography and space are probably the most basic sources of homophily (McPherson et al., 2001), as people are more likely to connect if they are geographically closer. Even if ICTs have technically and practically reduced the distance between people, especially for collaboration in science, geographical proximity is still an important determinant for forming ties. However, with time, geographical proximity may become less important for a pair of researchers who already know each other, thus overcoming the distance barriers.

Economic geographers have given great importance to co-location and its impact on learning and knowledge creation. More recently, other types of proximity, such as cognitive, organizational, social, and institutional, besides geographical proximity, have received great attention as a way to understand interactive learning (Boschma, 2005). Cassi and Plunket (2015) found that social, geographical, and organizational proximity act as substitutes. In this sense, geographical proximity is less important when individuals are connected through acquaintances or act under similar governance structures. Thus, one could argue that the relational determinants of research collaboration are more important for tie persistence, while the proximity determinants are so for tie formation.

Since our study is bounded to South Africa, and our data concerns researchers with a South African institutional affiliation, we do not focus our attention on geographical proximity. Rather, we give importance to other proximity variables such as organizational and cognitive proximity, which have also been claimed to fulfill a central role in interactive learning processes (Boschma, 2005).

Organizational proximity refers to the closeness of individuals in organizational terms (Boschma, 2005). Organizational distance creates costs as it acts as an obstacle due to different 'values' and the presence of different governance systems. It is often argued that organizational proximity can occur within or between organizations as soon as they share common organizational arrangements.

In South Africa, disparities in structures and governance systems exist between the main public universities, the technikons, the 'comprehensive' institutions that offer a mix of university and technikonlike programs, and the private higher education sector (Afeti et al., 2008).

Cassi and Plunket (2015) find that inter-organizational links are harder to predict and depend largely on the type of tie analyzed. One could argue that researchers that are members of a different organization are more distant. Hence, it is more difficult to collaborate given the different rules, funding mechanisms, and common language. This behavior is expected to vary by discipline, where very specialized disciplines will be more likely to collaborate across organizations. 


\subsubsection{Social and community structure}

Several studies have attempted to understand how social proximity and social connections affect the transmission of knowledge and, consequently, collaboration networks. Researchers who belong to the same social community have been more likely to collaborate and make their collaboration persist over time, particularly for those who have provided social support, are in frequent contact, or are kin (Wellman et al., 1997). Studies on how social membership persists over the long-run are scarcer. It is often believed that ties built on shared social structure and high social proximity are more likely to persist because of the relationship's nature, trust exchange, and frequent contact. However, in a study on personal communities in Toronto, Wellman et al. (1997) showed that intimacy in social networks is very unstable and that a large majority of personal ties do not persist over a 10 year period.

One could say that membership to a social group exhibits some specific characteristics. In his emblematic bibliometric research, Price's concept of invisible colleges referred to groups of interacting and productive scientists geographically distant and exchanging information to monitor progress in their field (Price, 1963). Even though Price focused on the formal ways of interaction (e.g., collaborative work, growth of scientific literature), his concept mostly emphasized the informal patterns of personal contact between the scientists.

Price (1963) characterized an invisible college of scientists as composed as a group of a maximum of 100 colleagues that have mechanisms for day-to-day communication. That share work in progress and results to be achieved. Thus, after a few years, members of an invisible college usually know each other or have worked with everybody else in the college at some point.

Other authors have also described invisible colleges as those that have a certain degree of predictable behavior (Griffith and Mullins, 1972), that carry out research within a subject specialty and that are clustered together in sub-topic areas (e.g., co-cited) according to similar research interests (Brunn and O'Lear, 1999). Others have characterized an invisible college as a tight community, with its own social norms (Paisley, 1968); while others argue that they are a concentration of research ties without clear boundaries, acting as diverse social groupings in constant change (Mulkay et al., 1975).

The qualitative literature on agglomerations argues that 'tacit' knowledge and personal face-toface contacts are more effective means of knowledge transmission than codified knowledge. Geographical and physical proximity or co-location play a role in building non-market-based social relationships (e.g., resulting from kinship, friendship, social gatherings, triadic relationships, etc.) also facilitate formal contractual and market-based relationships thanks to frequent interactions and other trust-building activities. Thus, two channels of knowledge transmission complement each other: the 
formal and the informal interactions, where social proximity and knowledge spillovers are central to the informal component.

Recent quantitative studies have tried to disentangle the formal or market-based component from the tacit/knowledge spillovers/externalities component, arguing that the available quantitative research on the geography of innovation has assumed that social ties are the main carriers of localized knowledge spillovers but have failed to demonstrate it. Breschi and Lissoni (2009), using U.S. patent citation data, found that the largest part of localized knowledge flows can be explained from formal interactions, such as consulting, mobility, and contract research. Non-market-based social ties explain that little. They argue that mobile inventors and short social chains of co-inventors are responsible for localizing knowledge flows. Zucker et al. (1998) also find that market exchange positively impacts universities and firms in American biotechnology research, contrasting to generalized knowledge spillovers. Indeed, research communities are composed of persons who have shared values and interests. The authors show that it is because of people's interests and 'intellectual human capital' that market-based relationships are created and sustained. In most cases, the social networks created are 'mobile', following the inventor or researcher's location and the formal structures they create (e.g., private companies the researchers or inventors create themselves).

Values and interests have an important role in network construction (Lazega et al., 2003), indeed. A stream of research from social sciences and economics uses network theory and network communities as a proxy for the unobserved similarity of actors' intrinsic characteristics (Evans et. al., 2011). In this research line, fit is mostly given when actors are similar, yielding homophily interaction, and less often when they are complementary. Whether homophily or complementarity is the 'true' driver of interaction depends on the level of detail.

Social proximity increases the chances of forming a tie between individuals that are indirectly connected. Triadic relationships tend to close over time, and social proximity has a big role in this. Cassi and Plunket (2015), in a study of co-inventor networks in genomics in France, found that closure ties happen among actors that are organisationally close to each other and share technological similarity. In contrast, bridging ties, or those that occur between individuals in two different network components, have been found to occur when individuals seek variety and diversity in collaboration, usually happening across organizational barriers, and for relationships for which technological distance is more important.

Regarding network distance, Fafchamps et al. (2010) found that new collaborations emerge faster between two researchers if they are "closer" in their co-authorship network. They estimate that being in a network distance of 2 instead of 3 can raise the probability of tie formation by 27 percent. Researchers have also found that when small organizations and communities are studied, these often display a core- 
periphery pattern. A large group of people, or a dominant coalition, is densely connected (Brass, 1985). Similar to the assortative pairing phenomena regarding rank status, preferential attachment, or the propensity of actors to link with individuals that are well connected in the network, it is a recurrent feature of network formation. This gives place to skewed-degree network distributions.

Often referred to as the 'within the network' determinants of collaboration, or those that look at how network shape and structure in the past affect network change, most of this research considers only individuals, e.g., the prior partners, a common friend, or the number of agents within the shortest path of two agents. However, when internal characteristics are exogenous, the correlation of individuals' characteristics will also enhance further clustered interactions. In a process where internal characteristics are endogenously becoming more similar through interaction, clustering of interaction will be reinforced.

However, whether intrinsic characteristics are endogenous or exogenous to interaction does not change the role that 'communities' take in this research. Communities reflect aggregate interaction, which is completely organized at an individual level (there is a one-way direction here - individuals create ties which results in patterns or "communities"). Their existence is assumed to result from unobserved internal characteristics to the extent that these patterns are not explained with observed internal characteristics (or an individual level social environment, such as referrals).

Thus, our approach to social distance and structure does not consider the co-authorship network only as a system of pipes channeling information (e.g., over the shortest path). Instead, we aim to use the collaboration network as a proxy for the formation of social groups by individuals, which affects interests, preferences, tastes, and information on a social level beyond the individual, thereby affecting subsequent groupings (again through tie formation among individuals). Under this approach, the community is a self-standing social entity that gives identity and a social context to the people within and outside the community and thereby directs (inter-)action.

This approach follows Coleman's theoretical orientation that conciliates social action as one governed by social norms, rules, and obligations, together with the social actor that acts independently and follows self-interested goals (Coleman, 1988). We aim to investigate how actions at the individual level create social entities and feed on individual action. This will help better understand how social interaction changes the researcher's behavior and/or preferences, i.e., even beyond dyadic/triadic relationships. 


\subsection{Data}

We rely on data of rated researchers from the National Research Foundation (NRF) of South Africa. The NRF is the South African research funding agency. A central component of the NRF's research support programs is awarding competitive peer-reviewed grants to individual researchers. The NRF rating system is one of the main mechanisms to grant these competitive research funds. The system works de-facto as a proxy benchmark to assess the national and international standing of researchers. ${ }^{7}$

The NRF dataset provides detailed information about each researcher that submits a rating application, including employment history, rating history, publication record, and personal characteristics, such as gender, age, and ethnicity. We make use of all these variables to understand what determines tie formation and persistence.

When submitting their application for rating to the NRF, every researcher must provide a list of publications they would want to be evaluated. We analyze individual NRF-rated scholars based on their peer-reviewed publications submitted at the moment of application and collaborators' networks evident from those publications and their NRF ratings and scientific domains. It is possible that we do not observe all the publication records of all researchers, but only of those publications submitted to the NRF Evaluation Committees.

We use Social Network Analysis (SNA) variables to explain tie formation and persistence in our econometric models. We build our social networks by using the researchers' publication records in our sample, where the links are based on co-authorship in a peer-reviewed research paper. We do not restrict the network to the period of analysis (i.e., 2000-2011) but rather calculate the co-authorship networks with all researchers' full publication data that received a rating in the analysis period. The publication record can thus go beyond this period. We consider this important, as regardless of whether the researcher received a rating in the period we are looking at, the researcher's role in the network can be influential for the characterization of the network itself.

We include all researchers who obtained a valid rating (including unsuccessful and excluding unprocessed ratings) at the NRF between 2000 and 2011 in our working sample. The initial sample is composed of 3,535 researchers.

In order to construct the panel data for the econometric analysis, we apply further sample restrictions. Firstly, we include only scientists with a complete publication record. We assume that the

\footnotetext{
${ }^{7}$ Further details on the functioning of the rating system of researchers of the NRF are provided in the literature and background section of Chapter 4 of this thesis.
} 
publication record is complete when the time from (first) PhD obtained to first publication is smaller or equal to five years. Secondly, we include only scientists who have been observed to publish many papers (10 papers from first publication up to the year of the last rating call they took part in). The reason is that more active scientists provide a stronger signal on their network position, in particular community membership. A third restriction is that first tie formation needs to occur within the observation period 2000-2011. Finally, we limit our sample to scientists working in the hard sciences. This results in a working sample of 1,773 scientists. Pairing these scientists creates $1,570,878$ dyads. From the total potential dyads, restrictions leave 2585 'successful' and 1,568,293 'unsuccessful' dyads.

Our econometric framework is applied to two different panel datasets: the formation panel and the persistence panel.

Dyads included in the estimation sample are called a focal dyad. Since we are interested in timevarying covariates, we include only dyads with full information from the first year at risk up to tie formation or, if no tie is formed, up to the end of our observation period ${ }^{8}$.

The formation panel is unbalanced, and the unit of analysis is the collaboration tie. A tie enters the panel dataset when both co-authors are at risk of collaboration. A dyad is at risk of forming a tie starting with the year where both scientists have published at least one paper. Thus, a dyad is observed first after both scientists started to publish and last until either of the two obtains his/her last rating in the period of analysis.

The number of potential dyads, about 1.5 million, is large compared to those dyads being observed to form a tie at one moment in time, 2585. Since some of the network measures are computationally costly (e.g., network distance), we refrain from analyzing all potential dyads. Instead, we include all dyads forming a tie (with probability 1 ) and the same number of dyads forming no tie (with probability 2585 over 1.5 million). Statistics are calculated using sampling weights, and we make sure that results are not due to an 'unusual' sample by replicating the study several times. We verified that the distribution of two variables, first year at risk and last observation period, are similar for all potential dyads and the (weighted) working sample.

Our tie formation models' final working sample includes 1773 scientists, 2082 dyads with 12234 dyad-year observations. The number of dyad-year observations decreases from 2082 cases in $t=0$ to 1194 cases in $t=5$ to 78 in $t=10$, where $t$ denotes the number of years since the first time at risk of forming a tie.

\footnotetext{
${ }^{8}$ More technically, we work with a right-censored sample with left-truncation excluded. More details are presented in the Methods section below.
} 
The persistence panel is a subset of the formation panel. It includes all those pairs of co-authors that make their collaboration persist over time. A tie thus enters the persistence unbalanced panel the year when it is formed. The co-authors collaborate for the first time and exit the panel when they make their collaboration persist in the analysis period.

\subsubsection{Variables}

Our main focus is to understand the determinants of tie formation and tie persistence and to see if these are similar or if they differ. The tie formation and tie persistence variables are coded as dummy variables in our panels, taking the value of 1 if a tie between individuals $i$ and $j$ was formed or persisted in year $t$, respectively.

\subsubsection{Cognitive proximity}

We test cognitive proximity by using several variables that proxy for similar social characteristics of the co-authors and similar academic interests and values.

Gender and ethnicity. Evidence has shown that researchers of the same gender are more likely to collaborate and to make their collaborations persist (McPherson et al., 2001). In our models, we use a dummy variable called same gender that captures whether the collaboration is conformed of co-authors of the same gender. Out of the 1773 researchers included in our sample, 452 or $25 \%$ are female, while 1292 -or $73 \%$ are male. The gender of the remaining $2 \%$ ( 29 researchers) is unknown.

We measure same ethnicity with a dummy variable that indicates whether a pair of co-authors has the same or different ethnicities, taking a value of 1 if co-authors have the same ethnicity and 0 otherwise. Authors are categorized into two broad ethnicity groups: white researchers and non-white researchers, where the 'non-white' category includes black, colored, and Indian researchers. $74 \%$ of researchers in our sample are white, while $24 \%$ are non-white $(13 \%$ are black, $7 \%$ are Indian, and $4 \%$ are colored researchers). The ethnicity of $2 \%$ of researchers in our sample is unknown.

The descriptive statistics show that co-authors with the same gender and the same ethnicity are more likely to form ties and make them persist. Among the unique number of ties formed in our working sample, $58 \%$ of the total (600 ties) were among co-authors of the same gender, and $67 \%$ of them (684 ties) were among co-authors of the same ethnicity. Among ties that persisted, $61 \%$ of the total (894) were among researchers of the same gender, and 75\% (1092) among a pair of authors of the same ethnicity.

Citizenship. As part of the NRF application, we have access to data on the citizenship of the researchers. We use the researcher's citizenship as a proxy of 'membership' to a political community or a state. Arguably, researchers who have the same citizenship will have closer values and national identity, 
share the same language, and a similar understanding of national belonging. This proximity is also likely to make it easier to form a tie. Citizenship data also allows us to understand whether the collaboration links are national or international.

The rise of international research collaboration is unprecedented. It is estimated that in $2017,60 \%$ of all high-quality research papers were internationally collaborative, involving co-authors from two or more countries. This rise is much more pronounced among emerging economies. While internationally co-authored papers have increased tenfold since 1991 in advanced economies, in countries such as Brazil, Russia, India, and China, they have increased twenty-fold in 1991-2017 (Wagner et al., 2019, Crew, 2019).

In the case of researchers in Africa overall, Kozma and Calero-Medina (2019) found that researchers tend to collaborate within their own countries than within their own organization. In South Africa, collaboration patterns seem to differ between researchers working in universities and research institutes. The former contributes predominantly to international collaborations and the latter to withincountry collaborations (Sooryamoorthy, 2014).

South African researchers largely dominate our working sample. Among our focal authors, $76 \%$ of all (1308 researchers) are South African or South African permanent residents (36). The most important nationalities that follow include the United Kingdom (4\%), Germany (3\%), and Nigeria (2\%).

We use the data on the Citizenship of the researchers to build a Same Citizenship dummy variable. As expected, given the characteristics of our sample, most of the co-authorships are between researchers of the same citizenship, representing $67 \%$ of all ties formed for the first time and $73 \%$ of all that persist beyond the first collaboration.

Scientific domain. Research has shown that ties and co-authorships across scientific domains are rare and that interdisciplinary collaborations are limited. We use the scientific domain as a rough measure of cognitive proximity. We developed a dummy variable that measures whether two co-authors are from the same broad scientific domain in year $t$. Our study is limited to the hard sciences and covers three scientific domains: Life and Health Sciences, Exact sciences and Engineering, and Natural and Environmental Sciences. ${ }^{9}$

A first look at the data shows that $76 \%$ of all co-authorships formed for the first time are within scientific domains. This share increases to $80 \%$ for co-authorships that persist. A more granular look at

\footnotetext{
${ }^{9}$ The scientific disciplines covered in each of the domains are as follows: Life and Health Sciences includes Health Sciences, Medical Sciences (Basic and Clinical), and Pharmaceutical Sciences; Exact Sciences and Engineering include Chemical sciences, Engineering sciences, Information and Computer science, Mathematical Sciences, Physical sciences and technologies, and applied sciences; and Natural and Environmental Sciences include Agricultural Sciences, Earth and Marine Sciences and Biological sciences.
} 
the data shows that most co-authorships are within scientific domains and scientific fields. Our working sample's largest share of co-authorships is within the Biological Sciences, Chemical Sciences, Health Sciences, the Physical sciences, and the Agricultural sciences (Table 2.1). This is the case for both, ties firstly formed and those that persist.

Even the ties across scientific domains are within disciplines with rather complementary specialties, such as the Biological Sciences and Health Sciences, Biological Sciences and the Medical Sciences, and the Biological Sciences and the Chemical sciences.

Table 2.1 Tie Formation and Persistence by scientific field of co-authorships

\begin{tabular}{|c|c|c|}
\hline Within scientific domains & Formation & Persistence \\
\hline Biological Sciences - Biological Sciences & $16 \%$ & $18 \%$ \\
\hline Biological Sciences - Agricultural Sciences & $8 \%$ & $10 \%$ \\
\hline Chemical Sciences - Chemical Sciences & $8 \%$ & $7 \%$ \\
\hline Health Sciences - Health Sciences & $8 \%$ & $8 \%$ \\
\hline Physical Sciences - Physical Sciences & $7 \%$ & $7 \%$ \\
\hline Agricultural Sciences - Agricultural Sciences & $5 \%$ & $5 \%$ \\
\hline Health Sciences - Medical Sciences: Basic & $3 \%$ & $4 \%$ \\
\hline Earth and marine Sciences - Biological Sciences & $3 \%$ & $3 \%$ \\
\hline Engineering Sciences - Engineering Sciences & $2 \%$ & $2 \%$ \\
\hline Medical Sciences: Clinical - Health Sciences & $2 \%$ & $3 \%$ \\
\hline Earth and marine Sciences - Earth and marine Sciences & $2 \%$ & $2 \%$ \\
\hline Chemical Sciences - Physical Sciences & $2 \%$ & $1 \%$ \\
\hline Technologies and applied Sciences - Chemical Sciences & $1 \%$ & $1 \%$ \\
\hline Mathematical Sciences - Mathematical Sciences & $1 \%$ & $2 \%$ \\
\hline Engineering Sciences - Physical Sciences & $1 \%$ & $1 \%$ \\
\hline Medical Sciences: Basic - Medical Sciences: Basic & $1 \%$ & $1 \%$ \\
\hline Across scientific domains & Formation & Persistence \\
\hline Biological Sciences - Health Sciences & $6 \%$ & $4 \%$ \\
\hline Biological Sciences - Medical Sciences: Basic & $3 \%$ & $3 \%$ \\
\hline Biological Sciences - Chemical Sciences & $2 \%$ & $2 \%$ \\
\hline Technologies and applied Sciences - Biological Sciences & $1 \%$ & $1 \%$ \\
\hline Technologies and applied Sciences - Health Sciences & $1 \%$ & $0 \%$ \\
\hline Other & $18 \%$ & $16 \%$ \\
\hline Total & $100 \%$ & $100 \%$ \\
\hline
\end{tabular}


Interestingly, the shares of most co-authorships within and across domains are overall the same for ties formed and those that persist, suggesting that collaborations within these disciplines do not become stronger when the collaboration is repeated.

\subsubsection{Status homophily}

We use five variables to measure the ascribed and achieved status of the researchers in our sample.

Ascribed status. Age similarity is an important homophily variable that causes ties to form and persist. Our variable Age difference measures whether co-authors with a similar age, measured by their absolute difference in age, are more likely to form ties and to make them persist. On average, the age difference between co-authors that form a first tie is of close to 12 years. Co-authors that persist their ties have an age difference of 10 years between them. However, the mode of both age distributions for tie formation and persistence is of 3 years difference between the co-authors. The researchers included in our working sample were, on average, 50 years old in 2011.

We include three variables to understand the effect of academic experience on tie formation and persistence: the experience difference between the co-authors, measured as the absolute difference of the number of years since obtaining their doctoral degree between co-authors $i$ and $j$; the publication intensity of the co-authors, measured as the sum of the total number of scientific publications published by co-authors $i$ and $j$ in t-1; and the publication history of the co-authors, measured as the sum of the total number of publications of $i$ and $j$ in their full academic history, up until 2011.

Descriptive statistics show that co-authors tend to collaborate with others of similar academic experience. The distribution of the experience difference variable is highly skewed, with most collaborations happening between co-authors that have an academic experience difference of three years. This is the case for both tie formation and persistence.

Concerning publication intensity, co-authors that make their ties persist are, on average, more productive than those that do not. Among researchers forming a first tie, their average number of publications in $t-1$ is 3.9 , compared to 6.7 for those that make their ties persist (Figure 2.1). The variable publication history also shows that, on average, ties that persist involve co-authors that are more productive, with an average of 127 publications through their full academic careers, compared to 102 publications for those that do not have persistent ties.

Achieved status. Collaboration is more likely to occur between researchers who are at similar stages of their research careers. However, it is also the case that collaboration across researchers with different tenure status might happen when more junior researchers join forces with seniors through 
symbiotic relations in which a junior brings new methodological skills and a senior offers access to resources (Dahlander and McFarland, 2013).

We measure achieved status by using the NRF rating received by the researchers. We use a measure of similarity in tenure status by coding a dummy variable equal to 1 when co-authors hold the same NRF rating in t-1 (same NRF rating $t-1$ ). We classify researchers into two rating categories: Low Ranks and High Ranks. Low Ranks include junior researchers with ratings $P, Y$, or $L$, while High Ranks include more senior researchers with ratings $A, B$, or $C$.

Figure 2.1 Number of publications of the co-authors (sum of $i$ and $j$ ): Tie formation vs. Tie persistence

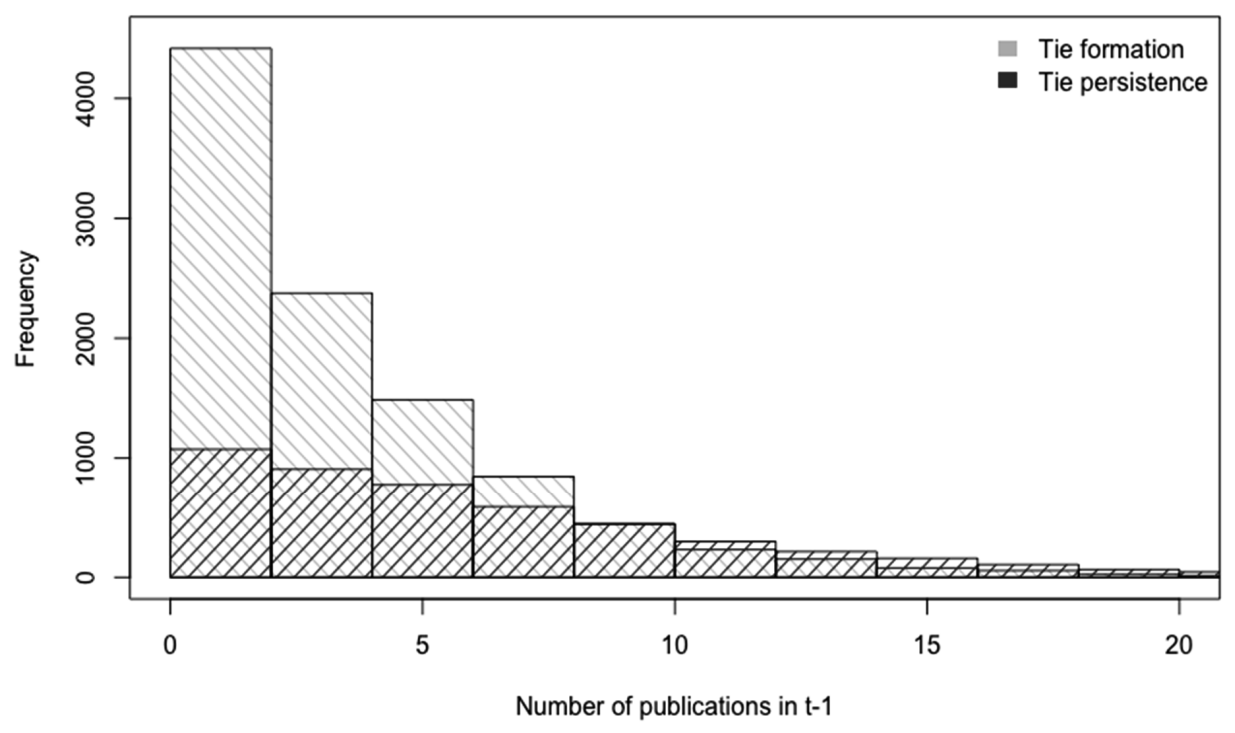

When looking at co-authors' characteristics in our sample, we note that the number of dyads formed between researchers of the same and different ratings is almost equal in number. The former represents $42 \%$ of the total, compared to $41 \%$ for the latter. The ties that persist, $34 \%$ of the total are among co-authors with different ratings, compared to $29 \%$ among pairs with the same rating.

\subsubsection{Organizational Proximity}

We use three variables to proxy for the co-authors' organizational proximity: whether the coauthors work in the Same organization, whether they are affiliated to a South African institution (South African employment) and whether both have the Same qualifications path.

Employment in the same academic institution. It is often suggested that ties across different institutions are rare because of organizational differences, ways of working (e.g., work philosophy, work 
values, etc.), and lack of physical proximity. We developed a dummy variable that measures whether two co-authors are from the same academic institution or university at the moment of collaboration. The university system in South Africa underwent a major reform around 2004, and in those reforms, several universities merged or changed names. We use the most recent name of the university to account for comparability before and after 2004.

About $50 \%$ of all NRF rated researchers in the period 2000-11 are concentrated in only five academic institutions: the University of Cape Town (12\%), the University of Pretoria (11\%), the University of Stellenbosch (10\%), the University of Witwatersrand (9\%), and the University of Kwa-Zulu Natal (8\%). About $22 \%$ of all dyads in the tie formation model involve a co-author of these top universities. This share increases to $36 \%$ of all dyads in the tie persistence model.

Most of the collaborations in our working sample are among co-authors in different organizations. About $15 \%$ of all ties formed are among co-authors in the same organization. This share, however, increases to $29 \%$ among ties that persist over time.

Table 2.2 Tie Formation and Persistence among co-authors of main institutional affiliations of NRF rated researchers

Tie Formation

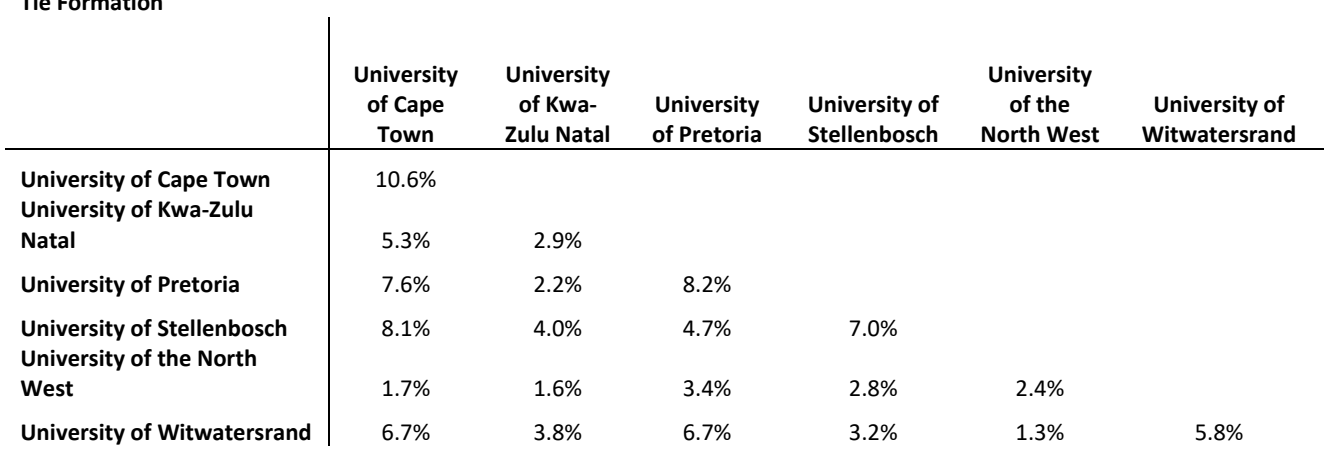

Tie Persistence

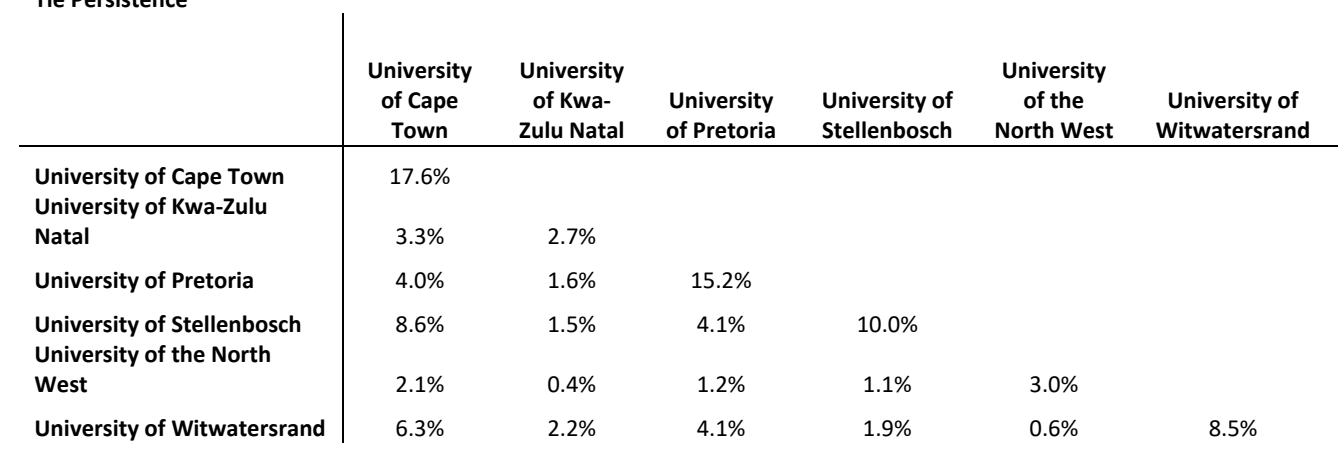


Table 2.2 shows the share of dyads among co-authors in the six universities with the most affiliations in our working sample. The largest share of formed ties is between co-authors affiliated to the University of Cape Town (10.6\%), followed by co-authorships between researchers of the University of Pretoria (8.2\%), and dyads of the University of Cape Town - University of Stellenbosch (8.1\%). The share of co-authorships increases mainly among co-authors of the same university, notably among researchers of the University of Cape Town (17.6\%), the University of Pretoria (15.2\%), and the University of Stellenbosch (10\%).

These initial descriptive statistics suggest that affiliation to the same academic institution is most important for making a tie persist over time, and less so to have it formed in the first place.

Employment in South Africa. One could expect that collaborations are more likely to happen among researchers that share common national values. Going beyond the institutional affiliation, we use a dummy variable to characterize if the co-authorships involve researchers employed by a South African institution. This variable also shows the extent of international collaborations of NRF researchers in the working sample.

South African employment seems to be an important determinant of forming and sustaining ties among NRF researchers. The majority of co-authorships happen between researchers with a South African affiliation. $71 \%$ of formed ties are among researchers in South Africa. This share increases to $92 \%$ of ties that persist over time.

Qualifications path. Our last variable aiming to understand the impact of the co-authors' organizational and institutional proximity is their qualifications path. We have access to data on where researchers received their academic training, in South Africa or abroad. The idea is that, as researchers follow a similar qualifications path, either by having all their academic training in South Africa, some training abroad, or all training abroad, this would signal a proximity element in the pair co-authors.

A first look at the data shows that the same qualifications path seems to be a more important determinant for tie persistence. About $41 \%$ of all co-authorships initially formed are among researchers with the same qualifications path. This share increases to $55 \%$ for ties that persist over time. Most of the researchers with the same qualifications path received all their education and training in South Africa, representing $30 \%$ of all ties formed and $48 \%$ of all ties that persisted.

\subsubsection{Social and community structure}

We use five broad Social Network Analysis (SNA) variables to understand how network structure and network characteristics influence tie formation and tie persistence: membership to network communities, tie intensity, the density of local neighborhoods, network distance, and triadic closure. 


\subsection{Membership to Network communities}

In network theory, communities are defined as sub-networks that are locally dense even though the network as a whole is sparse. Members are assigned to a community based on having more links within it than outside it. Communities typically correspond to functional subunits, namely sets of vertexes with a property or function in common.

From a technical point of view, community detection algorithms in network theory are used to identify different modules, and their hierarchical organization, by using the information encoded in the network topology. Traditional techniques to identify communities in networks use partitional clustering to find mutual similarity between vertices joined in groups (or communities) (Fortunato, 2010).

Because most community detection algorithms are not deterministic, and different algorithms use different community assignment criteria, we use five community algorithms offered by the i-graph package in R: fast greedy modularity optimization, the Infomap algorithm, walktrap community, multilevel optimization of modularity, and spinglass community.

Following the literature, we can expect that same social group members are likely to act in a similar way (1), are likely to be bounded to same academic disciplines, or to disciplines that are close enough from each other (e.g., life sciences and earth sciences; medicine and health, etc.) (2); and are likely to be part of the same organization (university, research center, etc.), and thus share similar academic 'values' (3). Moreover, if the community detection algorithm performs well, the researchers' membership to communities across years should be stable. Ideally, even if the partitioning results in changing the number of community members (i.e., we would expect that some researchers retire and others join the collaboration network over time). Community members should not change radically over time.

Community algorithms face a trade-off in partitioning the network. One common objective is to minimize the number of links that cross partitions. The trivial solution to that objective would be to consider the whole network as one partition. However, this is not informative. Further, opposing objectives need to be introduced to provide a 'reasonable' partitioning, such as equally sized partitions or a 'reasonable' number of partitions. Opposing objectives create a trade-off that is balanced by each algorithm in a certain way.

Table 2.3 provides basic descriptive statistics on the results of the five community algorithms. The number of components (or partitions) results from the algorithm itself, except for spinglass, which is fixed ex-ante and set at 10. Each community algorithm provides a certain balance between two opposing objectives. The number of ties within communities over the total number of ties should be relatively high 
(minimal cut). The number of potential ties within communities over total potential ties should be relatively low (many, equally sized partitions). The modularity measure combines both aspects.

In our econometric models, we incorporate the differences in membership affiliations between a pair of co-authors of each community detection algorithm as independent variables. Using these methods, we aim to identify different types of groups of researchers: those interacting in close networks, arguably fostering trust and the transfer of tacit knowledge, and those interacting in open networks, with structural holes and facilitating knowledge creation (Lambiotte and Panzarasa, 2009).

Table 2.3 Basic statistics on community algorithm results applied on the year 2010 network (20002009)

\begin{tabular}{rrrrrr}
\hline & infomap & walktrap & multilevel & fastgreedy & spinglass \\
\hline Components & 490 & 507 & 111 & 120 & 10 \\
Isolates & 0 & 30 & 0 & 0 & 0 \\
Pairs & 110 & 177 & 47 & 49 & 0 \\
Ties in comm. over total ties & 0.44 & 0.50 & 0.61 & 0.62 & 0.61 \\
Mot. ties in comm. over total pot. ties & 0.00 & 0.01 & 0.02 & 0.03 & 0.10 \\
Modularity & 0.80 & 0.80 & 0.87 & 0.87 & 0.54 \\
\hline
\end{tabular}

Before discussing our econometric models' results in the following section, we take a deeper look at what these algorithms explain and how we use them to interpret our results.

Social correlates of network communities. To what extent are co-author network partitions offered by community algorithms 'reasonable' from a social perspective? We investigate whether two scientists falling in the same community (i.e., network partition) tend to have common social characteristics, including gender, ethnicity, citizenship, broad scientific field, scientific domain, or same employing organization (at the end of the accumulation period).

Table 2.4 shows the probability of having a common characteristic (column: $D$ for Different and $S$ for Same) conditional on being a member of the same community (rows) under different partitioning algorithms applied on the 2010 network. For example, the coordinate 'Gender Infomap' tells that probability of having the same gender is 0.39 , given that two nodes are from different communities, and is 0.61 when scientists fall in the same community. We find a weak association between same community and gender/ethnicity/citizenship and a somewhat stronger association between same community and broad scientific field and same work affiliation. Tendencies are similar across community algorithms. 
Table 2.4 Social correlates of network communities

\begin{tabular}{ll|cccccccccc} 
& & \multicolumn{2}{c}{ Infomap } & \multicolumn{2}{c}{ Walktrap } & \multicolumn{2}{c}{ Multi-level } & \multicolumn{2}{c}{ Fastgreedy } & \multicolumn{2}{c}{ Spinglass } \\
& & D & S & D & S & D & S & D & S & D & S \\
\hline \multirow{2}{*}{ Gender } & D & 0,41 & 0,59 & 0,41 & 0,59 & 0,41 & 0,59 & 0,41 & 0,59 & 0,41 & 0,59 \\
\multirow{2}{*}{ Ethnicity } & S & 0,39 & 0,61 & 0,44 & 0,56 & 0,40 & 0,60 & 0,41 & 0,59 & 0,41 & 0,59 \\
& D & 0,34 & 0,66 & 0,34 & 0,66 & 0,34 & 0,66 & 0,34 & 0,66 & 0,34 & 0,66 \\
Citizenship & S & 0,25 & 0,75 & 0,24 & 0,76 & 0,30 & 0,70 & 0,28 & 0,72 & 0,33 & 0,67 \\
\multirow{2}{*}{ Scientific Field } & D & 0,36 & 0,64 & 0,36 & 0,64 & 0,36 & 0,64 & 0,36 & 0,64 & 0,35 & 0,65 \\
& S & 0,33 & 0,67 & 0,27 & 0,73 & 0,35 & 0,65 & 0,35 & 0,65 & 0,36 & 0,64 \\
Affiliation & D & 0,91 & 0,09 & 0,92 & 0,08 & 0,92 & 0,08 & 0,92 & 0,08 & 0,92 & 0,08 \\
& S & 0,62 & 0,38 & 0,77 & 0,23 & 0,77 & 0,23 & 0,77 & 0,23 & 0,88 & 0,12 \\
& D & 0,93 & 0,07 & 0,93 & 0,07 & 0,94 & 0,06 & 0,94 & 0,06 & 0,93 & 0,07
\end{tabular}

Besides organizational, scientific, and stable social characteristics, we expect that collaboration behavior differs across communities. One aspect of collaboration behavior is the number of co-authors per paper a member of a given community may have. We calculate the average number of co-authors on each scientist's papers within the period for network accumulation.

Figure 2.2 shows the distributions of the average number of co-authors per scientist ( $y$-axis) for communities with 20 or more scientists (x-axis). The example is in the year 2010 network with a partitioning obtained using the fastgreedy algorithm. The pattern is very similar across both time and community algorithms. A comparison of boxplots shows that the authoring behavior in terms of the average number of co-authors is different across communities. 
Figure 2.2 Boxplots of the average number of co-authors by partition (size larger than $\mathbf{2 0}$ members) obtained using the Fastgreedy algorithm on the 2010 co-authorship network.

The order of boxplots (i.e., partitions) is arbitrary. Distributions differ by partition.

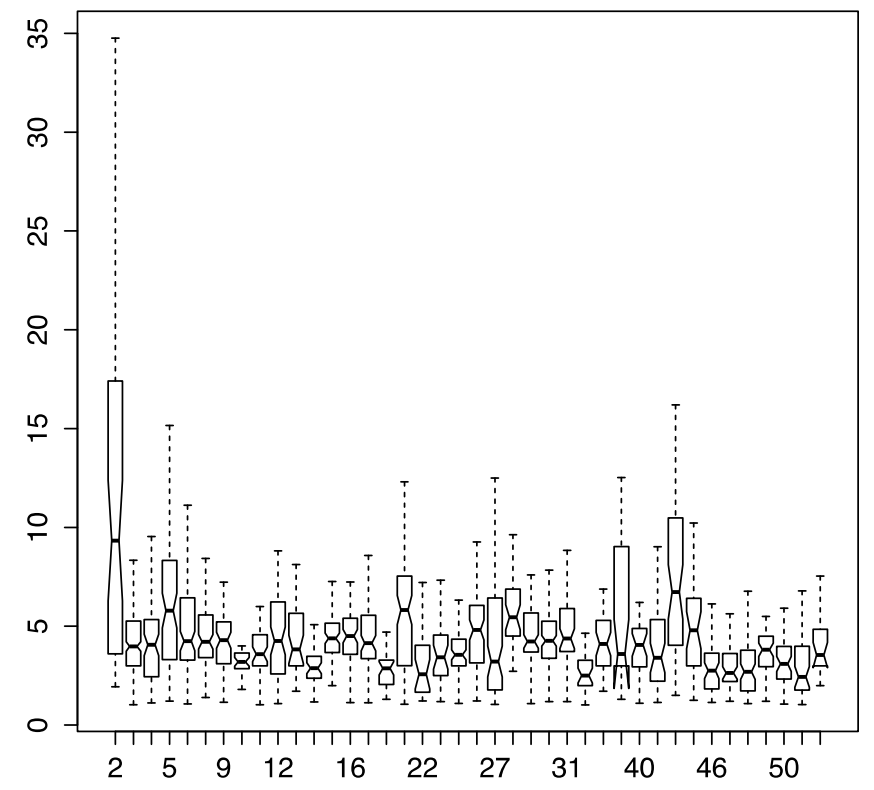

Differences in the average numbers of co-authors are typically thought to be caused by the scientific subject. For example, experimental proton physicists at a large hadron collider need to collaborate more extensively than traditional mathematicians due to the subject matter.

Community membership and tie formation. How is community membership (as measured with community detection algorithms on the prior, accumulated network) related to tie formation? We distinguish between pairs with a prior tie in the prior network (the same as used for community detection) and pairs without having a prior tie. We only consider dyads to be at risk of forming a tie when both dyad members actually formed a tie in the given year. Furthermore, we consider only nodes present in the prior network to not confuse tie formation with entrants and tie formation across communities.

Being grouped in the same community in the accumulated network (i.e., network 2000, 2005, or 2010 ) is informative for tie formation in the next year. Dyads without (with) prior ties have a probability of tie formation of around $0.001(0.4)$ when they are not in the same community and around $0.08(0.9)$ when they are in the same community. 
Out of 12,234 dyad-year observations in the formation panel, in 898 cases (7\%), a dyad is found to be in the same community with the fastgreedy community detection algorithm in the network of all rated SA scientists we have information about. $23(1.1 \%)$ dyads are in the same community throughout, 1731 (83.1\%) never in the same community, and $328(15.8 \%)$ dyads sometimes in the same community. This may be interpreted that community belonging is not a binary thing.

Community membership and tie persistence. Scientific communities can be relatively stable based on or result in stable factors such as a common identity, common language, common behavior, and fields of interest. Most community detection algorithms are applied to individual cross-section networks without a time dimension, including those we consider in this research. Partitioning subsequent networks create a problem of community identification. Therefore, we do not try to trace communities themselves, i.e., trying to map communities from one year to a subsequent year. Instead, we rely on relationships among community members.

Partitioning is stable if two agents falling into the same partition in one year tend to fall in the same partition in the next year. More detailed, we are interested in the probability that two agents $i$ and $j$ fall in the same partition in year $t$, conditional on them falling in the same partitioning in year $t-1$. A natural estimate of this is the corresponding fraction, or the pairs of agents that belong to the same community in two subsequent years (say 2009 and 2010), over the pairs of agents that belong to the same community in the prior year (2009) and that are also observed in the 2010 network.

Using the fastgreedy algorithm on the $2009 / 2010$ network yields a conditional probability of about $50 \%$, while for the walktrap algorithm, it is about $33 \%$. Hence, community membership may be (more or less) persistent depending on the community algorithm used. One plausible reason for the differences in the conditional probabilities is that walktrap compared to fastgreedy provides more components in general, and in particular more small communities of size one or two.

To see whether this is a valid explanation, we investigated the walktrap algorithm in greater detail. We ran the same test on pairs, which fell into communities with more than 10 members in the prior year. This, however, does not alter the conditional probabilities. Therefore, we restricted pairs falling into larger communities in the prior year and nodes falling into larger communities in the current year. This also does not alter the conditional probabilities. Further increasing the size of larger communities to 20 has no effect. Thus, it is not the case that many scientists are part of larger communities in one year and rather isolated in the next or prior year. This suggests that larger fractions of partitions in one year are combined in different partitions in the next year. The same holds for the fastgreedy algorithm (but on a higher overall level of 50\%). We made sure that non-persistence is not a result of algorithm randomness. Running the same exercise on the same network creates a conditional probability of one. 


\subsection{Other network characteristics}

Finally, we also include four additional network variables in our models: tie intensity, the density of local neighborhoods, network distance, and triadic closure.

Tie intensity. We measure tie intensity by counting and summing the number of ties a pair of coauthors $i$ and $j$ have in a given year. The idea is that co-authors with more ties and hence are more connected in the network have a higher propensity to seek out more ties and make these persist over time, including between each other.

Dyads that persist over time involve co-authors that have on average a larger number of ties. Ties that were successfully formed were among co-authors that had on average 4.8 ties in $t-1$. This number increases to 6.3 for those dyads that persisted over time.

Local neighborhoods. We measure each dyad's neighborhood's size, or the sum of the number of neighbors of each dyad, to understand how the local density of the co-author's neighborhood affects tie formation and persistence. One can expect that co-authors with many neighbors will be more likely to form and sustain ties.

Descriptive statistics show that, indeed, this is the case. All ties that persist over time involve coauthors that have on average 22 neighbors, which is about twice the number of neighbors of the tie formation dyads, of an average of 10 neighbors.

Network distance. We include four dummy variables to measure the effect of network distance in $t-1$ between the co-authors in a dyad on tie formation and persistence. The dummy variables would take the value of 1 if a pair of co-authors had a network distance of 2 in $t$-1 (Distance 2), 3 (Distance 3), 4 (Distance 4), or 5 and more (Distance $>=5$ ). We expect that co-authors closer to each other (i.e., with a shorter distance between them) to be more likely to form ties and make them persist.

Triadic closure. Finally, we include a dummy variable taking the value of 1 when co-authors $i$ and $j$ are linked by an indirect tie in $t-1$. We can expect that co-authors that share an indirect tie or common collaborator are more likely to form ties and also make them persist.

\subsection{Methodology}

We follow the estimation approach of Dahlander and McFarland (2013). We model the time to first tie formation of a dyad, and, if a first tie has formed, time to second tie formation, or tie persistence. Interest is in how several (time-varying) factors, or covariates, influence tie formation. The ties we consider are co-authorship ties for which we know the year when the paper was published. Dahlander and McFarland (2013) estimate a discrete-time hazard model of the form (notation as in Allison (1982)): 


$$
P_{i j, t}=\operatorname{Pr}\left(T_{i j}=t \mid T_{i j} \geq t, x_{i j, t}\right)
$$

where, $P_{i j, t}$ is the hazard rate of dyad $i j$ forming a first tie in $t$. The hazard rate is the conditional probability that the random variable $T_{i j}$, time to tie formation if a tie is formed, conditional on time duration being longer than $t$ and time-varying (dyad specific) covariates $x_{i j, t}$ (realized and hence lower case).

Allison (1982), citing Brown (1975), nicely shows that this discrete-time hazard model can be estimated by estimating a binomial model. For example, when we specify the hazard rate to be of the logit form, i.e.

$$
P_{i j, t}=\frac{\exp \left(x_{i j, t} \beta\right)}{1+\exp \left(x_{i j, t} \beta\right)}
$$

we may estimate the hazard rate model on data where we have one observation per dyad-year with a dependent variable $y_{i j, t}=0$ if no tie is formed and $y_{i j, t}=1$ if a tie is formed in that year. Other parameterizations are possible. We use a logit estimation.

We employ this setting for two analyses: i) first, tie formation and ii) second, tie persistence (forming a tie after the first tie). While our observation period is the same for both analyses, 2000 to 2012, dyad specific time obviously differs in the two analyses. When we model the tie formation, the dyad is at risk from when both researchers start to be actively publishing up to the year where they publish the first paper together, or the observation gets censored because the observation period ends. When we model tie persistence, the dyad is at risk from the first year after publishing their first paper up to publishing a second paper or, again, if not, the observation period ends.

In our sample, we observe many dyads that are not observed to form a tie before the end of observation period 2012. These observations are said to be "right-censored". We also observe dyads that start to be at risk before the beginning of observation period 2000. Some of these dyads form the first tie before 2000. Their whole time at risk is outside of the observation period. These dyads do not enter the sample. Some dyads are at risk before 2000. However, they also stay at risk beyond 2000 and form a tie within the observation period or become censored. These observations are left-truncated. Including these dyads is likely to create a bias in the regression estimates because, in order to enter the sample, they need to "survive" a sufficient time. It is possible to account for this effect in constant covariates $x_{i j}$ because one can then get the probability to survive that long for respective dyads, but this is not possible for time-varying covariates. Therefore, we need to drop left-truncated dyads from the sample. 
In other words: we distinguish two types of times - the first is the calendar time measured in years, e.g., our observation period goes from 2000 to $2011\left(t=1,2,3, \ldots, t_{i j}\right)$. If the first year at risk is greater equal 2000, it is not left truncated (but it may be right-censored). If the first year at risk is lower than 2000 , the dyad is left-truncated. Denote $s_{i j}$ the number of years it takes a dyad at risk to enter the observation period $\left(s_{i j}=\max (0,2000-\right.$ first year at risk)). It becomes evident with this notation that we create a biased estimate when we include left-truncated dyads.

Allison (1982) shows that the above discrete-time survival model can be estimated by maximizing the log-likelihood:

$$
\log L=\sum_{i j=1}^{n} \sum_{t=0}^{t_{i j}} y_{i j, t} \log \left(\frac{P_{i j, t}}{1-P_{i j, t}}\right)+\sum_{i j=1}^{n} \sum_{t=0}^{t_{i j}} \log \left(1-P_{i j, t}\right)
$$

where $y_{i j, t}$ is a dummy whether a dyad $i j$ formed a fist tie in $t$.

For left-truncated dyads, we can split the sums into time periods before and after entering the observation period (at $t=s_{i j}$ ):

$$
\log L=\sum_{i j=1}^{n} \sum_{t=0}^{s_{i j}-1} y_{i j, t} \log \left(\frac{P_{i j, t}}{1-P_{i j, t}}\right)+\sum_{i j=1}^{n} \sum_{t=0}^{s_{i j}-1} \log \left(1-P_{i j, t}\right)+\sum_{i j=1}^{n} \sum_{t=0}^{t_{i j}} y_{i j, t} \log \left(\frac{P_{i j, t}}{1-P_{i j, t}}\right)+\sum_{i j=1}^{n} \sum_{t=0}^{t_{i j}} \log \left(1-P_{i j, t}\right)
$$

The first term is always zero since no dyad is included in the sample, which formed a first tie before 2000. However, the second term cannot be specified since $P_{i j, t}$ is a function of the time-varying covariate $\left(x_{i j, t}\right)$, which is unmeasured and hence not available for years before the observation period. We may, at most, include the third and the fourth term in our likelihood. However, there is no reason to believe that maximizing only the last part of the likelihood yields the same coefficient estimates as maximizing the (non-feasible) complete likelihood. In principle, one may try to estimate the unmeasured covariate realizations jointly with the coefficient estimates, but that is likely too much.

The above justifies our decision of not including left-truncated observations in our regressions.

\subsection{Results}

Table 2.5 shows the results for the clogit tie formation models. All variables tested in each model are the same, except for the community detection method used for identifying the social communities of researchers (social proximity). Five different community detection algorithms are tested: Fast-greedy modularity optimization (Model 1), the Infomap method (Model 2), Walktrap community (Model 3), Multilevel optimization of modularity (Model 4), and Spinglass community (Model 5). Given the relatively higher correlations between the network distance variables (Network distance 2, 3, 4, and 5) and some 
of the community detection algorithms, the $\mathrm{B}$ models (Model 1B, 2B, 3B, 4B, and 5B) omit the network distance variables from the estimation. The results show that across models, there are no clear differences in the estimated significant coefficients.

Table 2.6 presents the results for the analysis of tie persistence. We used a clogit model in which time hazard dummies of years after first collaboration estimate tie persistence. The tie persistence dummy takes the value of 1 each year when the same pair of NRF authors repeated their collaboration through an NRF rated publication. Because ties in this analysis are conditional upon a tie having been formed, only those ties that actually formed in the first place are included in the persistence model. We mimicked the approach as for the tie formation model, testing different community detection algorithms from Models 6 to 10 (and with and without the network distance variables included - B models).

Below, we use the results presented in Tables 2.5 and 2.6 to interpret our findings. 


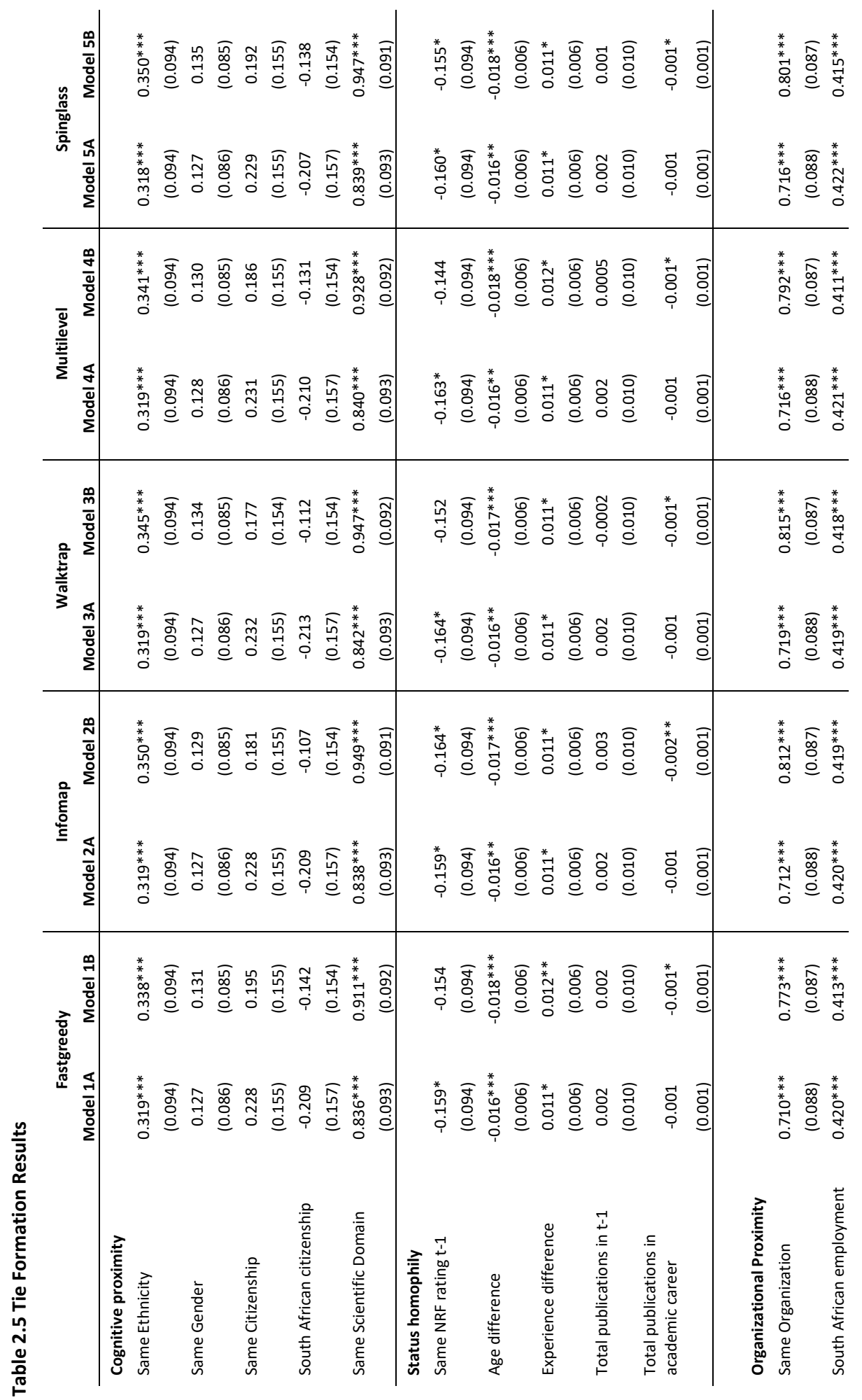




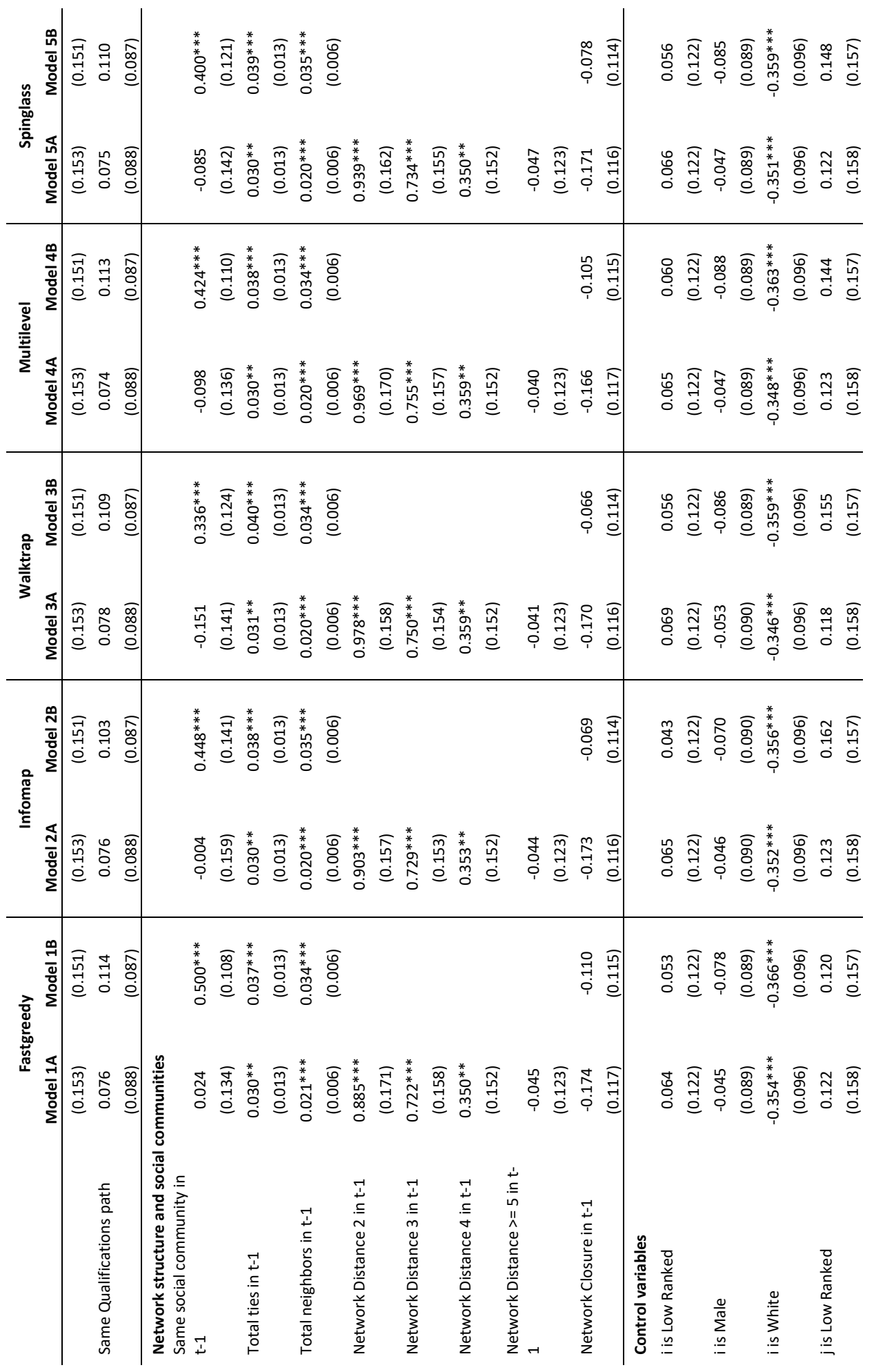




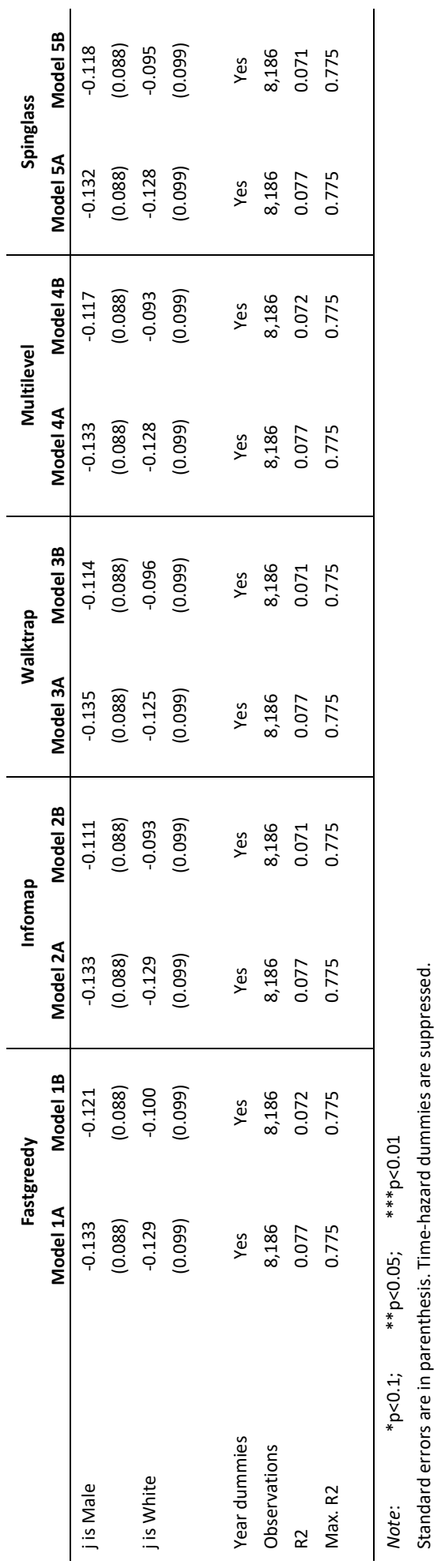




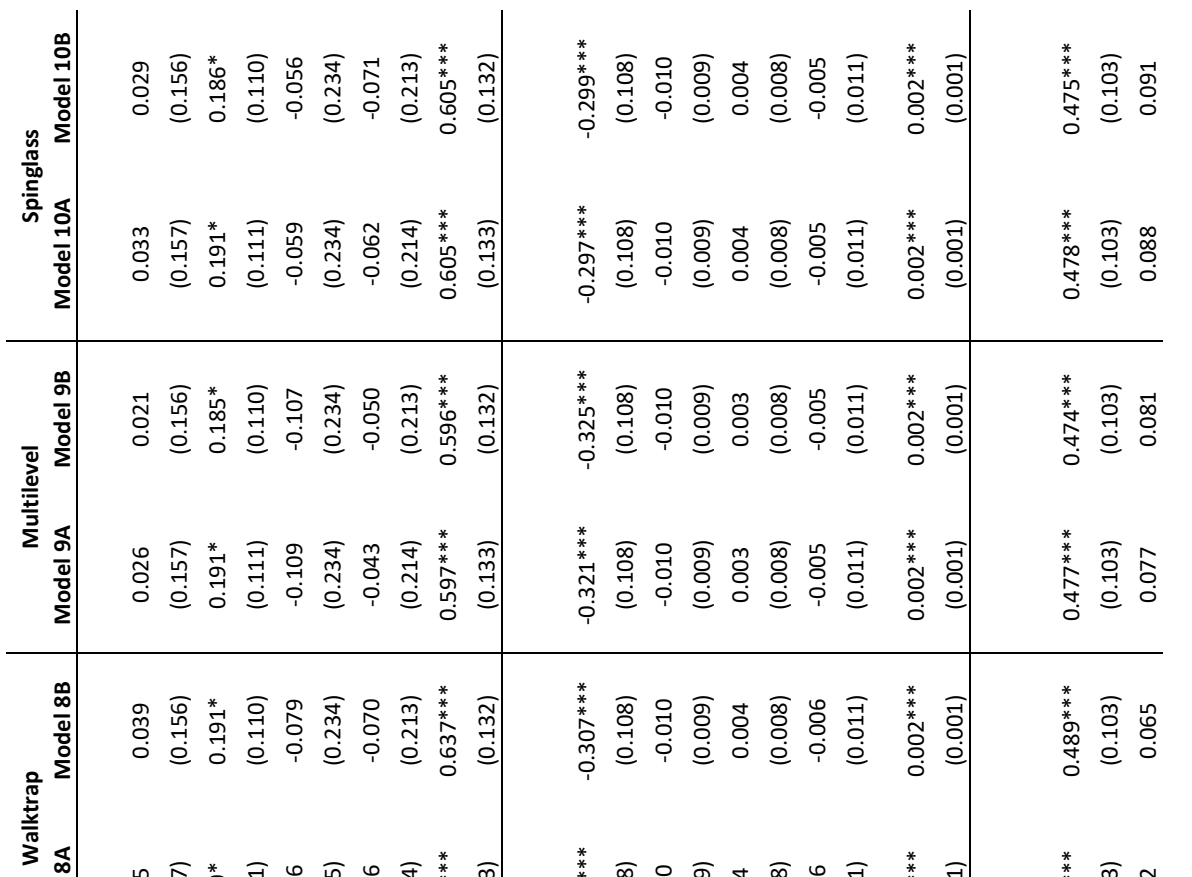

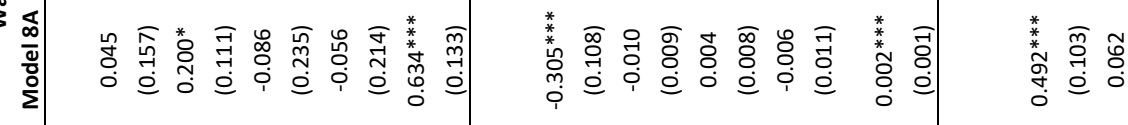

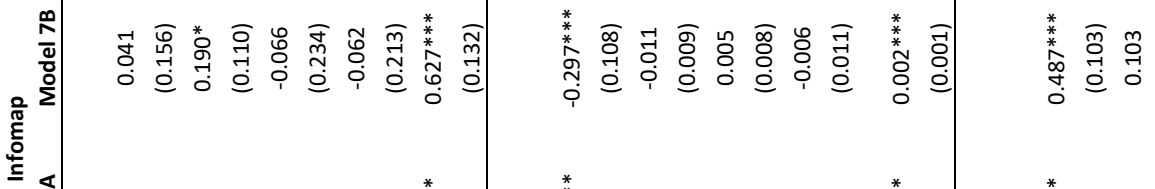

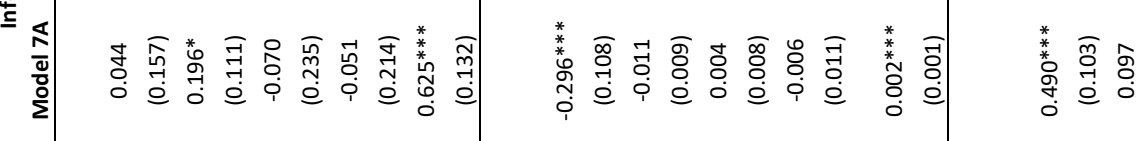

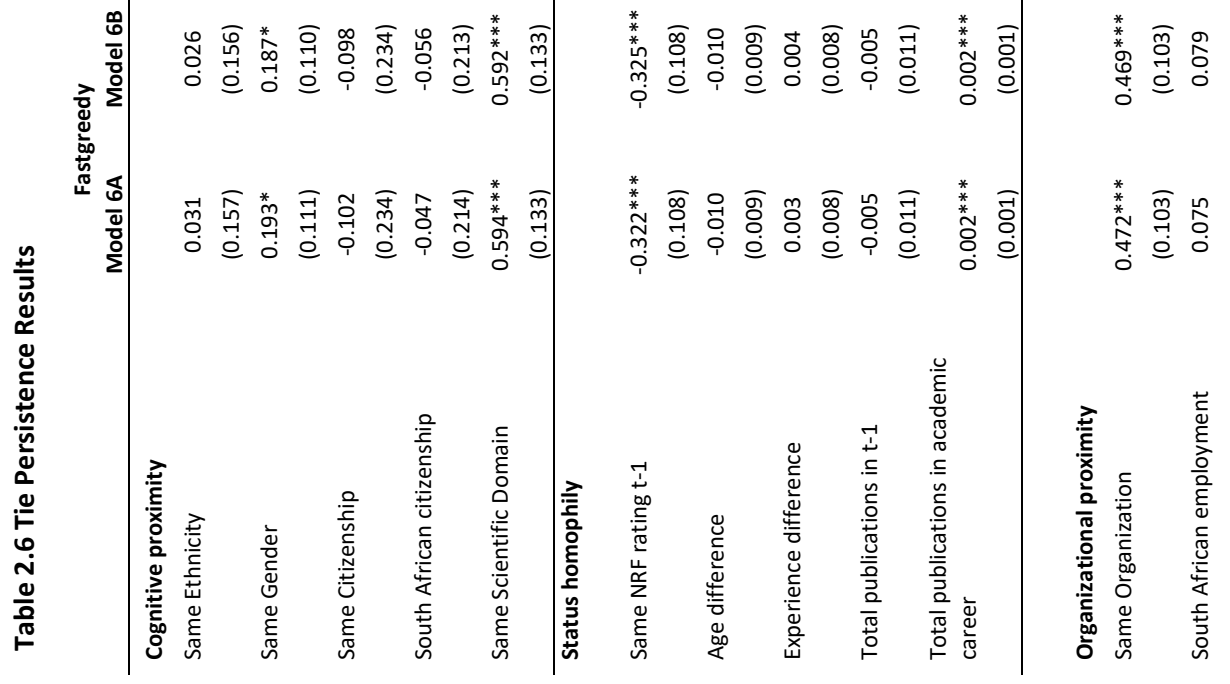




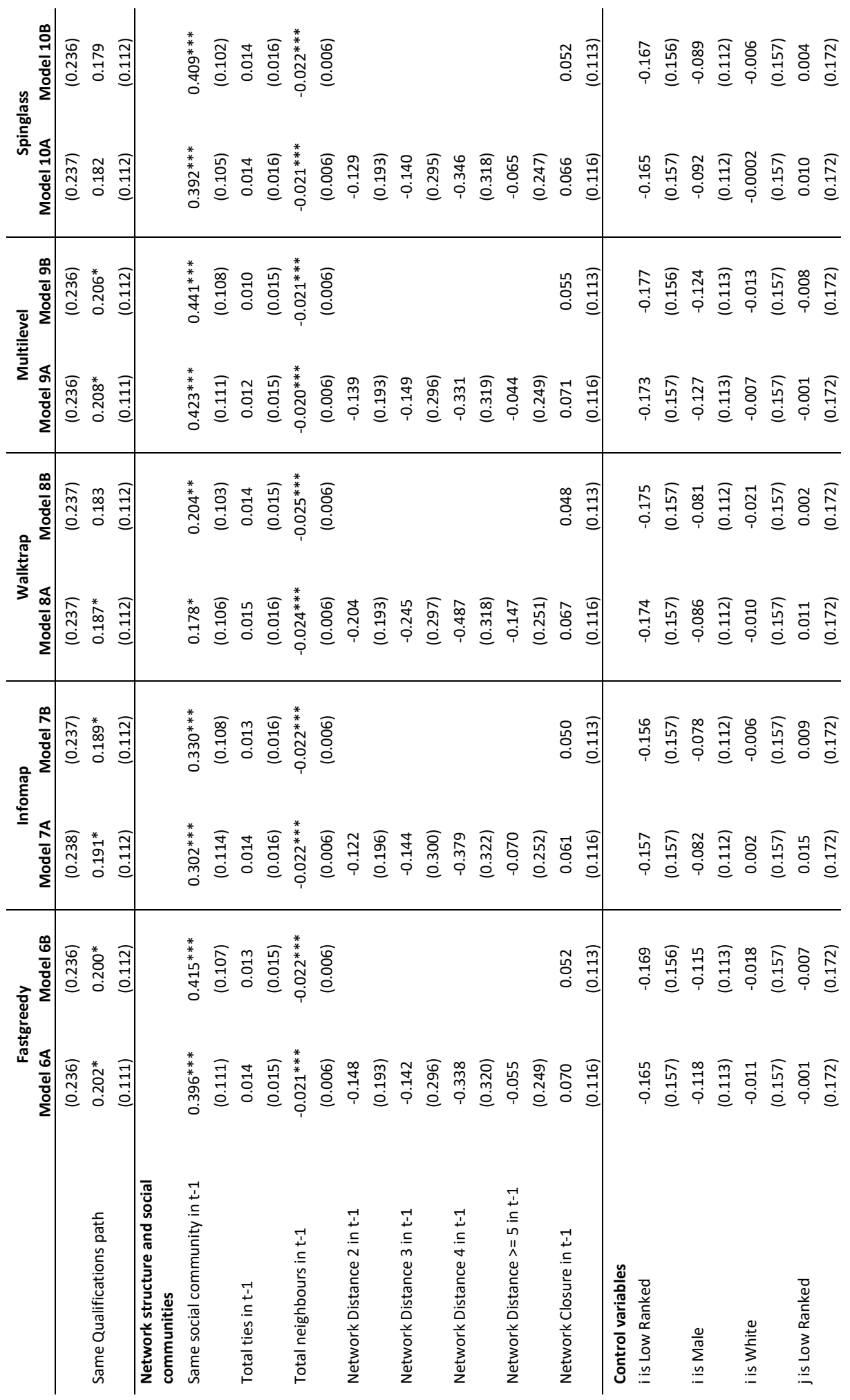


Chapter 2

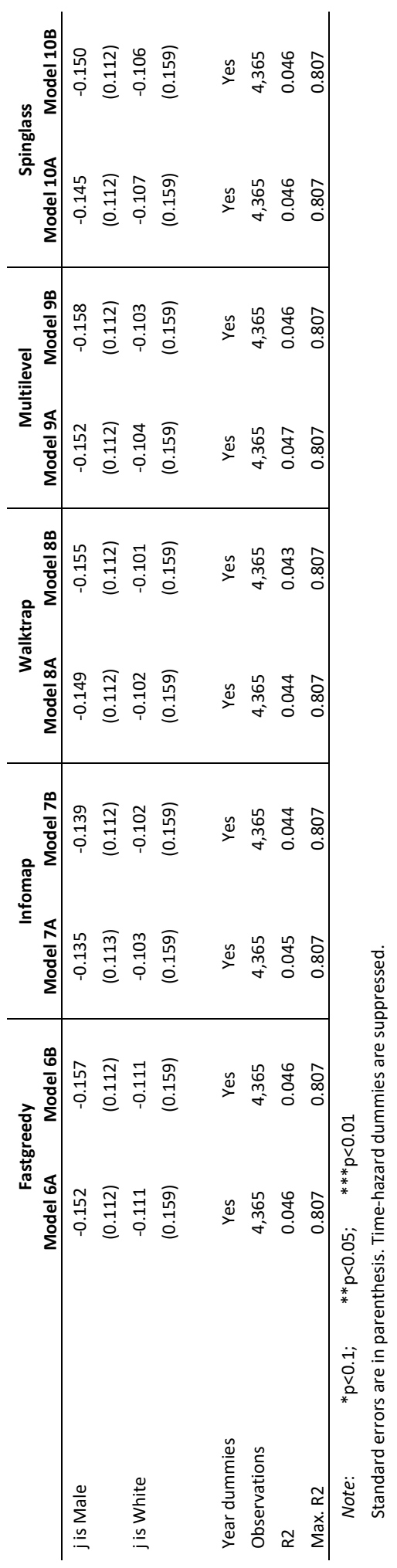




\subsubsection{Cognitive proximity}

We argued that researchers who share interests and similar social characteristics have more in common and are more likely to form ties. As these variables cannot change with time and thus cannot grow stronger, we argued that links that exist are likely to be homophilous, and thus cognitive proximity would have little (or less) influence on tie persistence.

We incorporate five variables related to the pair's cognitive proximity: same ethnicity, same gender, same citizenship, whether both researchers have South African citizenship, and same Scientific domain. Our regression results show that same Scientific domain is a positive and highly significant determinant of tie formation and tie persistence. This is expected.

For tie formation, same ethnicity is positive and significant, whereas same gender is so for tie persistence. These results suggest that when looking for a first-time collaborator, researchers look for someone with their same ethnicity: white researchers are most likely to collaborate with other whites and non-whites with non-whites. Once this initial link is done, for making a tie persist, researchers will look for others in the same gender group: females would stick to other females, and males would do the same. The cognitive preferences are thus adapted over time, prioritizing ethnicity and then gender.

\subsubsection{Status homophily}

We find that the determinants of tie formation and persistence are different concerning status homophily. Our results support the idea of complementarity of status and experience among researchers and the importance of heterophily for tie formation.

Collaborations are more likely to be formed among researchers with different acquired status or NRF rating, and those whose academic experience in length is different. In contrast, collaborations are less likely to happen for the first time among researchers whose age difference is higher. Researchers seem to look for complementary skills and knowledge when collaborating, which is in line with the increasing dominance of teams in publications patterns (Wuchty et al., 2007), giving rise to specialization and collaboration gains.

Interestingly, different NRF rating -or status heterophily, is even more important for making a tie persist. This result should be interpreted with care, as the regression results may simply mimic the structural characteristics of the community of NRF rated researchers, which is largely dominated by Low Ranks relative to High Ranks. High-ranked researchers might indeed surround themselves with Lowranked peers for doing the 'hard work'. At the same time, Low-ranks benefit from the collaboration by acquiring experience and reputation from the High-ranks. Given the low number of High-ranks, these might well be surrounded by a team of researchers that have not acquired High-rank status. 
The pair's joint overall productivity during their observed academic career is the only positive and significant determinant for tie persistence concerning their observed academic status. This shows that productivity overall is indeed a positive and important requirement for making a tie persist.

\subsubsection{Organizational proximity}

We include in our models three variables to understand the effects of organizational structures in research collaboration: whether the pair of researchers work in the same academic institution, whether both are employed in a South African institution, and whether both followed the same qualification paths (i.e., all obtained academic degrees are South African, a mix of foreign and South African degrees, or all foreign degrees).

The regression results show slight differences in tie formation and persistence. Organizational proximity -or working in the same organization, is key for making researchers know each other, as organizational foci expose individuals to one another. This is the case for tie formation and persistence, although much more important for tie formation. This finding is in line with previous research (Dahlander and McFarland, 2013, Evans et al., 2011, Reagans, 2010).

Having both a South African affiliation is also a positive and significant determinant for tie formation, but not for tie persistence. Having a South African affiliation is thus important initially but becomes less significant once the researchers know each other.

Having obtained the same qualifications path is only a positive and significant determinant of tie persistence and not of tie formation. In other words, once a tie is formed, researchers are more likely to pursue the collaboration further with others that share the same qualifications experience or have intellectual similarity acquired through its qualification and training experience.

\subsubsection{Network structure and social communities}

We include eight variables in our models to understand the effect of network structure and membership to social communities on tie formation and persistence.

We apply community-detection methods to partition the collaboration network. We aim to understand the effect of membership to the same social community on tie formation and persistence. We find that membership to the same community in $t-1$ is a positive and significant determinant of tie formation, only in our models where the Network Distance variables are excluded (B Models in Tables 2.5 and 2.6). Same social community is positive and significant for tie persistence in all our models (Tables 2.5 and 2.6), regardless of the community detection algorithm used. This finding supports the idea that 
social structure, beyond formal institutional and organizational structures, is important for tie formation and tie persistence.

By having a larger number of ties and neighbors, connectivity in the social network is also positive and significant for tie formation. However, surprisingly, it is not the case for tie persistence. In other words, researchers look for other researchers that are well connected in the network for a first collaboration. However, once a good fit is found, their peers' network position becomes irrelevant for making a tie persist. Even more, the aggregated number of neighbors of the pair of researchers becomes negative and significant for tie persistence, suggesting some saturation effects or 'exclusivity' effects on the collaboration.

The closer the researchers are from one another in $t-1$, measured by network distance, is also positive and significant for tie formation (up until distance 4, but not beyond), but it is not the case for tie persistence. This suggests that researchers tend to look for collaborators not far away from their network's neighborhood initially, and this selection becomes irrelevant once a first tie is made. Surprisingly, we find that network closure is not significant for tie formation or persistence.

\subsection{Discussion and Conclusions}

A large body of research argues that there are positive outcomes to research collaborations. To contribute to this research body for middle-income countries (MICs), we tested for tie formation and persistence determinants using a unique dataset on research collaborations from the National Research Foundation (NRF) of South Africa.

We highlight four factors: cognitive proximity, status homophily, organizational proximity, and social and community structure. We find that different factors are associated with the formation and persistence of research collaborations.

Tie formation is favored for researchers that are well connected and close to each other in the coauthorship network, have high cognitive and organizational proximity, and are part of the same social communities. In contrast, our results show that organizational proximity and social structure are the main factors making a tie persist over time. We find that first ties are more likely to be formed among researchers with the same ethnicity, while these are most likely to be sustained among researchers of the same gender.

Interestingly, the crude interpretation of tie persistence is that little matters apart from social structure and organizational proximity. Researchers thus give little attention to cognitive proximity and status homophily. What this suggests is that once a good fit between partners is found (in terms of the other explanatory variables), a tie will naturally persist within organizational boundaries since most of 
the explanatory variables do not change with time, so once a "good fit" is found, it is always a "good fit". Our findings thus contribute to differentiating the factors that determine the formation of ties vs. those that make ties be sustained over time.

Our findings suggest that NRF-researchers are not yet working in multi-disciplinary research. We discussed above that most co-authorships among NRF-rated researchers are within scientific domains and scientific fields. This finding suggests a rather 'classic' research system that does not reward or promote cross-domain and interdisciplinary collaborations. This is not exclusive of research systems in MICs. Interdisciplinary research is a difficult thing. It is often regarded as less quality. It is harder to publish, more difficult to fund, and less merited when seeking promotion.

However, there are no doubts about interdisciplinary research benefits, particularly for innovation, and in a world currently moving towards addressing global challenges through mission-oriented research (Mazzucato, 2018). Recent research has suggested that focusing on the researchers and their social interactions might help improve interdisciplinary research change, beyond focusing only on solving policy and structural issues to promote it (Callard and Fitzgerald, 2015).

As there is a lower tendency for NRF researchers to be involved in interdisciplinary research, it is also not surprising that research collaborations in our sample are more likely to happen within organizational boundaries. We find that organizational and physical proximity, as a consequence, is an important determinant of research collaboration among NRF-rated researchers. We showed as well that there is a high concentration of researchers and network ties in only a few academic institutions and a greater tendency to set-up initial research collaborations within South African academic institutions. This might reflect, once again, the characteristics of the reward and recognition system of the NRF rating system, and to a lesser extent, the 'inward' nature of the collaborations. In fact, our descriptive statistics show that for the full set of affiliations of the researchers in our working sample, going beyond the top South African universities, most collaborations happen across organizations.

Collaborations across organizations are likely to happen when researchers seek additional resources, being material, or in terms of human capital. Within-organizations collaborations might reflect highly competitive research environments and a more specialized labor division (Iglič et al., 2017). Some scientific disciplines and research fields, where researchers are bounded by specialized research infrastructures or laboratory work, might also explain collaborations within organizations. The fact that researchers collaborate more with researchers with different scientific status (or NRF rating) also supports the idea of division of labor in South African scientific teams. 
Next, how can we interpret our results on social structure coming from the community detection algorithms? We use these algorithms as a proxy to describe social structure. The idea is that community algorithms may provide a partitioning of co-authorship networks that proxies scientific communities. Hence, they are informative for co-authorship tie formation and persistence among scientists.

Ideally, we would like community membership in networks to actually say something about social membership and the structure of 'real-life' academic networks. In a similar manner as the emblematic Zachary Karate Club Model (Zachary, 1977), we are interested in knowing whether the researchers in our sample, beyond being linked through co-authorships, are related somehow beyond publication work. The idea is that community algorithms may provide a partitioning of co-authorship networks that proxies scientific communities. Hence, they are informative for co-authorship tie formation and persistence among scientists. In other words, in the absence of ground-truth benchmark networks for the NRF researchers' network, we hope that the communities we observe serve to explain other deep social information in our co-authorship networks.

Our methodological contribution in terms of the use of community detection algorithms is also, in a way, a methodological limitation. Above, we discussed possible interpretations of our social communities and social proximity results. However, one of the main challenges of the existing community detection methods in networks is their stochastic nature. Moreover, for all the algorithms we have tested, each vertex is assigned to a single cluster, while in (real) social networks, vertices, or researchers, are likely to be shared between two or more communities.

To account for this challenge, we have also tested the OSLOM (Order Statistics Local Optimisation Method) community detection algorithm, with similar results. OSLOM is a method based on the local optimization of a fitness function expressing the statistical significance of clusters to random fluctuations, estimated with Extreme and Order statistics tools. Thus, OSLOM results are somehow controlled for stochasticity. The algorithm can compute social communities' statistical significance using a tolerance $p$ value that is pre-defined as a fitness measure. Starting from one agent, it adds and subtracts agents until the partition is rejected at some level $p$. The higher $p$, the smaller the communities are because then communities are more easily rejected (likeliness to reject the null model - a random network).

However, Lancichinetti et al. (2011), the research team behind the OSLOM algorithm, remind us that 'in principle' one may never be able to sort out the influence of unobserved (potentially non-stable) characteristics of the agents from the effect of social interaction (per se) within the community. First, we would need to control for all internal characteristics (non-time variant characteristics could be controlled using fixed effects) and the time-varying characteristics; and most importantly, lower-level network measures such as prior ties, common partners, network distance, etc. 
Thus ideally, for future work, one should be able to sort out these both factors, the unobserved characteristics of agents' effect vs. the social interaction effect, as possible. In this direction, one could identify the probability of membership to the same community by producing a co-authorship matrix equal to the frequency with which an author $i$ is grouped with author $j$. If certain authors or groups of authors are frequently grouped, they would appear with high frequencies in the co-authorship matrix. The contrary would happen if the community memberships were highly variable. McNerney et al. (2013) follow a similar approach in the context of industry networks.

Additionally, one could characterize the community of which nodes ij are members, including measuring the effect of community size for pairs in the same community. This would approximate the community's encapsulation or non-openness because it is related to how unlikely a given community would be in a random network with degree sequence fixed. Communities with many within-links and few external-links would point to some inside/outside orientation of the members.

Moreover, at the beginning of the Chapter, we introduced that homophily can follow two mechanisms: it can be the consequence of personal choice, or structural opportunities for interactions can induce it. At best, the measurement of social communities is trying to serve as proxy explanations of choice homophily. Also, the organizational proximity variables can explain a part of induced homophily mechanisms. However, we are not able to distinguish these two mechanisms entirely separately from our data.

Clearly, more work in this area is needed. We hope to give some directions for further research with our findings.

Finally, and relevant to the following Chapters of this thesis (Chapter 3 and Chapter 4), gender and ethnicity are important determinants of scientific collaborations. We discussed above that the cognitive preferences of NRF researchers seem to adapt over time, prioritizing collaboration with other researchers of the same ethnicity for tie formation and others with the same gender for tie persistence.

As South African academic networks seem to be racially and gender homogenous, this finding points to the risk of segregation of non-white researchers and female researchers. Chapter 4 goes deeper into this issue by providing a close look at the interactions between gender and race in the South African context and their impact on scientific productivity for NRF researchers. The discussion section of Chapter 4 also expands on the implications from a research policy perspective, signalling the need to promote cross-race and cross-gender contacts and diversity in research networks. 


\section{Chapter 3. Micro and Macro effects of Gender Publication Productivity Gaps in Middle-Income Countries: an illustration for Mexico*}

Men largely dominate academia. Studies on women's presence in academia show that female researchers are seriously underrepresented in the highest hierarchy levels in virtually every country studied (Brouns, 2000, Timmers et al., 2010). What is the reason for this relatively weaker position of women in academia? Is the scant presence of women in the scientific community simply mirroring a pattern in society in general? How and why does career development differ among researchers? Do marriage, children, and other family-related factors influence research productivity? Are women in science in developing countries at a structural disadvantage relative to their male peers due to family responsibilities? Or, are women simply underperforming men in terms of research output?

This chapter's specific objective is to provide evidence of the existence and magnitude of the gender gap in scientific publication productivity in Mexico, controlling for various important determinants. The Chapter sheds light on the reasons for and consequences of inequality in female researchers' scientific performance and standing relative to male researchers in the Mexican context.

The Chapter is organized as follows. Section 2 discusses the determinants of the gender gap in scientific publication productivity following a revision of literature. Section 3 provides an overview of the Mexican scientific and research context. Section 4 explains the data, sample, methodological approach,

\footnotetext{
* This Chapter is based on joint work with Prof. Dr. Jacques Mairesse, and Prof. Dr. Robin Cowan. Previous versions of this Chapter were published as Rivera León et al., 2016 and Rivera León et al, 2017.
} 
and econometric framework. Section 5 presents our panel data econometric analysis findings, following an adapted version of an econometric approach developed by Mairesse and Pezzoni (2015). The analysis is performed on two large samples of Mexican researchers affiliated with public universities and public research centers (PRCS) that are members of the Mexican National System of Researchers (Sistema Nacional de Investigadores, or SNI). Section 6 presents counterfactual macro simulations to assess the magnitude of the macro-impacts of gender gaps and illustrate the potential impacts of a range of policy scenarios aimed at reducing them. Section 7 concludes with policy implications.

\subsection{Understanding the determinants of the gender productivity gap}

This Chapter focuses on what Cole and Zuckerman (1984) first referred to as the "productivity puzzle," or the lower comparative productivity of women in science, in almost all disciplines and regardless of the productivity measure used (Bellas and Toutkoushian, 1999). Many studies have documented this puzzle, but less research has been done to understand its possible causes. A few studies have assessed whether and to what extent factors affecting female and male scientists differently can account for it. Scholars are still striving to achieve clear explanations for the productivity gap between female and male scientists.

As summarized in Mairesse and Pezzoni (2015), past studies show the need to analyze the gender productivity puzzle together with dimensions other than gender, such as age and time period, disciplines and institutional frameworks, experience and professional status, personal capacities (usually unobserved but which can be proxied by observations on early performance), collaboration networks and "invisible colleges," and quantity and quality (such as the number of publications and impact factors of journal citations).

Sonnert and Holton (1995) suggest that the explanations for women's lower productivity can be classified into two categories, namely, the difference model and the deficit model. The difference model states that women act differently because they are different from men, specifically concerning motivation and commitment to a scientific career. These differences may be partly innate and partly due to social and cultural conditioning. Recent studies in sociology discard the argument of innate differences and posit that the social and cultural climate's effect drives women to choose specific educational patterns, select their time allocation between work and family care, and make decisions about their careers. By contrast, the deficit model states that external barriers, not intrinsic reasons, prevent women from performing the same as men in science. It argues that although women have the same goals and aspirations as men, they are treated differently. Their lower performance is mainly due to the lower opportunities offered, the more difficulties faced in their careers, and difficulties in raising funds for their research and collaborating with other scientists. Such obstacles prevent women from having the same 
career trajectory as men, for example, taking longer to be promoted, which directly and indirectly affects productivity.

Although Sonnert and Holton (1995) distinguish the two models, they point out that the models are not mutually exclusive. We concur that difference and deficit models should not be considered providing alternative or contradictory explanations; they are both relevant and complementary rather than competing. Factors in the two models may overlap, and in some cases, they may jointly be the source of other events affecting research productivity (Arensbergen et al., 2012).

A full model of the productivity puzzle would include explanatory factors from both the difference and the deficit models. Some of these factors can be easily measured and controlled for in a multivariate econometric model; others are more difficult to measure and fall in the mix of unexplained causes of productivity difference. Although motherhood, career status, quality of the work environment, and scientists' personal characteristics are all measurable (or can be well approximated by other variables), past literature has focused only selectively on them without an extensive approach to control for as many variables as possible.

Family engagements are perhaps the most frequently proposed explanations for the productivity puzzle. Among family engagements, motherhood is of interest to scholars because it is an easily identifiable event that may explain temporary shortfalls in young women's publication productivity. Studies that attempt to explain the effects of family engagement on scientific productivity have found mixed results. In general, the effect of having children is not strong and often disappears when scientists' personal characteristics, academic disciplines, work environment, and university characteristics are taken into account (Prozesky, 2008b). More recent research has found that having young children makes female academics face a "motherhood penalty", which mainly concerns having more difficulty accessing research funding and generating attention to their results than their male counterparts (Lawson et al., 2017). ${ }^{10}$

Studies have shown that women are rewarded less than men for their research achievements in a different vein. Women with comparable scientific productivity and reputation levels have lower wages, and their career advancement takes longer than men (Fox, 1981, Levin and Stephan, 1998, Long et al., 1993, Pezzoni et al., 2012). Difficulties in promoting women have an indirect impact on productivity by reducing the available resources for research, prestige, and influence. At the same time, lower

\footnotetext{
${ }^{10}$ Interestingly, the authors find that fatherhood is correlated with higher citation rates for male scientists among a sample of 262 male and female scientists at the University of Turin over a ten-year period. They argue that this might suggest the strategic decision of having a family until they feel their career is already safely established (Lawson et al., 2017).
} 
productivity decreases the chances for promotion to higher ranks. This bidirectional causal relationship between promotion and productivity raises an endogeneity problem. Several articles on gender gaps have identified career status as an important determinant of productivity without considering the endogeneity issue (Fox and Faver, 1985, Sax et al., 2002).

Gender gaps in income and job performance exist in academic science and industrial science and innovation. Recent studies find no gender differences in the quality of the inventions that female and male inventors produce but find differences in income (Hoisl and Mariani, 2017). These differences persist even when controlling for sources of heterogeneity. This strand of literature's interest remains high, considering the large number of young, predominately female professors who choose to postpone decisions about marriage and have children until they have received tenure.

Discipline specificities may have different effects on the gender productivity gap. In some disciplines, women may face more difficulties in becoming part of the scientific community, publishing in good journals, or entering prestigious institutions than in other disciplines. Sonnert and Holton (1995) and Zuckerman and Cole (1992) provide several examples. Faced with this apparent discrimination, women may behave differently by deciding not to pursue academic careers in traditionally maledominated disciplines.

Countries and organizations may also implement different policies aimed at limiting the gender gap (Mairesse and Pezzoni, 2015). Strong gender-sensitive policies may mitigate the effects of family duties on scientific productivity. While it is obviously important to know whether and which policies might affect gender imbalances, to date, the effects of the policies that favor women are still largely unexplored in the economics and sociology of science.

\subsection{The Mexican Science and Research context and the National System of Researchers (SNI)}

In the Mexican context, there are inequalities in research careers concerning both gender and age. Young researchers have trouble finding jobs: only 20 percent of researchers under 40 can find an academic research position (UAM-BUAP, 2009). Moreover, salaries are perceived as noncompetitive compared with employment in the private sector, especially in the early career stage. In this regard, the Organisation for Economic Co-operation and Development (OECD) has suggested that the base salary of academic staff in Mexico is meager and insufficient for sustaining a middle-class lifestyle (OECD, 2009). This clearly affects decisions made at a young age, which can have large knock-on effects but, in principle, should affect men and women similarly. 
Evidence of the gender productivity puzzle in developing countries in general and Latin American countries specifically is limited. In Mexico, Gonzalez-Brambila and Veloso (2007), using data on researchers from SNI, from 1991 to 2002, and on their Web of Science (WoS) publications since 1981, found that gender gaps in scientific production and productivity were not large overall at an aggregate level, but were more pronounced in scientific disciplines. Padilla-Gonzalez et al. (2011), in a comparative study of Canada, Mexico, and the United States, found important gender differences in scientific production and productivity not only across countries but also within countries across disciplines.

The Mexican National Development Plan has outlined institutional and policy actions to achieve social inclusiveness and gender equality in general. The Mexican Law on Science and Technology was also amended in 2013 to include aspects promoting gender equality in men and women's participation in scientific research and technology (Patiño Barba and Tagüeña Parga, 2014). Such a policy seems timely, given that the latest OECD (2017) Mexico Economic Survey showed that gender gaps remain high and that women's participation in the labor force remains lower than the OECD average. A study by Thévenon et al. (2012) suggested conclusions similar to that of an OECD (2014a) report, which estimates that a 25 percent reduction of the gender gaps in labor force participation by 2025 would lead to expected additional GDP growth of 1 percent in Mexico by the same year. However, there do not seem to be analyses focusing on the macro-effects of reducing gender gaps in scientific production and productivity in Mexico. Given that the number of women studying science, technology, engineering, and mathematics (STEM) disciplines in Mexico has increased rapidly in the last 20 years (Patiño Barba and Tagüeña Parga, 2014), these effects could also be very significant.

\subsubsection{The Mexican Science and Research Context}

Mexico's higher education system consists of public and private universities, institutes, centers, and teacher training (normal) schools and colleges. HEls have several missions, including training human resources, undertaking scientific research, and knowledge transfer. Universities can be public or private. Public universities are either financed by the federal budget (federal universities) or by the state budget (state universities), in which most cases they are autonomous.

Research is primarily conducted through research centers, public and private universities, and the private sector (private research centers and individual enterprises). PRCs can either be supervised by CONACYT, which accounts for about a third of PRCs' research activity; or by a sectoral ministry, notably Energy, Agriculture, and Health (OECD, 2009). The 27 CONACYT research centers are grouped into three main science and technology (S\&T) areas, notably mathematics and natural sciences, social sciences, and innovation and technology development. 
The most important HEls performing research and development (R\&D) in terms of scientific outputs in the period 2005-2011 were the National Autonomous University of Mexico (UNAM), the Center for Research and Advanced Studies (CINVESTAV), the National Polytechnic Institute (IPN), and EI Colegio de México, A.C (FCCYT, 2011). In 2011, 40 percent of all SNI researchers were from the UNAM, the IPN, and the CINVESTAV, all located in Mexico City (Gutiérrez, 2011). By 2014, 36 percent of the members of the National System of Researchers $(\mathrm{SNI})^{11}$ were affiliated with state-level public universities, followed by 34 percent from federal universities, and 12 percent from PRCs (Cabrero Mendoza, 2014).

According to the Ibero-American Ranking SIR 2013, Mexico ranks third in scientific production (i.e., number of scientific documents produced) in Ibero-America, just after Spain and Brazil. In terms of the number of HEls per country, Mexico ranks second just after Brazil (269 HEls contributing to its scientific productivity). However, Mexican scientific production is highly concentrated at the institutional level, with less than 10 percent of HEls (23) producing more than 85 percent of scientific output. During the period 2009-2013, the most prolific Mexican HEls were the UNAM (ranked second in Latin America), the Center for Advanced Studies of the IPN (12), the IPN (15), the UAM (27), and the University of Guadalajara (47) (SIR, 2013).

Regarding the performance of Mexican HEls, the Shanghai ranking of the top 500 universities identifies only the UNAM among the top 300. UNAM also appears among the top 400 in the World University Rankings 2015-2016 of the Times Higher Education. Among Latin American countries, only two Mexican universities are among the top 10 of the QS University Rankings in Latin America 2015/2016, with UNAM being the fourth highest-ranked Latin American university. Concerning the performance of Mexican science measured by scientific production through the number of publications and citations in 2009-2013, Mexico was 23rd in the world rankings, representing about 0.82 percent of the world's scientific production. In 2013, the number of Mexican scientific articles was 11,547, 3 percent higher than in 2012. ${ }^{12}$ During the period 2008-2012, the scientific articles produced by Mexicans received more than 175,432 citations, representing a growth of 5.8 percent to the period 2007-2011.

Mexico has experienced a slow increase in the number of FTE researchers over time. In 2012, it reached 43,592 (RICYT, 2014). Between 2008 and 2012, an average growth of 3.2 percent was recorded. This only represented 0.88 researchers per thousand in the labor force in 2012, which is below other Latin American countries, including Argentina (3.02 researchers per thousand labor force in 2012) and

\footnotetext{
${ }^{11} \mathrm{SNI}$ in Spanish standing for Sistema Nacional de Investigadores.

12 The academic topics that increased the most in number in the period 2008-2012 were Plants and Animals (14.4 percent), Medicine (11.5 percent), Physics (11.1 percent), Chemistry (10.2 percent), and Engineering (7.6 percent) (CONACYT, 2013).
} 
Uruguay (1.08); and is much lower than the OECD average (7.29), Spain (5.41), Greece (5), Italy (4.39), and Poland (3.86) (OECD, 2015).

The labor market of researchers is very competitive, with a set of formal and informal rules set by experienced researchers. Internal markets limit competition with entry barriers, depending on the level of research experience and adherence to similar (academic) ideologies. It is also a highly-institutionalized market. Vacant positions are usually given to experienced researchers in the same research team or research assistants linked to established scholars within the research institutions.

The base salary of academic staff in Mexico is meager and insufficient to sustain a middle-class lifestyle (OECD, 2009). Salaries are perceived as noncompetitive compared with employment in the private sector, especially in the early career stage. A Mexican researcher's salary is composed of the base salary, a merit-based component, and a supplement for SNI members. Thus, for an SNI researcher, the base salary only represents about one-third of the overall remuneration. Moreover, the SNI premium, even if not taxed, it does not count towards pension contributions. In this situation, retirement implies a loss in the order of some 75 to 80 percent of their total income. International panels of evaluators (OECD, 2009) have recommended making the non-taxable complement of the remuneration (i.e., SNI awards) part of the researchers' salary. This would have important implications for the provision of pensions and require amending labor laws, which is unlikely to occur.

Public universities concentrate a large part of their activities on teaching and training. In relative terms, research is still an under-developed activity among university researchers, as many of them dedicate most of their time to teaching. There is thus a sort of 'self-selection' in the research activity of university researchers. To promote scientific productivity, many public universities have implemented internal policies that provide financial incentives based on productivity, in addition to the SNI awards. In many cases, publications are required to obtain a promotion at universities and membership in the SNI and promotion in the system itself. In public universities at the state level, the Ministry of Education has encouraged all full-time professors to conduct research activities and academic management and training since 1997.

\subsubsection{The Mexican National System of Researchers}

This chapter uses data from the SNI. The SNI is a policy instrument implemented in Mexico in 1984 to identify, recognize, and to stimulate the production of high-quality scientific and technological knowledge (Cabrero Mendoza, 2014) through a merit-based scheme. Its main goal is to promote and strengthen the quality of scientific research and innovation produced in Mexico. The SNI was launched by Presidential agreement and at the request of the Mexican Academy of Scientific Research. It was 
established to mitigate the effects of the worsening remuneration and working conditions of researchers, and reducing the risks of brain drain, following the 1982 economic crisis in Latin America. The crisis brought important budget cuts at all government levels. One way to manage public universities' financial expenses was through support programs in differentiated incentives to researchers and professors.

Beneficiaries are individual researchers, who are involved systematically in research activities, and who either have a research contract or an institutional agreement with higher education institutions (HEIs) or research centers in the public, private, or social sectors in Mexico, ${ }^{13}$ or are Mexican and doing research abroad, in HEls or research centers and institutions in other countries. Non-Mexican researchers can also be SNI members, but it is a requirement that the foreign researchers had worked in a Mexican HEI or research center for at least one year before the application date. The National Council for Science and Technology (CONACYT) centrally manages the SNI. Researchers can apply for affiliation (entry, reentry, continuation, or upgrading of category/level) following an annual open call for applications launched by CONACYT.

Financial incentives are granted to member researchers based on a peer-review process, following the recognition of the researcher as a National Researcher, symbolizing the quality and prestige of the scientific contributions of the applicants. The financial incentives are granted in non-taxable complements to remuneration according to the category and level received. The federal government's monthly monetary stimulus award varies by category and level, ranging from three times the Mexican minimum wage (approximately US\$234.8 per month) to 15 times the minimum wage (approximately US\$1,174 per month). It is a voluntary process (i.e., researchers decide whether they want to be members and when), but membership is usually a prerequisite for being hired or promoted at Mexican universities and receiving public research grants from CONACYT.

Different managing authorities are involved in the selection of researchers for affiliation. First, different scientific committees review the applications, one committee for each of the eight broad academic areas covered in the SNI. ${ }^{14}$ These committees make a preliminary selection of candidates and decide on the entry, re-entry, continuation of affiliation, or upgrading the affiliation category/level. These committees are composed of fourteen evaluators selected from the highest-ranked SNI members in each

\footnotetext{
${ }^{13}$ In the case of affiliation to research centers and institutions in the private and social sectors, these must be part of the National Registry of Scientific and Technological Institutions and Enterprises (RENIECYT), and the institutions must have a collaboration agreement with the SNI.

${ }^{14}$ The eight broad disciplines or 'SNI Areas' are Exact Sciences (Physics, Mathematics, and Earth Sciences - Area I); Life Sciences (Chemistry and Biology - Area II); Health Sciences (Area III); Humanities (Area IV); Social Sciences and Economics (Area V); Agronomy and Biotechnology (Area VI); Engineering (Area VII); and Technological Sciences (Area VIII) - usually not numbered and named 'Horizontal Area').
} 
academic area. If a researcher disagrees with the committee's decision, the researcher can appeal to an Appeals Committee. Then, an Executive Secretary formulates the committees' proposals after consulting with the Advisory Forum for Science and Technology (FCCYT) and grants the affiliations to the SNI. Appendix 1 to this chapter presents a detailed description of SNI's managing authorities, composition, and main responsibilities. Appendix 2 presents the requirements for acquiring each of the three SNI categories and subcategories.

The outputs that are evaluated for entry, re-entry, and continuation of affiliation to the SNI are either research related (e.g., articles, books, book chapters; patents, development of new technologies, innovations, and technology transfer); or training activities, including supervision of graduate and postgraduate students and teaching. Other criteria also taken into account include participation in scientific and technology councils, editorial bodies, and Scientific Committees; participation as a technical evaluator in projects supported by CONACYT funds; linking research to the public, social, and private sectors; and active participation in the development and progress of the institution of affiliation, and the creation, updating, and strengthening of study and teaching plans and programs. In this sense, the SNI aims to promote an integrated approach to research that includes student training, teaching, outreach, and written products (i.e., high-quality articles), emphasizing consistency, and international recognition.

Journal impact factors are not officially used to determine research performance (i.e., this is not listed as a criterion for evaluation). However, internal criteria for some of the academic areas (e.g., biology and chemistry) require that academic articles are published in journals that are indexed with specific impact factors (e.g., higher than 2.1 for biology and chemistry). Evaluations focus on the quality, consistency, and coherence of research activities, leadership, and international recognition (Williams and Aluja, 2010). The quality of the research outputs of applicants are evaluated based on originality, how influential it is in the training of human resources; and the consolidation of research agendas and their impact on solving scientific and technological problems. Evaluation criteria are tailored according to the academic products that are relevant to each discipline. Researchers' performance from each discipline is evaluated according to each individual's merits and compared to researchers' average performance in that discipline (i.e., scientists do not compete with one another). Regardless of the above, Ricker et al. (2010) have argued that in practice, a researcher is rejected from the SNI if he/she does not have at least three ISI publications over a period of three years and that this remains the key element for determining the SNI level. ${ }^{15}$

${ }^{15}$ Ricker et al. (2010) also argue that when applying to the SNI, the researcher must enter online the journal name of each published article. The online system itself automatically reports the corresponding bibliometric indicators 
An OECD review and assessment of Mexican Innovation policy highlighted the role of the SNI in improving the productivity of Mexico's science system, especially in increasing the volume of scientific production and its quality; contributing to the number and density of internationally recognized Mexican researchers; developing a quality research base; and ensuring the attractiveness of research careers (OECD, 2009). However, the assessment also stated that the reward system, as it stands, by evaluating individual researchers and their scientific output, discourages researchers from undertaking long-term and multidisciplinary research and engaging in research collaboration with firms. Regarding the evaluation criteria for affiliation to the system, the assessment suggested reforming the system to better account for researchers' innovation-related output.

\subsection{Sample, data and methodological approach}

\subsubsection{The sample}

In our analysis, we differentiate between universities and PRCs. About 67 percent of CONACYT'S PRC personnel were research staff in 2006 (OECD, 2009), including 30 percent of researchers. ${ }^{16}$ Besides conducting R\&D and S\&T activities, CONACYT's PRCs offer teaching programs at the master's and PhD levels. The centers also work closely with the industry, promoting technology transfer and commercialization. An important share of PRCs' external funding comes from selling products and services to the private sector. Mexican PRCs are engaged in more than just research activities, affecting researchers' productivity and output.

This Chapter uses data provided by researchers affiliated with the SNI in 2013 and their ISI Web of Science (WoS) publications in previous years. The working sample was constructed by matching all SNI researchers' names in 2013 to authors and co-authors' names in Mexican WoS publications in 19902014. Considering the SNI system's characteristics, it is expected that the most productive researchers and those who are best known internationally are SNI members.

Details on how the study sample was built are presented in Appendix 3. The final panel data used consists of 44,535 WoS publications and 2,481 researchers, out of which 712 (28.7 percent) are women, and 1,769 (71.3 percent) are men. These researchers are affiliated with 41 public universities and 18 PRCs.

for each article, including the impact factor. This criterion thus becomes very important to evaluators when granting membership to the SNI.

16 There is no gender-disaggregated data on the number of researchers in PRCs or Mexican academia overall. However, a recent Elsevier (2017) report on Gender on the Global Research Landscape, using Scopus data in two time periods (1996-2000 and 2011-2015), estimated that 38\% of researchers in Mexico are female, with only a $4 \%$ increase in the number of female researchers in the two periods studied. 


\subsubsection{Description of the data}

We measure scientific productivity by looking at SNI researchers' WoS publications in the period 1993-2014. We also analyze the publications' quality, looking at the journals' five-year impact factors in which the articles are published, using the WoS Journal Citation reports. Thus, following Mairesse and Pezzoni (2015), our definition of publication productivity is the weighted sum of the articles published each year, taking as weights the five-year impact factors of the journals in which they are published. ${ }^{17}$

We use demographic information on individual researchers affiliated to the SNI: their dates of birth, their gender, their academic rankings in the period 2002-2013, their affiliation in 2013, the year the PhD (or highest academic degree) was granted, and the country where the PhD was obtained. We include information on when each of the researchers was promoted across the different SNI ranks. Given the requirements needed to achieve each SNI rank, we partition them into two broad categories: low rank, including the Candidate level and Level 1 researchers, and high ranks, for Level 2 and Level 3 researchers. We exclude Emeritus researchers, which are considered outliers.

Table 3.1 shows that about 40 percent of all researchers older than 40 have a high rank. Among younger researchers, high-ranked researchers' share varies by gender and affiliation, with women being the least represented, especially in PRCs. Overall, women are underrepresented in the high ranks for all age groups and affiliations and overrepresented in the low ranks in all age groups and affiliations. This underrepresentation is relatively more important for women in PRCs.

We gathered the information on annual publication rates from the WoS data and considered each researcher's career starting from the year of his or her first publication. Based on these publication data, we constructed two unbalanced panels, one for university researchers and a second one for those working in PRCs.

Table 3.2 reports SNI researchers' annual average productivity in our sample by gender and affiliation, the median, standard deviations, and the corresponding number of observations. Productivity corresponds to WoS core publications. We have also looked at the means and medians of publications recorded by all researchers in our sample, including WoS core and WOS SciELO, finding no differences than what is presented on the table for WoS core only (see Appendix 3 for details on WoS SciELO data). ${ }^{18}$

\footnotetext{
${ }^{17}$ This scientific impact measurement looks at the average number of citations of the papers published in the journal in the five preceding years. In a way, it is a measure of scientific prestige that goes beyond the individual level. We use this measure instead of individual citation counts because we are more concerned with measuring the collective impact and SNI members' global prestige.

${ }^{18}$ Most of the publications found in WoS SciELO are in social sciences and humanities, while our sample is limited to hard sciences.
} 
The upper part of the table presents statistics for all years, including 'non-publishing years'. We define a 'non-publishing year' as a year in which the researcher has zero WoS articles. The table's middle and bottom parts present similar annual statistics but excluding non-publishing years, in counts, and logarithms, respectively. Taking logarithms has the benefit of normalizing the statistical distribution of the observed productivity itself, which is preferable for econometric analysis. The data show that men in PRCs are the most productive, with 1.65 articles per year, followed by men in universities (1.59), women in universities (1.24), and women in research centers (1.14). The gender gap is much stronger in SNI affiliates in research centers, where women have 31 percent lower productivity than men. This gender gap is lower for SNI researchers in public universities, where women underperform men by 22 percent on average. Overall, the gender gap is most marked among PRC affiliates, as reflected in the median of productivity values when excluding non-publishing years (middle part of Table 3.2).

Table 3.1 Number and Proportion of Female and Male Researchers in Public Universities and Research Centers in Two Age Groups and Low and High Ranks in 2013

\begin{tabular}{|c|c|c|c|c|c|c|}
\hline \multirow[b]{2}{*}{ Researchers } & \multicolumn{2}{|c|}{ Public universities } & \multirow{2}{*}{$\begin{array}{l}\text { Total } \\
\text { universities }\end{array}$} & \multicolumn{2}{|c|}{ Public research centers } & \multirow{2}{*}{$\begin{array}{l}\text { Total public } \\
\text { research } \\
\text { centers }\end{array}$} \\
\hline & Women & Men & & Women & Men & \\
\hline \multicolumn{7}{|c|}{ Less than $\mathbf{4 0}$ years } \\
\hline \multicolumn{7}{|c|}{ Low Ranks (Candidate, } \\
\hline Level 1) & $96 \%$ & $94 \%$ & $95 \%$ & $97 \%$ & $86 \%$ & $90 \%$ \\
\hline \multicolumn{7}{|c|}{ High Ranks (Level 2, } \\
\hline \multirow[t]{2}{*}{ Level 3) } & 10 & 25 & 35 & 1 & 9 & 10 \\
\hline & $4 \%$ & $6 \%$ & $5 \%$ & $3 \%$ & $14 \%$ & $10 \%$ \\
\hline \multirow[t]{2}{*}{ Sub Total } & 245 & 447 & 692 & 34 & 65 & 99 \\
\hline & $100 \%$ & $100 \%$ & $100 \%$ & $100 \%$ & $100 \%$ & $100 \%$ \\
\hline \multicolumn{7}{|c|}{40 years and more } \\
\hline \multicolumn{7}{|c|}{ Low Ranks (Candidate, } \\
\hline \multirow[t]{2}{*}{ Level 1) } & 289 & 591 & 880 & 42 & 95 & 137 \\
\hline & $76 \%$ & $56 \%$ & $61 \%$ & $79 \%$ & $46 \%$ & $53 \%$ \\
\hline \multicolumn{7}{|c|}{ High Ranks (Level 2, } \\
\hline \multirow[t]{2}{*}{ Level 3) } & 91 & 460 & 551 & 11 & 111 & 122 \\
\hline & $24 \%$ & $44 \%$ & $39 \%$ & $21 \%$ & $54 \%$ & $47 \%$ \\
\hline \multirow[t]{2}{*}{ Sub Total } & 380 & 1051 & 1431 & 53 & 206 & 259 \\
\hline & $100 \%$ & $100 \%$ & $100 \%$ & $100 \%$ & $100 \%$ & $100 \%$ \\
\hline \multicolumn{7}{|l|}{ All } \\
\hline \multicolumn{7}{|c|}{ Low Ranks (Candidate, } \\
\hline \multirow[t]{2}{*}{ Level 1) } & 524 & 1013 & 1537 & 75 & 151 & 226 \\
\hline & $84 \%$ & $68 \%$ & $72 \%$ & $86 \%$ & $56 \%$ & $63 \%$ \\
\hline \multicolumn{7}{|c|}{ High Ranks (Level 2, } \\
\hline \multirow[t]{2}{*}{ Level 3) } & 101 & 485 & 586 & 12 & 120 & 135 \\
\hline & $16 \%$ & $32 \%$ & $28 \%$ & $14 \%$ & $44 \%$ & $38 \%$ \\
\hline \multirow[t]{2}{*}{ Subtotal } & 625 & 1498 & 2123 & 87 & 271 & 358 \\
\hline & $100 \%$ & $100 \%$ & $100 \%$ & $100 \%$ & $100 \%$ & $100 \%$ \\
\hline
\end{tabular}


The evidence given in the middle and lower panels of the table filter out the non-publishing years, showing less striking but still large gender productivity gaps. These correspond to 24 percent in PRCs (down from 31 percent) and 16 percent for universities (down from 22 percent). In logarithms, the logdifferences between female and male SNI researchers are of similar magnitude, about -0.12 for university researchers and -0.23 for those in PRCs.

Table 3.2 Descriptive Statistics on Average Unweighted Publication Productivity for Female and Male Researchers in Public Universities and Research Centers, Including and Excluding Non-publishing Years

\begin{tabular}{|c|c|c|c|c|c|c|}
\hline \multirow[b]{2}{*}{ Researchers } & \multicolumn{2}{|c|}{ Public universities } & \multicolumn{4}{|c|}{ Public Research Centers } \\
\hline & Women & Men & $\begin{array}{l}\text { W/M } \\
\text { (or W-M in logs) }\end{array}$ & Women & Men & $\begin{array}{l}\text { W/M } \\
\text { (or W-M in logs) }\end{array}$ \\
\hline \multicolumn{7}{|c|}{ Including non-publishing years } \\
\hline Mean & 1.24 & 1.59 & 0.78 & 1.14 & 1.65 & 0.69 \\
\hline Median & 1 & 1 & 1.00 & 1 & 1 & 1.00 \\
\hline Std Dev & 1.47 & 1.98 & & 1.39 & 1.86 & \\
\hline Obs. & 6525 & 18389 & & 917 & 3703 & \\
\hline \multicolumn{7}{|c|}{ Excluding non-publishing years } \\
\hline Mean & 2.00 & 2.37 & 0.84 & 1.84 & 2.42 & 0.76 \\
\hline Median & 2 & 2 & 1.00 & 1 & 2 & 0.50 \\
\hline Std Dev & 1.40 & 2.00 & & 1.35 & 1.78 & \\
\hline Obs. & 4049 & 12338 & & 567 & 2516 & \\
\hline \multicolumn{7}{|c|}{ In logarithms (excluding non-publishing years) } \\
\hline Mean & 0.51 & 0.63 & -0.12 & 0.43 & 0.67 & -0.23 \\
\hline Median & 0.69 & 0.69 & 0.00 & 0.00 & 0.69 & -0.69 \\
\hline Std Dev & 0.57 & 0.65 & & 0.55 & 0.64 & \\
\hline Obs. & 4049 & 12338 & & 567 & 2516 & \\
\hline
\end{tabular}

Table 3.3 presents similar statistics but divides the publication sample by the five-year average impact factor of the publications' journals. On average, the SNI researchers in our sample publish in journals with an average impact factor of 1.49. Women publish in journals with higher impact factors than men, with an average impact factor of 1.55 compared to 1.47 . Comparatively, SNI researchers working in universities publish in journals with higher impact factors than those in PRCs: 1.51 vs. 1.37, respectively. The middle part of Table 3.3 presents a sub-sample of observations for researchers who have ever published in journals with an impact factor higher than 2, and the bottom part those who have ever published in journals with an impact factor higher than 4 . The statistics show that the gender gaps are the same in universities and research centers for publications in journals with an average impact factor higher than 2. In contrast, the gender gap almost doubles for those working in research centers publishing in journals with an impact factor higher than 4. Interestingly, when we look at the publications in low-impact journals (i.e., those in journals with an impact factor lower than 2), the gender gap is 
relatively low in the case of researchers in universities $(-0.09)$ but remains very large in research centers $(-0.31)$. Thus, we observe important differences in the gender gap by type of affiliation and the quality of the research produced. While the gap in research centers is larger when the research quality is higher, the gap is similar for all public universities' publication quality levels.

Table 3.3 Descriptive Statistics on Average Unweighted Log Publication Productivity for Female and Male Researchers in Public Universities and Research Centers, for Different Average Impact Factor Levels

\begin{tabular}{|c|c|c|c|c|c|c|}
\hline \multirow[b]{2}{*}{ All publications } & \multicolumn{3}{|c|}{ Public universities } & \multicolumn{3}{|c|}{ Public research centers } \\
\hline & Women & Men & W-M & Women & Men & W-M \\
\hline \multicolumn{7}{|c|}{ In logs (excluding non-publishing years) } \\
\hline Mean & 0.51 & 0.63 & -0.12 & 0.43 & 0.67 & -0.23 \\
\hline Median & 0.69 & 0.69 & 0.00 & 0.00 & 0.69 & -0.69 \\
\hline Std Dev & 0.57 & 0.65 & & 0.55 & 0.64 & \\
\hline Obs. & 4049 & 12338 & & 567 & 2516 & \\
\hline \multicolumn{7}{|c|}{$\begin{array}{l}\text { IF > } \\
\text { In logs (excluding non-publishing years) }\end{array}$} \\
\hline Mean & 0.46 & 0.59 & -0.13 & 0.42 & 0.55 & -0.13 \\
\hline Median & 0.00 & 0.69 & -0.69 & 0.00 & 0.69 & -0.69 \\
\hline Std Dev & 0.54 & 0.62 & & 0.54 & 0.59 & \\
\hline Obs. & 2416 & 6020 & & 288 & 1077 & \\
\hline \multicolumn{7}{|c|}{$\begin{array}{l}\text { IF > } \\
\text { In logs (excluding non-publishing years) }\end{array}$} \\
\hline Mean & 0.36 & 0.48 & -0.12 & 0.26 & 0.46 & -0.21 \\
\hline Median & 0.00 & 0.00 & 0.00 & 0.00 & 0.00 & 0.00 \\
\hline Std Dev & 0.49 & 0.57 & & 0.42 & 0.61 & \\
\hline Obs. & 499 & 1111 & & 39 & 173 & \\
\hline
\end{tabular}

Further, the number of non-publishing years is similar for men and women, and also by affiliation. Table 3.4 shows that conditional on ranks, both the frequency of non-publishing spells and logproductivity increase with age only for researchers in high ranks, notably in universities. Researchers older than 40 years of age and having a low rank have a similar number of non-publishing years on average as do researchers younger than 40 .

However, since promotion to high ranks increases with age, and there are relatively few SNI high ranks younger than 40 , understanding the effects of seniority and age on the gender productivity gap is not straightforward. To assess both effects separately, we propose an econometric framework based not only on a productivity equation but also on two other equations to measure promotion and another for non-publishing spells. As explained below, these two equations will allow us to correct for the endogeneity of promotion and the selectivity of publishing spells in SNI researchers' productivity. 
A first look at the data shows that about 77 percent of men in public universities were not promoted in 2002-2013, compared to 64 percent of men in PRCs. This compares to about 89 percent of women who are not promoted, both in universities and research centers (Table 3.5).

Table 3.4 Proportion of Non-publishing Years for Female and Male SNI Researchers in Universities and Research Centers, in Two Age Groups and Low and High Ranks

\begin{tabular}{llcllll}
\hline Researchers & \multicolumn{2}{c}{ Universities } & W-M & $\begin{array}{c}\text { Public research } \\
\text { centers } \\
\text { Women }\end{array}$ & Men \\
\hline & Women & Men & & Wom \\
\hline Less than 40 years of age & & & & & & \\
Low Ranks (Candidate, Level 1) & $33 \%$ & $30 \%$ & $3 \%$ & $32 \%$ & $29 \%$ & $2 \%$ \\
High Ranks (Level 2, Level 3) & $13 \%$ & $10 \%$ & $3 \%$ & $14 \%$ & $7 \%$ & $7 \%$ \\
Sub Total & $43 \%$ & $38 \%$ & $5 \%$ & $45 \%$ & $40 \%$ & $4 \%$ \\
\hline 40 years and older & & & & & & \\
Low Ranks (Candidate, Level 1) & $32 \%$ & $30 \%$ & $2 \%$ & $31 \%$ & $29 \%$ & $2 \%$ \\
High Ranks (Level 2, Level 3) & $19 \%$ & $18 \%$ & $1 \%$ & $15 \%$ & $13 \%$ & $2 \%$ \\
Sub Total & $32 \%$ & $29 \%$ & $3 \%$ & $29 \%$ & $26 \%$ & $4 \%$ \\
\hline All & & & & & & \\
Low Ranks (Candidate, Level 1) & $32 \%$ & $30 \%$ & $2 \%$ & $31 \%$ & $29 \%$ & $2 \%$ \\
High Ranks (Level 2, Level 3) & $18 \%$ & $17 \%$ & $1 \%$ & $15 \%$ & $12 \%$ & $2 \%$ \\
Sub Total & $38 \%$ & $33 \%$ & $5 \%$ & $38 \%$ & $32 \%$ & $6 \%$ \\
\hline
\end{tabular}

Table 3.5 Promotion from Low Ranks to High Ranks by Affiliation and Gender

\begin{tabular}{llll|lll} 
& \multicolumn{3}{c|}{$\begin{array}{c}\text { Public Universities } \\
\text { Men } \\
\text { Last rating in period }\end{array}$} & & \multicolumn{3}{c}{$\begin{array}{c}\text { Public Research Centers } \\
\text { Men } \\
\text { Last rating in period }\end{array}$} \\
\hline $\begin{array}{llllllll}\text { First rating in } \\
\text { period }\end{array}$ & Low Rank & High Rank & Total & Low Rank & High Rank & Total \\
\hline Low Rank & 1013 & 299 & 1312 & 151 & 84 & 235 \\
High Rank & 0 & 186 & 186 & 0 & 36 & 36 \\
Total & 1013 & 485 & 1498 & 151 & 120 & 271 \\
& & Women & & & Women & \\
& & Last rating in period & & & Last rating in period \\
\hline First rating in \\
period & Low Rank & High Rank & Total & Low Rank & High Rank & Total \\
\hline Low Rank & 524 & 68 & 592 & 75 & 9 & 84 \\
High Rank & 0 & 33 & 33 & 0 & 3 & 3 \\
Total & 524 & 101 & 625 & 75 & 12 & 87 \\
\hline
\end{tabular}

We also calculated the medians of the harmonic averages of the number of authors of articles each year. They are respectively 5.9 and 5.2 authors per article for universities and research centers, or 6 
authors per article for women as compared to 5.5 for men, and of 6 authors per article for candidates and Level 1 researchers, compared to 5.6 and 5.4 for Level 2 and Level 3 researchers, respectively.

Regarding the gender of the co-authors, Table 3.6 presents the share of observations in which an SNI researcher co-authored with other SNI researchers by affiliation and gender. The data show that women and men in universities collaborate most frequently with men in universities, while women and men in PRCs collaborate mostly with men in PRCs. Interestingly, the second most frequent co-author type for researchers in universities (either male or female) is female university researchers, while researchers in PRCs have university men as the second most frequent co-authors. In most cases, women collaborate more with other women than men, except for researchers in PRCs, where men have a larger share of papers with university female co-authors than women (28 percent vs. 24 percent respectively).

It is also important to keep in mind that individual productivity distributions are very dispersed, as shown in Table 3.2, with wide standard deviations in absolute levels and logarithms. Moreover, as we highlighted above, the gender gap is considerably reduced or even favors women in universities once the publications' quality is considered. The researchers' weighted log-productivity gender gap is equal to 0.05 in universities (favoring women) and -0.03 for research centers. Using men's mean productivity in each institutional setting as benchmarks, 43 percent of women in universities, and 38 percent of women in research centers exceed this benchmark in terms of unweighted publications. When publications are weighted by impact factor, these numbers rise to 53 and 48 percent, respectively (Figure 3.1).

Table 3.6 Gender and Affiliation of SNI Co-authors, Share of Total (multiple choice allowed)

\begin{tabular}{lllll}
\hline & \multicolumn{2}{c}{ Universities } & \multicolumn{2}{c}{ Public research centers } \\
& Women & Men & Women & Men \\
\hline Co-authored with University Female & 51.12 & 43.57 & 23.61 & 28.04 \\
Co-authored with University Male & 77.29 & 79.30 & 43.78 & 58.00 \\
Co-authored with Research Centre Female & 15.26 & 13.45 & 33.48 & 29.84 \\
Co-authored with Research Centre Male & 46.37 & 32.58 & 69.10 & 68.23 \\
Observations & 1612 & 4058 & 233 & 831 \\
\hline
\end{tabular}

The reductions in the average gender productivity gap when non-publishing years are considered are equally pronounced for universities and research centers and women and men. We would have expected to see more differences between both types of organizations, especially since researchers in universities usually engage in other types of activities, such as teaching and mentoring, which one could argue reduces the time they can devote to research. However, researchers in PRCs also focus on commercialization activities and technology transfer, competing with scientific production. 
Figure 3.1 Distribution of Observed Weighted Log-productivity for Female and Male SNI Researchers Affiliated with Public Universities and Public Research Centers

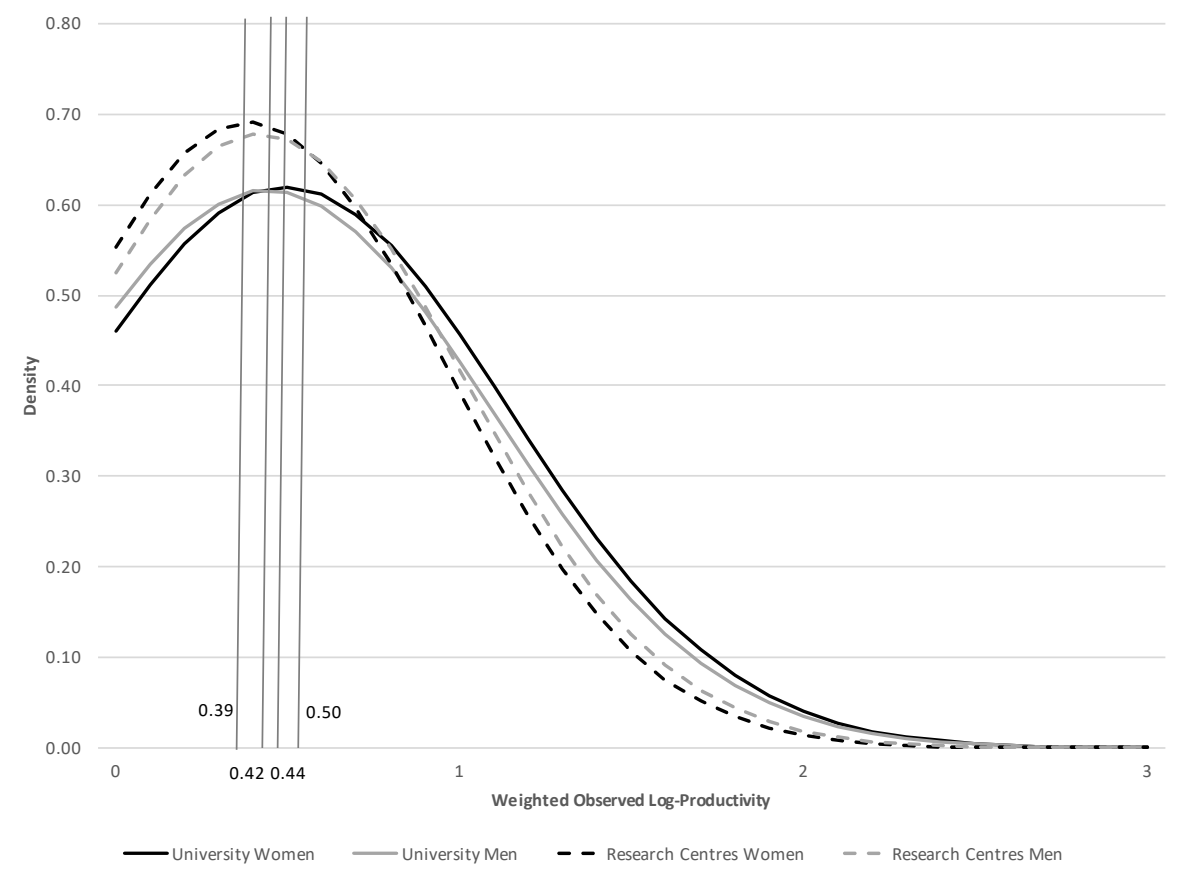

\subsubsection{Methodological approach: econometric panel data analysis at the individual researcher level}

This Chapter implements an adapted version of the econometric approach developed by Mairesse and Pezzoni (2015) to account for the gender productivity gap for physicists in French universities and in the CNRS (Centre National de la Recherche Scientifique, which is the major French public research organization in this field). ${ }^{19}$

Ultimately, our goal is to specify and estimate an econometric productivity equation relating to publication productivity, as defined above, for both female and male researchers with other variables that can be measured. Simple estimation faces three challenges: specification errors regarding publishing occurrence selectivity, the endogeneity of promotion to higher professional ranks or status, and unobserved individual heterogeneity, resulting in significant biases in the estimated parameters. We

\footnotetext{
${ }^{19}$ The same approach is used in Chapter 4 to analyze publication productivity gender gaps in the research and academic system of South Africa.
} 
address these challenges by specifying and estimating, jointly with the productivity equation, two other equations: a probit for publishing occurrence selectivity and another for promotion.

\subsubsection{The Promotion probit equation}

Career advancement and scientific productivity are strongly related. The most productive researchers are more likely to be promoted from a lower to a higher rank and, when promoted, to have more opportunities for collaboration and better access to resources, which helps them be more productive. This two-way causality creates a source of endogeneity biases when including seniority as an explanatory variable in the productivity regression.

Thus, the promotion (probit) equation aims to correct for endogeneity biases related to the correlation between career advancement and scientific productivity by including the factors likely to have a large influence on individual researchers' career achievements. The binary promotion variable is modeled as being determined by gender $(G)$, age $(A)$, year dummy variables $(t)$, past publications $(P P)$, quality of past publications, the origin of the last academic degree completed (foreign vs. local), and academic discipline.

Critical is the introduction of interactions of gender with age, given the obvious conflicts that women face between personal, family, and working life and their effect on promotion (i.e., women have less effective time for career development relative to men). (Eq. 1).

$$
\text { Rank }=f(G, A, P P, t)
$$

Promotion is defined as a change from a lower to a higher rank in the SNI system. The period we consider is 2002-2013. Our promotion equation is specified as a simple probit equation built over a binary promotion variable that takes the value of 1 in the panel in the year when a researcher advanced in his/her career from a low rank to a high rank. We consider age and gender; age squared with and without the interactions, and past productivity as career advancement determinants. Age is measured in years and centered on 40 years (divided by 10 for easy reading of the estimates). Regarding past productivity, we account for the number of publications and the absence of unproductive years before promotion, and the corresponding average five-year impact factor of the journals in which the articles were published in logarithms in the previous three years. We define the average impact factor as the share of the weighted average impact factor of the publication's journals divided by the number of publications in logarithms, $\log$ (weighted average impact factor) - log(number of publications). We also introduce a variable indicating whether the PhD was obtained in Mexico or abroad. Finally, and in line with recent research (Sarsons, 2017) showing that women's contribution to academic research is less recognized in collaborative work when a co-author is a man, we include two variables related to the gender of the co- 
authors. The first is a lagged dummy variable of whether the researcher had a male co-author in the previous year. The second is the interaction of this dummy variable with gender to capture gender differences of the effects of the co-authors' characteristics on promotion.

\subsubsection{The Publishing spell selection probit equation}

The selectivity equation takes care of the fact that during a career, all researchers have periods when they do not publish (or publish in non-indexed, very low visibility journals) and that these periods do not occur at random. It thus estimates the probability of having non-publishing periods given a set of determinants, such as past productivity history ( $\theta$ in Equation 2), the interaction of gender with age $(G, A, G * A)$, and time $(t)$.

$$
\text { (2) } \varphi=f(G, A, \theta, t)
$$

The publishing spell selection equation is a probit equation similar to that for promotion. The dependent variable is a binary indicator equal to 1 for a publishing year and equal to zero otherwise. The variables on age and gender and their interactions are the same as for the promotion equation. We also include as explanatory variables the persistence of their publication activities in a past set of years using three binary dummies. These dummies (noted Persistence 111, Persistence 110/101/011, and Persistence 100/010/001), respectively, indicate that SNI researchers have published at least one article in three consecutive years, or two consecutive years, or in one. The three dummies are lagged by one year, covering the time span from $t-1$ to $t-3$. We also control for calendar years by using time dummies.

\subsubsection{The Productivity Regression}

The productivity equation is a basic linear regression of log-productivity, weighted by the publications' journals' impact factor. It includes four groups of explanatory variables and time dummies (Equation 3).

$$
\text { (3) } \log (y)=f(G, A, I C, \delta, \operatorname{Prob}(\operatorname{Rank}), \varphi, t)
$$

The first group is gender $(G)$ and age $(A)$ and their interactions $(G * A)$, as implemented in the promotion and selection equations. The second group relates to each researcher's initial productivity in the first year where we observe them (IC in Equation 3, or Initial Characteristics), and that was kept aside in the construction of our panel data samples. We distinguish between the quantity and quality of the initial productivity through two variables, one measuring the number of publications in logarithms (denoted log first Article). The other is noting the average five-year impact factor (log average first Impact Factor), also in logarithms. These variables act as a proxy for unobserved heterogeneity. The idea behind 
including initial productivity in the regression is to account for the process of cumulative advantage and to reflect the effects of early career success (or lack of it) on scientific productivity.

The third group consists of the predicted probabilities of promotion (Prob (Rank)) and nonpublishing years $(\varphi)^{20}$ coming from the promotion (Equation 1) and selection equations (Equation 2), respectively. These are included in the productivity equation to correct the endogeneity of holding a high academic rank and publishing spells' selectivity.

The fourth group is composed of collaboration variables $(\delta)$. We computed 16 variables related to the collaborations' characteristics and the researchers' co-authors in our sample.

We have grouped these variables into three blocks: the first with the overall characteristics of the collaborations (noted Collaborations); the second referring to the seniority of the co-authors, and the third related to the gender and affiliation of the co-authors. In the collaborations group, we include the harmonic average of the number of authors of the articles published by the researcher (lagged one year and in logarithms, noted log No. of authors harmonic average in $t-1)$. We also include two variables of the average log-productivity of the co-authors, again in terms of quantity (number of co-authors - log articles SNI co-authors in t-1) and quality (average five-year impact factor) of the co-authors' productivity ( $\log$ Impact Factor SNI co-authors in $t-1$ ). We limit these two variables to those co-authors that are SNI researchers and for which we know their productivity in a given year. The fourth collaboration variable is the average number per year of co-authors of the SNI co-authors themselves of the researchers in our sample (log SNI co-authors' co-authors in t-1). To avoid double-counting, we exclude publications where the co-authors published with our sample researchers. We add one additional binary variable for completeness, characterizing whether the SNI co-authors had no publication themselves (SNI co-author No publications in $t$-1). Finally, since we are lagging by one year all our collaboration variables, we include a final dummy variable when the researchers did not publish in a given year (No publication in $t-1$ ).

In the group of variables Seniority of co-authors, we include four dummy (lagged) variables that show whether our sample researchers have co-authors that are either Candidates, Level 1, Level 2, or Level 3 SNI researchers in a given year. Finally, in the block of variables Gender and Affiliation of coauthors, we note whether a researcher has foreign co-authors (Foreign co-author in $t-1$ ), whether the collaboration is inter-institutional between a researcher in a university, and one in a research center -

20. The correction for non-publishing spells comes from the results of the selectivity equation. The dependent variable of the selectivity equation refers to the probability of publishing. However, when obtaining the results, the model calculates the inverse correction or the probability of non-publishing spells. This is why the correction in the productivity equation is computed as the probability of non-publishing spells. 
Coll. University - $P R C$ in $t-1$ ), and four other dummy variables that consider whether the researcher collaborated with a female or male researcher, respectively, in a university or PRC in the previous year.

Time dummies and academic discipline dummies are also included in the equation to control for general unobserved factors. Finally, for all equations, we proceed to two separate econometric analyses for researchers in public universities and researchers affiliated to PRCS (including the CONACYT research centers and the Ministry of Education research centers. See Appendix 4 and 5 for a full list of the institutions covered).

\subsection{Econometric findings}

Tables 3.7 and 3.8 show the promotion and publishing spell selectivity probit equations results for public universities and PRCs. Table 3.9 presents the results for the productivity equation.

\subsubsection{The promotion probit equation}

The coefficient estimates of the promotion probit equation confirm our expectations. Past publication productivity, the intensity of this productivity (number of WoS publications in the past), and the quality of these publications are major determinants of the probability of promotion from low SNI ranks (Candidate and Level 1 ) to high ranks (Levels 2 and 3 ) for researchers in both public universities and PRCs. The exceptions are the average impact factor of publications in year $\mathrm{t}-1$ and the impact factor for t-3 for PRC researchers, which are not significant for all models. This suggests that promotion has a long(er)-term memory regarding quality, especially for university researchers, and in the short term, what matters most is the intensity of the researcher's productivity. As expected, the probability of promotion varies with age following an inverted u-shaped curve, suggesting that this probability is lower for younger SNI researchers and very senior researchers who have not already been promoted. ${ }^{21}$ Having a male SNI co-author in the past has a positive effect on promotion. However, collaboration with men harms the promotion of university women. Having acquired a foreign academic degree increases the probability of promotion for all SNI researchers. Finally, we also find that conditional on past productivity and age, SNI female researchers, in both universities and PRCs, have significantly lower probabilities of promotion than their male colleagues. This is much more marked and important for SNI members in research centers.

\footnotetext{
${ }^{21}$ The estimated maximum probability of promotion is high for all researchers, varying by gender and between university and PRCs: about 65 years for university women, 60 for university men, 50 for women in research centers, and 55 for men in research centers.
} 
Table 3.7 Promotion Probit Equation for SNI Researchers Affiliated with Public Universities and Public Research Centers, with and without Age*Gender Interactions

\begin{tabular}{|c|c|c|c|c|}
\hline Rank indicator & Universities & $\begin{array}{c}\text { Research } \\
\text { centers }\end{array}$ & Universities & $\begin{array}{c}\text { Research } \\
\text { centers }\end{array}$ \\
\hline \multicolumn{5}{|l|}{ Age and Gender } \\
\hline Woman (=1) & $-0.167^{* * *}$ & $-0.434 * * *$ & $-0.220 * * *$ & $-0.347^{*}$ \\
\hline$($ Age-40)/10 & $0.715^{* * *}$ & $1.156 * * *$ & $0.688 * * *$ & $1.217^{* * *}$ \\
\hline$((\text { Age }-40) / 10)^{\wedge} 2$ & $-0.230 * * *$ & $-0.531 * * *$ & $-0.230 * * *$ & $-0.542 * * *$ \\
\hline$($ Age-40)/10 * Woman & & & $0.148^{*}$ & -0.339 \\
\hline$\left((\text { Age-40)/10 })^{\wedge} 2 *\right.$ Woman & & & 0.00439 & -0.159 \\
\hline \multicolumn{5}{|l|}{ Lagged productivity } \\
\hline Publications in t-1 & $0.0750^{*}$ & $0.182^{*}$ & $0.0772^{*}$ & $0.179 *$ \\
\hline Publications in $\mathrm{t}-2$ & $0.231 * * *$ & $0.413^{* * *}$ & $0.232 * * *$ & $0.414 * * *$ \\
\hline Publications in t-3 & $0.250 * * *$ & $0.210 * *$ & $0.250 * * *$ & $0.205^{* *}$ \\
\hline Log No. Publications in t-1 & $0.127^{* * *}$ & $0.184 * * *$ & $0.128 * * *$ & $0.195^{* * *}$ \\
\hline Log No. Publications in t-2 & $0.186^{* * *}$ & $0.254 * * *$ & $0.185^{* * *}$ & $0.261 * * *$ \\
\hline Log No. Publications in t-3 & $0.228 * * *$ & $0.330 * * *$ & $0.229 * * *$ & $0.343^{* * *}$ \\
\hline Log. Avg. Impact Factor in t-1 & 0.0213 & 0.0924 & 0.0240 & 0.0975 \\
\hline Log. Avg. Impact Factor in t-2 & $0.0623 * *$ & $0.105^{*}$ & $0.0618^{* *}$ & $0.106^{*}$ \\
\hline Log. Avg. Impact Factor in t-3 & $0.0903 * * *$ & 0.0859 & $0.0909^{* * *}$ & 0.0904 \\
\hline \multicolumn{5}{|l|}{ Co-authors } \\
\hline Male co-author in t-1 & $0.261^{* * *}$ & $0.413 * * *$ & $0.291 * * *$ & $0.365 * * *$ \\
\hline Male co-author in $\mathrm{t}-1 *$ Woman & & & $-0.151^{* *}$ & 0.334 \\
\hline Foreign Degree & $0.199 * * *$ & $0.176 * * *$ & $0.201 * * *$ & $0.187^{* * *}$ \\
\hline Time dummies & Yes & Yes & Yes & Yes \\
\hline Discipline dummies & Yes & Yes & Yes & Yes \\
\hline Constant & $-2.500 * * *$ & -7.435 & $-2.491 * * *$ & -7.649 \\
\hline Observations & 24914 & 4620 & 24914 & 4620 \\
\hline Pseudo R2 & 0.23 & 0.33 & 0.23 & 0.34 \\
\hline
\end{tabular}

\subsubsection{The publishing spell selection probit equation}

Similarly, the coefficient estimates of the publishing spell selection probit equation also confirm our expectations. The probability of publishing is significantly higher for all SNI researchers who are more persistent in publishing in the previous three years relative to those who are less persistent or are not publishing at all in the previous three years. Also, since both the estimated coefficient of the interaction term (age* woman) and the estimated coefficient with age are positive, the probability of non-publishing increases more rapidly for women over 40 than for men at the same age. 
Table 3.8 Publishing Yearly Selection Probit Equation for SNI Researchers Affiliated with Public Universities and Public Research Centers, with and without Age*Gender Interactions

\begin{tabular}{|c|c|c|c|c|}
\hline Publishing indicator & Universities & $\begin{array}{c}\text { Research } \\
\text { centers }\end{array}$ & Universities & $\begin{array}{c}\text { Research } \\
\text { centers }\end{array}$ \\
\hline \multicolumn{5}{|l|}{ Age and Gender } \\
\hline Woman (=1) & $-0.106 * * *$ & $-0.119 * *$ & $-0.116 * * *$ & -0.0977 \\
\hline$($ Age-40)/10 & $0.111^{* * *}$ & $0.161^{* * *}$ & $0.107^{* * *}$ & $0.152^{* * *}$ \\
\hline$((\text { Age }-40) / 10)^{\wedge} 2$ & $-0.0502 * * *$ & $-0.0540 * * *$ & $-0.0517^{* * *}$ & $-0.0479 * *$ \\
\hline$($ Age-40)/10 * Woman & & & 0.0183 & 0.0316 \\
\hline$\left((\text { Age-40)/10 })^{\wedge} 2 *\right.$ Woman & & & 0.0101 & -0.0351 \\
\hline \multicolumn{5}{|l|}{ Productivity persistence } \\
\hline L. Persistence 111 & $1.128 * * *$ & $1.073^{* * *}$ & $1.128^{* * *}$ & $1.072 * * *$ \\
\hline L. Persistence 110/101/011 & $0.646 * * *$ & $0.673 * * *$ & $0.645^{* * *}$ & $0.672 * * *$ \\
\hline L. Persistence 100/010/001 & $0.388 * * *$ & $0.394 * * *$ & $0.387^{* * *}$ & $0.392 * * *$ \\
\hline Reference L. Persistence 000 (ref.) & - & - & - & - \\
\hline Time dummies & Yes & Yes & Yes & Yes \\
\hline Discipline dummies & Yes & Yes & Yes & Yes \\
\hline Constant & $0.659 * * *$ & $0.628 * * *$ & $0.661 * * *$ & $0.625 * * *$ \\
\hline Observations & 24914 & 4620 & 24914 & 4620 \\
\hline Pseudo R2 & 0.10 & 0.12 & 0.10 & 0.13 \\
\hline
\end{tabular}

\subsubsection{The productivity regression}

The productivity equation, as defined in the previous section, includes four groups of explanatory variables. We find that all four groups of variables have statistically significant impacts on scientific productivity. The results suggest that some of these have long-lasting effects, such as the initial productivity variables. The publications' quality at the beginning of the career predicts higher scientific productivity in the future for all SNI members, particularly for those in public universities relative to research center affiliates. The control for the endogeneity of rank (the predicted probability of promotion to higher ranks) has a large and significant impact on productivity, with a particularly high impact among researchers in public universities relative to those in PRCs. The control for publishing selectivity (predicted yearly probability of non-publishing) does not significantly impact productivity. 
Table 3.9 Productivity Equation for SNI Researchers Affiliated with Public Universities and Public Research Centers, with and without Gender Interactions ${ }^{22}$

\begin{tabular}{|c|c|c|c|c|}
\hline Productivity: (log) Prod & Universities & $\begin{array}{l}\text { Research } \\
\text { centers }\end{array}$ & Universities & $\begin{array}{l}\text { Research } \\
\text { centers }\end{array}$ \\
\hline \multicolumn{5}{|l|}{ Age and gender } \\
\hline Woman (=1) & $0.063 * * *$ & 0.039 & $0.083^{* * *}$ & 0.024 \\
\hline$($ Age-40)/10 & $-0.091 * * *$ & $-0.13^{* * *}$ & $-0.093 * * *$ & $-0.12 * * *$ \\
\hline$\left((\text { Age-40)/10 })^{\wedge} 2\right.$ & $0.018 * * *$ & $0.041^{* * *}$ & $0.023 * * *$ & $0.038^{* * *}$ \\
\hline (Age-40)/10 * Woman & & & 0.0085 & 0.0015 \\
\hline$((\text { Age- } 40) / 10)^{\wedge} 2 *$ Woman & & & $-0.026 * *$ & 0.025 \\
\hline \multicolumn{5}{|l|}{ Initial productivity } \\
\hline $\log ($ first Article) & 0.0027 & -0.016 & 0.0031 & -0.017 \\
\hline log(average first Impact Factor) & $0.19^{* * *}$ & $0.14^{* * *}$ & $0.19^{* * *}$ & $0.14^{* * *}$ \\
\hline \multicolumn{5}{|l|}{ Promotion and nonpublishing spells } \\
\hline Prob(promotion) & $1.05^{* * *}$ & $0.39 * * *$ & $1.04^{* * *}$ & $0.35^{* * *}$ \\
\hline Prob(nonpublishing spells: lambda) & 0.033 & -0.056 & 0.032 & -0.064 \\
\hline \multicolumn{5}{|l|}{ Collaboration } \\
\hline $\log$ (No. of authors harmonic average) in $\mathrm{t}-1$ & $0.16^{* * *}$ & $0.15^{* * *}$ & $0.16^{* * *}$ & $0.15^{* * *}$ \\
\hline $\log$ (articles SNI coauthors) in t-1 & -0.017 & 0.033 & -0.017 & 0.034 \\
\hline $\log ($ Impact Factor SNI co-authors) in t-1 & $0.28^{* * *}$ & $0.17^{* * *}$ & $0.28^{* * *}$ & $0.17^{* * *}$ \\
\hline $\log (\mathrm{SNI}$ coauthors' coauthors) in t-1 & $-0.062 * *$ & $-0.13^{* *}$ & $-0.061 * *$ & $-0.13^{* *}$ \\
\hline SNI coauthor No publications in t-1 & 0.069 & -0.017 & 0.071 & -0.021 \\
\hline No publication in $\mathrm{t}-1$ & $0.23^{* * *}$ & $0.18^{* * *}$ & $0.23^{* * *}$ & $0.18^{* * *}$ \\
\hline \multicolumn{5}{|l|}{ Seniority of co-authors } \\
\hline SNI co-author Candidate in t-1 & -0.024 & 0.020 & -0.024 & 0.022 \\
\hline SNI co-author Level 1 in t-1 & $-0.053^{* *}$ & 0.034 & $-0.054 * *$ & 0.032 \\
\hline SNI co-author Level 2 in t-1 & 0.00057 & 0.0072 & 0.00020 & 0.0051 \\
\hline SNI co-author Level 3 in t-1 & 0.021 & -0.035 & 0.020 & -0.034 \\
\hline \multicolumn{5}{|l|}{ Gender and affiliations of co-authors } \\
\hline Foreign co-author in $\mathrm{t}-1$ & 0.022 & $0.074 *$ & 0.021 & $0.076^{*}$ \\
\hline Coll. University - PRC in t-1 & -0.054 & 0.041 & -0.054 & 0.041 \\
\hline Female University & -0.0055 & 0.010 & -0.0046 & 0.012 \\
\hline Male University & -0.036 & -0.049 & -0.036 & -0.045 \\
\hline Female PRC & -0.020 & 0.050 & -0.020 & 0.052 \\
\hline Male PRC & 0.0044 & -0.028 & 0.0045 & -0.027 \\
\hline Time dummies & yes & yes & yes & yes \\
\hline Discipline dummies & yes & yes & yes & yes \\
\hline Constant & $0.21^{* * *}$ & $0.41^{* * *}$ & $0.21^{* * *}$ & $0.42^{* * *}$ \\
\hline Observations & 24,914 & 4,620 & 24,914 & 4,620 \\
\hline Observations npub $!=0$ & 16,387 & 3,083 & 16,387 & 3,083 \\
\hline Pseudo R2 & 0.189 & 0.167 & 0.189 & 0.167 \\
\hline
\end{tabular}

Significance: ${ }^{* * *} p<0.01,{ }^{* *} p<0.05,{ }^{*} p<0.1$

22 Estimated coefficients, based on OLS corrected for promotion endogeneity and non-publishing selectivity. See Appendix to Chapter 3 for details on the implementation of these corrections. 
Among the collaboration variables, we find that the average number of co-authors positively affects productivity, with similar intensity for all SNI researchers. However, given that there is a positive correlation between the number of co-authors and productivity, this finding does not prove a causal relation. The evidence also shows that the nature and quality of the collaborations matter for productivity. Researchers who collaborate with other SNI members publishing in high(er) impact factor journals are more productive. These results suggest a co-selection process between the most productive researchers, pointing to the importance of the researcher's working environment and research network.

Inter-institutional collaboration, or that between a university researcher and one in a PRC, does not affect productivity. One interesting result is that having no publications in the previous year is a significant predictor of being productive in the following year among all researchers. This is similar to the findings of Mairesse and Pezzoni (2015) for French physicists. They suggest that non-publishing years are usually followed by, or alternate with, publishing years. The randomness in the duration of the refereeing and publishing process also explains this finding. Even if a researcher produces papers at an absolutely un-varying rate, if different papers take different (and even random) lengths of time to be published, we would expect to see a negative autocorrelation in publishing.

Overall, the co-authors' level of seniority does not seem to affect productivity, except for Level 1 co-authors, where it seems to affect university researchers' productivity negatively. The gender and affiliation of the co-authors do not seem to have a significant effect on productivity.

The group of factors analyzed, including collaboration, probabilities of promotion, and initial productivity, account significantly for differences in scientific productivity. Taken together, we find that they invalidate the gender productivity puzzle and even reverse it for all SNI researchers, and particularly for SNI members in public universities. In the Appendix to Chapter 3, we explain in more detail the different pieces of the gender productivity puzzle.

The results of Table 3.9 above can be illustrated more simply by Figure 3.2, which can be compared to Figure 3.1. The model we have estimated proposes several factors that explain researcher productivity. Some are intrinsic to the researcher (gender, age); some due to academic choices (discipline, affiliation); some due to feedbacks from the SNI promotion system; and some due to underlying unobserved factors, such as family engagements, which are likely to explain the occurrence of non-publishing spells. Although our model only captures part of what drives publication productivity, it allows us to assess the productivity, un-confounded by our explanatory variables, or predicted productivity, across different types of researchers (men, women, crossed with universities and research centers). This distribution of predicted productivity, holding constant all explanatory variables (at their average levels), is shown in Figure 3.2. 
Figure 3.1 showed observed productivity differences among the four types of researchers, particularly with high standard deviations. Figure 3.2 shows that the average predicted productivity of men and women by affiliation is very similar, with an estimated average of weighted log-production of 0.64 for men in universities (or 1.89 equivalent articles per year in WoS journals IF-weighted); 0.65 for men in research centers (1.91 equivalent articles); 0.66 for women in research centers (1.94 equivalent articles), and 0.79 for university women (2.20 equivalent articles). After introducing our model's corrections, we find that university women have the highest predicted weighted log-productivity. We do not find a statistically significant role of gender in explaining productivity gaps in research centers after including our corrections. By and large, gender and institution type has little effect on an individual's productivity, after controlling for promotion and non-productive spells.

Figure 3.2 Distribution of Weighted Predicted Log-productivity for Representative Female and Male SNI Researchers Affiliated with Public Universities and Public Research Centers

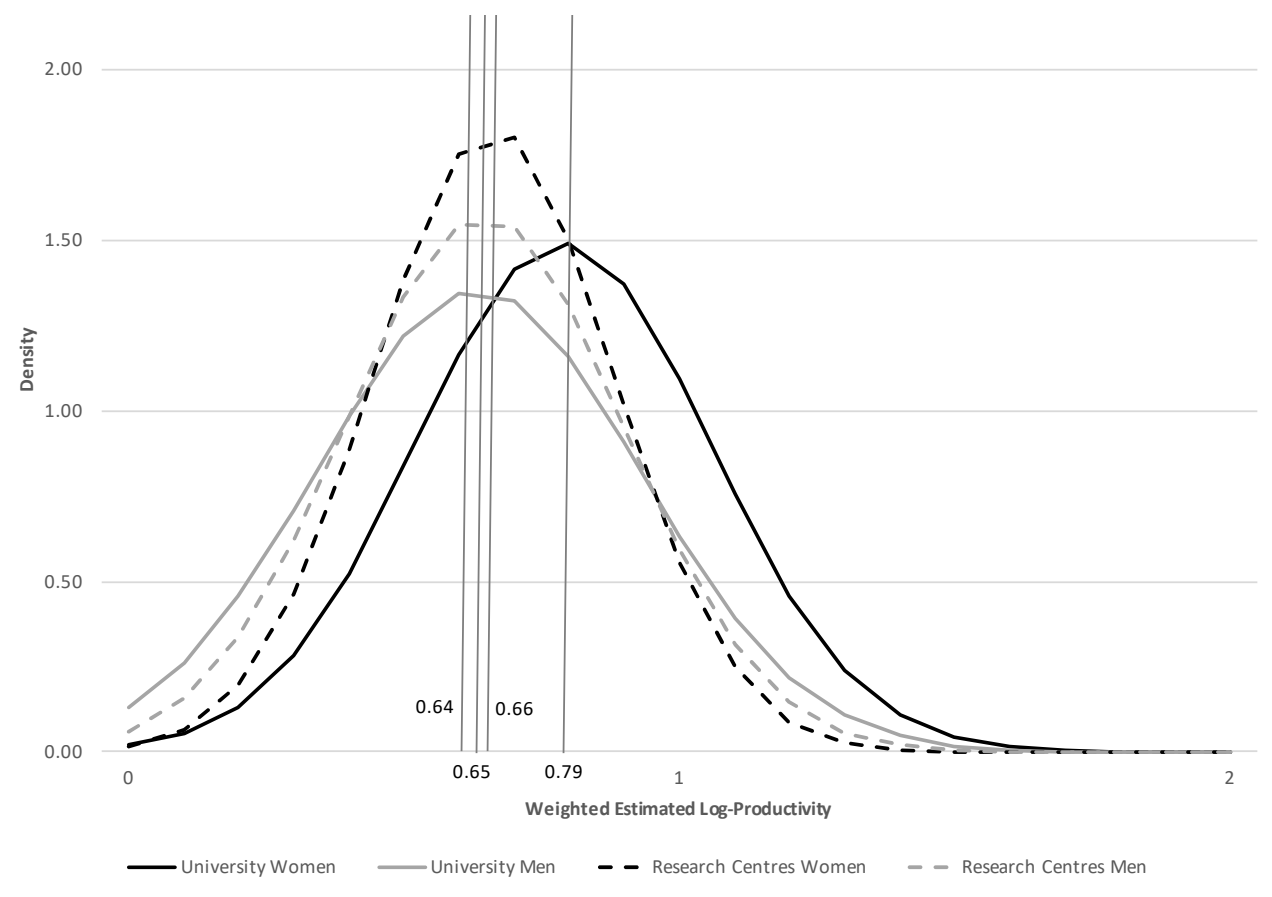

Figure 3.3 shows how age and gender interact significantly concerning predicted productivity. It shows how gender gaps change at different ages. It indicates that estimated productivity decreases rapidly with age for all SNI researchers, particularly for women in public universities. Male researchers see their productivity increase slightly after age 70 , while women in research centers see their 
productivity increase after age 55 to levels comparable to those at age 45 . University women are always more productive than men and women in research centers between ages 35 and 50 .

Figure 3.3 Change with Age of Estimated Log-productivity for Representative Female and Male SNI Researchers Affiliated with Public Universities and Public Research Centers

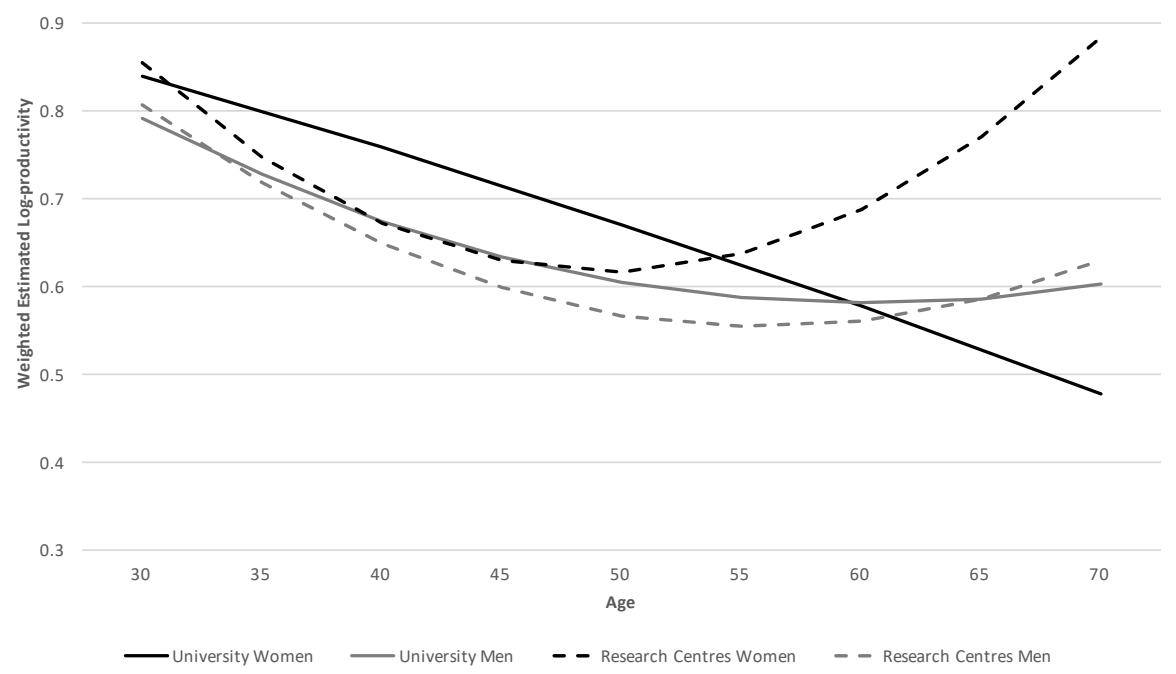

To illuminate the contributions of each correction to the gender productivity gap, Tables A3.7 and A3.8 in the Appendix to Chapter 3 include the productivity equations for researchers in universities and research centers, respectively, with no corrections, with the endogeneity correction, with the selectivity correction, and with both corrections. At the individual level, it is difficult to understand each contribution's effect, especially because, in many cases, they represent external constraints that are difficult or impossible to change for the individual researcher. However, collectively, these constraints can be exogenous and cannot be addressed from the public policy standpoint. For instance, gender equality in promotion depends greatly on the working environment and can be encouraged through incentives. Selectivity, or the absence of non-publishing spells, is more difficult to address from the policy standpoint, as it can reflect a variety of external activities, such as conflicting teaching and management responsibilities and other family engagements.

Rank and promotion are major sources of endogeneity for productivity. To control for this and to calculate this correction alone (second column in Tables A3.7 and A3.8), we specify the productivity and 
promotion equations jointly to estimate them as a system of simultaneous equations. We assume that the lagged explanatory variables of promotion are predetermined concerning productivity in time $t$. Thus, we can estimate the promotion equation separately in a first step, and in a second step, we estimate the productivity equation by including in it the predicted probability of promoting to high ranks (denoted Prob. Promotion).

To calculate the selectivity correction (third columns in Tables A3.7 and A3.8), we estimate the selectivity equation with the productivity equation as a two-equation Tobit-type model. We rely on Heckman's two-step method, where the probit equation is estimated in the first step. The productivity equation follows in the second step, including an additional explanatory variable, the first-step inverse Mill's ratio, or the predicted probability of non-publishing (denoted Prob non-publishing spells).

Tables A3.7 and A3.8 show that either the endogeneity correction alone or the selectivity equation alone make the gender productivity gap disappear among SNI researchers. When combined, women become about 8 percent more productive than men in public universities and about 2 percent more productive in PRCs (even if not significant in our model) (Table 3.9). The explanatory power of the models also increases when both corrections are introduced.

Table 3.10 Observed and Predicted (Weighted and Unweighted) Publication Productivity, Individual and System Gains

\begin{tabular}{|c|c|c|c|c|}
\hline & $\begin{array}{l}\text { University } \\
\text { women }\end{array}$ & $\begin{array}{l}\text { University } \\
\text { men }\end{array}$ & $\begin{array}{l}\text { Research } \\
\text { center } \\
\text { women }\end{array}$ & $\begin{array}{l}\text { Research } \\
\text { center men }\end{array}$ \\
\hline Observed weighted productivity & 1.64 & 1.56 & 1.47 & 1.52 \\
\hline Estimated weighted productivity & 2.20 & 1.89 & 1.94 & 1.91 \\
\hline Differential gains in weighted productivity & 0.56 & 0.33 & 0.47 & 0.39 \\
\hline Observed number of publications & 1.24 & 1.59 & 1.14 & 1.65 \\
\hline Estimated number of publications & 2.17 & 2.32 & 2.22 & 2.62 \\
\hline Differential gains in number of publications & 0.93 & 0.73 & 1.09 & 0.97 \\
\hline Total observed weighted publications & 666 & 1925 & 83 & 383 \\
\hline Total estimated weighted publications & 891 & 2330 & 110 & 480 \\
\hline Overall productivity gains & 225 & 405 & 27 & 97 \\
\hline Percentage increase & $33.8 \%$ & $21.0 \%$ & $31.9 \%$ & $25.3 \%$ \\
\hline
\end{tabular}

One interesting finding from our models' results is the differentials concerning observed and estimated publication productivity. Table 3.10 computes these differentials as the number of weighted and unweighted publications per year (de-logged). The results show that correcting for the existence of promotion and selectivity biases would produce overall average gains of one additional weighted publication every two years for women ( 0.56 publications per year for university women and 0.47 for 
research center women) and around one additional publication every three years for men ( 0.33 per year for university men and 0.39 for research centers). The gains would be even greater in terms of the unweighted number of publications, corresponding to one publication more per year for all researchers, except for university men, who would have an average increase of 0.73 publications per year.

Table 3.10 presents the overall gains for our sample of researchers. We have calculated this based on the non-censored observations in our panel. Our results show that controlling for selectivity and promotion in science would increase the total number of publications by more than 30 percent for women and between 21 and 25 percent for men. Productivity gains are observed for all SNI members, men, and women, even if the expected gains are higher for women relative to men.

\subsection{Counterfactual analysis at the Macro level}

Given the results presented above, one of the main concerns for policymakers is what the science system would gain or lose by reducing or eliminating gender productivity gaps.

We use the results from our econometric models to formulate a set of policy scenarios to assess the magnitude of these potential impacts. We focus on understanding the impacts and effects of both corrections on the following issues: promotion practices (i.e., what would be the changes if women had the same probabilities of promotion as men) (i); publication intensity (i.e., the same probabilities of not publishing for men and women) (ii); collaboration practices (iii); and age (iv).

Table 3.11 presents a summary of our findings related to the impacts of promotion, selectivity, collaboration, and age on researchers' log-productivity. The first part of the table shows a series of descriptive statistics by affiliation and gender. The second part of the table summarizes the contributions computed to log-weighted productivity of the different variables in our simulations. We use our productivity model with corrections for selectivity and promotion to calculate these contributions. The third part of the table shows our sample's total productivity and the gains in the total number of weighted publications following the different simulations. The last part of the table shows the computed gains in researchers' total publications.

We explore the productivity gains if females had the same probability of promotion as men (1); and if females had the same probability of not publishing as men (2). The idea is to understand the gains if there were no promotion discrimination against females and no researchers' selectivity based on gender.

We find that if women in our sample had the same probability of promotion as men, they would have jointly produced an additional 22 publications in universities and an additional 2 publications in research centers in our period of analysis, representing $2.4 \%$ of all publications in universities and $1.7 \%$ 
in research centers. Similarly, we find that having the same probability of not publishing as men would enable women in universities to produce $0.9 \%$ more publications in our period of analysis. This relatively low gain from equality in selectivity is in line with the number of non-publishing spells found between men and women. ${ }^{23}$

The results suggest that policy should focus on enabling equal opportunities for promotion for women in Mexican academia.

Table 3.11 Summary Results of Individual and System Gains Based on Simulation of Different Scenarios

\begin{tabular}{|c|c|c|c|c|}
\hline & $\begin{array}{l}\text { University } \\
\text { Women }\end{array}$ & $\begin{array}{l}\text { University } \\
\text { Men }\end{array}$ & $\begin{array}{l}\text { Research } \\
\text { Centres } \\
\text { Women }\end{array}$ & $\begin{array}{l}\text { Research } \\
\text { Centres } \\
\text { Men }\end{array}$ \\
\hline \multicolumn{5}{|l|}{ Statistics } \\
\hline Harmonic average authors & 6.54 & 6.13 & 6.00 & 5.65 \\
\hline Arithmetic average authors & 6.77 & 6.69 & 6.14 & 5.94 \\
\hline Non-censored observations & 4049 & 12338 & 567 & 2516 \\
\hline Number of researchers & 625 & 1498 & 87 & 271 \\
\hline Censored observations & 2476 & 6051 & 350 & 1187 \\
\hline \multicolumn{5}{|l|}{ Contributions computed } \\
\hline log productivity & 0.80 & 0.66 & 0.63 & 0.62 \\
\hline Probability of promotion & 0.05 & 0.10 & 0.02 & 0.05 \\
\hline Probability of observing a non-productive spell & 0.02 & 0.00 & 0.00 & 0.00 \\
\hline Collaboration variables & 0.22 & 0.21 & 0.15 & 0.16 \\
\hline Age + gender interactions & -0.02 & -0.01 & 0.03 & -0.01 \\
\hline Constant & 0.21 & 0.21 & 0.42 & 0.42 \\
\hline \multicolumn{5}{|l|}{ Productivity gains at system level - Scenario simulation } \\
\hline Total number of publications - conditional & 901.12 & 2387.15 & 106.46 & 467.71 \\
\hline $\begin{array}{l}\text { If women had the same promotion probabilities as men... } \\
\text { If women had the same probability of not publishing as }\end{array}$ & 21.82 & & 1.76 & \\
\hline men... & 8.18 & & 0.00 & \\
\hline If women had the same collaboration as men & -5.02 & & 0.66 & \\
\hline If women had the same age as men & 3.99 & & -2.29 & \\
\hline \multicolumn{5}{|l|}{ Scenario simulation - Percentage over total } \\
\hline $\begin{array}{l}\text { If women had the same promotion probabilities as men... } \\
\text { If women had the same probability of not publishing as }\end{array}$ & $2.4 \%$ & & $1.7 \%$ & \\
\hline men... & $0.9 \%$ & & $0.0 \%$ & \\
\hline If women had the same collaboration as men & $-0.6 \%$ & & $0.6 \%$ & \\
\hline If women had the same age as men & $0.4 \%$ & & $-2.2 \%$ & \\
\hline
\end{tabular}

${ }^{23}$ It is important to keep in mind that selectivity biases can arise from family reasons (e.g., motherhood, childcare) and non-family related reasons (e.g., teaching responsibilities, taking administrative tasks, participating in academic committees, etc.). Eliminating selectivity biases is not straightforward. In the academic environment, if women are released from non-family related reasons causing such biases, then men would have to take over these tasks, which would also affect the overall productivity of men and the net system gains. Chapter 4 digs further into this question for the case of South Africa. 
We have also tested the possible overall productivity gains in our sample of SNI researchers if women had the same collaboration characteristics as men (3) and the same age as their male counterparts (4).

For the collaboration variables, we obtained the contribution of the 16 collaboration variables used in our productivity equation as defined in our methodological approach section, including the collaborations' overall characteristics, the seniority of the co-authors, and the gender and affiliation of the co-authors. We used a similar approach to understand the effects of age on productivity by obtaining predictions based on the age variables' contribution (squared and centered), and our gender interacted variables.

Although the contribution of the collaboration variables to productivity is similar between women and men with the same institutional affiliations, our predictions show that if women had the same type of collaboration characteristics as men, they would produce around $0.6 \%$ fewer publications in universities, compared to a $6 \%$ increase in research centers.

Finally, we find that if women had the same age as men, they would be $4 \%$ more productive overall in universities; and $2.2 \%$ less productive in research centers.

\subsubsection{Policies and initiatives focusing on decreasing gender gaps in the promotion of researchers}

Our findings suggest that promotion is an issue that affects females in both PRCs and universities. The results also show that promotion is a strong explanatory factor of the gender productivity gap in Mexico.

Promotion in science itself is a human process in which more senior researchers evaluate junior ones based on a set of pre-established criteria. Some authors have argued that this process is, in most cases, implicitly biased because the academic profession is stereotypically male (Castillo et al., 2014).

Gender equality in science has received attention in Latin America only in the last few years. Thus, correcting for this implicitly male-biased process is still in the early stages.

We mentioned above that the SNI evaluation process for entering and being promoted to higher SNI ranks starts with the scientific committees' recommendations. These committees are usually composed of 14 members from the highest SNI levels that make an initial evaluation of the SNI applications. Table 3.12 presents the number of male and female scientific committees' members by 
academic area in 2015-2016. ${ }^{24}$ The table shows that only one committee in 2015 and two in 2016 was gender-balanced. There was only one female member of the Engineering Committee in both years. Moreover, only one president in 2015 and three in 2016 were female.

This rather anecdotal example shows that the SNI has been unable to integrate women into its evaluation framework, and the male-dominated scientific committees could also play a role in reinforcing gender biases in the promotion of researchers. ${ }^{25}$

Table 3.12 Number of Male and Female Members on the SNI Disciplinary Committees, 20152016

\begin{tabular}{|c|c|c|c|c|c|c|}
\hline \multirow[b]{2}{*}{ SNI area } & \multicolumn{3}{|c|}{2015} & \multicolumn{3}{|c|}{2016} \\
\hline & Female & Male & President & Female & Male & President \\
\hline Physics, Mathematics and Earth Sciences & 2 & 12 & M & 3 & 11 & M \\
\hline Biology, Chemistry and Life Sciences & 7 & 7 & $\mathrm{~F}$ & 5 & 9 & M \\
\hline Medicine and Health Sciences & 4 & 10 & M & 7 & 7 & M \\
\hline Humanities and Behavioral Sciences & 4 & 10 & M & 7 & 7 & $\mathrm{~F}$ \\
\hline Social Sciences & 4 & 10 & M & 4 & 10 & M \\
\hline Biotechnology and Agro-fisheries & 4 & 10 & M & 3 & 11 & $\mathrm{~F}$ \\
\hline Engineering & 1 & 13 & $M$ & 1 & 13 & $M$ \\
\hline Technology Sciences & 2 & 12 & $M$ & 2 & 12 & $\mathrm{~F}$ \\
\hline
\end{tabular}

CONACYT'S PRCs have introduced a series of internal policies, projects, and programs to promote gender equality among their employees. These programs focus mainly on communication activities and awareness-raising (e.g., CIMAV, CIDETEQ). Some others have implemented research projects to map women's needs, focusing on indigenous women (e.g., CIESAS). Some have more formal structures, with codes of conduct and internal committees focusing on non-discrimination against women in the workplace and on preventing and sanctioning sexual harassment (e.g., CIDE, CIATEQ, CIQA).

Since 2012, the CIATEQ research center focused on advanced technologies, has provided subsidies for childcare for female employees, and since 2013 it has had policies in place to increase women's participation in higher academic ranks and management positions.

\footnotetext{
24 Public data obtained from CONACYT's website. See www.conacyt.mx/index. php/el-conacyt/convocatorias-yresultados-conacyt/convocatorias-sistema-nacional-de-investigadores-sni/miembros-de-comisionesdictaminadoras.

${ }^{25}$ One must be very careful, though, in thinking that gender balance in committees is the solution. Bagues et al. (2017) find that, in the context of promotion to associate and full professors in Italy and Spain, a larger presence of women on evaluation committees does not improve or favor female candidates' outcomes. Further, male evaluators appear to judge female candidates more harshly when some committee members are also female.
} 
It is clear from the results above that the two main controls we introduce, the endogeneity (promotion) and selectivity corrections, help to eliminate the gender gap among Mexican SNI researchers. Our results in Table 3.11 show that overall system gains would be achieved by correcting for both factors. Moreover, our scenarios on promotion practices, selectivity, collaboration, and age show that by eliminating the less advantageous position of women in academia relative to men, gains could be achieved for women with overall gains at the system level of around $1 \%$.

\subsection{Conclusions}

This Chapter provides evidence on the existence and determinants of the publication-productivity gender gap in Mexico at the individual level and its consequences for the productivity of the Mexican scientific system at the aggregate level.

The Chapter specifies and performs a panel data analysis based on a sample of Mexican researchers who were members of the National System of Researchers (SNI) of Mexico in 2002-2013. It corrects for a selectivity bias -the existence of periods with no (or low-quality) publications; and an endogeneity bias -promotion to higher academic ranks. It defines and implements counterfactual simulations to assess the magnitude of macro-impacts of existing gender gaps and illustrate the potential effects of a range of policy scenarios. The results show no significant gender gaps for an average SNI researcher. Moreover, after correcting for endogeneity and selectivity biases, the study finds that the average female researcher in public universities is around 8 percent more productive than her male peers. Most of the observed productivity is explained by gender differentials in the propensity to have no quality publication periods. Barriers to promotion to higher academic ranks are highest among females in public research centers (PRCs).

The study's macro scenarios on promotion practices, selectivity, collaboration, and age show that eliminating gender gaps would increase aggregate productivity by an average of $1 \%$ for university women. Eliminating promotion biases would result in the largest contribution to aggregate productivity. Female researchers in universities would increase their productivity by $2.4 \%$, and females in research centers would be $1.7 \%$ more productive.

The findings are interesting in several aspects. The study's descriptive statistics show a gender gap in productivity, narrowing when the publications' quality, measured by the impact factor of the journals where they appear, is considered. The factors analyzed, including collaboration, probability of promotion, and initial productivity, account significantly for the differences in scientific productivity among SNI researchers. Taken together, we find that they invalidate the gender productivity puzzle and even reverse it for all SNI researchers, especially for SNI members in public universities. 
We find that scientific productivity declines with age. We show that, despite the common belief of the existence of a gender gap in publishing selectivity, or the presence of non-productive years, female researchers only have between 5 and 6 percent more non-publishing years than male researchers and, at senior levels, female researchers only have 1 percent more non-publishing years than men. We also find that the gender of the co-authors does not affect the productivity of SNI researchers.

Previous research in France, using the same econometric framework at the micro-individual level, also found that gender inequalities prevent women scientists from being promoted to higher academic ranks. ${ }^{26}$ Examining French physicists working in the Centre National de la Recherche Scientifique (CNRS) and in French public universities, it was learned that female physicists are 6.3 percent less likely to be promoted within CNRS and 16.3 percent less likely to be promoted within universities, conditional on past productivity and age (Mairesse and Pezzoni, 2015). ${ }^{27}$ The French case found an observed average publication productivity gap of female physicists compared to males of about one-third, in both CNRS and universities. The publication productivity gap disappeared for women in the CNRS and favored women significantly in universities when controls for promotion and frequent non-publishing spells were introduced. ${ }^{28}$

Policies encouraging the promotion of female researchers and academics to higher ranks in the form of support grants exclusive to females (e.g., the Dutch Aspasia Program) ${ }^{29}$ could alleviate the underrepresentation of senior female researchers, particularly in male-dominated environments. Several of the CONACYT PRCs have integrated a gender agenda into the research centers' activities. However, none

\footnotetext{
${ }^{26}$ In this chapter, we have used the same econometric framework originally used for France's case by Mairesse and Pezzoni (2015). The two studies are not, however, completely comparable. The French study focused exclusively on physicists, while this study for Mexico covers various hard sciences. The two countries also differ in the academic context and institutional characteristics and functions. For example, most Mexican public research centers also have a training function; thus, affiliated researchers split their work time between teaching and research. In the French CNRS, researchers can focus primarily on academic research.

${ }^{27}$ These lower probabilities of promotion for female physicists correspond to a representative physicist's case, with average productivity of six articles every three years and an average journal impact factor of 5 and aged 40 in the period 2003-2005.

${ }^{28}$ Regarding the quality of the publications, important differences exist between the studies of Mexico and France. In the French study, the average publication productivity in a 3-year period for a female CNRS physicist was equal to a 38.5 impact factor weighted by the number of articles, or 3.9 in terms of an equivalent number of articles in a 3-year period in journals with an impact factor of 10. In Mexico, the impact factor of the journals where SNI Mexicans publish is considerably lower. On average, the SNI researchers in our sample publish in journals with an average impact factor of 1.49. Females publish in journals with a higher impact factor than men, 1.55, compared to 1.47 for male researchers.

${ }^{29}$ The Dutch Aspasia Program aims to ensure that more female assistant professors progress to associate or full professor level. Prizes are awarded to universities that promote female recipients of research grants to senior lecturer or professorial positions within one year of the relevant grant award. See: www.nwo.nl/en/funding/ourfunding-instruments/nwo/aspasia/aspasia.html
} 
of them seems to be actively providing support for female researchers' promotion and career development.

Regarding selectivity, science systems in middle-income countries should ensure similar working conditions for women and men in academia, including policies that reduce self-selection as a source of inequality in the research system. Interpreting our findings in practice, however, is not straightforward. Our selectivity correction can account for a variety of external activities, such as conflicting teaching and management responsibilities, as well as other family engagements and responsibilities. Since this correction is not significant for all SNI researchers' productivity, it is plausible to conclude that the conflict between teaching and training activities and research activities does not play an important role in the presence of non-publishing years among SNI members.

Policy solutions that have proved successful in many developed countries to address women's family responsibilities as a source of selectivity issues include public support for childcare, maternal leave, and flexible work schedules (Castillo et al., 2014). As we outlined above, these policies already exist in some PRCs, but the long-term effects remain to be seen.

The SNI itself has adapted its regulations regarding researchers who become pregnant while being SNI members. They are given an extra year to apply for an extension of their membership, and that year is not considered when evaluating their scientific output. These policies have been implemented only recently, and their effects might not yet be evident. 



\section{Chapter 4. A continuation for South Africa: Micro and Macro Effects of gender productivity gaps and their interaction with ethnicity*}

Following the research design of chapter 3, the main objective of this Chapter is to assess the existence of publication productivity gender gaps in South African academic research and to understand the extent to which it can be attributed to differences in age, scientific fields, and other personal characteristics, to research collaborations and academic environment, and inequalities in careers and particularly in early years. It quantifies the effects of such gaps at micro individual levels and the macro academic system level.

Although there are other studies focused on understanding gender differences in publication productivity in the South African context, to our knowledge, this is the first attempt at measuring these differences among rated researchers of the National Research Foundation (NRF) of South Africa. We hope to contribute methodologically to developing more substantial econometric tools for measuring the micro and macro effects of these gaps.

The Chapter is organized as follows. Section 1 complements the literature review on gender productivity gaps presented in Chapter 3 . It discusses the available literature and existing empirical evidence of such gender gaps in South Africa. Section 2 presents a brief description of the national rating system of the NRF, aiming at providing background and framework to our empirical study. Section 3 presents the data used, the working sample, and further details of how the methodological framework

\footnotetext{
* This Chapter is based on joint work with Prof. Dr. Jacques Mairesse, and Prof. Dr. Robin Cowan.
} 
used in Chapter 3 was adapted to the realities of South Africa as an empirical case. Section 4 presents the findings of our panel data econometric analysis at the micro-level. Section 5 presents the econometric findings at the macro level. Finally, section 6 discusses the main findings and concludes.

\subsection{Gender productivity gaps in South Africa}

Chapter 3 presented a short literature section aiming at understanding the determinants of gender productivity gaps. Notably, this included discussing how the difference and deficit models of Sonnert and Holton (1995) could be used to develop a fully quantitative model that can measure gender productivity gaps. This discussion raised the challenges and limitations of such models to understand the productivity puzzle, most related to data availability, which allows the appropriate measurement of these phenomena.

We also discussed in Chapter 3, the existence of a general structural bias against women in academia. However, female scientists often face a particularly dire situation (Butler-Adam, 2015).

According to the latest South African National Survey of Research and Experimental Development (HSRC, 2017), out of the more than 26,000 Full-Time Equivalent (FTE) researchers in South Africa surveyed in $2015 / 16,44 \%$ of them were female. The male-female ratio has remained unchanged in the past years. Non-white researchers, including African, colored, and Indian researchers, represented $48 \%$ of all researchers in the same years.

Race and the interaction of race with gender are interesting variables to study in South Africa, given its history concerning race segregation. It is often argued that in academia, gender and racial aspects are closely linked.

It is well known that the science system in South Africa served mostly the white population during the apartheid regime. Apartheid education shaped the educational opportunities and attainment of South African women. Its effects on women's access to higher education and women's progress through university and into their academic careers have resulted in further under-representation, segregation, and women's subordination, particularly black women.

Heidi Prozesky has studied largely the existence of gender productivity gaps in South Africa (Prozesky, 2006a, Prozesky, 2008b, Prozesky and Boshoff, 2012, Prozesky, 2006b). In her doctoral dissertation, she showed that those who publish the most in South Africa are white males aged over forty and that are employed as professors at Historically Advantaged Universities (HAUs) ${ }^{30}$. She also found that

${ }^{30}$ HAUs are considered major research universities and are the University of Cape Town, Pretoria, the Witwatersrand, Natal, and Stellenbosch. 
black women's output is lower than that of black males, and even more white researchers' output, both male and women. In this sense, she argued that black women in South Africa face a "double burden" in an academic environment dominated by white male researchers (Prozesky, 2006b).

In her 2006 article and thesis, Prozesky summarized the existing literature supporting publication productivity gaps in South Africa (Prozesky, 2006a, Prozesky, 2006b). She found that men published on average at least thirty percent more journal publications than women and that a large part of the observed productivity gap could be explained by differences among the most prolific researchers and the least prolific. In other words, women are under-represented among the most prolific researchers and over-represented among the least prolific (i.e., in both extremes of the distribution of the number of articles published). This extreme skewness in the number of articles published in specialized journals has also been observed by Jacobs and Ingwersen (2000) in the fields of Physics; Chemistry; Plant and Animal Sciences; and Biochemistry/Microbiology in 10 selected South African universities.

In explaining gender productivity gaps in South Africa from the viewpoint of Sonnert's difference model (Sonnert, 1999) ${ }^{31}$, Prozesky (2006a) argues that the level of qualification and race play an important role in the levels of self-esteem and self-confidence and their links to the ability to conduct research. Indeed, women with no postgraduate training, and black women experience a lack of confidence in conducting research and publishing (Maürtin-Cairncross, 2003).

Walker (1998) collected extensive evidence on women's marginalization in South African universities in the 1990s. She argued that male and masculine roles carried gender cultural prestige and proved the large representation of women in lower academic ranks and their under-representation among the professoriate and South African universities' governing bodies.

Most recent research looking at the most visible scientists in South Africa shows too few black women among high-profiled scientists. Joubert and Guenther (2017) find that despite representing only $8 \%$ of the South African population, the majority of most visible scientists in South Africa (or $78 \%$ ) are white, and a large share of them (63\%) are men. There were only 17 black women identified as visible scientists $^{32}$. It is argued that these high-profiled scientists often outperform their less visible peers in terms of scientific productivity and scientific impact.

\footnotetext{
${ }^{31}$ According to the difference model, gender differences in career achievement are found within women themselves. Differences are innate or the result of gender roles, socialization, or cultural patterns.

32 The research focuses on measuring scientists' participation in public life, popular culture, and scientists' engagement with society. Under this focus, the authors define public visibility of academics as active participation in public science communication, together with an amplification of the individual scientist's points of view and voice as captured by traditional and digital media platforms (Joubert and Guenther, 2017).
} 
Rabe and Rugunanan (2012) show that black women are highly concentrated in low-level academic positions in South African academic departments of sociology. They also show that gender issues are surpassed largely by racial issues. Most specifically, race challenges dominate gender challenges for black female academics, especially for those younger than 40 . Gender discrimination is often felt only once women reach high ranks or senior positions, particularly white women, most often when they are older than 40. Black women often face the combined effect of race and gender discrimination. Continuous pressures to prove themselves also lead black females to abandon their academic careers.

Racial lines define the creation of higher education in South Africa, with the so-called "black" and "white" academic institutions (Rabe and Rugunanan, 2012). Walker (1998) argued that in the absence of targeted action and more equal professional opportunities, it would take at least 30 years for black academics to comprise $50 \%$ of South African universities' overall academic staff. Race is thus still deeply embedded within social institutions, and institutional structures have reinforced women's disadvantage, particularly black women, in South African science.

During apartheid, the so-called 'black' universities also had to cope with additional challenges, such as high dropout rates, lower public investments, uncaring attitudes of lecturers towards students, and physical, political, and academic isolation. As a result, it was more difficult to build relevant research infrastructures and to attract renowned researchers to join them (Jacobs and Ingwersen, 2000).

Maürtin-Cairncross (2003) studied the links between race, gender, and publication activities of academic women at historically black universities (HBUs) in South Africa. She found that barriers to publishing are often related to the historical political origins of HBUs. The transformation of higher education (HE) has been a policy priority in South Africa since the end of apartheid. It is often argued that $\mathrm{HE}$ institutions have a dual role in the country, driving social and economic development; and reducing apartheid-related inequalities (Subotzky, 2001).

In a study of lived experiences of black women academics in South Africa, Ramohai (2014) found that their perception is that of illegitimacy (i.e., no legitimate right to access and meaningful participation), which contrasts with the right to access. The author called this "marginalized access" or that in which, even though black women academics have entered academic institutions in large numbers, their presence is not validated. Social, cultural, and institutional practices still act as barriers that prevent their successful participation.

Research for this paper started earlier than the research for Chapter 3 on Mexico. The original aim for both chapters was to test the methodology developed by Mairesse and Pezzoni (2015) to understand 
gender productivity gaps, originally tested in the French context. Chapter 3 extends the original methodology to measure the effects at the macro level of such gaps.

This Chapter follows that extended methodology ${ }^{33}$. We use the same research design. However, very early in the process, while analyzing our South African working sample's descriptive statistics, we realized that the data showed us a different story. One in which gender is only a component of a system largely influenced by race and age. Race became an important component of this chapter. As a consequence, we divide our working sample into two groups: white and non-white researchers and discuss the results for these two groups separately ${ }^{34}$.

By no means this chapter aims to understand ethnicity or race productivity gaps in South Africa fully. However, our findings give some initial hints and contribute to discussing how gender productivity gaps should not be dissociated from race in the South African context.

\subsection{Understanding the National Rating system of Researchers of the South African Research Foundation (NRF)}

As this Chapter relies on data on rated researchers from the NRF of South Africa, this section aims to set our empirical study in context by introducing the rating system of researchers of the NRF briefly.

The NRF is the South African research funding agency. Its main mission is the development of research capacity in South Africa ${ }^{35}$. A central component of the NRF's research support programs is awarding competitive peer-reviewed grants to individual researchers at universities and technikons (technical colleges). One of the mechanisms to grant these competitive research funds is through a research evaluation rating system in all scientific fields ${ }^{3637}$. Implemented in 1984 by the former FRD in South Africa, the grant approach consists of applicants' rating by evaluating their research outputs. The system works de-facto as a proxy benchmark to assess the national and international standing of

\footnotetext{
${ }^{33}$ The extension to the original methodology results from the research project on gender productivity gaps that we did on behalf of the Inter-American Development Bank (IDB) further explained in Chapter 3.

${ }^{34}$ This contrasts with Chapter 3, where the research sample was divided by researchers' affiliation: universities vs. research centers (i.e., closer and more similar to the original design of Mairesse and Pezzoni (2015).

35 The NRF was established in 1999, combining the mandates of the former Foundation for Research Development (FRD) and the Centre for Science Development (CSD) of the Human Sciences Research Council (Pouris, 2007). The National Research Foundation Act of 1998 sets the NRF's mandate as follows: "to support and promote research through funding, human resource development and the provision of the necessary research facilities ... to facilitate the creation of knowledge, innovation and development in all fields of science and technology, ...". (RSA, 1998).

${ }^{36}$ Un-rated researchers can also get NRF grants.

${ }^{37}$ The rating system was initially only applied to the natural sciences and engineering. The first evaluation and rating of social sciences and humanities researchers took place in 2002.
} 
researchers. Among other things, it was implemented in response to the perception in the 1980s that the allocation of research funding in South Africa was not based on well-defined criteria (Pouris, 2007).

The NRF uses the rating process to increase the country's research capacity, complement the investment in research available in higher education institutions, and promote research excellence (Pienaar et al., 2000).

Ratings are granted based on the applicants' research outputs in the five years before the evaluation. The evaluation is conducted by national and international peers who review the applicants' research outputs' quality. For the 2018 call for applicants, the ratings that are awarded fall within five categories ${ }^{38}$ :

- A - Leading international researchers

- $\quad$ B - Internationally acclaimed researchers

- $\quad$ C-Established researchers

- $\quad$ P-Prestigious awards

- $\quad \mathrm{Y}$ - Promising young researchers.

The classification of researchers has changed over time. An overview of the main changes to definitions and classifications of the rating categories in 1984-2003 is available in Krige (2007). For this Chapter, we use the rating categories that were applicable up to 2012. The main difference between the ratings used in our research and the currently applied ratings is the $L$ (latecomer) rating, which was discontinued in $2014^{39}$.

In our analysis period, senior researchers may have obtained ratings $A, B$, or $C$, while junior researchers may have obtained rating $\mathrm{P}, \mathrm{Y}$, or $\mathrm{L}$, where the order is always from highest to lowest rating. Within each of the broader categories, there are further sub-categories, rating researchers in a finer way. Table 4.1 presents the details of the definition of the rating categories included in our analysis.

\footnotetext{
${ }^{38}$ See also: http://www.nrf.ac.za/rating.

${ }^{39}$ The $L$ rating was initially introduced in 1995 to address some of the inequalities created under apartheid in the education system. The category included researchers who had demonstrated potential in their careers but were impeded to realize this potential by external factors. In 1997, the definition was adjusted to include researchers that had returned to the academic environment after long periods in industry. In 2002, the definition was further revised by focusing on researchers with potential from disadvantaged backgrounds and women. Candidates eligible for this category included black researchers, female researchers, those employed in a higher education institution that lacked a research environment, and those researchers that had returned to a research environment after periods outside academia (Krige, 2007).
} 
Table 4.1 Definitions of NRF research ratings ${ }^{40}$

\begin{tabular}{|c|c|c|c|}
\hline Category & Definition & $\begin{array}{l}\text { Sub- } \\
\text { category }\end{array}$ & Description \\
\hline \multirow[b]{2}{*}{ A } & \multirow{2}{*}{$\begin{array}{l}\text { Leading international researcher } \\
\text { Researchers who are unequivocally } \\
\text { recognized by their peers as leading } \\
\text { international scholars }\end{array}$} & A1 & Recognized by all reviewers as a leading scholar \\
\hline & & $\mathrm{A} 2$ & $\begin{array}{l}\text { Recognized by the overwhelming majority of } \\
\text { reviewers as a leading scholar }\end{array}$ \\
\hline \multirow{3}{*}{ B } & \multirow{3}{*}{$\begin{array}{l}\text { Internationally acclaimed researcher } \\
\text { Researchers who enjoy considerable } \\
\text { international recognition by their } \\
\text { peers }\end{array}$} & B1 & $\begin{array}{l}\text { All reviewers are firmly convinced that the applicant } \\
\text { enjoys considerable international recognition. }\end{array}$ \\
\hline & & B2 & $\begin{array}{l}\text { The overwhelming majority of reviewers are firmly } \\
\text { convinced that the applicant enjoys considerable } \\
\text { international recognition. }\end{array}$ \\
\hline & & B3 & $\begin{array}{l}\text { Most reviewers are firmly convinced that the } \\
\text { applicant enjoys considerable international } \\
\text { recognition. }\end{array}$ \\
\hline \multirow{3}{*}{$\mathrm{C}$} & \multirow{3}{*}{$\begin{array}{l}\text { Established researcher } \\
\text { Researchers with a sustained recent } \\
\text { record of productivity in the field who } \\
\text { are recognized by their peers as } \\
\text { having produced a body of quality } \\
\text { work }\end{array}$} & $\mathrm{C} 1$ & $\begin{array}{l}\text { All of the reviewers are firmly convinced that the } \\
\text { applicant is an established researcher. }\end{array}$ \\
\hline & & $\mathrm{C} 2$ & $\begin{array}{l}\text { The overwhelming majority of reviewers concur that } \\
\text { the applicant is an established researcher. The } \\
\text { applicant may, or not, enjoy some international } \\
\text { recognition for the quality and impact of his/her } \\
\text { research outputs. }\end{array}$ \\
\hline & & C3 & $\begin{array}{l}\text { Most of the reviewers concur that the applicant is an } \\
\text { established researcher. }\end{array}$ \\
\hline$P$ & \multicolumn{2}{|c|}{$\begin{array}{l}\text { Prestigious Awards } \\
\text { Young researchers (normally younger than } 35 \\
\text { years of age) who have held a doctorate or } \\
\text { equivalent qualification for less than five years at } \\
\text { the time of application and are considered likely } \\
\text { to become future international leaders in the field }\end{array}$} & $\begin{array}{l}\text { Recognized by all or the overwhelming majority of } \\
\text { reviewers as having demonstrated the potential of } \\
\text { becoming future international leaders in the }\end{array}$ \\
\hline \multirow[t]{2}{*}{ Y } & \multirow{2}{*}{$\begin{array}{l}\text { Promising Young Researchers } \\
\text { Young researchers ( } 40 \text { years or } \\
\text { younger) who have held a doctorate } \\
\text { or equivalent qualification for less } \\
\text { than five years at the time of } \\
\text { application and who are recognized } \\
\text { as having the potential to establish } \\
\text { themselves as researchers within five } \\
\text { years after evaluation }\end{array}$} & Y1 & $\begin{array}{l}\text { Young researcher (within } 5 \text { years from PhD) who is } \\
\text { recognized by all or the overwhelming majority of } \\
\text { reviewers as having the potential to establish } \\
\text { him/herself as a researcher and that he/she has the } \\
\text { potential to become a future leader in his/her field }\end{array}$ \\
\hline & & Y2 & $\begin{array}{l}\text { Recognized by all or the overwhelming majority of } \\
\text { reviewers as having the potential to establish } \\
\text { himself/herself as a researcher }\end{array}$ \\
\hline$L^{41}$ & \multicolumn{2}{|c|}{$\begin{array}{l}\text { Researchers with Potential } \\
\text { Persons (normally younger than } 55 \text { years) who } \\
\text { were previously established as researchers or who } \\
\text { previously demonstrated potential through their } \\
\text { research products, and who are considered } \\
\text { capable of fully establishing or re-establishing } \\
\text { themselves as researchers within five years after } \\
\text { evaluation. }\end{array}$} & $\begin{array}{l}\text { Category introduced to draw an increased number of } \\
\text { researchers with potential from disadvantaged } \\
\text { backgrounds and women into research. It also caters } \\
\text { to persons previously established as researchers who } \\
\text { have returned to a research environment after } \\
\text { periods in industry or elsewhere. }\end{array}$ \\
\hline
\end{tabular}

Source: (NRF, 2005a, NRF, 2014)

\footnotetext{
${ }^{40}$ See also: http://www.researchsupport.uct.ac.za/rating-categories

${ }^{41}$ In our panel dataset (see Section 3), we have a total of 66 observations where a researcher held an $L$ rating. This corresponds to 61 researchers in our sample, or $4.2 \%$ of the total.
} 
Barnard et al. (2016) argue that NRF ratings are useful to understand the quality of research in the academic community in South Africa because they require extensive detail and contain little missing information. Researchers have to submit curriculum vitae information at the moment of application, including a list of peer-reviewed and other publications, reports and students supervised, patents if any, and conference proceedings, all for the corresponding assessment cycle. The application should also include a self-assessment, detailing the researcher's contributions to each research outcomes produced.

The selection process involves assessment panels divided by broad scientific fields. Each application is peer-reviewed by a panel comprising between three and six experts, usually three proposed by the applicant and three other independent experts. All reviewers produce reports on the quality and outstanding of the researchers and his/her research outcomes. Based on the reports, the committee then proposes a rating category for the applicant. An analysis of all independent reviewers up to 2000 showed that $76 \%$ were foreigners (Pienaar et al., 2000).

Obtaining an NRF rating is an achievement by itself and a way to categorize and identify the best researchers that produce (or would eventually produce) the best research outcomes and that have the potential to provide the best training to other researchers in the South African academic community.

Financial research support is granted to rated researchers, and the amount of support is linked to the rating obtained. Thus, higher-rated researchers usually receive a comprehensive research grant, while junior researchers receive fewer funds (Pienaar et al., 2000). Researchers are overall free to use the research funds granted at their discretion for four years. At the end of the reviewing period, researchers are encouraged to re-apply for a rating. If the rating is increased based on their research performance, they generally receive more research funds for the upcoming cycle. If they did not perform, they usually fail to maintain their ratings and lose or decrease their research grant for the cycle.

Nearly all top-researchers in the South African academic research community are NRF-rated, and the rigor of the review process further suggests that the ratings are reliable. Estimations of coverage suggest that about $90 \%$ of all South African peer-reviewed research outputs correspond to researchers that are NRF-rated.

Even if not an intended objective of the program itself, the NRF ratings are often used as an indicator of performance and a criterion to promote and recruit academic staff in higher education institutions. At the institution level, the ratings also help to understand the academic staff's research strengths and monitor the institutions' excellence and growth performance overall. Many South African universities use the rating process outcomes to categorize and position themselves as being researchintensive. 
The NRF rating system has been widely acclaimed, attracting favorable comments from the international community over the years. The system was reviewed on two occasions. In 1991 through the 'Hawkins Report', and then in 1996 through the MacKenzie Report that focused on evaluating the period 1990-1994. Although several suggestions were given in both reviews to improve the system, they agree that the rating system has been effective in developing the researcher base in South Africa (Krige, 2007). It has also been argued that the system has helped in stimulating competition between researchers, promoting excellence in research, made South African research known internationally, and addressing the research biases that are particular to countries with a relatively small science base (NRF, 2005b, Pienaar et al., 2000). There are also some dissenting voices as to what does not work with the rating system. The most often argued is that the system is elitist, as it discriminates against those that have not had access to training and research facilities (Wingfield and Vaughan, 2017).

\subsection{Sample, data and Methodological Approach}

\subsubsection{The sample}

NRF micro-data was used to construct the working sample. As was previously mentioned, the NRF dataset includes publication data for each researcher who applied for the NRF rating. Only articles in refereed/peer-reviewed journals at the moment of application are considered. The working sample is restricted to those researchers who have applied for an NRF rating in 2002-2011, while the publication record considered corresponds to 1994-2011. We exclude from our sample all researchers that saw their rating lapse in the period of analysis. The working sample is limited to the following Science and Engineering disciplines: Agriculture, Biology, Chemistry, Earth Sciences, Engineering, Health Sciences, IT, Mathematics, Physics, Technologies, and Medicine.

The unbalanced panel data consists of 54,715 publications and 1,444 rated researchers, out of which 437 are female researchers (30.3\%), and 1,007 are male researchers (69.7\%).

In our analysis, we differentiate researchers by ethnicity. We divide researchers using two broad categories: white researchers and non-white researchers. ${ }^{42}$ Non-white researchers include black researchers (59.3\% of all non-white researchers), Indian (23.1\%), and colored researchers (17.6\%). Nonwhite researchers correspond to $29 \%$ of the working sample.

\footnotetext{
42 "Non-white" is a term not used in South Africa; "black" is preferred to refer to that population. However, "black" is a term not used in Western Europe and North America. With apologies to our South African colleagues, the term "non-white" is employed throughout this thesis.
} 
Based on publication data, we constructed two unbalanced panels on which all our econometric models are run, one for white researchers and one for non-white researchers. While it would have been methodologically possible to implement the econometric models using our full sample (i.e., and not dividing the sample by ethnicity), we opted for separating them to more clearly understand and differentiate the effects of all individual variables on the productivity of our sample of researchers by ethnicity. As seen in the data section description, there are clear differences between the two subsamples, not only on how gender and age interact with productivity but also on how promotion practices are affected by gender and ethnicity. We want to make these differences clear, and is it will be seen, differentiating the sample into two groups enriches the study, as it sheds light on the complex mechanisms that affect scientific productivity in South African academia.

\subsubsection{Description of the data}

We measure scientific productivity by looking at the submitted publication data of NRF rated researchers at the moment of application. In contrast to Chapter 3 on Mexico, we do not have access to data on the publications' quality (e.g., as measured through journal impact factors or other metrics such as citation counts). ${ }^{43}$ Thus, in the absence of quality of publication data per se, the definition of publication productivity used in this Chapter corresponds to simple unweighted counts of the articles (in logarithms) published each year by NRF researchers in refereed/peer-reviewed journals. This choice approximated the most our measurement of scientific productivity to the one used in Chapter 3. Each researcher's career was considered starting from the year where the first publication was observed or where the first NRF rating was received.

We use the demographic information included in the NRF filings to complete our data. Each file includes socio-demographic data (age, gender, race, marital status); academic information (disciplines, degrees); and professional experience (career profile, previous positions, institutions granting the PhD).

We use the researchers' NRF ratings as a proxy of seniority (Table 4.1). Given the type of requirements needed to achieve each of the NRF ratings, similarly to the Mexican case presented in Chapter 3, we partition researchers into two broad categories. Low Ranks include researchers rated $P, Y$

\footnotetext{
${ }^{43}$ Many publications in refereed journals submitted to the NRF in the application process do not appear either in Scopus or in the Web of Science. Consequently, the identification of an impact factor for all publications included in the working sample was impossible.
} 
or L, but also those that received a "Rating Unsuccessful" status and a "Not Processed" status; ${ }^{44}$ while High Ranks are those researchers that received A, B, or C ratings in a given year.

Table 4.2 shows that about $78.4 \%$ of all researchers older than 45 had a high-rank in $2011^{45}$. Among young researchers (younger than 45), the share of high-ranked men and women is similar, except for non-white men -under-represented at the high ranks relative to non-white women in their early career years. Among young women, non-whites are slightly better represented in the higher ranks than are whites ( $50 \%$ vs. $46 \%$ respectively). This contrasts with what is observed for researchers over 45 years of age. Non-white female researchers are under-represented in the higher ranks compared to their white female peers ( $54 \%$ vs. $77 \%$ respectively).

Table 4.2 Number and proportion of female and male, white and non-white researchers in two age groups and Low and High ranks in 2011

\begin{tabular}{|c|c|c|c|c|c|c|}
\hline \multirow[t]{2}{*}{ Researchers } & \multicolumn{2}{|c|}{ White } & \multirow{2}{*}{$\begin{array}{l}\text { Total } \\
\text { White }\end{array}$} & \multicolumn{2}{|c|}{ Non-white } & \multirow{2}{*}{$\begin{array}{l}\text { Total } \\
\text { Non- } \\
\text { white }\end{array}$} \\
\hline & Women & Men & & Women & Men & \\
\hline \multicolumn{7}{|l|}{ Less than 45 years } \\
\hline \multirow[t]{2}{*}{ Low Ranks (Other ${ }^{46}$ ) } & 92 & 160 & 252 & 24 & 91 & 115 \\
\hline & $54 \%$ & $54 \%$ & $54 \%$ & $50 \%$ & $63 \%$ & $60 \%$ \\
\hline \multirow[t]{2}{*}{ High Ranks (C, B, A) } & 79 & 139 & 218 & 24 & 53 & 77 \\
\hline & $46 \%$ & $46 \%$ & $46 \%$ & $50 \%$ & $37 \%$ & $40 \%$ \\
\hline \multirow[t]{2}{*}{ Sub Total } & 171 & 299 & 470 & 48 & 144 & 192 \\
\hline & $100 \%$ & $100 \%$ & $100 \%$ & $100 \%$ & $100 \%$ & $100 \%$ \\
\hline \multicolumn{7}{|l|}{45 years and more } \\
\hline \multirow[t]{2}{*}{ Low Ranks (Other) } & 40 & 42 & 82 & 21 & 66 & 87 \\
\hline & $23 \%$ & $11 \%$ & $15 \%$ & $46 \%$ & $36 \%$ & $38 \%$ \\
\hline \multirow[t]{2}{*}{ High Ranks (C, B, A) } & 132 & 342 & 474 & 25 & 117 & 142 \\
\hline & $77 \%$ & $89 \%$ & $85 \%$ & $54 \%$ & $64 \%$ & $62 \%$ \\
\hline \multirow[t]{2}{*}{ Sub Total } & 172 & 384 & 556 & 46 & 183 & 229 \\
\hline & $100 \%$ & $100 \%$ & $100 \%$ & $100 \%$ & $100 \%$ & $100 \%$ \\
\hline \multicolumn{7}{|l|}{ All } \\
\hline \multirow[t]{2}{*}{ Low Ranks (Other) } & 132 & 202 & 334 & 45 & 157 & 202 \\
\hline & $38 \%$ & $30 \%$ & $33 \%$ & $48 \%$ & $48 \%$ & $48 \%$ \\
\hline \multirow[t]{2}{*}{ High Ranks (C, B, A) } & 211 & 478 & 689 & 49 & 170 & 219 \\
\hline & $62 \%$ & $70 \%$ & $67 \%$ & $52 \%$ & $52 \%$ & $52 \%$ \\
\hline \multirow[t]{2}{*}{ Sub Total } & 343 & 680 & 1023 & 94 & 327 & 421 \\
\hline & $100 \%$ & $100 \%$ & $100 \%$ & $100 \%$ & $100 \%$ & $100 \%$ \\
\hline
\end{tabular}

\footnotetext{
44 The reason for including researchers that did not receive a rating at the moment of application ("Rating Unsuccessful") and those that submitted one that was "Not Processed" is that receiving such an outcome by itself constitutes an attempt to enter the NRF system that should be accounted for.

${ }^{45} 2011$ is the last year of our observation period. Table 4.2 is showing the characteristics of our sample at the end of the observation period.

${ }^{46}$ Low Ranks include researchers rated P, Y or L, but also those that received a "Rating Unsuccessful" status and a "Not Processed" status.
} 


\subsubsection{Descriptive statistics of publication productivity by gender}

We measure scientific productivity by looking at the publication record submitted at the moment of application to the NRF. Only articles in refereed/peer-reviewed journals are considered. Publication productivity in a given year is the sum of the number of peer-reviewed publications in that year as reported in the researcher's application file to the NRF. Table 4.3 reports the annual average productivity of NRF researchers by gender and ethnicity, median, standard deviations, and the corresponding number of observations. In a similar fashion to Chapter 3, the upper part of the table presents statistics for all years, including the non-publishing years. We define a 'non-publishing year' as those with truly zero peerreviewed articles reported in the applicants' NRF records. The table's middle and bottom parts present similar annual statistics, excluding non-publishing years and in logarithms, respectively. The figures in logarithms also exclude the non-publishing years, with the benefit that this also normalizes the statistical distribution of the observed productivity itself.

Table 4.3 Descriptive statistics on average publications per year ${ }^{47}$ for female and male, white and non-white researchers, including and excluding non-publishing years

\begin{tabular}{|c|c|c|c|c|c|c|}
\hline Researchers & Women & Nhite & $\begin{array}{c}\mathrm{W} / \mathrm{M} \\
\text { (or W-M in } \\
\text { logs) }\end{array}$ & Women & n-white & $\begin{array}{c}\text { W/M } \\
\text { (or W-M } \\
\text { in logs) }\end{array}$ \\
\hline \multicolumn{7}{|c|}{ Including non-publishing years } \\
\hline Mean & 3,38 & 3,14 & 1,08 & 2,30 & 2,23 & 1,03 \\
\hline Median & 2 & 2 & 1,00 & 1 & 1 & 1,00 \\
\hline Std. Dev & 4,73 & 4,45 & & 3,88 & 3,51 & \\
\hline Obs. & 4290 & 9266 & & 1085 & 3941 & \\
\hline \multicolumn{7}{|c|}{ Excluding non-publishing years } \\
\hline Mean & 4,91 & 4,57 & 1,07 & 3,82 & 3,68 & 1,04 \\
\hline Median & 3 & 3 & 1,00 & 2 & 2 & 1,00 \\
\hline Std. Dev & 5,00 & 4,72 & & 4,38 & 3,87 & \\
\hline Obs. & 2955 & 6323 & & 653 & 2389 & \\
\hline \multicolumn{7}{|c|}{ In logarithms (excluding non-publishing years) } \\
\hline Mean & 1,20 & 1,14 & 0,06 & 0,99 & 0,95 & 0,04 \\
\hline Median & 1,10 & 1,10 & 0,00 & 0,69 & 0,69 & 0,00 \\
\hline Std. Dev & 0,87 & 0,86 & & 0,78 & 0,81 & \\
\hline Obs. & 2955 & 6323 & & 653 & 2389 & \\
\hline
\end{tabular}

The data show that white women are the most productive with 3.38 articles per year, followed by white men (3.14), non-white women (2.30), and non-white men (2.23). Ethnicity plays a significant role

${ }^{47}$ Only peer-reviewed research outputs are considered. 
in the overall productivity of researchers. Women are slightly more productive than men among white and non-white researchers, with white researchers always more productive than non-white. White women are about $8 \%$ more productive than white men, while non-white women are $3 \%$ more productive than non-white men. The median of white researchers' productivity is equal to 2 for females and males and equal to 1 for non-white researchers. When non-publishing years are excluded, the medians are equal to 3 for all white researchers and 2 for non-white.

This could suggest that ethnicity has more explanatory power than does gender for understanding productivity gaps. However, as was discussed in the literature section, there may be a bias in who applies to be rated. Women, and in particular non-white women, might be less likely to apply for a rating overall.

Table 4.3 also shows that when we exclude non-productive years, the gap between white men and white women remains practically unchanged. A similarly unchanged productivity gap is observed among non-white researchers when non-productive years are excluded.

Figure 4.1 shows the distribution of observed log-productivity for female and male researchers by ethnicity. As was discussed using Table 4.3, white women are the most productive, followed by white men, non-white women, and non-white men. Using the mean log-productivity of white and non-white men as benchmarks, 53 percent of white women and 52 percent of non-white women exceed this benchmark, respectively.

\section{Figure 4.1 Distribution of Observed Log-Productivity for Female and Male, NRF researchers by ethnicity}

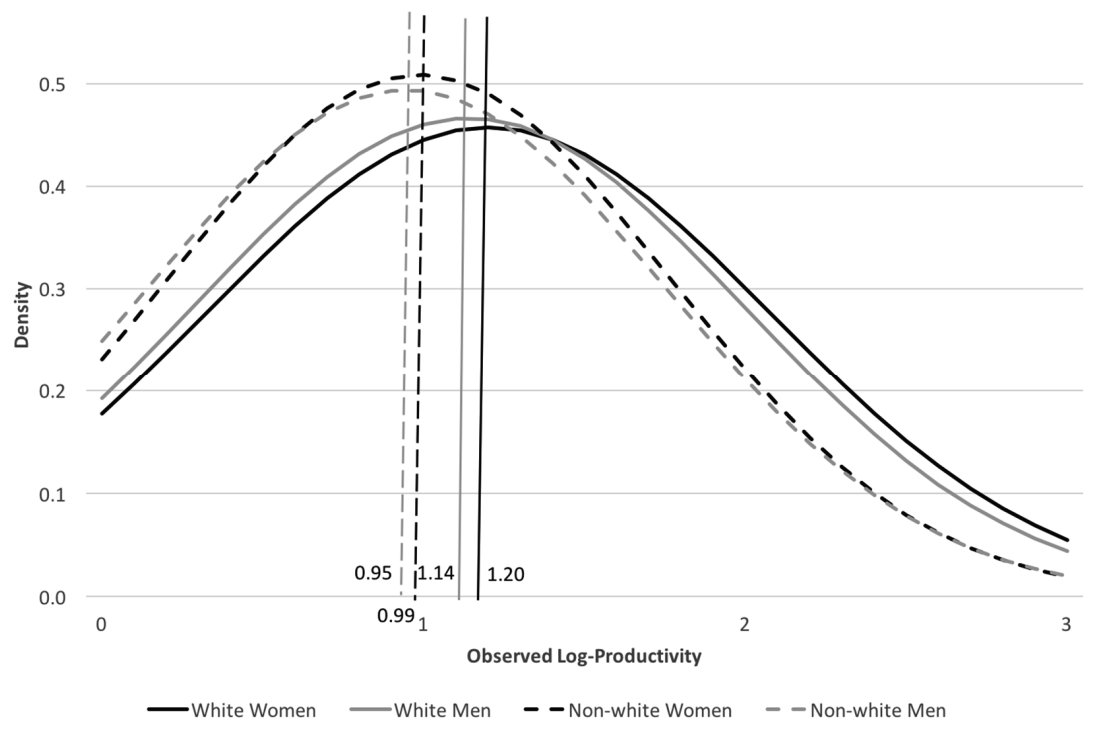


If observed in an aggregate manner, there are no marked differences in the number of nonproductive years between male and female researchers. White researchers have fewer non-publishing years (31\% of all observations) relative to non-white $(40 \%)$ (Table 4.4$)^{48}$. However, when the nonpublishing years are analyzed by ethnicity and age groups, more marked differences emerge. Table 4.4 shows that the frequency of non-publishing is higher among non-white researchers, particularly among those older than 45 years of age and having a low rank. Surprisingly, white men older than 45 and holding a high rank have a larger proportion of non-publishing years than their white female counterparts of the same age and rank. In contrast, non-white males, older than 45 and in high ranks have a proportionally lower share of non-publishing years than non-white old female researchers. Again, this first descriptive view shows that the largest differences in the frequency of non-publishing years are mostly explained by age and ethnicity, rather than by gender.

Table 4.4 Proportion of Non-publishing years for Female and Male NRF researchers, White and Nonwhite researchers, in Two Age Groups and Low and High Ranks

\begin{tabular}{|c|c|c|c|c|c|c|}
\hline \multirow[b]{2}{*}{ Researchers } & \multicolumn{2}{|c|}{ White } & \multicolumn{4}{|c|}{ Non-White } \\
\hline & Women & Men & W-M & Women & Men & W-M \\
\hline \multicolumn{7}{|l|}{ Less than 45 years } \\
\hline Low Ranks (Other) & $32 \%$ & $32 \%$ & $0 \%$ & $39 \%$ & $39 \%$ & $1 \%$ \\
\hline High Ranks (C, B, A) & $20 \%$ & $24 \%$ & $-4 \%$ & $20 \%$ & $33 \%$ & $-13 \%$ \\
\hline Sub Total & $30 \%$ & $30 \%$ & $0 \%$ & $37 \%$ & $38 \%$ & $-1 \%$ \\
\hline \multicolumn{7}{|l|}{45 years and more } \\
\hline Low Ranks (Other) & $38 \%$ & $36 \%$ & $2 \%$ & $49 \%$ & $49 \%$ & $0 \%$ \\
\hline High Ranks (C, B, A) & $29 \%$ & $32 \%$ & $-6 \%$ & $46 \%$ & $31 \%$ & $14 \%$ \\
\hline Sub Total & $33 \%$ & $34 \%$ & $-1 \%$ & $48 \%$ & $42 \%$ & $6 \%$ \\
\hline \multicolumn{7}{|l|}{ All } \\
\hline Low Ranks (Other) & $33 \%$ & $33 \%$ & $0 \%$ & $42 \%$ & $41 \%$ & $0 \%$ \\
\hline High Ranks (C, B, A) & $25 \%$ & $29 \%$ & $-3 \%$ & $31 \%$ & $32 \%$ & $-1 \%$ \\
\hline Sub Total & $31 \%$ & $31 \%$ & $0 \%$ & $40 \%$ & $39 \%$ & $0 \%$ \\
\hline
\end{tabular}

\subsubsection{Descriptive statistics of promotion of NRF researchers}

As will be explained further in our methodological section below, we define promotion as the change from Low Ranks to High Ranks in 1994-2011. Low Ranks include the ratings P, Y, L but also Rating Unsuccessful, Not Processed, and Rating Pending. High Ranks includes the ratings C, B, and A.

When we look at the career paths of the researchers, we observe that there are no large differences in the promotion patterns of white researchers by gender: about $60.1 \%$ of white men with

\footnotetext{
${ }^{48}$ One observation refers to a calendar year for each of the researchers included in the final sample.
} 
Low Ranks were not promoted to High Ranks in the period 1994-2011, compared to $60.6 \%$ of women (Table 4.5). Once again, the ethnicity gap seems to be more important: $70.4 \%$ of non-white men and $69.2 \%$ of non-white women were not promoted.

Table 4.5 also shows that out of the 680 white men in our sample, 344 of them or $53 \%$, received as first rating in the observation period a High Rank, that is obtaining an A, B, or C rating, or held already a senior rating during the observation period. This high share of High Ranks among white men contrasts with $36 \%$ of High Ranks among white women (125 researchers out of 343 ), 32\% among non-white men, and $31 \%$ of High Ranks among non-white women (29 out of 94).

Table 4.5 Promotion from Low Ranks to High Ranks by Ethnicity and Gender

\begin{tabular}{|c|c|c|c|c|c|c|}
\hline & \multicolumn{3}{|c|}{$\begin{array}{l}\text { Men } \\
\text { Last rating in period }\end{array}$} & \multicolumn{2}{|c|}{$\begin{array}{l}\text { Men } \\
\text { Last rating in period }\end{array}$} & \\
\hline $\begin{array}{l}\text { First rating } \\
\text { period }\end{array}$ & Low Rank & High Rank & Total & Low Rank & High Rank & Total \\
\hline Low Rank & 202 & 134 & 336 & 157 & 66 & 223 \\
\hline High Rank & 0 & 344 & 344 & 0 & 104 & 104 \\
\hline \multirow[t]{2}{*}{ Total } & 202 & 478 & 680 & 157 & 170 & 327 \\
\hline & \multicolumn{3}{|c|}{$\begin{array}{l}\text { Women } \\
\text { Last rating in period }\end{array}$} & \multicolumn{3}{|c|}{$\begin{array}{l}\text { Women } \\
\text { Last rating in period }\end{array}$} \\
\hline $\begin{array}{l}\text { First rating } \\
\text { period }\end{array}$ & Low Rank & High Rank & Total & Low Rank & High Rank & Total \\
\hline Low Rank & 132 & 86 & 218 & 45 & 20 & 65 \\
\hline High Rank & 0 & 125 & 125 & 0 & 29 & 29 \\
\hline Total & 132 & 211 & 343 & 45 & 49 & 94 \\
\hline
\end{tabular}

However, as we go more into detail in the change of ratings, we observe more granular differences by gender and ethnicity. Our Low-Rank category includes, in effect, also researchers that did not receive any rating (e.g., Rating Unsuccessful, Not Processed, and Rating Pending) even after applying for it. For instance, from the 202 white male researchers that did not change their Low-Rank status in the period of analysis (Table 4.5), 38\% or 76 white male researchers did not receive a rating at all (i.e., remained with a "No Rank" in (Table 4.6).

As discussed above, non-white researchers are less likely to be promoted from Low Ranks to High Ranks. Table 4.6 shows that they are also less likely to be promoted from No Ranks to Low Ranks relative to white researchers. About 88 researchers in our sample or $6 \%$ of all researchers analyzed, obtained a High Rank after not having a rating (No Rank). However, all of these cases were changes from No Rank to a Rating $\mathrm{C}$, which is certainly an achievement but not something uncommon for outstanding researchers 
with good publication records. $43 \%$ of these cases are white men, followed by non-white men (25\%), white women $(23 \%)$, and non-white women (9\%, or only 8 researchers).

Table 4.6 Changes from No Ranks to Low Ranks and High Ranks by Ethnicity and Gender

\begin{tabular}{|c|c|c|c|c|c|c|c|c|}
\hline \multicolumn{9}{|c|}{ Last Rating received } \\
\hline \multicolumn{5}{|c|}{ White Men } & \multicolumn{4}{|c|}{ Non-white Men } \\
\hline received & No Rank & Low Rank & High Rank & Total & No Rank & Low Rank & High Rank & Total \\
\hline No Rank & 76 & 0 & 38 & 114 & 86 & 0 & 22 & 108 \\
\hline Low Rank & 0 & 126 & 96 & 222 & 0 & 71 & 44 & 115 \\
\hline High Rank & 0 & 0 & 344 & 344 & 0 & 0 & 104 & 104 \\
\hline Total & 76 & 126 & 478 & 680 & 86 & 71 & 170 & 327 \\
\hline \multicolumn{5}{|c|}{ White Women } & \multicolumn{4}{|c|}{ Non-white Women } \\
\hline No Rank & 49 & 0 & 20 & 69 & 24 & 0 & 8 & 32 \\
\hline Low Rank & 0 & 83 & 66 & 149 & 0 & 21 & 12 & 33 \\
\hline High Rank & 0 & 0 & 125 & 125 & 0 & 0 & 29 & 29 \\
\hline Total & 49 & 83 & 211 & 343 & 24 & 21 & 49 & 94 \\
\hline
\end{tabular}

The issue of promotion will be discussed in more detail in this Chapter's methodological and discussion sections. However, it is worth mentioning that our sample's characteristics highly drove the choice of categories for explaining promotion (i.e., only having two broad categories and not granular categories that follow more the NRF rating system). We did not have enough observations to model more detailed promotion steps and achievements in an NRF researcher's career. For instance, we had few observations in particular for the promotion of non-white women to High Ranks. The fact that very few non-white female researchers are promoted to High Ranks is an interesting finding in itself.

Generally, it is only in rare cases that a researcher will get immediately rated at the start of their academic career. It is much more common to apply and obtain a rating after working in academia as an assistant professor for a few years. In this sense, it is worth mentioning that, even if not included in our analysis, obtaining a rating in itself is a promotion and a great achievement for any researcher in South Africa.

\subsubsection{Co-authorship}

In a similar fashion to Chapter 3, we have calculated the medians of the harmonic averages of the number of authors per article each year. They are, respectively, 3.6 authors for white researchers and 3.4 for non-white researchers. This compares to 3.9 authors per article for women and 3.4 for men, and 3.6 authors per article for High Ranks and 3.5 for Low Ranks. If there is a difference in co-authorship practices among the different groups, it seems that here the division is along with gender rather than 
ethnic lines. However, these differences may be driven by disciplinary practices rather than behavioral differences between genders. We include academic discipline dummies in all our econometric models to control for these differences (see Section 3.3 below).

Table 4.7 presents the summary statistics of the average number of co-authors by gender and ethnicity. Only the co-authorships that involve other NRF-rated researchers for which ethnicity and gender are known are considered. On average, all researchers, regardless of ethnicity and gender, collaborate mostly with white men. White men and women then collaborate mostly with white females: with an average of 1.56 white female researchers per year for white women and 0.88 for white men. In contrast, non-white researchers, regardless of gender, collaborate then the most on average with nonwhite males ( 0.71 on average per year for non-white men vs. 0.60 for non-white women). Co-authorships with non-white women always come at last for all researchers.

When looking at the data as a share of the total, we confirm the previous findings. All researchers collaborate mostly with white men, regardless of their ethnicity and gender. For white researchers, the second most frequent co-author is white women, while for non-white researchers, the second most frequent collaborator is non-white men. Non-white women are the least frequented co-authors, even for non-white females themselves.

Table 4.7 Gender and Ethnicity of NRF co-authors

Average number of co-authors by gender and ethnicity

\begin{tabular}{lllll} 
& \multicolumn{2}{c}{ White } & \multicolumn{2}{c}{ Non-white } \\
& Women & Men & Women & Men \\
\hline Co-authored with white female & 1,56 & 0,88 & 0,56 & 0,29 \\
Co-authored with white male & 2,75 & 2,20 & 1,29 & 0,92 \\
Co-authored with non-white female & 0,14 & 0,08 & 0,18 & 0,14 \\
Co-authored with non-white male & 0,27 & 0,26 & 0,60 & 0,71 \\
\hline Share of total (\%, multiple choice allowed) & 29,74 & 18,39 & 15,30 & 8,55 \\
\hline Co-authored with white female & 44,90 & 39,36 & 27,83 & 22,38 \\
Co-authored with white male & 4,57 & 2,81 & 7,37 & 4,59 \\
Co-authored with non-white female & 8,28 & 8,17 & 16,87 & 17,00 \\
Co-authored with non-white male & 4290 & 9217 & 1085 & 3941 \\
\hline Observations & & & & \\
\hline
\end{tabular}




\subsubsection{Methodological Approach - A continuation for South Africa}

\subsubsection{Micro-Level Analysis}

The methodological approach used in this chapter is the same as that used in Chapter 3. We investigate gender productivity gaps from two perspectives. First, we look at the determinants of these gaps at the individual researcher level (1); and second, we rely on the econometric results of the first part to calibrate counterfactual simulations, with the dual purpose of assessing the magnitude of macroimpacts of existing gender gaps and of illustrating the potential impacts of a range of policy scenarios (2).

As was explained in Chapter 3, when trying to understand scientific productivity, we face three major specification issues - publishing occurrence selectivity, the endogeneity of promotion to higher professional ranks or status, and unobserved individual heterogeneity - which can result in significant biases in the estimated parameters of productivity determinants of main interest and hence on their impact on gender gaps. We take care of such biases by specifying and estimating jointly with the productivity equation two other equations, a probit equation for publishing occurrence 'selectivity' and another for 'promotion'.

\section{The Promotion Probit Equation}

The promotion probit equation (Eq. 1) aims to correct endogeneity biases related to the correlation between career advancements and scientific productivity by including the factors likely to have a large influence on individual researchers' career achievements. It explains a binary promotion variable to a higher academic rank or status by gender $(G)$, age $(A)$, past productivity $(P P)$, and time $(t)$. As for the case of Mexico, we give importance to the interactions of gender with age.

$$
\text { (Eq. 1) } \quad \text { Rank }=f(G, A, P P, t)
$$

We define promotion (Rank) as a change from Low Ranks ( $\mathrm{P}, \mathrm{Y}, \mathrm{L}$, Rating Unsuccessful, Not Processed) to High Ranks (C, B, A) in the NRF system. The period we consider is 1993-2010. The variables included in the equation are comparatively very similar to those included and analyzed for Mexico in Chapter 3. We consider age and gender, and age squared with and without the interactions. Age is centered on 45 years and divided by 10 for easy reading of the estimates. We also include variables accounting for past productivity: we include the number of publications and the absence of unproductive years in the 3 years before promotion. We also include a variable for whether the PhD was obtained in South Africa or abroad. Finally, we also include two variables accounting for the gender of the co-authors: a lagged dummy variable on whether the researcher had a male co-author in the previous year; and the interaction of this variable with gender, to capture gender differences of the effects of the co-authors' characteristics on promotion. 


\section{The Publishing Spell Selection Probit Equation}

The selectivity probit equation accounts for the fact that all researchers have periods when they do not publish during the academic career and that these periods do not occur at random. It thus estimates the probability of not having publishing periods subject to a set of determinants, such as past productivity history ( $\theta$ in Equation 2), the interaction of gender with age $(G, A, G * A)$, and time $(t)$.

$$
\text { (Eq. 2) } \varphi=f(G, A, \theta, t)
$$

This chapter's selection equation has the same construction as the one used in Chapter 3: a probit equation taking the value of 1 for a publishing year and zero otherwise. The variables on Age $(A)$ and gender $(G)$ and their interactions $(G * A)$ are the same as those used in the promotion equation. Finally, productivity history $(\theta)$ is measured using three binary dummies, noted Persistence 111 , Persistence 110/101/011, and Persistence 100/010/001. These indicate those NRF researchers that have published at least one article in three consecutive years, at least one article in two of the last three years, or at least one article in one of the last three years. ${ }^{49}$ The three Persistence dummies are lagged by one year. They cover three years, from $t-1$ to $t-3$. The equation also includes time dummies for controlling for calendar years.

\section{The Productivity Regression}

The productivity equation is a basic linear regression of log-productivity on different groups of explanatory variables and time dummies (Equation 3).

$$
\text { (Eq. 3) } \log (y)=f(G, A, I C, \delta, \operatorname{Prob}(\operatorname{Rank}), \varphi, t)
$$

The first group is gender $(G)$ and age $(A)$ and their interactions $(G * A)$, as implemented in the promotion and selection equations. The second group concerns the initial productivity and the First rating of the researcher -or initial seniority (IC in Equation 3, or Initial Characteristics), which also act as a proxy for unobserved heterogeneity. The initial productivity variable measures the initial number of articles in logarithms for each of the researchers. This is a measure of how productive each of the researchers was in their first academic year. Overall, one can expect that the most productive researchers will continue a highly productive career over the years. The initial seniority corresponds to the first rating observed for each of the researchers. We include three dummy variables, differentiating whether the researchers

\footnotetext{
${ }^{49}$ Each digit represents the publishing behavior in one of the previous three years. 101, for example, means the scientist published in year $t-3$ and $t-1$ but not in year $\mathrm{t}-2$. We aggregate by the number of publishing years in the previous three.
} 
started with a Rating A, B, or C. It is expected that the researchers starting with the most senior ratings will be more productive than those with lower ratings.

The third group of variables consists of the predicted probabilities of promotion (Prob (Rank)) and non-publishing years $(\varphi)$, coming from the promotion (Equation 1) and selection (Equation 2) equations, respectively. These are included in the productivity equation to correct the endogeneity of high academic ranks and publishing selectivity.

The fourth group refers to collaboration variables $(\delta)$, explaining the work environment's influence on scientific productivity. Similar to the Mexican case presented in Chapter 3, we have computed three groups of collaboration variables. The first one includes the co-authors' characteristics (Collaborations); the second relates to the co-authors' seniority, and the third group looks at the gender and the ethnicity of the co-authors. All collaboration variables are built only for those collaborations that occurred between two NRF-rated researchers for which personal characteristics are known. All variables are constructed similarly as for Mexico, and all details are presented in Chapter 3. There are two exceptions. First, we do not have access to the Journal impact factor (IF) of NRF publications, and hence we do not include variables on the quality of publications measured by IF. Second, we measure the effect of the gender and affiliations of the co-authors on scientific productivity (instead of looking only at the affiliation of the co-authors).

Time dummies $(t)$ and academic disciplines dummies are also included in the equation to control for general unobserved factors.

\subsubsection{Macro-Level Analysis}

We rely on the econometric results at the micro level that we regard as the most robust and significant to calibrate counterfactual simulations at the macro level to illustrate the potential impact of a set of policy scenarios. We focus on understanding the impacts and effects of four issues: promotion practices (1) (what would be the overall gains for female researchers if women had the same promotion probabilities as men); publication intensity (2) (if women had the same probability of non-publishing as men); collaboration practices (3) (if women had the same collaboration characteristics as men); and age (4) (if women had the same age as men). 
We use the results of the productivity equation with the corrections for selectivity and endogeneity to compute the contributions to the estimated publication productivity of (1) promotion, (2) selectivity, (3) the collaboration variables, and (4) age and gender interactions, by gender and ethnicity. The productivity gains at the system level for female researchers are computed using the following (Equation 4):

$$
\text { (Eq. 4) } \quad z_{y}=\frac{\left(e^{p p_{x}^{c}}-e^{p p_{y}^{c}}\right) * n_{y}}{10}
$$

where $z_{y}$ are the productivity gains at the system level for female researchers; $p p_{x}$ is the predicted productivities for men of each of the policy scenarios tested in logarithms; $c$ is the 4 policy scenarios defined above (characteristics); $p p_{y}$ is the predicted productivities for women for each of the scenarios in logarithms, and $n_{y}$ are the number of female non-censored observations in our sample.

For each policy scenario $c$, we change the average value of the characteristic $c$ for women by attributing women the same value as men. We then predict women's productivity with the values attributed by $p p_{x}^{c}$ and then subtract from this prediction the predicted productivity of women with their actual average value of the characteristic $c$ in $p p_{y}^{c}$. Finally, to get the macro scenario, we multiply the difference in productivity obtained in $\left(e^{p p_{x}^{c}}-e^{p p_{y}^{c}}\right)$ by the number of women in our sample $n_{y}$.

Comparatively, the productivity gains at the system level for male researchers are computed using the following (Equation 5):

$$
\text { (Eq. 5) } \quad z_{x}=\frac{\left(e^{p p_{y_{-}}^{c}}-e^{p p_{x}^{c}}\right) * n_{x}}{10}
$$

where $z_{x}$ are the productivity gains at the system level for male researchers and $n_{x}$ are the number of male non-censored observations in our sample.

The productivity gains are calculated separately for white and non-white researchers. ${ }^{50}$ The following sections (Section 4 and Section 5) present our micro and macro-econometric findings.

\subsection{Econometric Findings at the Micro Level}

\subsubsection{The Promotion Probit Equation}

The promotion equation results show that the probability of being promoted to high ranks decreases with age, though much less rapidly for white females than for white males and more rapidly for non-white females than for non-white males.

\footnotetext{
${ }^{50}$ And for men and women when relevant.
} 
Past productivity is measured in two ways. First, we introduce three dummy variables (Publications in $t-1$, in $t-2$, and $t-3)$ which measure whether a researcher published in any of the three previous years (i.e., the variable takes the value of 1 if the researcher published at least once in a given year, and 0 otherwise). Second, we also account for the intensity of the past productivity with variables Log No. Publications in $t-1, t-2$ and $t-3$, which measure the number of publications in logarithms of the previous 3 years.

Like the findings for Mexico, past publication productivity (or lagged productivity) reported in the NRF filing applications is a major determinant of the probability of promotion, both for white and nonwhite researchers. A small exception is the presence of publications in $t-1$ for non-white researchers (Publications in t-1), which is not significant. However, the number of publications in $t-1$ is significant (Log No. Publications in $t-1$ ) and with a higher intensity than for white researchers. This signals that when these are observed, the quantity of publications in the past is a strong determinant of promotion, even more than for white researchers.

Table 4.8 Promtion Probit Equation for NRF Researchers by ethnicity, with and without Age * Gender Interactions

\begin{tabular}{|c|c|c|c|c|}
\hline Rank Indicator & White & Non-white & White & Non-white \\
\hline \multicolumn{5}{|l|}{ Age and Gender } \\
\hline Woman (=1) & $-0.254 * * *$ & $-0.151 * *$ & $-0.378 * * *$ & $-0.367^{* * *}$ \\
\hline$($ Age-45)/10 & $0.768 * * *$ & $0.720 * * *$ & $0.725^{* * *}$ & $0.767 * * *$ \\
\hline$\left((\text { Age-45)/10 })^{\wedge} 2\right.$ & $-0.331 * * *$ & $-0.542 * * *$ & $-0.336 * * *$ & $-0.714 * * *$ \\
\hline$($ Age-45)/10 * Woman & & & $0.156^{* * *}$ & $-0.201 * *$ \\
\hline$\left((\text { Age-45)/10 })^{\wedge} 2 *\right.$ Woman & & & 0.0302 & $0.605^{* * *}$ \\
\hline \multicolumn{5}{|l|}{ Lagged productivity } \\
\hline Publications in t-1 & $0.128 * * *$ & 0.0825 & $0.127^{* * *}$ & 0.0825 \\
\hline Publications in $\mathrm{t}-2$ & $0.174^{* * *}$ & $0.151^{* *}$ & $0.172 * * *$ & $0.154^{* *}$ \\
\hline Publications in $\mathrm{t}-3$ & $0.192 * * *$ & $0.221 * * *$ & $0.187^{* * *}$ & $0.218^{* * *}$ \\
\hline Log No. Publications in t-1 & $0.0381^{*}$ & $0.110^{* *}$ & $0.0373^{*}$ & $0.113^{* * *}$ \\
\hline Log No. Publications in t-2 & $0.121^{* * *}$ & $0.127^{* * *}$ & $0.120 * * *$ & $0.132 * * *$ \\
\hline Log No. Publications in t-3 & $0.149^{* * *}$ & $0.207^{* * *}$ & $0.149 * * *$ & $0.215^{* * *}$ \\
\hline \multicolumn{5}{|l|}{ Co-authors } \\
\hline Male co-author in t-1 & $0.0851^{* *}$ & 0.00418 & 0.0367 & 0.0513 \\
\hline Male co-author in $\mathrm{t}-1 *$ Woman & & & $0.191^{* * *}$ & -0.178 \\
\hline Foreign PhD & $0.126^{* * *}$ & -0.0184 & $0.120 * * *$ & 0.0106 \\
\hline Time dummies & yes & yes & yes & yes \\
\hline Discipline dummies & yes & yes & yes & yes \\
\hline Constant & $-0.231 * * *$ & -0.187 & $-0.202 * *$ & -0.138 \\
\hline Observations & 13,507 & 5,026 & 13,507 & 5,026 \\
\hline Pseudo R2 & 0.3050 & 0.2922 & 0.3067 & 0.3009 \\
\hline
\end{tabular}


Based on the promotion probit equation results, and controlling for age and gender, lagged productivity, and the co-authors' characteristics, we calculate the average estimated probability of promotion of all NRF researchers in our sample. We find that the probability of promotion is higher for white researchers than for non-white researchers: 0.34 and 0.21 , respectively. The estimated maximum age of promotion varies largely by ethnicity and gender and is equal to 45 for non-white men, compared to 51 for white men, 54 for white women, and 66 for non-white women.

Having a male NRF co-author in the past has a positive and significant effect in promotion only for white researchers. Having acquired a PhD abroad increases the probability of promotion, again only for white researchers.

\subsubsection{The Publishing Spell Selection Probit Equation}

Similar to what was found for the Mexican case, the probability of publishing is significantly higher for NRF researchers who are more persistent in publishing in the previous three years relative to those who are less persistent or are not publishing in the previous three years. This is the case, regardless of whether the researchers are white or non-white. In other words, and not surprisingly, researchers that are steady publishers are less likely to have non-publishing years.

The selection equation also shows that gender is not a significant predictor of publishing. The probability of publishing is also much lower for older non-white researchers than for younger ones. These differences are much smaller among white researchers.

Table 4.9 Publishing Yearly Selection Probit Equation for NRF researchers by ethnicity, with and without Age*Gender Interactions

\begin{tabular}{|c|c|c|c|c|}
\hline Publishing indicator & White & Non-white & White & Non-white \\
\hline \multicolumn{5}{|l|}{ Age and Gender } \\
\hline Woman (=1) & -0.0224 & $-0.0842^{*}$ & -0.0298 & -0.0497 \\
\hline$($ Age-45)/10 & $-0.0340 * *$ & $-0.123 * * *$ & -0.0269 & $-0.123 * * *$ \\
\hline$((\text { Age- } 45) / 10)^{\wedge} 2$ & $-0.0334 * * *$ & $-0.0567 * *$ & $-0.0346 * *$ & -0.045 \\
\hline$($ Age-45)/10 * Woman & & & -0.0227 & -0.00879 \\
\hline$(($ Age-45)/10)^2* Woman & & & 0.0017 & -0.0506 \\
\hline \multicolumn{5}{|l|}{ Productivity persistence } \\
\hline L. Persistence 111 & $1.613 * * *$ & $1.417 * * *$ & $1.613 * * *$ & $1.416 * * *$ \\
\hline L. Persistence 110/101/011 & $1.017^{* * *}$ & $0.769 * * *$ & $1.017^{* * *}$ & $0.768 * * *$ \\
\hline L. Persistence 100/010/001 & $0.608 * * *$ & $0.453^{* * *}$ & $0.608 * * *$ & $0.452 * * *$ \\
\hline Reference L. Persistence 000 & - & - & - & - \\
\hline Time dummies & Yes & Yes & Yes & Yes \\
\hline Discipline dummies & Yes & Yes & Yes & Yes \\
\hline Constant & $-0.818^{* * *}$ & $-0.549 * * *$ & $-0.814 * * *$ & $-0.556 * * *$ \\
\hline Observations & 13507 & 5026 & 13507 & 5026 \\
\hline Pseudo R2 & 0.1558 & 0.1421 & 0.1558 & 0.1422 \\
\hline
\end{tabular}


Finally, given that the age-gender interaction term and the estimated coefficient of age are both negative, the probability of publishing decreases less rapidly for women over 45 than for men at the same age.

\subsubsection{The Productivity Regression}

The productivity equation includes four groups of explanatory variables: gender and age (1); initial productivity and seniority (2); predicted probabilities of promotion and non-publishing years (3); and collaboration and co-author characteristics (4). We find that all groups of variables have statistically significant impacts on scientific productivity.

The initial productivity and seniority variables have long-lasting effects on the productivity of the researchers. Researchers with higher initial productivity and ratings are more productive. Like the Mexican case, the control for the predicted probability of promotion to higher ranks has a large and significant impact on productivity. This impact is slightly higher among white researchers relative to nonwhite. The control for publishing selectivity has a significant negative effect on productivity only among white researchers. As shown in Table 4.4, white and non-white researchers have almost the same number of non-publishing years. There are some variations among researchers with High Ranks, in particular white. Overall, non-white researchers are very similar regarding publishing selectivity, although some differences can be observed by gender among non-white researchers with High Ranks that are younger than 45 when compared with those that are older than 45 .

Concerning the collaboration variables, we observe a negative and significant effect on productivity of having a larger number of co-authors in $t-1$, particularly among non-white researchers. The fact that we observe a more marked effect among non-white researchers could also be a consequence of the co-authors' large heterogeneity. As we showed before, our sample's racial distribution, particularly among different rating categories, is large. Higher transaction and coordination costs of larger research teams could also explain this negative effect.

As expected, and similar to Mexico's findings, researchers that have very productive co-authors are themselves more productive (log articles NRF co-authors in $t$-1). This suggests the important role that the working environment and the research network have on productivity.

Concerning the seniority of the co-authors, measured by the NRF rating each co-author has at the moment of the collaboration, we find that having a rated co-author has a positive effect on productivity. However, to our surprise, the effect's intensity is not higher when the co-authors are more senior. On the contrary, we find that the intensity of the effects is stronger when co-authoring with researchers with less senior ratings (e.g., the coefficients of $L P Y$-rated co-authors are higher than those of C-rated, etc.). 
Collaborating with junior co-authors has a higher positive effect on productivity. This suggests the importance of complementary teams and skills within research teams, where more senior researchers benefit from more junior colleagues' skills.

Co-authoring papers with foreign researchers has a positive and significant effect on both white and non-white researchers. ${ }^{51}$ The effect on productivity of the gender and ethnicity of the co-authors differs largely by ethnicity. We find that for non-white researchers, the largest positive and significant effects on productivity are from collaborating with white researchers, regardless of their gender. For white researchers, the largest positive and significant effects on productivity result from collaborating with non-white researchers, particularly non-white females.

Interestingly, our variable that measures the effect on collaborations that involve white and nonwhite researchers shows a negative effect on all researchers' productivity. However, this is only significant for non-white researchers. A possible explanation for this is that there are too few white researchers who collaborate with non-white to get a significant coefficient when the focal researcher is white. As mentioned before, white researchers also see their productivity increase when they collaborate with non-white researchers with an intensity that more than compensates for the inter-ethnicity collaboration's negative effect. For non-white researchers, the positive effect of collaborating with white researchers gets almost eliminated by the negative and significant effects of the inter-ethnicity collaboration.

This negative effect could be explained by the higher transaction costs of the inter-ethnicity collaboration. Another reason could also be institutional. White scholars and researchers still dominate the "top" South African universities, and this dominance was even more pronounced in the time period covered in this research. ${ }^{52}$

\footnotetext{
${ }^{51}$ Foreign co-authors are those listed in the submitted NRF applications with a foreign affiliation (i.e., non-South African affiliation). Foreign researchers are not included in the dataset and are only considered when listed as coauthors in NRF applicants' publications.

52 We develop more on this issue in the Discussion section below.
} 
Table 4.10 Productivity Equation for NRF Researchers by Ethnicity, with and without Gender-Age Interactions ${ }^{53}$

\begin{tabular}{|c|c|c|c|c|}
\hline Productivity: (log) Prod & White & Non-White & White & Non-White \\
\hline \multicolumn{5}{|l|}{ Age and Gender } \\
\hline Woman $(=1)$ & $0.062^{* * *}$ & 0.014 & $0.077^{\star \star *}$ & $0.12^{\star * *}$ \\
\hline$($ Age-45)/10 & $-0.22^{\star * *}$ & $-0.11^{* * *}$ & $-0.22^{* * *}$ & $-0.10^{* * *}$ \\
\hline$\left((\text { Age-45)/10 })^{\wedge} 2\right.$ & $0.041^{* * *}$ & $0.024^{*}$ & $0.047^{* * *}$ & $0.058^{* * *}$ \\
\hline$($ Age-45)/10* Woman & & & -0.0058 & -0.0061 \\
\hline$\left((\text { Age-45)/10 })^{\wedge} 2 *\right.$ Woman & & & -0.023 & $-0.14^{* * *}$ \\
\hline \multicolumn{5}{|l|}{ Initial productivity and NRF ratings } \\
\hline $\log$ (initial number of articles) & $0.097^{\star * *}$ & $0.094^{* * *}$ & $0.097^{\star \star *}$ & $0.095^{\star * *}$ \\
\hline First Rate A & $0.28^{* * *}$ & & $0.30^{* * *}$ & \\
\hline First Rate B & $0.10^{\star * *}$ & $0.23^{\star \star *}$ & $0.099^{* * *}$ & $0.22^{\star * *}$ \\
\hline First Rate C & -0.015 & $0.038^{*}$ & -0.016 & $0.040^{*}$ \\
\hline \multicolumn{5}{|l|}{ Promotion and non-publishing } \\
\hline Prob(promotion) & $1.10^{\star \star *}$ & $0.94^{\star * *}$ & $1.10^{\star * *}$ & $0.90^{\star * *}$ \\
\hline Prob(non-publishing: lambda) & $-0.20^{* * *}$ & -0.031 & $-0.20^{* * *}$ & -0.035 \\
\hline \multicolumn{5}{|l|}{ Collaboration } \\
\hline $\log ($ No. of authors harmonic average) in $\mathrm{t}-1$ & $-0.039^{*}$ & $-0.094^{\star * *}$ & $-0.039^{*}$ & $-0.095^{\star * *}$ \\
\hline $\log ($ articles NRF coauthors) in $\mathrm{t}-1$ & $0.10^{\star * *}$ & $0.083^{\star * *}$ & $0.10^{* \star *}$ & $0.083^{\star * *}$ \\
\hline $\log (N R F$ coauthors' coauthors) in t-1 & 0.0064 & 0.045 & 0.0067 & 0.046 \\
\hline NRF coauthor No publications in $\mathrm{t}-1$ & 0.040 & 0.078 & 0.035 & 0.079 \\
\hline No publication in $\mathrm{t}-1$ & $0.100^{* * *}$ & -0.039 & $0.097^{* * *}$ & -0.038 \\
\hline \multicolumn{5}{|l|}{ Seniority of the co-authors } \\
\hline NRF coauthor $A$ in $t-1$ & 0.033 & -0.046 & 0.032 & -0.057 \\
\hline NRF coauthor $B$ in $t-1$ & $0.034^{* *}$ & -0.035 & $0.036^{\star *}$ & -0.036 \\
\hline NRF coauthor $\mathrm{C}$ in $\mathrm{t}-1$ & $0.044^{* * *}$ & $0.055^{*}$ & $0.044^{* * *}$ & $0.058^{* *}$ \\
\hline NRF coauthor LPY in t-1 & $0.072^{* * *}$ & $0.12^{\star \star \star}$ & $0.071^{* * *}$ & $0.11^{* * *}$ \\
\hline NRF coauthor Not successful in t-1 & $0.066^{* * *}$ & $0.088^{* *}$ & $0.064^{* * *}$ & $0.089^{* * *}$ \\
\hline \multicolumn{5}{|l|}{ Gender and Ethnicity of the co-authors } \\
\hline Foreign co-author in $\mathrm{t}-1$ & $0.11^{* * *}$ & $0.080^{\star * *}$ & $0.11^{* * *}$ & $0.080^{* * *}$ \\
\hline Coll. White - Non-White in t-1 & -0.084 & $-0.16^{\star * *}$ & -0.083 & $-0.17^{* * *}$ \\
\hline Female White in $\mathrm{t}-1$ & $0.069^{\star * *}$ & $0.18^{\star * \star}$ & $0.068^{\star * *}$ & $0.19^{\star * *}$ \\
\hline Male White in $\mathrm{t}-1$ & $0.047^{\star *}$ & $0.17^{\star \star *}$ & $0.045^{\star *}$ & $0.18^{\star * *}$ \\
\hline Female Non-White in $\mathrm{t}-1$ & $0.19^{* * *}$ & 0.045 & $0.18^{* * *}$ & 0.043 \\
\hline Male Non-White in $\mathrm{t}-1$ & $0.14^{\star *}$ & $0.090^{* * *}$ & $0.13^{\star *}$ & $0.090^{\star * *}$ \\
\hline Time dummies & yes & yes & yes & yes \\
\hline Discipline dummies & yes & yes & yes & yes \\
\hline Constant & $0.55^{\star * *}$ & $0.54^{\star * *}$ & $0.56^{* * *}$ & $0.53^{* * *}$ \\
\hline Observations & 13,507 & 5,026 & 13,507 & 5,026 \\
\hline Observations npub != 0 & 9,278 & 3,042 & 9,278 & 3,042 \\
\hline Pseudo R2 & 0.283 & 0.242 & 0.282 & 0.238 \\
\hline
\end{tabular}

Significance: $* * * p<0.01, * * p<0.05, * p<0.1$

\footnotetext{
${ }^{53}$ Estimated coefficients, based on OLS corrected for promotion endogeneity and non-publishing selectivity.
} 
The four groups of variables we analyze account significantly for differences in scientific productivity. We find that there is no gender productivity puzzle among our sample of NRF researchers. In contrast, our findings suggest the existence of a race productivity gap.

Below, we present the contributions of each of the corrections we implement in explaining the different pieces of the gender productivity puzzle (Table 4.11 and Table 4.12). The methodology for estimating each of the corrections separately is explained in detail in Chapter 3.

Without the corrections for endogeneity and selectivity, the productivity equation results show no significant gender productivity gaps for an average white or non-white researcher at age 45 . Higher-rated researchers in the past are more productive overall, and the average productivity of all researchers tends to decrease rapidly with age.

Once the correction for endogeneity is introduced, being female has a positive and significant effect on publication productivity among whites and non-whites. The effect of introducing the endogeneity correction is higher among non-white researchers. The selectivity correction alone seems to have little or no effect in explaining reductions or increases in the gender productivity gap of NRF researchers. This finding is consistent with our descriptive statistics presented before, where we did not find marked differences in the number of non-productive years between male and female researchers.

When both corrections are implemented, we find the gender gap favors women for all researchers, white and non-white. White women appear to be $8 \%$ more productive than white men for the average 45 -year-old researcher, while non-white women are $12 \%$ more productive than non-white men. 
Table 4.11 Productivity Equation for NRF White Researchers, without and with corrections

\begin{tabular}{|c|c|c|c|c|}
\hline Productivity: (log) Prod & $\begin{array}{c}\text { No } \\
\text { Corrections }\end{array}$ & $\begin{array}{c}\text { Endogeneity } \\
\text { correction }\end{array}$ & $\begin{array}{l}\text { Selectivity } \\
\text { correction } \\
\end{array}$ & $\begin{array}{c}\text { Endogeneity + } \\
\text { Selectivity } \\
\text { corrections } \\
\end{array}$ \\
\hline \multicolumn{5}{|l|}{ Age and Gender } \\
\hline Woman (=1) & -0.019 & $0.13^{* * *}$ & -0.029 & $0.077^{* * *}$ \\
\hline$($ Age-45)/10 & $-0.044 * * *$ & $-0.30 * * *$ & -0.015 & $-0.22 * * *$ \\
\hline$(($ Age-45)/10)^2 & $-0.028 * * *$ & $0.063 * * *$ & $-0.013^{*}$ & $0.047^{* * *}$ \\
\hline (Age-45)/10* Woman & -0.0034 & $-0.025^{*}$ & 0.0072 & -0.0058 \\
\hline$\left((\text { Age-45)/10 })^{\wedge} 2 *\right.$ Woman & 0.016 & $-0.052 * * *$ & $0.028^{* *}$ & -0.023 \\
\hline \multicolumn{5}{|l|}{ Initial productivity and NRF ratings } \\
\hline $\log$ (initial number of articles) & $0.16 * * *$ & $0.13 * * *$ & $0.10 * * *$ & $0.097 * * *$ \\
\hline First Rate A & $0.60 * * *$ & $-0.29 * * *$ & $0.34 * * *$ & $0.30 * * *$ \\
\hline First Rate B & $0.28 * * *$ & $-0.45 * * *$ & $0.14 * * *$ & $0.099 * * *$ \\
\hline First Rate C & $0.054 * * *$ & $-0.49 * * *$ & -0.020 & -0.016 \\
\hline \multicolumn{5}{|l|}{ Promotion and non-publishing } \\
\hline Prob(promotion) & $0.11 * * *$ & $1.59 * * *$ & $0.072 * * *$ & $1.10^{* * *}$ \\
\hline Prob(non-publishing: lambda) & & & $-0.50 * * *$ & $-0.20 * * *$ \\
\hline \multicolumn{5}{|l|}{$\begin{array}{l}\text { Collaboration } \\
\log (\text { No. of authors harmonic average) in } \\
t-1\end{array}$} \\
\hline $\log$ (articles NRF coauthors) in t-1 & $0.13 * * *$ & $0.11^{* * *}$ & $0.11^{* * *}$ & $0.10^{* * *}$ \\
\hline $\log ($ NRF coauthors' coauthors) in t-1 & 0.026 & 0.017 & 0.0099 & 0.0067 \\
\hline NRF coauthor No publications in t-1 & 0.053 & 0.045 & 0.043 & 0.035 \\
\hline No publication in t-1 & $-0.22 * * *$ & $-0.15^{* * *}$ & $0.17^{* * *}$ & $0.097 * * *$ \\
\hline \multicolumn{5}{|l|}{ Seniority of co-authors } \\
\hline NRF coauthor $A$ in $t-1$ & $0.066 * *$ & $0.071^{* * *}$ & 0.024 & 0.032 \\
\hline NRF coauthor B in t-1 & $0.063 * * *$ & $0.058 * * *$ & $0.040 * *$ & $0.036 * *$ \\
\hline NRF coauthor $\mathrm{C}$ in $\mathrm{t}-1$ & $0.057 * * *$ & $0.041^{* *}$ & $0.053 * * *$ & $0.044 * * *$ \\
\hline NRF coauthor LPY in t-1 & $0.11 * * *$ & $0.091 * * *$ & $0.082 * * *$ & $0.071 * * *$ \\
\hline NRF coauthor Not successful in t-1 & $0.11^{* * *}$ & $0.077^{* * *}$ & $0.079 * * *$ & $0.064^{* * *}$ \\
\hline \multicolumn{5}{|l|}{ Gender and Ethnicity of co-authors } \\
\hline Foreign co-author in t-1 & $0.22 * * *$ & $0.18^{* * *}$ & $0.13^{* * *}$ & $0.11^{* * *}$ \\
\hline Coll. White - Non-White in t-1 & $-0.18^{* *}$ & $-0.14^{*}$ & -0.10 & -0.083 \\
\hline Female White in t-1 & $0.11 * * *$ & $0.089 * * *$ & $0.085 * * *$ & $0.068 * * *$ \\
\hline Male White in t-1 & $0.059 * * *$ & 0.013 & $0.076 * * *$ & $0.045^{* *}$ \\
\hline Female Non-White in t-1 & $0.33^{* * *}$ & $0.24 * * *$ & $0.24 * * *$ & $0.18^{* * *}$ \\
\hline Male Non-White in t-1 & $0.30 * * *$ & $0.21 * * *$ & $0.18^{* * *}$ & $0.13^{* *}$ \\
\hline Time dummies & yes & yes & yes & yes \\
\hline Discipline dummies & yes & yes & yes & yes \\
\hline Constant & $0.45^{* * *}$ & 0.088 & $1.35^{* * *}$ & $0.56 * * *$ \\
\hline Observations & 13,507 & 13,507 & 13,507 & 13,507 \\
\hline Observations npub $!=0$ & 9,278 & 9,278 & 9,278 & 9,278 \\
\hline Pseudo R2 & 0.301 & 0.335 & 0.249 & 0.282 \\
\hline
\end{tabular}

Significance: $* * * p<0.01, * * p<0.05, * p<0.1$ 
Table 4.12 Productivity Equation for NRF Non-White Researchers, without and with corrections

\begin{tabular}{|c|c|c|c|c|}
\hline Productivity: (log) Prod & $\begin{array}{c}\text { No } \\
\text { Corrections }\end{array}$ & $\begin{array}{c}\text { Endogeneity } \\
\text { correction }\end{array}$ & $\begin{array}{l}\text { Selectivity } \\
\text { correction }\end{array}$ & $\begin{array}{c}\text { Endogeneity }+ \\
\text { Selectivity } \\
\text { corrections }\end{array}$ \\
\hline \multicolumn{5}{|l|}{ Age and Gender } \\
\hline Woman (=1) & 0.011 & $0.12 * * *$ & 0.036 & $0.12 * * *$ \\
\hline (Age-45)/10 & $-0.050 * * *$ & $-0.17 * * *$ & 0.029 & $-0.10 * * *$ \\
\hline$\left((\text { Age-45)/10 })^{\wedge} 2\right.$ & -0.012 & $0.072 * * *$ & 0.0016 & $0.058^{* * *}$ \\
\hline$($ Age-45)/10 * Woman & 0.0051 & 0.016 & -0.014 & -0.0061 \\
\hline$((\text { Age- } 45) / 10)^{\wedge} 2 *$ Woman & $-0.053^{*}$ & $-0.16 * * *$ & -0.044 & $-0.14 * * *$ \\
\hline \multicolumn{5}{|l|}{ Initial productivity and NRF ratings } \\
\hline log(initial number of articles) & $0.13^{* * *}$ & $0.12 * * *$ & $0.095 * * *$ & $0.095^{* * *}$ \\
\hline \multicolumn{5}{|l|}{ First Rate A } \\
\hline First Rate B & $0.42^{* * *}$ & $0.37^{* * *}$ & $0.25^{* * *}$ & $0.22 * * *$ \\
\hline First Rate C & $0.076^{* * *}$ & $0.068^{* * *}$ & $0.043^{*}$ & $0.040 *$ \\
\hline \multicolumn{5}{|l|}{ Promotion and non-publishing } \\
\hline Prob(promotion) & $0.11 * * *$ & $1.17^{* * *}$ & $0.068 * *$ & $0.90 * * *$ \\
\hline Prob(non-publishing: lambda) & & & $-0.28 * * *$ & -0.035 \\
\hline \multicolumn{5}{|l|}{ Collaboration } \\
\hline $\log ($ No. of authors harmonic average) in t-1 & $-0.15 * * *$ & $-0.12 * * *$ & $-0.12 * * *$ & $-0.095 * * *$ \\
\hline $\log$ (articles NRF coauthors) in t-1 & $0.12^{* * *}$ & $0.096 * * *$ & $0.095^{* * *}$ & $0.083^{* * *}$ \\
\hline $\log ($ NRF coauthors' coauthors) in t-1 & 0.041 & 0.052 & 0.042 & 0.046 \\
\hline NRF coauthor No publications in t-1 & 0.065 & 0.074 & 0.068 & 0.079 \\
\hline No publication in t-1 & $-0.36 * * *$ & $-0.28 * * *$ & -0.0088 & -0.038 \\
\hline \multicolumn{5}{|l|}{ Seniority of co-authors } \\
\hline NRF coauthor $A$ in $t-1$ & -0.062 & -0.085 & -0.026 & -0.057 \\
\hline NRF coauthor B in t-1 & $-0.11 * * *$ & $-0.090 * *$ & -0.036 & -0.036 \\
\hline NRF coauthor $\mathrm{C}$ in $\mathrm{t}-1$ & 0.034 & 0.033 & $0.061^{* *}$ & $0.058 * *$ \\
\hline NRF coauthor LPY in t-1 & $0.12 * * *$ & $0.097 * *$ & $0.13^{* * *}$ & $0.11 * * *$ \\
\hline NRF coauthor Not successful in t-1 & $0.16 * * *$ & $0.13^{* * *}$ & $0.12 * * *$ & $0.089 * * *$ \\
\hline \multicolumn{5}{|l|}{ Gender and Ethnicity of co-authors } \\
\hline Foreign co-author in t-1 & $0.18^{* * *}$ & $0.13 * * *$ & $0.11 * * *$ & $0.080 * * *$ \\
\hline Coll. White - Non-White in t-1 & $-0.19 * * *$ & $-0.18 * *$ & $-0.18 * * *$ & $-0.17 * * *$ \\
\hline Female White in t-1 & $0.24 * * *$ & $0.21 * * *$ & $0.20 * * *$ & $0.19 * * *$ \\
\hline Male White in $\mathrm{t}-1$ & $0.28 * * *$ & $0.25^{* * *}$ & $0.19 * * *$ & $0.18^{* * *}$ \\
\hline Female Non-White in $\mathrm{t}-1$ & $0.15^{* * *}$ & $0.12 * *$ & 0.051 & 0.043 \\
\hline Male Non-White in t-1 & $0.16^{* * *}$ & $0.12^{* * *}$ & $0.11 * * *$ & $0.090 * * *$ \\
\hline Time dummies & yes & yes & yes & yes \\
\hline Discipline dummies & yes & yes & yes & yes \\
\hline Constant & $0.57^{* * *}$ & -0.064 & $1.19 * * *$ & $0.53 * * *$ \\
\hline Observations & 5,026 & 5,026 & 5,026 & 5,026 \\
\hline Observations npub $!=0$ & 3,042 & 3,042 & 3,042 & 3,042 \\
\hline Pseudo R2 & 0.274 & 0.300 & 0.211 & 0.238 \\
\hline
\end{tabular}

Significance: ${ }^{* * *} p<0.01,{ }^{* *} p<0.05,{ }^{*} p<0.1$ 
Although our models only capture parts of what drives publication productivity, they allow us to assess an average researcher's predicted productivity, un-confounded by our explanatory variables. Figure 4.2 shows the distribution of the predicted productivity for the representative female and male, white, and non-white researcher with the two corrections for endogeneity and selectivity. For white researchers, females remain the most productive (1.53 log articles per year for women vs. 1.49 for men). The average productivity of non-white researchers, male and female, is practically the same $(1.29 \mathrm{log}$ articles for non-white females vs. 1.28 for non-white males). The average predicted productivity of women and men within the same ethnicity is very similar.

Figure 4.2 Distribution of predicted log-productivity for the representative female and male, white and non-white NRF researcher, with the corrections for endogeneity and selectivity

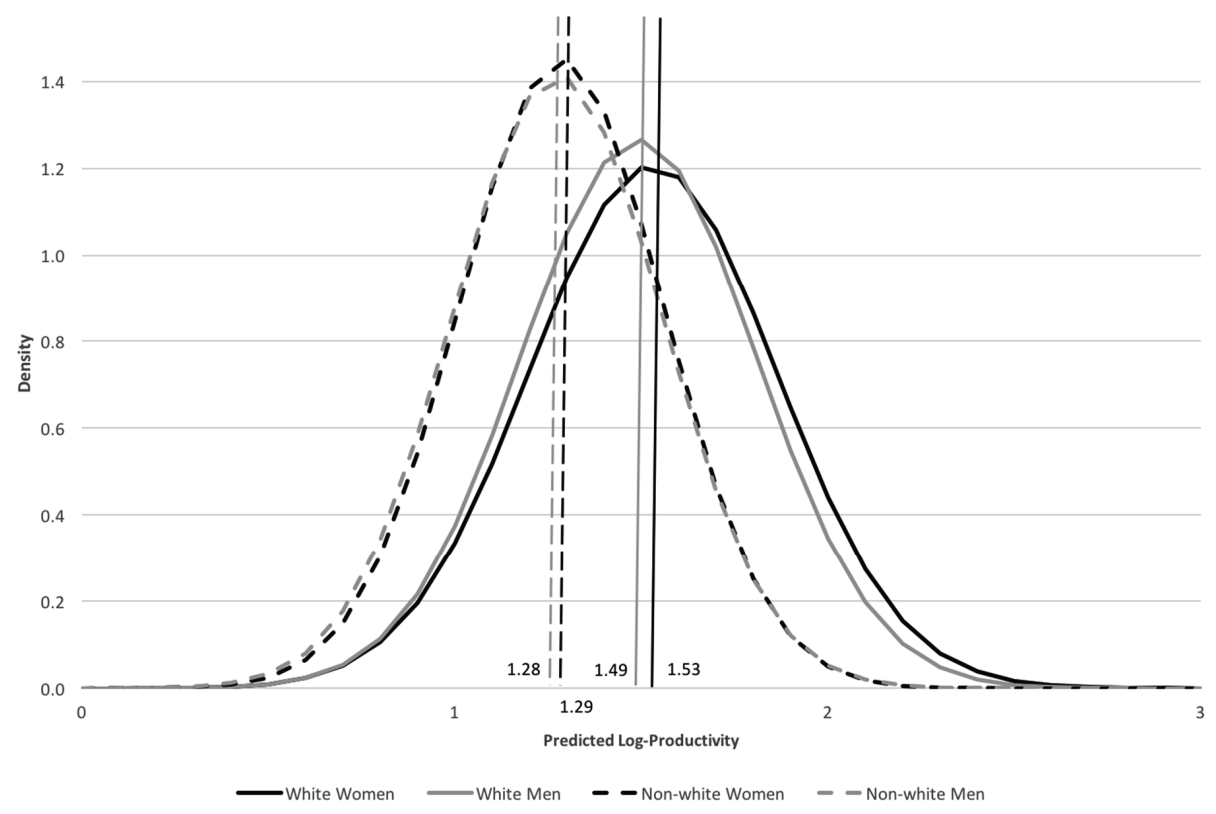

We find a statistically significant role of gender in explaining productivity gains among white and non-white researchers. However, unlike many other studies in this setting, women are more productive than men. The ethnicity gaps remain.

Figure 4.3 shows how age and gender interact with the predicted publication productivity, including our two corrections for promotion and non-publishing years. It shows that for all NRF researchers, estimated productivity decreases rapidly with age, particularly for non-white women. Nonwhite men see their productivity increase after 55 to levels that are higher than those they had at age 
40. White researchers, males, and females are always more productive than non-white women. Nonwhite men are more productive than all other NRF researchers after 60 years of age. This last result should be interpreted with care. With only 183 non-white men aged more than 45 , representing about $12.7 \%$ of our working sample (Table 4.2 ), the results might be driven out of sample prediction.

Figure 4.3 Change with Age of Predicted productivity for representative Female and Male NRF Researchers by Ethnicity

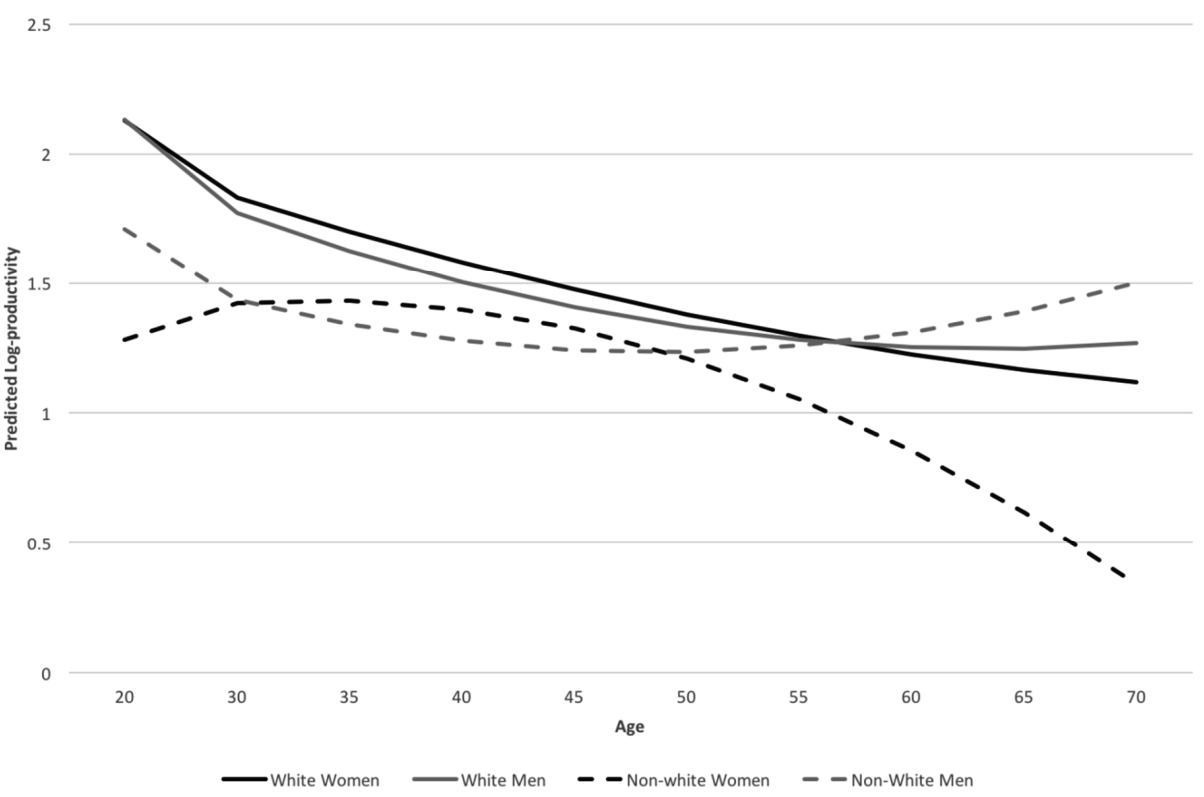

\subsection{Econometric Findings at the Macro Level}

Similar to what was presented in Chapter 3 in this section, we formulate a set of policy scenarios to assess the potential impacts of eliminating gender productivity gaps based on our model that considers corrections for selectivity and endogeneity. We focus on understanding the impacts and effects of four issues: (1) promotion practices; (2) publication intensity; (3) collaboration practices; and (4) age.

Table 4.13 presents a summary of the simulation results. The first part of the table shows descriptive statistics by ethnicity and gender. The second part of the table summarizes the contributions to log-productivity estimated for all variables in our simulations. The contributions were calculated using the productivity model with both corrections. The third part of the table shows the total productivity for our working sample and the gains in the total number of publications for the different simulations. The bottom of the table presents the gains as a share of all researchers' publications in our working sample. 
The first counterfactual simulation looks at the effects on scientific productivity of eliminating promotion biases. The probability of promotion in our contributions computed is always larger for men. If promotion biases based on gender were eliminated, an additional 39 publications for white researchers and 5 for non-white researchers would be jointly produced by females per year. This would represent an overall $2.8 \%$ increase in white females' productivity and a $1.9 \%$ increase for non-white females over our analysis period.

Table 4.13 Summary results of individual and systems gains based on simulation of different scenarios

\begin{tabular}{cccc}
$\begin{array}{c}\text { White } \\
\text { Women }\end{array}$ & $\begin{array}{c}\text { White } \\
\text { Men }\end{array}$ & $\begin{array}{c}\text { Non- } \\
\text { white } \\
\text { Women }\end{array}$ & $\begin{array}{c}\text { Non- } \\
\text { white } \\
\text { Men }\end{array}$ \\
\hline
\end{tabular}

\begin{tabular}{|c|c|c|c|c|}
\hline \multicolumn{5}{|l|}{ Statistics } \\
\hline Harmonic average authors & 4.43 & 3.99 & 4.11 & 3.97 \\
\hline Arithmetic average authors & 4.88 & 4.38 & 4.42 & 4.2 \\
\hline Non-censored observations & 2955 & 6323 & 653 & 2389 \\
\hline Number of researchers & 343 & 680 & 94 & 327 \\
\hline Censored observations & 4290 & 9217 & 1085 & 3941 \\
\hline \multicolumn{5}{|l|}{ Contributions computed } \\
\hline log productivity & 1.53 & 1.48 & 1.36 & 1.34 \\
\hline Probability of promotion & 0.33 & 0.42 & 0.17 & 0.23 \\
\hline Probability of observing a non-productive year & -0.09 & -0.09 & -0.02 & -0.02 \\
\hline Collaboration variables & 0.27 & 0.22 & 0.15 & 0.12 \\
\hline Age + gender interactions & 0.16 & 0.09 & 0.1 & 0.06 \\
\hline Constant & 0.56 & 0.56 & 0.53 & 0.53 \\
\hline \multicolumn{5}{|l|}{ Productivity gains at system level - Scenario simulation } \\
\hline Total number of publications - conditional & 1364.67 & 2777.66 & 254.42 & 912.37 \\
\hline If women had the same promotion probabilities as men... & 38.71 & & 4.79 & \\
\hline If women had the same probability of not publishing as men... & 0.00 & & 0.00 & \\
\hline If men had the same probability of not publishing as women... & & 0.00 & & 0.00 \\
\hline If women had the same collaboration as men & -18.88 & & -2.24 & \\
\hline If women had the same age as men & -23.44 & & -2.83 & \\
\hline \multicolumn{5}{|l|}{ Scenario simulation - Percentage over total } \\
\hline If women had the same promotion probabilities as men... & $2.8 \%$ & & $1.9 \%$ & \\
\hline If women had the same probability of not publishing as men... & $0.0 \%$ & & $0.0 \%$ & \\
\hline If men had the same probability of not publishing as women... & & $0.0 \%$ & & $0.0 \%$ \\
\hline If women had the same collaboration as men & $-1.4 \%$ & & $-0.9 \%$ & \\
\hline If women had the same age as men & $-1.7 \%$ & & $-1.1 \%$ & \\
\hline
\end{tabular}

Interpreting the results of the aggregated impacts of eliminating selectivity biases is less straightforward. As discussed in the literature review section of Chapter 3, researchers might experience 
non-productive periods for several reasons. The ones that interest gender economists the most are those related to family responsibilities or motherhood. Women might experience more non-publishing periods after giving birth, because of childcare or raising young children to bear family and home responsibilities. However, non-productive periods can also arise for reasons that are not family-related, such as teaching responsibilities, taking administrative tasks, participating in academic committees, etc. Thus, eliminating selectivity biases is more difficult if one thinks exclusively of non-family related responsibilities in the academic environment. If female researchers are freed from these responsibilities, men have to complete this work, affecting their overall productivity and overall net system gains.

The contributions computed for the probability of non-publishing are practically the same for women and men within their ethnicity group, which is in line with our descriptive statistics presented in Table 4.4. In other words, there are no large differences in the number of non-publishing years between men and women in our sample. Consequently, this scenario results in no productivity gains at the system level either when testing if women had the same probability of not publishing as men or if men had the same probability of not publishing as women. ${ }^{54} 55$

We have also tested the overall gains if women had the same collaboration characteristics as men (3) and women had the same age as men (4). For the collaboration variables, we obtained the contribution of the 16 collaboration variables used in the productivity equation (e.g., overall characteristics of the collaboration; seniority of the co-authors; and the co-authors' gender and affiliation). Regarding age, we obtained the predictions based on the contributions of the age variables and the age-gender interacted variables.

We find that if women had the same type of collaboration characteristics as men, white women would produce $1.4 \%$ fewer publications in our analysis period, compared to $0.9 \%$ fewer publications for non-white women. The productivity losses at the system level result from the higher contributions computed for women from their collaboration practices. Finally, if women had the same age as men in

\footnotetext{
${ }^{54}$ For completeness, we have also computed a scenario that looks at the aggregate effects if men had the same probability of non-publishing as women. For the "men as women" estimation, we change the average value of the probability of not publishing for men, attributing to men the same value as women. Once again, since the not publishing the predicted probabilities are the same between men and women, the system level's macro-effects are equal to zero.

55 The probability of non-publishing is the same for men and women in our working sample. Let us think of a situation where this is not the case. If one would think of a situation where non-publishing years were exclusively non-family related, eliminating gender gaps, either by freeing the time of women or men's time, would result in a net overall effect close to zero. The overall productivity losses of men would eliminate the productivity gains for women.
} 
our sample, white females would be $1.7 \%$ less productive overall; and non-white women would be $1.1 \%$ less productive.

Our measurement of gender parity impacts results in a rather small number of publications gains (and losses) at the system level. This is expected since these impacts do not rely on the observed gender gaps but rather on the estimated gaps. The productivity gains for eliminating promotion biases are the largest amongst our computed scenarios.

Finally, it is important to notice a caveat in the computation and interpretation of these macro scenarios. The computed estimates of effects make strong assumptions about the way variables (do not) interact. Thus, the results presented should not be treated as predictions but rather as indications of the magnitude and direction of such effects.

\subsection{Discussion and Conclusions}

This chapter has applied a micro and macro-econometric framework to understand gender publication productivity gaps in South Africa. The results show that female researchers are more productive than men, even when looking at the raw publishing data. Descriptive statistics show that white women are about $8 \%$ more productive than white men, while non-white women are $3 \%$ more productive than non-white men. We find that ethnicity plays an important role in the researchers' overall productivity, and it has more explanatory power than gender for understanding productivity gaps. White researchers are always more productive than non-white. Descriptive statistics show that white women are, on average, $47 \%$ more productive than non-white women, while white men are $41 \%$ more productive than non-white men.

We do not find marked differences in the number of non-productive years of male and female researchers. Again, even a descriptive view shows that the largest differences in the frequency of nonpublishing years are mostly explained by age and ethnicity, rather than gender. White researchers have fewer non-publishing years relative to non-white.

Our findings are similar when considering the promotion of researchers to high ranks. Non-white researchers are less often promoted from Low Ranks to High Ranks, but also from No Ranks to Low Ranks relative to white researchers. We do not find large differences in the promotion patterns of researchers by gender. Similarly, ethnicity and then same-gender explain the average and most frequent coauthorship relationships among NRF researchers.

Our econometric findings follow our descriptive findings. The productivity equation results show that even without the corrections for endogeneity and selectivity, there are no significant gender productivity gaps for an average white or non-white researcher at age 45 . We show that the probability 
of being promoted to high ranks decreases with age, though much less rapidly for white women than for white men and more rapidly for non-white women than for non-white men. We also find that gender is not a significant predictor of publishing and that the probability of publishing is much lower for old nonwhite researchers than for young ones, while these differences are much smaller among white researchers.

Once the correction for endogeneity is introduced, being female has a positive and significant effect on all researchers' productivity, regardless of their ethnicity. The effect of the endogeneity correction is higher among non-white researchers. In contrast, we find that the selectivity correction alone has little or no effect in explaining gender productivity gaps. This finding is in line with the descriptive statistics of our working sample. However, once both corrections are introduced, we find that the gender gap favors women regardless of ethnicity. For an average 45-year old researcher, white women are $8 \%$ more productive than their male white peers, while non-white women are $12 \%$ more productive than non-white male researchers.

Our findings invalidate the existence of the "productivity puzzle" (Cole and Zuckerman, 1984) among NRF rated researchers. This finding differs from existing quantitative research in the field, notably the research by Prozesky (2006a, 2006b, 2008b). There are important differences between Prozesky's research and ours. Our working sample focuses specifically on NRF rated researchers in hard sciences and engineering (vs. social sciences covered in Prozesky's research). We also cover different periods.

NRF ratings are usually a sign of seniority and scientific achievement in South Africa. In this regard, our findings may be an artifact of sampling selectivity. By focusing on NRF-rated researchers, we observe and analyze outstanding female researchers, successful and outstanding 'fighters' in South African academia, and leave out female 'survivors' in the academic world. Prozesky (2006a) also discusses why gender productivity gaps can be larger, favoring men in the social sciences. She argues that women often choose lines of research that face higher obstacles of publishing in accredited journals. Articles in the social sciences are often longer and published jointly with larger teams with more co-authors, resulting in lower publication counts when fractional counting methods are used to measure research productivity.

Our results point to the existence of an ethnicity productivity gap. Race is, without doubt, and historically, a central carrier of power in South Africa. In our view, and similar to Walker (1998), these results should not eliminate the fact that gendered relations of power still shape academic systems worldwide. Women are part of an academic landscape that is layered and shaped by gender, class, and race. 
Educational attainment and opportunities for women have increased considerably since the end of apartheid. However, as discussed earlier in this chapter, research has pointed out that even if the access of previously marginalized groups (i.e., women and in particular black women) has increased, social and cultural practices remain a barrier to the successful participation of black women in universities (Ramohai, 2014). Black female academics often have to define and defend their presence and positions even after gaining access to academic institutions (Harris, 2007). In the context of white-dominated institutions, Harris (2007) finds that black female academics are often subjected to prejudice and discrimination that diverts them from advancing in their academic careers.

Indeed, our results point to a complex picture of gender inequalities in South African academia, one where both ethnicity and age are largely significant. Mixing gender, ethnicity, age, and disciplinary dimensions of inequalities in publication and career development, the results show that the South African science system is gender-biased, particularly concerning female researchers' promotion to higher academic ranks. Female researchers have fewer chances than men to be promoted in their academic careers, and they are under-represented in the highest levels of seniority. Implicitly, our results suggest that women have to work harder than men to increase their chances of being promoted to higher academic ranks, and most often, they fail to get their promotions even when they are equally or even more productive than their male peers.

In a qualitative study among black female academics in South Africa, Ramohai (2014), also gathered evidence that black female academics often feel they have to work harder than their white peers to prove themselves and survive in academia.

The difficulties encountered by black women academics to be promoted are well documented in the literature (Ramohai, 2014, Lloyd-Jones, 2009, Maürtin-Cairncross, 2003). In South Africa, black female academics are often concentrated in junior positions -junior lecturer and lecturer level. They are underrepresented at the senior level; and are almost absent at professorial levels. Research has suggested that a "white male domination" prevails and that white males act as "gatekeepers" and often decide on the criteria for promotion that are based on their own academic experiences (Ramohai, 2014).

Moreover, it is often argued that upward mobility in academia relies heavily on research outputs. Our results show that women, including non-white women, are as productive as men.

The findings suggest a direction for public policy intervention. Initially introduced in the Education White Paper 3-A Programme for Higher Education Transformation, the idea of "Fair chances of success to all" is much still needed in South African academia (NCHE, 1997). This is, however, a known challenge for South African policymakers. The Report on the Stakeholder Summit on Higher Education 
Transformation (DHET, 2010) already highlighted the need to enhance black academics' opportunities, and in particular black women. The report also suggests the need to "develop programs to improve young black women's academic opportunities, including mentorship programs, promotion policies, and the provision of other career development opportunities".

Our results show that once women get to the point in their careers where they decide to apply for an NRF rating, they are as productive, if not more productive, as men. This suggests that policy intervention is needed before this decisive point in their careers.

We show that productivity gains for eliminating promotion biases are the largest amongst the macro policy scenarios tested. Policy intervention is, thus, most needed to address the promotion of women to senior academic positions.

Science systems in MICs should enable similar framework conditions for women and men in academia, including policies that reduce the possibilities of self-selection as a source of inequalities in the research system. The academic system would benefit most if more male and female researchers' diversity is observed at all ranks. However, as Rabe and Rugunanan (2012) show, access and change in academic institutions' demographics are often not enough, and it should be accompanied by sensitivity to heterogeneity both at individual and institutional levels. ${ }^{56}$ The ultimate aim should be to build capacity that enables black women academics to work on equal chances and opportunities as their white male peers.

Our findings also show that research collaborations that involve white and non-white researchers harm the productivity of non-white researchers only. What is behind this finding could be a simple reflection of the institutional rigidities of the South African higher education system, where white academics still dominate top universities or the most research-oriented. We discussed some of the existing literature in this regard at the beginning of this chapter.

Finally, we believe that one of this chapter's main contributions is methodological by offering a first quantification of the magnitude at the macro level of gender productivity gaps. We believe that the computation of these macro scenarios and their corresponding effects will complement the evidence for policymakers concerned in improving national research performance.

\footnotetext{
${ }^{56}$ Some authors have argued that more heterogeneity at the institutional level would also require black women's participation in academic institutions' decision-making processes (Ramohai, 2014). However, regarding the gender composition of scientific committees for promoting academics from associate to full professorships in Italy and Spain, Bagues et al. (2017) found that female evaluators are not more favorable towards female candidates. At the same time, male evaluators are less favorable towards female candidates when a female evaluator is part of the evaluation committee.
} 



\section{Chapter 5. Access to international knowledge and its impact on academic upgrading in Mexico*}

The number of internationally educated people has seen a dramatic increase in recent decades: since 2000, the number of students enrolled outside their own countries has more than doubled, passing from 2.1 million in 2000 to 4.5 million in 2012 worldwide (OECD, 2014b). Moreover, many governmental and non-governmental institutions have spent considerable amounts of money promoting international student and researcher mobility, both in the developed and developing worlds. The Marie Curie Programme in Europe, the Colombian Colfuturo, the Brazilian Capes, the Panamanian SENACYT, or the Mexican CONACYT scholarships for graduate studies are just some examples of schemes providing domestic graduates and researchers with scholarships to study and do research abroad. The general belief underlying these initiatives has been that foreign-educated students can carry new knowledge and capabilities to their country of origin and facilitate contacts with other foreign scientists and institutions (Scellato et al., 2015).

The economics of science has also been concerned with the phenomenon of 'brain drain/brain gain', particularly concerning access to foreign knowledge and its effects on research collaboration and productivity. It has often been investigated whether scientists in developing countries that received their $\mathrm{PhD}$ training in developed countries can remain embedded in international co-publication networks after their return (Jonkers and Tijssen, 2008, Murakami, 2014, Ynalvez and Shrum, 2009, Jonkers and CruzCastro, 2013).

\footnotetext{
* This Chapter is based on joint work with Simone Sasso. A previous version of this Chapter was published as Sasso and Rivera León, 2018.
} 
It is argued that most of the motivations for collaboration are productivity-oriented, often focused on knowledge sharing (of both tacit knowledge and technique). However, evidence shows that the productivity of researchers in developing countries that received their PhDs abroad differs considerably by discipline (Gonzalez-Brambila and Veloso, 2007, Marmolejo-Leyva et al., 2015). This lack of systematic higher productivity of researchers trained abroad has been explained by the fact that locally trained PhDs find partners easier locally or know how to obtain research resources (Gonzalez-Brambila and Veloso, 2007). Other explanations include "brain drain", or the fact that the most productive researchers stay abroad, phenomena often called negative return selection (Baker and Finn, 2003); and the fact that often the training environment abroad is not valuable to the researcher after return to the country of origin (Thorn and Holm-Nielsen, 2008).

Based on the above, this chapter investigates the scientific collaborations of academic scientists that are members of the National System of Researchers (SNI) of Mexico in the period 2008-2012 to understand the role of foreign-trained researchers to accelerate the introduction of external knowledge into the Mexican scientific community. Furthermore, it analyses how receiving a foreign academic degree facilitates the researchers' career position.

Our results suggest that senior foreign-educated researchers - by developing more global contacts with international scientists than locally-educated - can represent important conduits of knowledge for the Mexican scientific system. Like previous studies, we find that foreign-educated researchers are not more productive than locally-trained ones. However, they have a connector role in the Mexican collaboration network. Moreover, after controlling for possible endogenous sample selection, we find that foreign education brings disadvantages to individual researchers' career advancement, decreasing their probability of reaching higher levels of the Mexican research ranking system.

The Chapter is organized as follows. Section 1 discusses recent trends and the drivers, the prerequisites, the advantages, and the limitations of international scientific collaboration. Section 2 emphasizes the importance of international scientific collaborations for local upgrading and development of middle-income countries and foreign-educated scientists' key role in this process. Section 3 describes the structure and characteristics of the Mexican Science System. Section 4 presents the data, explains the methodology and the variables of our analysis. Section 5 presents the findings. Finally, in section 6 , a discussion and conclusions on the results are drawn. 


\subsection{Conceptual Framework}

\subsubsection{International Scientific Collaboration}

Scientific collaboration can be defined as the collaboration among two or more scientists, which allows them to share knowledge and complete research tasks under a common shared aim. A form of and the most commonly used proxy for - scientific collaboration are co-authored articles. Even if coauthorship is an imperfect indicator of collaboration (Katz and Martin, 1997), co-authored papers constitute a verifiable collaboration measure, comparable across countries, disciplines, and time.

In the last couple of decades, domestic and international scientific collaboration has registered a remarkable increase (Wagner and Leydesdorff, 2005, Mindeli and Markusova, 2015). The US National Science Board (2014) has reported that the share of world articles in all fields authored by multiple authors is over $90 \%$. International collaborations - whose share has risen from $16 \%$ to $25 \%$ of world articles between 1997 and 2012 - are growing faster than domestic ones. The diffusion of international large-scale science projects - where often hundreds of authors are involved in writing a common piece of research ("hyper-authorship") - has speeded up this trend and made the average number of co-authors per paper almost double in the last two decades (e.g., between 1990 and 2010, in the U.S. the average number of co-authors moved from 3.2 to 5.6 authors per article (ibidem)).

Mexico is no exception in this process and has experienced similar trends, at times, even in a more pronounced way. In general, the number of scientific articles in Mexico has increased by $6.67 \%$ annually between 2006 and 2013 (CONACYT, 2015), making Mexico the second most important Latin American country in scientific articles produced after Brazil. Whereas until the first half of the nineties, singleauthored papers represented roughly $40 \%$ of Mexico's total production (Luna-Morales, 2012). Since the mid-nineties, they have dramatically decreased, and Mexico has been more and more integrated into international scientific collaboration networks. Recent data show that the percentage of papers with international co-authors between 2007 and 2011 was 39\%. This share is considerably higher than the world average of internationally co-authored papers. It is also higher than the Mexican share of international co-patenting (OECD, 2014c). ${ }^{57}$ The distribution of co-authored papers reveals that whereas until 2010 the majority of co-authored papers was represented by papers coming only from Mexican institutions (e.g., in 1997, almost 60\% of co-authored publications in Mexico were domestic), in very recent years, this tendency has reversed: in 2012 almost 52\% of all the co-authored publications in

\footnotetext{
57 Only 23\% of the Mexican domestic patent applications filed between 2007 and 2011 have at least one coinventor located in a country different than Mexico (OECD, 2014b).
} 
Mexico involved international research institutes and universities (National Science Foundation, 2014) whereas around $48 \%$ was developed with domestic institutions only.

It is argued that different factors have driven the acceleration in recent years. First, especially in certain disciplines, there has been an increasing need for specialization in terms of skills and instrumentation, which often makes no single researcher, research institute, or even country able to perform all the tasks needed to conduct high-level academic research in certain fields (Cantner and Rake, 2014, Katz and Martin, 1997). Similarly, some topics and research subjects' inter-disciplinary nature increasingly requires scientists from different scientific areas to work jointly. Third, the development of ICTs and the reduction in travel costs have significantly facilitated keeping contacts at a distance and working with people located in another region or country. Finally, an increasing number of grants and policy schemes have been explicitly promoting the creation of national and international networks of researchers (Defazio et al., 2009).

The literature has suggested that the benefits that researchers can enjoy from collaborating with others are several. First, working together allows researchers to share and access knowledge and techniques, especially tacit ones that are otherwise difficult to acquire. Next, collaborating can increase the scientific productivity of a researcher. Lee and Bozeman (2005) found that a researcher's productivity - measured by normal counts of his/her publications - is positively and statistically correlated with the number of collaborators. ${ }^{58}$

More recently, Hu et al. (2014) have confirmed that the number of publications is positively correlated with the number of unique collaborators that a scientist has during a certain period, defined as the "scope" of collaboration.

Additionally, scientific collaborations also allow scientists to share opinions and ideas with other colleagues and receive perspectives on their research that they may not have grasped independently. In fact, scientists working together can benefit from mutual cross-checking, i.e., a sort of "internal refereeing", increasing the frequency of acceptance for publication in peer-reviewed journals (Gordon, 1980). Finally, scientific collaboration allows scientists to overcome the intellectual isolation that often characterizes the research tasks (Katz and Martin, 1997), and it can motivate them to complete their work on time (Bozeman et al., 2015).

\footnotetext{
${ }^{58}$ However, Lee and Bozeman (2005) indicate that when productivity is measured by fractional count (i.e., dividing the numbers of publications by the number of authors), the relation is not clear-cut. The number of collaborators cannot be considered a significant predictor of their publishing activity.
} 
However, scientific collaboration also brings costs and challenges. First, working with others means investing time to keep in touch with them, wait for their comments, or keep them informed about the work's progress (Lee and Bozeman, 2005). Second, collaborating with researchers in different places usually implies travel and subsistence costs, which would not occur when researchers work independently or with local colleagues. Third, differences in work styles and work paces require flexibility from each co-author and may represent a drag on most efficient researchers (Bozeman et al., 2015). More generally, working with others may bring tensions (e.g., linked to real or perceived exploitation of co-authors or legal disputes about intellectual property), especially when collaboration management strategies are poorly designed (Youtie and Bozeman, 2014).

In brief, the literature has shown that scientific collaboration can bring advantages such as letting scientists share (tacit) knowledge, increase their research productivity, or enhance the impact and diffusion of their research. However, collaborating also entails costs and efforts for the researchers involved, and it does not always result in a valuable joint-research outcome. The striking increase in the share of co-authored papers over the last fifteen years seems to indicate that benefits tend, on average, to outweigh inefficiencies and costs largely.

\subsubsection{Access to foreign knowledge and scientific upgrading in Middle-income countries}

Scholars have consistently pointed out that global connections are important ways to achieve local upgrading, both for technologically advanced countries and - even more for developing economies (Fagerberg et al., 2010, Fu et al., 2011). Global connections can provide countries with access to external knowledge and technology and therefore accelerate their technological learning and economic growth. Countries behind the technological frontier have an even stronger interest in establishing international connections as the potential for learning can be higher the larger the technology-gap between the countries involved (Abramovitz, 1986, Fagerberg, 1987).

Over the past years, scholars have studied several ways through which global connections can be established. This includes how knowledge is transferred, such as foreign direct investments (Marin and Bell, 2006, Jacob and Sasso, 2015), international trade (Coe and Helpman, 1995), the mobility of skilled personnel (Moen, 2005), integration into the emerging global production chains (Pietrobelli and Rabellotti, 2011), and, the channel analyzed in this Chapter, the participation in international scientific collaborations. Collaborating with others allows scientists to access tacit knowledge and techniques that would otherwise be difficult to reach and which might prove crucial to upgrade the local knowledge base and avoid lock-in, especially for countries behind the technological frontier. 
Developing international scientific collaborations is not easy and requires, on the one hand, the knowledge and skills to carry out the research activities with the other potential co-authors and, on the other hand, the right contacts (i.e., the right "professional social capital") in foreign countries (Jonkers and Tijssen, 2008). In this chapter, we focus on a category of scientists who appear ideally placed to establish global connections, i.e., researchers who have received their postgraduate education abroad and have returned to their country of origin, i.e., Mexico, after the completion of their studies. In fact, studying abroad can address both the pre-requisites for international collaboration. By being geographically close to other scientific communities during their studies, foreign-educated researchers can develop contacts and mutual trust with other students, researchers, and professors. This, in turn, can increase possibilities to access their (tacit) knowledge and develop cognitive proximity (Boschma, 2005) with them. The knowledge and the social capital acquired abroad can make foreign-educated individuals play a key role in transferring technological knowledge when they return to their country of origin.

First, by bringing with them the knowledge, expertise, and know-how acquired abroad, they can become strategic "knowledge spillover agents" (Trippl and Maier, 2011) in their home countries. They can also promote new combinations of scientific, technical, and managerial knowledge. Second, by maintaining contact with people in the country of study (abroad), they can continue tapping new foreign knowledge, and they can plug other local researchers into wider global scientific communities and knowledge pools.

Global connections are not per se sufficient to reach local technological upgrading. The literature has unanimously argued that a certain level of local absorptive capacity and adaptation capability (Cohen and Levinthal, 1990, Fu et al., 2011) is a sine qua non to benefit from international knowledge. When the cognitive distance (Boschma, 2005) between local and global scientific capacity is too large, external knowledge cannot be adequately absorbed and used locally. Additionally, local connections are crucial to let scientists with international experience disseminate their learning locally. Thus, establishing global pipelines is not per se beneficial for local learning if vibrant local connections are not in place (Bathelt et al., 2004).

Acquiring and maintaining global connections is often seen at odds with keeping or developing local ones, despite increasing research finding the opposite (Barnard et al., 2012, Barnard et al., 2015). For instance, when individuals go abroad to get a postgraduate degree, contacts with friends and colleagues in their original countries may get severed, and once they are back, local connections might not necessarily get restored for different reasons. Due to time-constraints, foreign-educated researchers may prefer to invest their time and effort with foreign collaborators because they are more competent and efficient or because the research interests of the local scientific community are too different from 
the ones of the international research community they are connected to (Pouris and Ho, 2014). On the other hand, one could argue that once foreign-educated researchers are back in their countries, geographical proximity with local scientists can favor the development of new local collaborations at the expense of global ones, which, on the contrary, are likely to become weaker over time.

In fact, evidence suggests that this trade-off between local and global connections comes from an overly-simplified view of scientific collaboration networks between technologically advanced and technologically-backward countries (Barnard et al., 2012, Barnard et al., 2015) for a set of different reasons.

First, knowledge runs "two-ways," and all the countries involved in the collaboration can benefit from it, not only the less technologically-advanced ones. The literature on diaspora networks (Meyer, 2001) has shown that this remains true even when researchers do not return to the country of origin. In fact, if they maintain contact with people back in the regions of origin, scientists can represent important "brain banks" (Agrawal et al., 2011), i.e., sources of knowledge and contacts for those scientists who did not migrate even when they remain abroad. In this respect, Regets (2007) found a strong positive correlation between the log of the number of PhD received in the US by individuals born in a certain (developing) foreign country and the percentage of that foreign country's internationally co-authored articles with US researchers. Scellato et al. (2015) found that migrant scientists are likely to collaborate with individuals from their home country, even when working or studying in a third country. Baruffaldi and Landoni (2012), analyzing foreign researchers in Italy and Portugal, have found a consistent increase in their productivity when maintaining contact with researchers of their country of origin.

Second, there is extensive evidence that the professional social capital that scientists built up during the time spent in foreign research systems does not get weaker once they return to their home countries. Jonkers and Tijssen (2008) found that leading Chinese researchers who returned from a research period spent in the US, in Western Europe, or Japan produced a consistently higher number of international co-publications with researchers from their host region. Murakami (2014) found very similar results for Japanese scientists returning from the US, Ynalvez and Shrum (2009) for Philippines scientists returning after obtaining a PhD in Japan, and Jonkers and Cruz-Castro (2013) for Argentinean return scientists. More broadly, Scellato et al. (2015) showed that returnees coming from 16 different countries (both developed and developing ones) had maintained consistently larger international research networks than local researchers who did not have international experience.

Third, scientists with international experience are not necessarily less connected locally, and their engagement with global partners does not preclude participation in local scientific communities. Gibson and McKenzie (2014), looking at the scientific mobility in the developing countries of the Pacific, found 
that return migrants who had migrated overseas for postgraduate education represent the main source of knowledge research transfer between international and local researchers. Similarly, in a study on scientific collaboration, Barnard et al. (2012) found no evidence that world-leading researchers working in South Africa are worse connected locally than other researchers within their country. On the contrary, thanks to their better connections to external sources of knowledge and their higher productivity, worldclass researchers appear to have significantly accelerated the introduction of new knowledge into the country. More recently, Barnard et al. (2015) - comparing South African scientists who have received a $\mathrm{PhD}$ from a foreign university with those who have received it from a South African one - found that the former publish on average about one paper more than the latter and that this higher productivity translates, on average, into a difference of approximately 3 co-authors and 4 foreign co-authors. These studies showed that world-leading researchers (Barnard et al., 2012) and foreign-trained PhDs (Barnard et al., 2015) play a connector role thanks to their better international connections and higher productivity. This seems to confirm that global and local connections can be mutually reinforcing elements rather than opposing forces.

Conversely, recent studies (Gonzalez-Brambila and Veloso, 2007, Marmolejo-Leyva et al., 2015) for Mexico have shown that foreign-trained researchers working in Mexico are not systematically more productive than researchers trained locally.

All in all, several studies have investigated the positive relationship between scientific collaboration, productivity, and citations and the impact of return scientists on international collaboration. However, to the best of our knowledge, little has been done in testing the role that returnscientists play in upgrading the knowledge base of their home countries by maintaining, at the same time, global and local connectedness.

Building on Barnard et al. (2012, 2015), we aim to investigate the extent to which foreign-trained researchers in Mexico can access external knowledge and share it inside the Mexican scientific community by maintaining global and local co-authorship patterns.

\subsection{Data and Methods}

This Chapter uses data of researchers affiliated with the National System of Researchers (SNI) of Mexico and their ISI Web of Science (WOS) publications. The SNI's functioning and a discussion on the Mexican academic system were presented thoroughly in Chapter 3 . The study population used is thus the same as in Chapter 3, but the working sample differs.

The working sample is constructed by matching all SNI researchers' names that received affiliation to the SNI in 2013 to the author and co-author names in WoS publications where at least one of the co- 
authors was affiliated to a Mexican institution/organization in the period 2008-2012. We restrict our working sample to seven broad scientific disciplines (life sciences, medicine and health sciences, physics and astronomy, technology sciences and informatics, mathematics, and chemistry) and researchers who were active members of the SNI in 2013.

The cross-section data consists of 25,320 publications and 2921 researchers, out of which 2888 researchers have no missing data and are included in our econometric estimations. Data from the SNI database includes basic socio-demographic information (i.e., age and gender) and professional information (e.g., highest academic degree obtained, country of the latest academic degree obtained, academic discipline, employment affiliation, etc.). We also have access to some personal data, notably the place of birth (Mexico or abroad), and for the case of those researchers born in Mexico, the name of the Mexican state of birth. ${ }^{59}$

We implement an adapted version of a model developed by Barnard et al. (2015) to measure the role of foreign-trained PhD on scientific catch-up in developing countries. We analyze how foreigntrained PhDs connect to the global science system and the local research/scientific community and accelerate new knowledge diffusion. Additionally, we investigate the extent to which receiving a foreign degree facilitates Mexican researchers' career advancement.

Using social network analysis techniques, we measure each SNI researcher's network position within the co-authorship network accumulated over 2008-2012. We consider foreign co-authors all those scientists who are not SNI-members and are affiliated to at least one non-Mexican institution. Similarly, we consider domestic non-SNI co-authors all those affiliated only to (one or more) Mexican institutions and that are not SNI-affiliated researchers.

Each researcher corresponds to one node of the network, and two researchers are connected if they have co-authored at least one paper. We follow the weighting approach developed by Newman (2001) based on the assumption that each researcher collaborates equally among his/her co-authors in a research project. Therefore, each link generated by a paper with $n$ co-authors weights $1 /(n-1)$. The total weight of the link between two researchers is then given by the sum of the weights of all the papers on which they appear as co-authors during the period 2008-2012.

\footnotetext{
${ }^{59}$ Mexico is a federal republic composed of 32 states. The states of Mexico are first-level administrative territorial entities.
} 


\subsubsection{The gatekeeping function of foreign-educated researchers}

To measure to which extent SNI-researchers could tap into global knowledge and facilitate its transmission into the Mexican research system - in a similar fashion to Barnard et al. (2012; 2015) - we develop a "gatekeeping" index, which measures both the researcher's access to outside knowledge (bridging-component) and his/her distance to other Mexican researchers (bonding-component). The gatekeeping index for researcher $i$ is thus defined as follows:

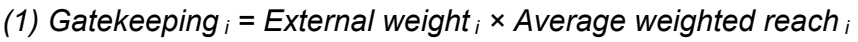

The external weight reflects the intensity of collaboration with international scientists through the (weighted) number of papers with foreign scholars. Thus, the higher the external weight, the more the researcher $i$ can tap into global knowledge pools. On the other hand, the bonding component is represented by the average weighted reach, i.e., the average of the inverse of the shortest weighted path of a researcher to all other researchers in the network ${ }^{60}$ :

$$
\text { (2) Averageweighted reach }{ }_{i}=\sum_{i \neq j} \frac{1}{d(i, j)}
$$

where $d(i, j)$ is given by the shortest weighted path between researcher $i$ and researcher $j$ and $n$ is the total number of researchers in the network ${ }^{61}$. Therefore, the higher the average weighted reach of researcher $i$, the closer they are to the other Mexican SNI researchers in the network, the better his/her position to diffuse knowledge locally. ${ }^{62}$ As a result, our gatekeeping index increases as the researcher's external weight increases, and as the average weighted reach to other SNI researchers of the network increases.

\subsubsection{Estimation and testing}

We model and estimate two different equations. Firstly, we look at how foreign training affects the career of the researcher itself. Since this is the effect of foreign training on the individual, we call this

\footnotetext{
${ }^{60}$ The average shortest weighted path is calculated among SNI-researchers in all components in the collaboration network.

${ }^{61} \mathrm{~A}$ path is a list of researchers $(i, k, l, \ldots, m, j)$ where researchers reported consecutively have co-authored (at least) one paper. The shortest weighted path $d(i, j)$ between two researchers $i$ and $j$ is the path that minimizes $\sum 1 / w_{i, k}+$ $1 / w_{k, l}+\ldots+1 / w_{m, j}$ where $w_{i, k}$ is the strength or weight of the link between $i$ and $k$.

62 We use the average weighted reach, instead of any other centrality measure such as betweenness centrality in our gatekeeping index, as a proxy of the researcher's 'power' within the collaboration network. Indeed, researchers who can reach other researchers at shorter path lengths have favored positions in the network and experience a structural advantage. Having a higher reach allows the researcher to spread knowledge faster within the Mexican research community. With the gatekeeping index, we care about the researcher's 'power' in the network and not only the researcher's centrality.
} 
the impact-on-self model. Secondly, we look at the 'outward' effects of foreign training by looking at how it influences its position in the network and disseminates knowledge nationally and internationally. We call this later the impact-on-others model.

\subsubsection{Impact on others}

To estimate to which extent foreign education/training determines the researcher's position in the Mexican scientific community while addressing selection issues ${ }^{63}$, we use a treatment effect endogenous model, comparing Mexican SNI researchers trained abroad to those trained locally in Mexico. We employ a Heckman-type two-stage estimation, including a selection equation and an outcome equation. We follow the treatment effect methodology derived by Maddala (1983) and further developed by Wooldridge (2002). The decision to take a foreign degree depends on a set of individual observable characteristics $Z_{i}$ (e.g., the period of graduation, discipline, gender, age, etc.) and a set of individual unobservable characteristics $v_{i}$. Thus, we define the selection equation as follows:

$$
\text { (3) } D_{i}^{*}=Z_{i} \alpha+v_{i}, D_{i}=1 \text { if } D_{i}^{*} \geq 0, D_{i}=0 \text { otherwise. }
$$

We then define the outcome equation measuring the impact of studying abroad on the position of the researcher in the Mexican scientific community network as follows:

$$
\text { (4) } Y_{i}=D_{i} \varphi+X_{i} \omega+\epsilon_{i}
$$

where $Y_{i}$ is the gatekeeping index of researcher $i, X_{i}$ is a vector of observable characteristics, and $D_{i}$ is a dummy variable assuming value $D_{i}=1$ if the researcher has received his/her latest academic degree from a foreign university, and value $D_{i}=0$ if the researcher received his training from a Mexican university.

As a result, the gatekeeping measure is given by $Y_{i}=f\left(Z_{i} \alpha+v_{i}\right) \varphi+X_{i} \omega+\varepsilon_{i}$ for those researchers who received their training abroad and by $Y_{i}=X_{i} \omega+\varepsilon_{i}$ for those researchers who received their degrees in Mexico, resulting in an incidental truncation (or sample selection). To estimate the coefficient $\varphi$ while controlling for the selection bias induced by the non-ignorable assignment, we apply a Maximum Likelihood Estimation and get Average Treatment Effects (ATEs) (Holland, 1986, Ward and

\footnotetext{
${ }^{63}$ Researchers trained abroad could have been accepted as PhD candidates in foreign institutions thanks to individual characteristics that could have influenced their career advancement regardless of the country where the foreign education was received. Therefore, as those researchers who got a PhD abroad do not represent a random sample of the Mexican researchers, we face an endogenous sample selection issue.
} 
Ahlquist, 2018). The ATE measure estimates the difference in average outcomes for the researchers who received training abroad relative to those trained in Mexico.

\subsubsection{Impact on self}

To estimate the extent to which receiving training abroad facilitates the researcher's career position, we employ a simultaneous two-equation estimation in which the errors share a multivariate normal distribution (Roodman, 2011). The researcher's probability of undertaking his/her education abroad $\left(\widehat{D}_{l}\right)$ based on a set of personal characteristics as in equation (3) is estimated through a probit model.

We then define the SNI level of each researcher $i$ as:

$$
\text { (5) } R_{i}=P_{i} \beta+\hat{D}_{i} \delta+\vartheta_{i} R_{i}=0,1,2,3
$$

where $R_{i}$ is the SNI level of researcher $i$ (e.g., the SNI National Researcher Level 1 corresponds to 1). $P_{i}$ is a vector of observable characteristics, and $\widehat{D}_{l}$ is the fitted values coming of the estimated probability of undertaking education abroad given the researcher's personal characteristics. To estimate the coefficient 6 while controlling for the selection bias, we apply an ordered probit model.

\subsection{Results}

In a similar fashion as Barnard et al. (2015), we look at how the education and professional social capital gained through receiving training abroad are related to the individual's career position and the creation and diffusion of knowledge in the Mexican research system. Our results show that Mexican SNI researchers who have obtained their latest academic degrees abroad, compared to national/Mexican training, have a broader network of international co-authors in their academic careers. They are also the largest majority among the most senior Level 3 researchers of the SNI in our sample. Our results suggest that international training/education is a paying investment for the Mexican scientific community as it guarantees better connectedness internationally. However, this increased connectedness comes with a cost to the individual researcher who has more difficulties in advancement in his individual professional career than their nationally-trained peers.

Our main findings are presented and discussed in detail in the following sub-sections.

\subsubsection{The role of foreign training and education in the Mexican science system}

From our sample of SNI researchers, a total of 1,846 (63.2\%) received their latest academic degree in Mexico, and 1,075 (36.8\%) obtained it abroad. Figure 5.1 shows the percentage of researchers within each SNI level achieved in 2013 by the origin of the latest academic degree received. Across SNI levels, 
the largest majority of researchers, or $60.1 \%$ of all in our sample, have a Level 1 , and $30.7 \%$ of these have obtained their academic degrees abroad. Only $9.9 \%$ of all observed researchers have the highest Level 3, with as high as $55.2 \%$ of them holding a foreign degree. Level 1 and Level 2 researchers largely obtained their academic degrees in a Mexican institution/university $(69.3 \%$ and $57 \%$ of the total in each level, respectively) (left-hand side of Figure 5.1). Generally, researchers that received their training abroad have also achieved higher SNI levels.

Of all researchers who hold a foreign degree, $50 \%$ of the total had a Level 1 in 2013 , compared to $66 \%$ of all who hold a Mexican degree (right-hand side of Figure 5.1). Foreign-degree holders also have more senior SNI levels than those holding a Mexican degree: 15\% of all researchers with a foreign degree were Level 3 in 2013, compared to 7\% of all holding a Mexican degree.

Figure 5.1 SNI level shares (2013) by latest academic degree received and origin of training

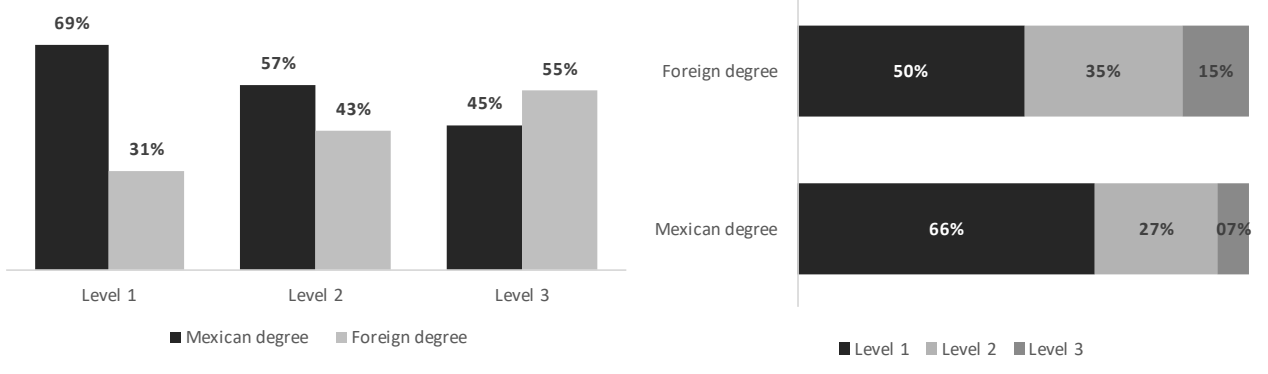

Additional research is required to assess whether the relationship between foreign training and SNI level is causal. However, similar research in the South African context (Barnard et al., 2015) has argued that even if the quality of the foreign training is similar to the local training, foreign-trained researchers have greater global visibility, and holders of a foreign academic degree have arguably higher research potential (i.e., as a requirement of acceptance to world-leading international institutions, showing a sort of selection effect). Thus, their status and visibility locally and abroad help them have a central role in the domestic upgrading of their academic fields.

It can also be argued that the science system may benefit directly from having foreign-trained researchers, as one of the main criteria for obtaining higher ratings and seniority is the scientific productivity of the researcher. Arguably, foreign-trained researchers, being exposed to international research standards, might be more productive than their Mexican-trained peers. To understand this link, we have gathered information on WoS publications per year for 2008-2012.

Descriptive statistics show productivity gaps, even if small, between Mexican-trained and foreigntrained researchers (Table 5.1). There are also important differences by SNI levels. When looking at the 
average number of publications at the aggregate level, foreign-trained researchers are slightly more productive than nationally trained researchers, although the difference is marginal. Within the different SNI levels, only those at Level 2 are more productive than the researchers with a Mexican degree, when the number of publications is adjusted for age. ${ }^{64}$

Table 5.1 Average number of WoS publications and weighted average 5-year Impact Factor by SNI level and origin of academic degree, 2008-2013.

\begin{tabular}{lcccccc} 
& \multicolumn{3}{c}{ Number of publications } & \multicolumn{2}{c}{ Weighted Average Impact } \\
& \multicolumn{2}{c}{ Average } & Age-adjusted average ${ }^{65}$ & \multicolumn{2}{c}{ Factor } \\
\cline { 2 - 7 } SNI Level & $\begin{array}{c}\text { Mexican } \\
\text { degree }\end{array}$ & $\begin{array}{c}\text { Foreign } \\
\text { degree }\end{array}$ & $\begin{array}{c}\text { Mexican } \\
\text { degree }\end{array}$ & $\begin{array}{c}\text { Foreign } \\
\text { degree }\end{array}$ & $\begin{array}{c}\text { Mexican } \\
\text { degree }\end{array}$ & $\begin{array}{c}\text { Foreign } \\
\text { degree }\end{array}$ \\
\hline Level 3 & 15,25 & 13,02 & 12,57 & 11,30 & 2,68 & 2,54 \\
Level 2 & 10,88 & 10,54 & 10,19 & 10,27 & 2,42 & 2,15 \\
Level 1 & 6,85 & 6,19 & $\mathbf{7 , 2 2}$ & 6,62 & 2,27 & 2,05 \\
\hline Total & $\mathbf{8 , 5 3}$ & $\mathbf{8 , 7 4}$ & $\mathbf{8 , 5 3}$ & $\mathbf{8 , 7 4}$ & $\mathbf{2 , 3 4}$ & $\mathbf{2 , 1 6}$
\end{tabular}

In a previous study on Mexico, González-Brambila and Veloso (2007), using a similar approach than ours based on data of SNI researchers from 1991 to 2002, and ISI WoS publications between 1981 and 2002, found that researchers who earned their PhD in the United States or Europe published about 0.16 papers less per year than those who earned their PhD in Mexico or other countries. However, GonzálezBrambila and Veloso advised caution in interpreting these results, arguing that their dataset did not include publications that might have been published by the researcher in an institution outside Mexico (i.e., those that were published when the researcher was studying for the $\mathrm{PhD}$ abroad). ${ }^{66}$

The authors also adjusted for the quality of publications by using the number of citations per 4 years. Their results show almost no difference in citations depending on the country where the PhD was earned, even when correcting for publications published before the year of graduation. Our findings are

\footnotetext{
64 In our sample, SNI researchers with a Mexican degree are on average 48 years old, compared to 51 for those with a Foreign degree. The most important age differential appears at Level 1, 45 for those with a Mexican degree vs. 47 for those with a foreign one. The number of publications is adjusted by age to account for the fact that Mexican trained researchers have, on average, a longer academic career than the foreign-trained.

65 To obtain the age-adjusted number of publications, we calculate the researchers' average age at different SNI levels and by the degree's origin. We obtain each group's age share to the total population on which no age differences at different SNI levels are accounted for. This share is applied as a weighting factor to the average number of publications by SNI level and origin of the degree. The lowest age weight applied is equal to 0.82 for Level 3 researchers with a Mexican degree, while the largest applied is equal to 1.07 for Level 1 researchers with a Foreign degree.

66 They also found slight differences in productivity by area of knowledge: researchers in exact sciences and social sciences and humanities with foreign PhDs were found to be more productive; health sciences and agricultural sciences and biotechnology researchers with a European PhD were slightly less productive; while no significant difference was found in biology and chemistry researchers.
} 
similar. Table 5.1 also shows the 5-year weighted average Impact Factor (IF) of SNI researchers' WoS publications. As expected, higher-ranked SNI researchers have a higher number of publications with higher IFs. Researchers with a Mexican degree always have higher IF publications than those with a foreign degree, even if the differences are not large at all levels.

The arguments put forward by Gonzalez-Brambila and Veloso (2007) on the absence of higher productivity of researchers trained abroad include brain-drain (i.e., the most productive researchers that earned their academic degrees abroad stay in other countries); and the fact that peer reviewers of the SNI do not make a distinction on the country of origin of the researchers' degree, as everybody is expected to show the same scientific productivity to progress across levels. In our view, however, this argument assumes that the researchers always have in mind the reviewer's assessment and that the reviewers are actually 'blind' to the origin of the degree. Ultimately, what the SNI reviewers look at should not matter for scientific productivity and the publications' respective quality.

Table 5.2 shows SNI researchers' productivity differences by the origin of the latest academic degree and broad scientific discipline. The productivity gaps differ considerably by discipline. On average, researchers with a foreign degree are more productive by 0.20 publications (one-fifth of publication) in a 5-year period. The greatest gaps observed in favor of foreign training are in Physics and Astronomy and Earth Sciences. While there are overlaps in the publication productivity of foreign-trained and locallytrained researchers (e.g., when looking at the standard deviation by discipline and origin of the degree), we note that these also vary largely by discipline. Life sciences and Chemistry are disciplines in which there are no productivity differences between locally and foreign-trained researchers.

Table 5.2 Average number and standard deviation of WoS publications by scientific discipline and origin of academic degree, 2008-2012.

Average

\begin{tabular}{lccccccc}
\multicolumn{1}{c}{$\begin{array}{c}\text { Scientific } \\
\text { discipline }\end{array}$} & $\begin{array}{c}\text { Mexican } \\
\text { degree }\end{array}$ & $\begin{array}{c}\text { Foreign } \\
\text { degree }\end{array}$ & $\begin{array}{c}\text { All } \\
\text { researchers }\end{array}$ & $\begin{array}{c}\text { Productivity } \\
\text { gap (Foreign } \\
\text { - Mexican } \\
\text { degree) }\end{array}$ & $\begin{array}{c}\text { Mexican } \\
\text { Degree }\end{array}$ & $\begin{array}{c}\text { Foreign } \\
\text { Degree }\end{array}$ & $\begin{array}{c}\text { All } \\
\text { researchers }\end{array}$ \\
\hline Physics and & 8,19 & 11,19 & 9,12 & 3,00 & 7,29 & 9,02 & 7,97 \\
Astronomy & 7,16 & 8,49 & 7,81 & 1,33 & 6,92 & 6,92 & 6,94 \\
Earth Sciences & 7,45 & 8,46 & 7,95 & 1,01 & 5,95 & 6,94 & 6,48 \\
STS & 8,51 & 8,56 & 8,53 & 0,05 & 6,56 & 6,36 & 6,49 \\
Life sciences & 8,43 & 8,30 & 8,39 & $-0,12$ & 7,06 & 7,07 & 7,05 \\
Chemistry & 7,06 & 5,83 & 6,43 & $-1,23$ & 7,19 & 4,23 & 5,85 \\
Mathematics & 10,60 & 9,88 & 10,49 & $-0,72$ & 7,98 & 7,25 & 7,88 \\
Medicine and & 8,53 & 8,73 & 8,61 & 0,20 & 6,95 & 6,96 & 6,95 \\
Health Sciences & 10,05 &
\end{tabular}


Table 5.3 shows the average number of papers and types of co-authors for the period 2008-2012. On average, foreign-trained researchers have 3 co-authors more than their Mexican-trained peers, all of whom are foreign. Indeed, and as expected, foreign-trained researchers are, on average, more connected internationally than those with a Mexican degree. Mexican and foreign-trained appear to have the same number of Mexican co-authors on average.

Table 5.3 Number of publications and number of (foreign, unique foreign) listed co-affiliations ${ }^{67}$ within the five-year period before the rating (2008-2012), mean.

\begin{tabular}{lccccc} 
No. Papers & $\begin{array}{c}\text { Total co- } \\
\text { authors } \\
\text { (reported } \\
\text { affiliations) }\end{array}$ & $\begin{array}{c}\text { Total } \\
\text { Mexican co- } \\
\text { authors } \\
\text { (reported } \\
\text { affiliations) }\end{array}$ & $\begin{array}{c}\text { Total foreign } \\
\text { co-authors } \\
\text { (reported } \\
\text { affiliations) }\end{array}$ & $\begin{array}{c}\text { Co-authorships } \\
\text { exclusively with } \\
\text { foreign co-authors } \\
\text { (reported affiliations) }\end{array}$ \\
\hline Mexican degree & 8,53 & 26,58 & 19,59 & 7,00 & 0,17 \\
Foreign degree & 8,74 & 29,83 & 20,06 & 9,77 & 0,26 \\
\hline
\end{tabular}

Table 5.3 also presents the total number of papers with only foreign co-authors. These are publications that involve only one Mexican researcher, embedded in a team of exclusively foreign coauthors. Foreign-trained researchers have a higher number of publications exclusively with foreign coauthors than Mexican-trained researchers ( 0.26 vs. 0.17 papers, respectively). On average, foreign coauthors represent $23.9 \%$ of all co-authors of researchers with a foreign degree, compared to $17.8 \%$ of total co-authors for researchers with Mexican degrees (Figure 5.2).

Figure 5.2 Boxplot of the share of foreign co-authors among all co-authors.

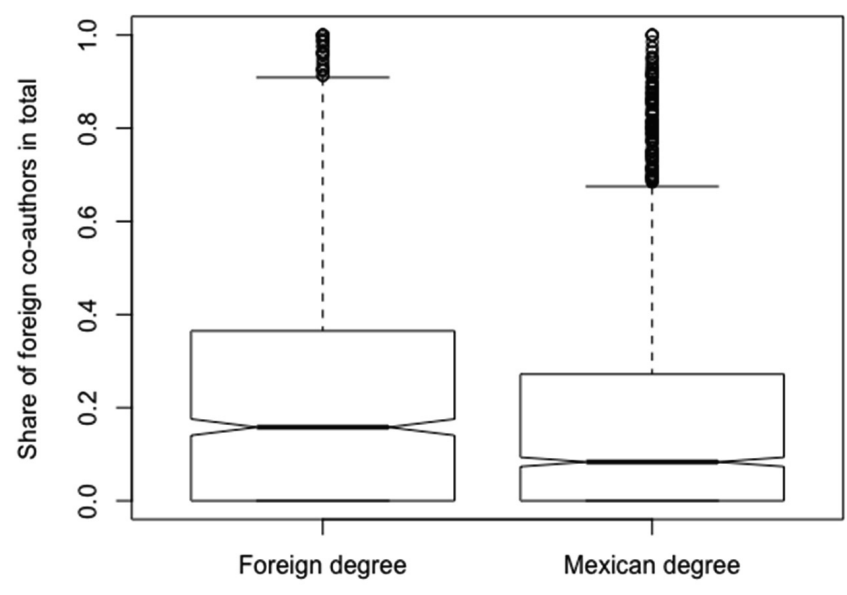

${ }^{67}$ Listed co-affiliations refer to the number of distinct affiliations listed in each Web of Science publication records. 
We have also looked at how collaborations vary by SNI level and the origin of the researchers' academic degree. Table 5.4 shows that, on average, Level 1 researchers with a Mexican degree collaborate mostly with other Mexican researchers. In contrast, researchers who received their training abroad collaborate mostly with foreign researchers, no matter their SNI level.

Table 5.4 Average number of co-authors by SNI level and origin of academic degree.

Mexican Degree

\begin{tabular}{|c|c|c|c|c|c|c|}
\hline \\
\hline & Level 1 & Level 2 & Level 3 & Foreign & Total & $\begin{array}{l}\text { Foreign/ } \\
\text { Mexican }\end{array}$ \\
\hline Level 1 & 3,56 & 1,38 & 0,61 & 5,29 & 10,83 & 0,96 \\
\hline Level 2 & 4,57 & 1,92 & 0,89 & 8,80 & 16,18 & 1,19 \\
\hline Level 3 & 5,62 & 2,12 & 1,30 & 16,02 & 25,05 & 1,77 \\
\hline \multicolumn{7}{|c|}{ Foreign Degree } \\
\hline & Level 1 & Level 2 & Level 3 & Foreign & Total & \\
\hline Level 1 & 2,93 & 1,09 & 0,36 & 7,00 & 11,37 & 1,60 \\
\hline Level 2 & 3,88 & 1,71 & 0,60 & 11,72 & 17,91 & 1,89 \\
\hline Level 3 & 4,61 & 2,19 & 0,89 & 14,46 & 22,16 & 1,88 \\
\hline
\end{tabular}

Level 1 researchers with a foreign degree have 32\% more foreign researchers on average than Level 1 researchers with a Mexican degree ( 7 foreign co-authors for researchers with a foreign degree vs. 5.29 for those with a Mexican one). This difference increases slightly for Level 2 researchers, where those with a foreign degree have $33 \%$ more foreign co-authors than those with a Mexican degree at the same SNI level. Surprisingly, on average, Level 3 researchers with a Mexican degree have $9 \%$ more foreign coauthors than their foreign-trained peers (16.02 foreign co-authors vs. 14.51 respectively). This suggests that international linkages increase with seniority and that the benefits of international training in terms of international connections disappear at the highest levels of seniority. When looking at the ratio of foreign/Mexican co-authors by origin for Level 3 researchers, we note that the ratio is rather stable between foreign-trained and locally-trained researchers. This suggests that good researchers are made by getting exposed to foreign training and embedding themselves in international networks, but great researchers are born, and with seniority, the origin of the degree becomes irrelevant with regards to international connections.

The formation and characteristics of international research networks vary considerably by academic discipline. However, we find that, on average, SNI researchers with a Mexican degree in all disciplines have fewer foreign co-authors than researchers with a foreign degree except for Level 3 researchers. Also, on average, researchers with a foreign degree have a higher number of co-authors in all disciplines, except for Mathematics, where Mexican-trained have 1.8 more co-authors than their 
foreign-trained peers (Table 5.5). Also, in mathematics, researchers with a foreign degree have 6 out of 7 co-authors that are foreign (or $80 \%$ ), compared to 4 out of $9(47 \%)$ foreign co-authors for researchers with a Mexican degree. In the field of Earth Sciences, researchers with a Mexican degree have almost the same share of all co-authors that are foreign compared to researchers with a foreign degree in the same field: 10 out of 15 co-authors (71\% of total) of researchers with a Mexican degree are foreign, compared to 15 out of 19 co-authors (75\%) of those with a foreign degree.

When we analyze the gatekeeping index by SNI level and degree origin (Table 5.6 and Table 5.7), we note that the largest differences are among SNI levels, rather than by origin of degree. As one would expect, scores are higher for higher SNI levels. Level 3 researchers have an average score 2.3 times higher than the average Level 1 researcher. The highest differential is on the external weight or bridging component of the gatekeeping index. Surprisingly, there are no large differentials in the gatekeeping and the external weight scores by the academic degree's origin. This contrasts with the differences identified in Tables 5.4 and 5.5 .

Table 5.5 Average number of co-authors by the origin of co-author and SNI level, discipline, and origin of the latest academic degree.

\begin{tabular}{|c|c|c|c|c|c|c|}
\hline \multicolumn{7}{|c|}{ Mexican degree } \\
\hline Discipline & Candidates & Level 1 & Level 2 & Level 3 & Foreign & Total \\
\hline Life sciences & 1,01 & 4,29 & 1,60 & 0,71 & 6,29 & 13,90 \\
\hline Medicine and Health Sciences & 0,85 & 4,98 & 1,46 & 0,97 & 13,09 & 21,34 \\
\hline Physics and Astronomy & 0,82 & 2,89 & 1,51 & 0,74 & 6,99 & 12,96 \\
\hline STS & 0,86 & 3,83 & 1,66 & 0,60 & 3,42 & 10,37 \\
\hline Earth Sciences & 0,53 & 2,03 & 1,34 & 0,40 & 10,32 & 14,63 \\
\hline Mathematics & 0,41 & 2,50 & 1,12 & 0,71 & 4,18 & 8,91 \\
\hline Chemistry & 0,73 & 3,94 & 1,83 & 0,79 & 4,54 & 11,83 \\
\hline \multicolumn{7}{|c|}{ Foreign Degree } \\
\hline Discipline & Candidates & Level 1 & Level 2 & Level 3 & Foreign & Total \\
\hline Life sciences & 0,97 & 4,20 & 1,63 & 0,56 & 10,50 & 17,86 \\
\hline Medicine and Health Sciences & 0,63 & 3,73 & 1,43 & 0,90 & 19,69 & 26,37 \\
\hline Physics and Astronomy & 0,82 & 3,16 & 1,80 & 0,82 & 14,13 & 20,73 \\
\hline STS & 0,89 & 3,48 & 1,33 & 0,35 & 5,79 & 11,84 \\
\hline Earth Sciences & 0,70 & 2,23 & 1,36 & 0,51 & 14,67 & 19,47 \\
\hline Mathematics & 0,19 & 0,58 & 0,36 & 0,31 & 5,69 & 7,14 \\
\hline Chemistry & 0,79 & 3,12 & 1,43 & 0,49 & 6,07 & 11,89 \\
\hline
\end{tabular}


Researchers with a foreign degree collaborate more on average with foreign researchers than those with a Mexican degree. However, given their similar scores in the gatekeeping index, the interaction with foreign co-authors is less intense (i.e., less frequently and/or within larger co-author teams).

Table 5.6 Gatekeeping and External Weight scores by SNI level, mean and standard deviation, 20082012.

\begin{tabular}{lccccc}
\multicolumn{1}{c}{ SNI Level } & \multicolumn{2}{c}{ Gatekeeping } & \multicolumn{2}{c}{ External weight } \\
& Observations & Mean & Std. Dev. & Mean & Std. Dev. \\
\hline Level 3 & 292 & 0,29 & 0,35 & 2,91 & 2,90 \\
Level 2 & 878 & 0,21 & 0,27 & 2,21 & 2,31 \\
Level 1 & 1761 & 0,13 & 0,18 & 1,44 & 1,64 \\
\hline
\end{tabular}

Table 5.7 Gatekeeping and External Weight scores by origin of latest academic degree, mean and standard deviation, 2008-2012.

\begin{tabular}{lccccc}
\multicolumn{1}{c}{ Origin of degree } & & \multicolumn{2}{c}{ Gatekeeping } & \multicolumn{2}{c}{ External weight } \\
& Observations & Mean & Std. Dev. & Mean & Std. Dev. \\
\hline Foreign Degree & 1075 & 0,15 & 0,22 & 1,81 & 2,05 \\
Mexican Degree & 1846 & 0,17 & 0,24 & 1,80 & 2,05 \\
\hline
\end{tabular}

Figure 5.3 below presents the graphical representation of the network of SNI co-authors. The researchers that are not part of the SNI and all foreign co-authors have been removed from the network for simplicity. Thus, a disconnected node is not necessarily an isolate in the network, but it could also be connected to other non-SNI co-authors or foreign co-authors. Red nodes denote a foreign degree, while grey nodes denote a Mexican degree.

The network graph serves as an illustration of network links. A closer look at the network data shows that out of the 13,401 edges among SNI co-authors, a total of 7,278 edges (54.3\%) are between researchers with a Mexican degree; followed by co-authorships between a researcher with a Mexican degree and one with a foreign degree (across-group collaborations) (34.4\%), and lastly, those involving two SNI researchers with a foreign degree (10.5\%). The majority of collaborations happen between researchers of the same degree origin.

Table 5.8 shows the average geodesic distance among researchers with Mexican and foreign degrees, or the average count of the number of links in the shortest path between researchers. Researchers with a Mexican degree and a Foreign degree have relatively similar distances ( 9.90 vs. 9.95, respectively). This suggests that information travels relatively in a similar fashion among researchers with 
a Mexican degree than among those with a foreign degree. The average network distance independent of degree origin is lower and equal to 6.93.

Figure 5.3 Network graph of SNI co-authors.

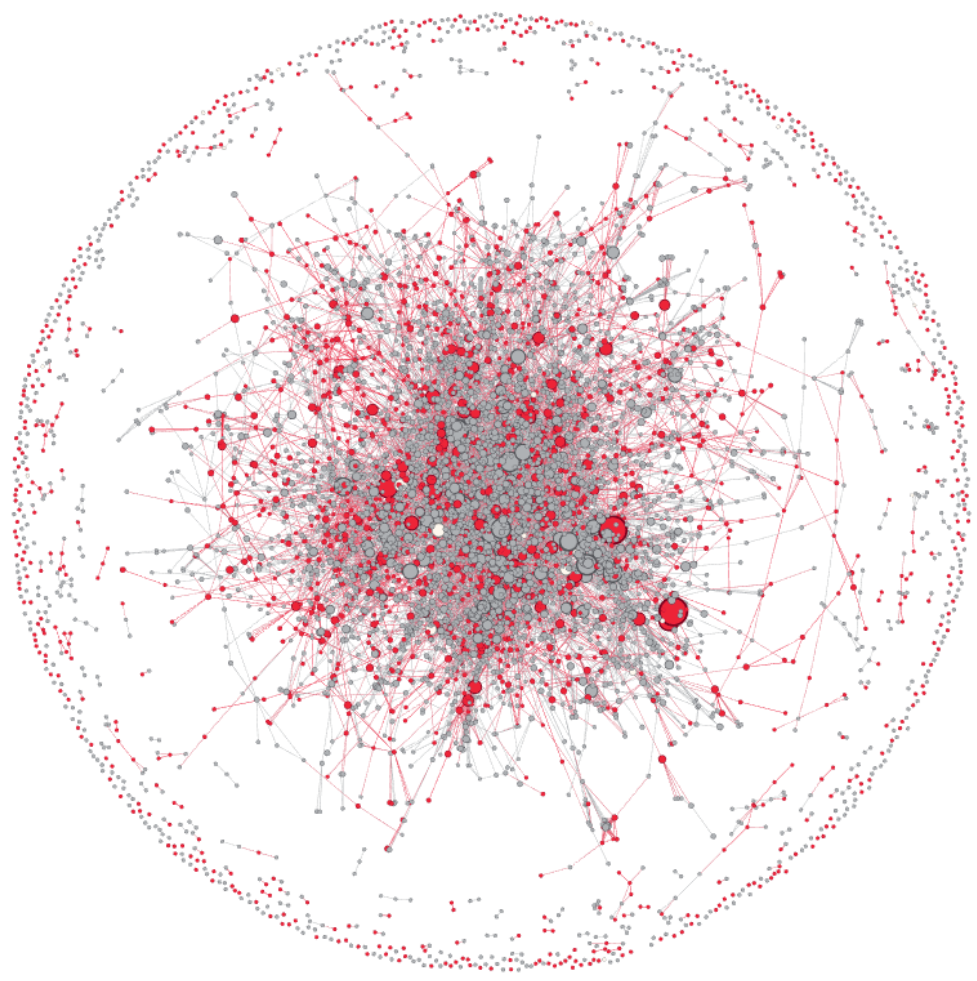

To validate the idea that information travels similarly between Mexican and foreign-trained researchers, we have also performed a randomization test. We have randomly assigned each researcher the origin of the degree and then obtained the average distance between the pairs by random degree origin. The randomization test shows that the average distance among Mexican and Foreign researchers would be virtually the same (9.96 vs. 9.97 respectively), confirming our findings on the real network. 
Table 5.8 Average distance among researchers with Mexican and foreign degrees, reachable pairs ${ }^{68}$

\begin{tabular}{lcc} 
& $\begin{array}{c}\text { Collaboration } \\
\text { network }\end{array}$ & $\begin{array}{c}\text { Randomization } \\
\text { test }\end{array}$ \\
\hline Researchers with a Foreign degree & 9,95 & 9,97 \\
Researchers with a Mexican degree & 9,90 & 9,96 \\
Average network distance (independent of degree origin) & 6,93 & \\
\hline
\end{tabular}

Figure 5.4 presents a simplified network of co-authorships by SNI level and origin of the academic degree. The edges' width shows the intensity, or weight, of the network's type of collaborations. The size of the node shows the number of researchers in each category. From the total number of co-authorship links, the most frequent are between pairs of researchers with a Mexican degree and an SNI Level 1 (19.2\% of all links), followed by pairs of researchers with a Mexican degree and an SNI Level 1 and Level $2(13.1 \%)$, and between pairs combining a researcher with a Mexican degree Level 1 and another with a Foreign Degree Level 1 (8.8\%). Indeed, researchers with a Level 1 represent $60.1 \%$ of the working sample, with Level 1 researchers with a Mexican degree accounting for as much as $41.6 \%$ of all researchers in the sample.

Figure 5.4 Simplified network of co-authorships by SNI level and degree origin

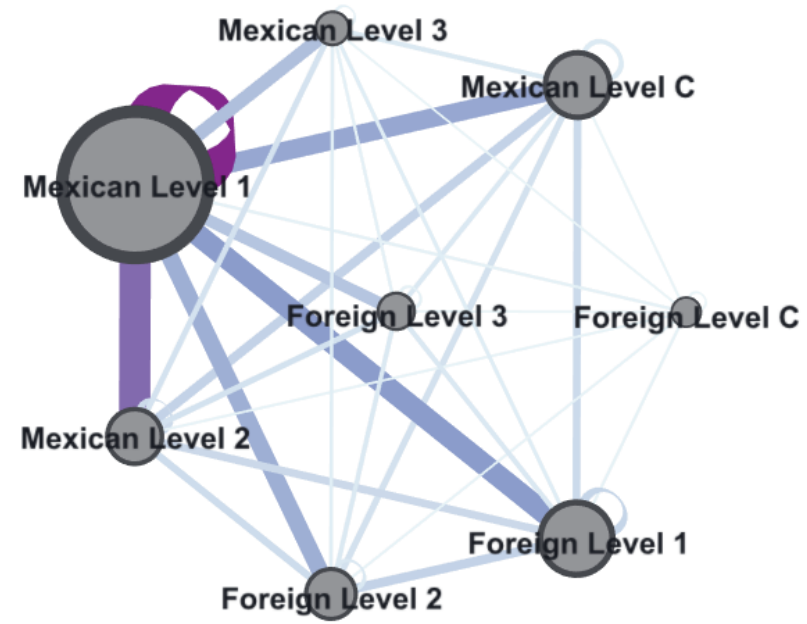

${ }^{68}$ The average distance is calculated for the network of SNI co-authors, or that depicted in Figure 3. Researchers that are not part of the SNI and all foreign co-authors are not included in the network for simplicity. The statistics show the distance between reachable SNI co-authors only. 
If one looks at the total number of links, out of the total that involved at least one researcher with training abroad, 45.2\% of these links are with Level 1 researchers trained in Mexico, followed by Level 2 with a Mexican degree (14.8\%), and SNI candidates with a Mexican degree (12.6\%).

Out of the 13,401 links in the collaboration network, $64.8 \%$ or 8686 links, were among researchers with the same degree origin. To understand whether the origin of the degree influences research collaboration, one additional network was constructed, one where two researchers are connected if both have the same degree origin (e.g., if both had a Mexican degree, or if both had a foreign degree). A correlation analysis was done between this 'same degree origin' network and the overall collaboration network. The results show an extremely weak (equal to 0.0003 ) but still positive correlation between the same origin of the latest degree and research collaboration.

To confirm this absence of (or low) correlation, and following Krackhardt (1988), a Quadratic Assignment Procedure (QAP) correlation test was run to understand systematic connections between these two different relations. The results showed that when 1,000 random permutations are performed on the collaboration network, $13.2 \%$ of all showed a higher positive correlation than the Pearson correlation value of 0.0003 . Most of the permuted values found no correlation between 'same degree origin' and research collaboration (Figure 5.5). This indicates that the observed correlation is not significantly different from a random assignment of co-authorship.

Figure 5.5 Estimated density of QAP replications, correlation between same degree origin and research collaboration

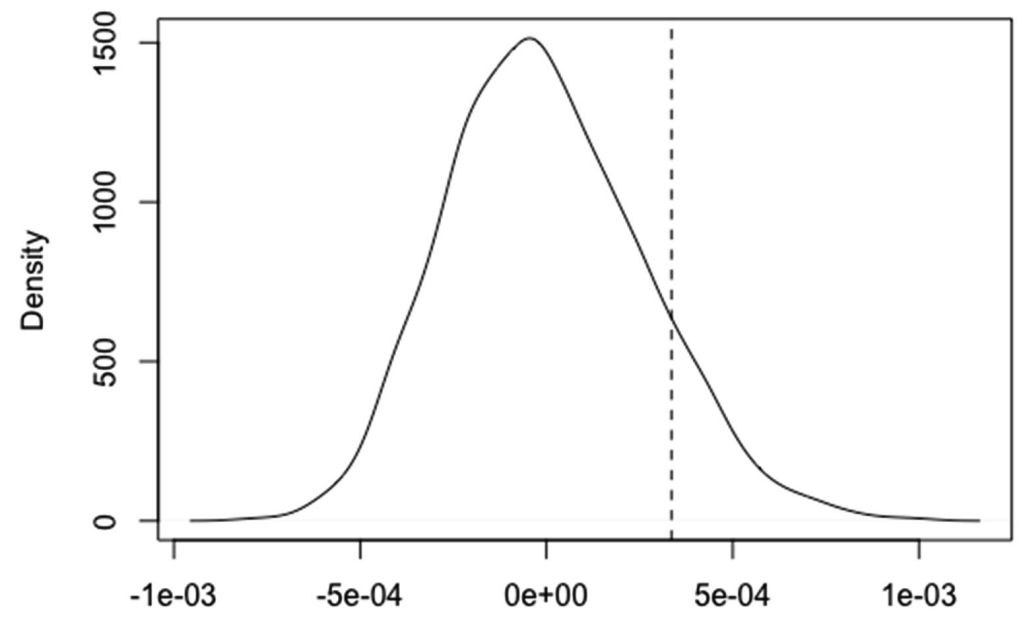

Test Statistic 


\subsubsection{Impact on self}

The impact-on-self model aims to analyze whether foreign education translates into better career prospects for individual researchers. We run three different models for understanding the effect of foreign training on the researcher's career. We use three ordered probit models (Table 5.9, Models 1 , $2 B$, and $3 B$ ), where the dependent variable is the SNI levels obtained by each researcher in 2013. In Model 1 , we run an ordered probit without controlling for endogenous sample selection. In Models 2 and 3, we control for endogenous sample selection by estimating simultaneously a system of two equations in which the errors share a multivariate normal distribution (Roodman, 2011). The system is made up of a first equation -estimated through a probit model - where we estimate the researchers' probability of undertaking their education abroad (Models $2 \mathrm{~A}$ and $3 \mathrm{~A}$ ), and a second equation (Models $2 \mathrm{~B}$ and $3 \mathrm{~B}$ ), where we estimate, through an ordered probit model, their probability of reaching a certain SNI level in 2013. Model 2 controls for all variables taken after the $\mathrm{PhD}$, thus excluding the measures characterizing the co-authors, the impact factor of the publications, and the researchers' affiliations, as these could be potentially alternative measures of the outcome variable.

Model 1 shows that having a foreign degree is significantly associated with reaching higher SNI ranks. However, after controlling for endogenous sample selection, Model 2 and Model 3 show that studying abroad reduces the likelihood of a researcher to have a high SNI level. To some extent, these results are counter-intuitive, especially compared to the descriptive statistics previously presented in this Chapter, where we found a positive correlation between studying abroad and the SNI level.

A sampling effect could be at play in explaining these results. The descriptive statistics presented before demonstrate that researchers studying abroad are more likely to have higher, more senior SNI levels. However, it is important to note that these researchers (Level 3) only represent $9 \%$ of our working sample. The large majority of the sample comprises Level 1 researchers, which are mostly trained in Mexico. Moreover, the sample includes only researchers that applied for SNI membership. Membership to the SNI is mostly relevant in the Mexican context (i.e., it is less meaningful for researchers working abroad). Membership gives local reputation, in addition to the salary increase, which remains the main incentive for application. As previously discussed, SNI members are also given preference when applying for CONACYT public research funds. Our sample does not include all researchers that stayed abroad and are exposed more directly and actively to international research networks.

Models $2 \mathrm{~A}$ and $3 \mathrm{~A}$ show that, relative to female researchers, men have higher probabilities of having a foreign degree. The model reveals that those born in a Mexican state with a GDP per capita 
below $75 \%$ of the average GDP per capita in Mexico have lower probabilities of studying abroad. ${ }^{69}$ In our final sample, $28.27 \%$ of researchers were born in a Mexican state with a GDP per capita below $75 \%$ of the national average. Being born in these states is significantly and negatively associated with the probability of studying abroad.

The models also show that age at the beginning of the degree (Age at degree start) is an important driver of the selection equation. In other words, younger researchers are more likely to study abroad.

After controlling for endogenous sample selection for those researchers who obtained a foreign degree, Models 2B and 3B confirm that men also have higher probabilities of reaching the top SNI levels. As expected, seniority (i.e., Years since the latest academic degree) is a significant and positive predictor of career advancement.

The results also point to the existence of a discipline effect. There are clear discipline differences in career advancements, but also on the probability of obtaining foreign training. Models 2A and 3A show that most disciplines, to different extents, have a positive and significant probability of studying abroad. The only exception is Medicine and Health Sciences, which is linked to a negative and significant foreign training probability. This is not surprising, considering that medical degrees are rarely recognized across countries, and as a consequence, medical students might select themselves 'out' of foreign education.

While Science and Technology sciences and Earth Sciences have the highest probabilities of foreign training (relative to the baseline discipline Physics and Astronomy), these same disciplines do not exhibit significant higher or lower probabilities of reaching high SNI levels, once the endogenous sample selection of those trained abroad is controlled for. On the contrary, mathematicians are significantly associated with a higher probability of getting a foreign degree and higher probabilities to reach a high SNI level (Model 3B).

Model 3B shows that the researchers' quality of work (measured as the 5-year average weighted impact factor of the journals where they publish their peer-reviewed research) is a significant and positive predictor of the likelihood of being in a higher SNI level. Similarly, having co-authors that are SNI members or co-authors who have an affiliation to U.S. academic institutions increases the chances of reaching higher SNI ranks.

69 The average GDP per capita for each Mexican state and researcher is calculated as the average of the previous 5 years before starting the latest academic degree. 
Table 5.9 Impact on self. Ordered probit regressions of SNI level with and without the predicted probability of foreign academic degree.

\begin{tabular}{|c|c|c|c|c|c|}
\hline Variables & \begin{tabular}{|c|} 
Model (1) \\
Ordered probit \\
DV = SNI level
\end{tabular} & \begin{tabular}{|c|} 
Model (2A) \\
Probit \\
DV = Foreign degree
\end{tabular} & $\begin{array}{c}\text { Model (2B) } \\
\text { Ordered probit } \\
\text { DV = SNI level }\end{array}$ & \begin{tabular}{|c|} 
Model (3A) \\
Probit \\
DV = Foreign degree
\end{tabular} & $\begin{array}{c}\text { Model (3B) } \\
\text { Ordered probit } \\
\text { DV = SNI level }\end{array}$ \\
\hline Foreign Degree & $\begin{array}{l}0.095^{*} \\
(0.056)\end{array}$ & & $\begin{array}{c}-0.98^{* k \star} \\
(0.15)\end{array}$ & & $\begin{array}{c}-1.06^{\text {k*k }} \\
(0.11)\end{array}$ \\
\hline Years since latest academic degree & $\begin{array}{l}0.089^{* * *} \\
(0.0043)\end{array}$ & & $\begin{array}{l}0.077^{* * *} \\
(0.0051)\end{array}$ & & $\begin{array}{l}0.076^{* * *} \\
(0.0047)\end{array}$ \\
\hline Male & $\begin{array}{l}0.32^{* * *} \\
(0.057)\end{array}$ & $\begin{array}{l}0.38^{* * *} \\
(0.060)\end{array}$ & $\begin{array}{l}0.38 \\
(0.056)\end{array}$ & $\begin{array}{l}0.38^{m+n} \\
(0.060)\end{array}$ & $\begin{array}{l}0.41^{\cdots} \\
(0.057)\end{array}$ \\
\hline State with GDP $<75 \%$ of national mean & & $\begin{array}{l}-0.090^{*} \\
(0.049)\end{array}$ & & $\begin{array}{l}-0.082^{*} \\
(0.048)\end{array}$ & \\
\hline Age at degree start & & $\begin{array}{l}0.084^{*} \\
(0.036)\end{array}$ & & $\begin{array}{l}0.081^{* *} \\
(0.035)\end{array}$ & \\
\hline$(\text { Age at degree start })^{\wedge} 2$ & & $\begin{array}{c}-0.0019^{* k x} \\
(0.00058)\end{array}$ & & $\begin{array}{c}-0.0019^{* k \hbar} \\
(0.00057)\end{array}$ & \\
\hline Disciplines & & & & & \\
\hline Physics and Astronomy & baseline & baseline & baseline & baseline & baseline \\
\hline Life Sciences & $\begin{array}{l}-0.57^{* k \hbar} \\
(0.085)\end{array}$ & $\begin{array}{l}0.29^{2 * *} \\
(0.083)\end{array}$ & $\begin{array}{l}-0.29^{* k *} \\
(0.081)\end{array}$ & $\begin{array}{l}0.30^{* 2 *} \\
(0.082)\end{array}$ & $\begin{array}{l}-0.37^{* k *} \\
(0.083)\end{array}$ \\
\hline Medicine and Health Sciences & $\begin{array}{l}-0.050 \\
(0.096)\end{array}$ & $\begin{array}{l}-0.27^{* x} \\
(0.11)\end{array}$ & $\begin{array}{l}-0.049 \\
(0.099)\end{array}$ & $\begin{array}{l}-0.26^{* *} \\
(0.11)\end{array}$ & $\begin{array}{l}-0.20^{* k} \\
(0.10)\end{array}$ \\
\hline STS & $\begin{array}{l}-0.45^{* * *} \\
(0.090)\end{array}$ & $\begin{array}{l}0.58^{* \cdots} \\
(0.088)\end{array}$ & $\begin{array}{c}-0.15 \\
(0.096)\end{array}$ & $\begin{array}{l}0.58^{* \cdots} \\
(0.087)\end{array}$ & $\begin{array}{c}-0.12 \\
(0.092)\end{array}$ \\
\hline Earth Sciences & $\begin{array}{l}-0.17 \\
(0.14)\end{array}$ & $\begin{array}{c}0.66^{* * *} \\
(0.12)\end{array}$ & $\begin{array}{c}0.12 \\
(0.11)\end{array}$ & $\begin{array}{c}0.66^{m *} \\
(0.12)\end{array}$ & $\begin{array}{l}0.098 \\
(0.11)\end{array}$ \\
\hline Mathematics & $\begin{array}{c}0.14 \\
(0.14)\end{array}$ & $\begin{array}{c}0.56^{* *} \\
(0.17)\end{array}$ & $\begin{array}{c}0.13 \\
(0.16)\end{array}$ & $\begin{array}{c}0.57^{* \ldots *} \\
(0.17)\end{array}$ & $\begin{array}{l}0.37^{* *} \\
(0.16)\end{array}$ \\
\hline Chemistry & $\begin{array}{c}-0.42^{* k *} \\
(0.11) \\
\end{array}$ & $\begin{array}{c}0.14 \\
(0.11) \\
\end{array}$ & $\begin{array}{l}-0.25^{\star *} \\
(0.10)\end{array}$ & $\begin{array}{c}0.14 \\
(0.11) \\
\end{array}$ & $\begin{array}{c}-0.29^{\text {*n* }} \\
(0.10)\end{array}$ \\
\hline \multicolumn{6}{|l|}{ Co-authors and impact factor } \\
\hline Co-authors USA & $\begin{array}{l}0.27^{*} \\
(0.051)\end{array}$ & & & & $\begin{array}{l}0.24^{w *} \\
(0.044)\end{array}$ \\
\hline Co-authors SNI Candidate & $\begin{array}{l}0.31^{\cdots} \\
(0.062)\end{array}$ & & & & $\begin{array}{l}0.26 * \\
(0.044)\end{array}$ \\
\hline Co-authors SNI Lev. 1 & $\begin{array}{l}0.21^{* *} \\
(0.083)\end{array}$ & & & & $\begin{array}{l}0.17^{*} \\
(0.067)\end{array}$ \\
\hline Co-authors SNI Lev. 2 & $\begin{array}{l}0.15^{*} \\
(0.052)\end{array}$ & & & & $\begin{array}{l}0.12^{* *} \\
(0.047)\end{array}$ \\
\hline Co-authors SNI Lev. 3 & $\begin{array}{l}0.20^{* 2 *} \\
(0.060)\end{array}$ & & & & $\begin{array}{l}0.17^{* \cdots} \\
(0.042)\end{array}$ \\
\hline Weighted average impact factor & $\begin{array}{l}0.075^{* n} \\
(0.018)\end{array}$ & & & & $\begin{array}{l}0.069^{* * *} \\
(0.015)\end{array}$ \\
\hline Affiliations & & & & & \\
\hline CONACYT research centers & $\begin{array}{c}0.14 \\
(0.088)\end{array}$ & & & & $\begin{array}{l}0.13^{*} \\
(0.066)\end{array}$ \\
\hline Federal public university & $\begin{array}{c}0.074 \\
(0.064)\end{array}$ & & & & $\begin{array}{c}0.068 \\
(0.054)\end{array}$ \\
\hline State public university & $\begin{array}{l}-0.27^{* * *} \\
(0.062)\end{array}$ & & & & $\begin{array}{l}-0.20^{* \times *} \\
(0.054)\end{array}$ \\
\hline Constant & & $\begin{array}{c}-1.64^{n k x} \\
(0.56)\end{array}$ & & $\begin{array}{c}-1.59^{* \times *} \\
(0.16)\end{array}$ & \\
\hline Constant SNI level 2 & $\begin{array}{c}2.34^{k * *} \\
(0.15)\end{array}$ & & $\begin{array}{l}1.21^{* *} \\
(0.12)\end{array}$ & & $\begin{array}{l}1.81^{k *} \\
(0.20)\end{array}$ \\
\hline Constant SNI level 3 & $\begin{array}{c}3.77^{*} \\
(0.16)\end{array}$ & & $\begin{array}{c}2.37^{*} \\
(0.18)\end{array}$ & & $\begin{array}{l}3.00^{*} \\
(0.14)\end{array}$ \\
\hline $\begin{array}{l}\text { Pseudo R2 } \\
\text { Athrho }\end{array}$ & 0.2276 & 0.0720 & 0.1850 & $\begin{array}{l}0.0720 \\
0.92^{* \ldots .}\end{array}$ & 0.2276 \\
\hline $\begin{array}{l}\text { Log (pseudo)likelihood } \\
\text { Observations (n) }\end{array}$ & $\begin{array}{c}-2000.88 \\
2888\end{array}$ & $\begin{array}{c}-3865.56 \\
2888\end{array}$ & & $\begin{array}{c}-3750.74 \\
2888\end{array}$ & \\
\hline
\end{tabular}

Standard errors in parentheses. Significance values: $* * * p<0.01, * * p<0.05, * p<0.1$. 
We have included dummy variables on the researchers' academic affiliations by type (Model 1 and Model 3B). Affiliations were classified into three types: researchers working on research centers of the National Council for Science and Technology (CONACYT) of Mexico, where researchers are mainly devoted to research (1); those working in federal public universities (2); and those affiliated to public universities in a Mexican state (3). Researchers affiliated with public universities usually must combine teaching with research activities. Several CONACYT research centers also have training functions, but arguably at lower volumes than public universities. Generally, federal public universities have larger and better research infrastructures than state-level universities. We find that the probability of having a higher SNI level decreases if the researcher is affiliated with a public university located in a Mexican state.

Finally, it is important to note that the correlation of the probit's error terms athrho is significant and positive. This confirms the need to use a Heckman-type regression. It also highlights that the effect of foreign degree on career achievement (SNI level) is over-estimated.

Table 5.10 shows the average marginal effects on the probability of being in a certain SNI level, calculated using Model 3. On average, the predicted probability of having an SNI Level 1 (the lowest in our sample) is $30.74 \%$ higher for researchers with a foreign degree than those with a Mexican degree. In contrast, foreign-trained individuals have a lower probability of being Level 2 or Level 3 researchers (16.09\% and $14.65 \%$ lower probability, respectively) compared to researchers who received their latest academic degree from a Mexican university.

The marginal effects of studying abroad are only positive for SNI Level 1, and they decrease and become negative for Levels 2 and Levels 3 . Life scientists appear to be less likely to be SNI researchers level 2 and 3 (5.58\% and 5.61\% less likely, respectively). Being affiliated to a CONACYT research center increases by approximately $2 \%$ the chances of reaching higher SNI ranks, whereas being affiliated to a State public university decreases these chances by approximatively $3 \%$. 


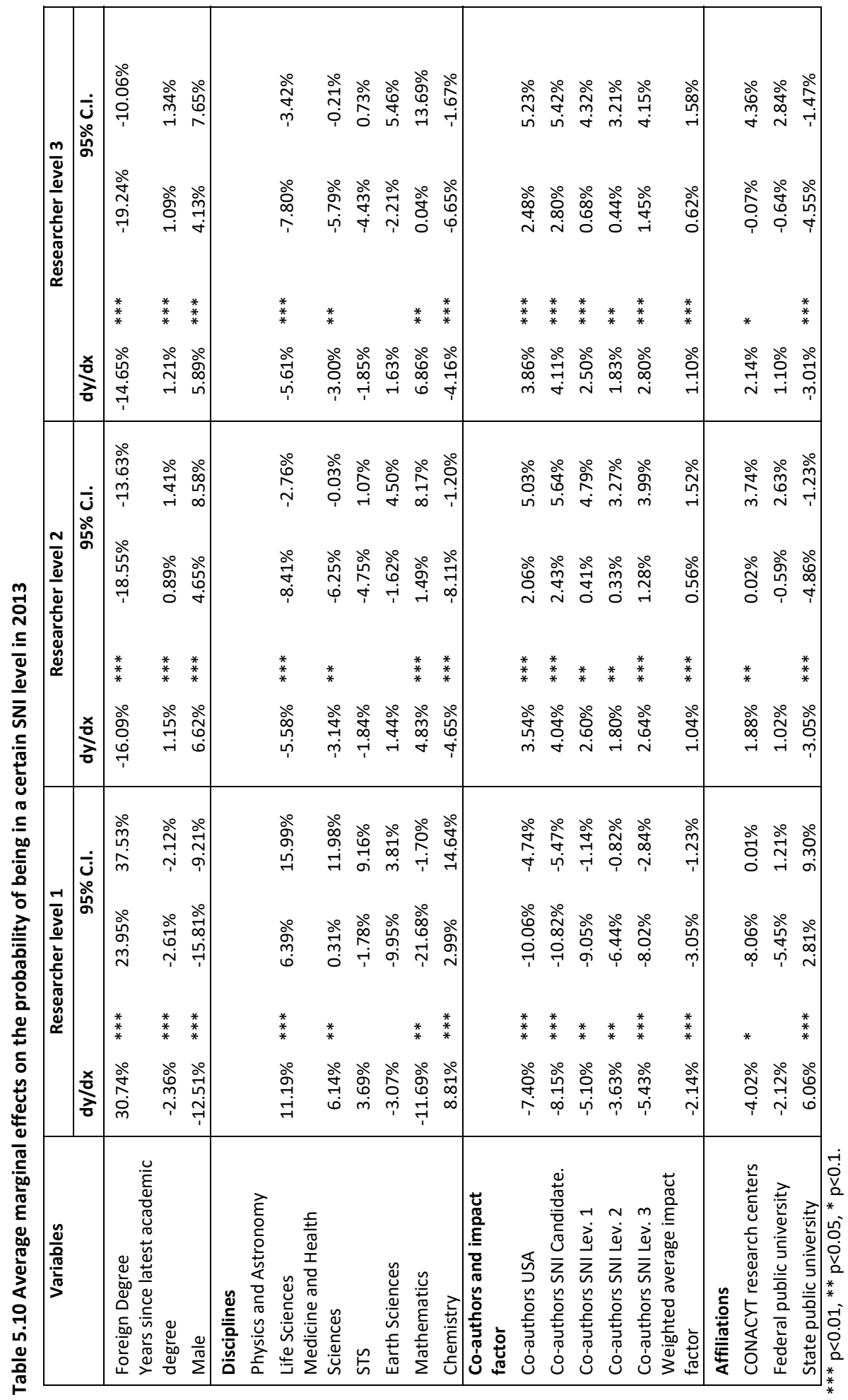




\subsubsection{Impact on others}

As previously noted, the impact on others is measured by the Gatekeeping index, which aims to account for knowledge spillovers to the local scientific community. Researchers with higher gatekeeping scores give higher value to the academic system in social capital for colleagues. They are also considered as possible entry points for foreign collaborations in the Mexican scientific network.

Table 5.11 shows the results of the Impact on others models. Model 4 uses the gatekeeping scores as the dependent variable for the outcome equation (Model 4B). Our dummy identifying if the researcher was born in a Mexican state with a GDP per capita that is lower than $75 \%$ of the national average, as well as the researchers' age at the start of the last academic degree, work as exclusion restrictions for our selection equation (Model 4A). The results reveal that obtaining foreign education gives Mexican researchers a better position to tap into global knowledge and facilitate its transmission into Mexican science networks. The average treatment effect (ATE) of having a foreign degree is equal to 0.31 (Model 4B). In other words, Model 4B confirms that having a foreign degree can more than double the average gatekeeping score of the researchers in our sample. The Wald test of independent equations strongly rejects the null hypothesis that unobservables, which affect gatekeeping scores, do not occur with unobservables, which affect the likelihood of getting a foreign degree, confirming the consistency of our treatment effect endogenous model.

Our selection equation reports similar results to those of Model 3A. On average, men have a higher probability of having a foreign degree; and researchers born in a Mexican state with GDP per capita lower than $75 \%$ of the national average have lower probabilities to study abroad. Regarding disciplinary differences, we observe that researchers in Medicine and Health Sciences have lower probabilities to study abroad, which, as discussed before, is somehow expected given the local/national specificities of medical programs. However, Model 4B shows that, once the endogenous sample selection is controlled, medical doctors and health scientists have higher gatekeeping scores than researchers of our reference academic discipline (Physics and Astronomy). 
Table 5.11 Impact on others, Average Treatment Effect. Regressions with endogenous treatment effects.

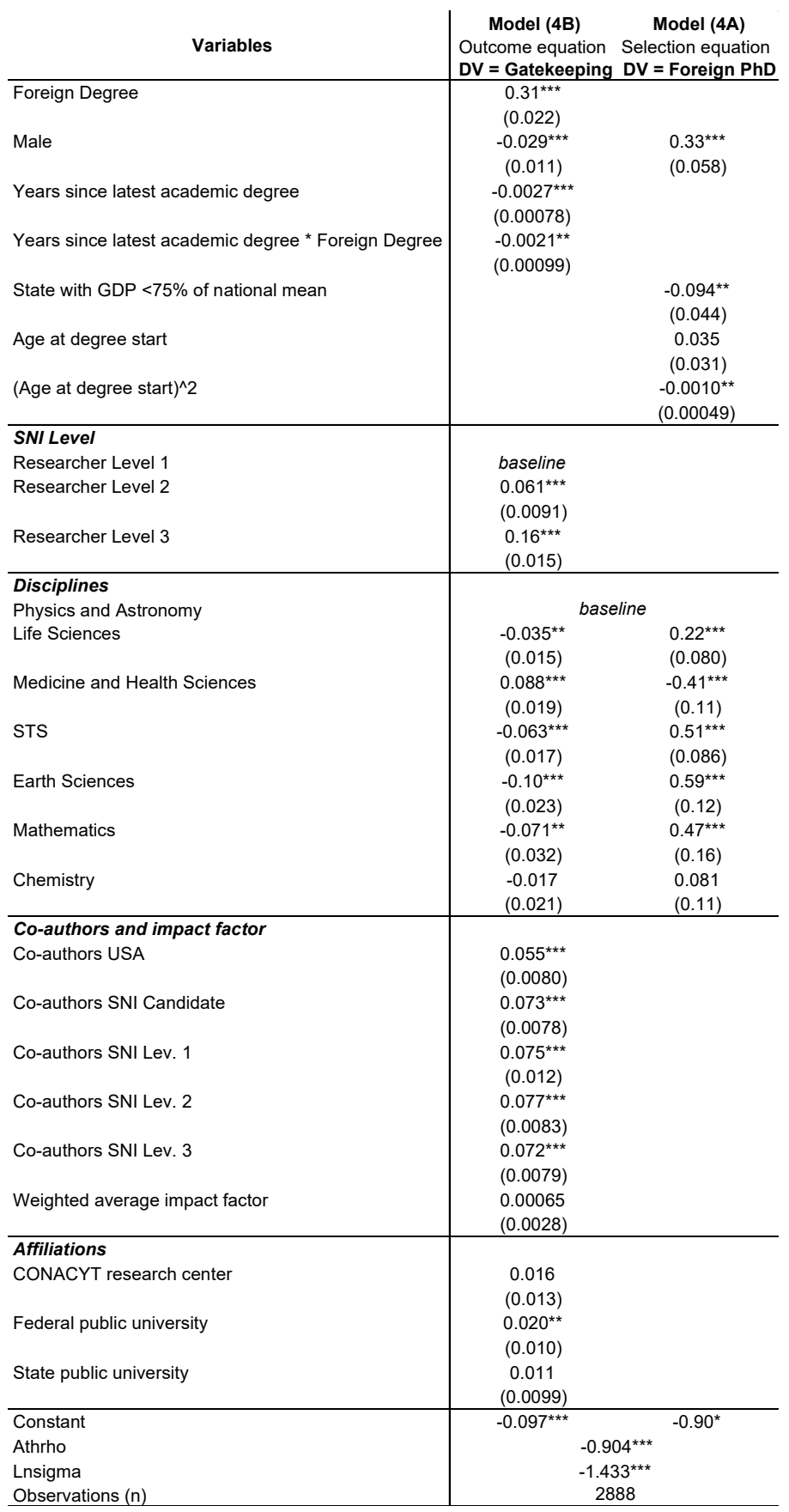

Standard errors in parentheses. Significance values: $* * * p<0.01, * * p<0.05, * p<0.1$. 
Surprisingly the length of the academic career of the researcher (Years since the latest academic degree in our regressions) has a statistically meaningful negative effect on the gatekeeping scores, even if it is quite negligible in terms of magnitude (e.g., having 20 additional years of academic experience is associated only to a 0.04 reduction in the gatekeeping score).

When we look at co-authors, all variables are significant and positive. This is not surprising, considering how the gatekeeping index is defined and constructed. However, and surprisingly, the coefficients are similar to each other regardless of the co-author's SNI level or if the co-author is based in the United States or not, for instance. This reveals that the co-author's seniority does not give a relative advantage to the researcher for having higher gatekeeping scores. Rather, what is important is to have connections with other researchers that are SNI members. Comparatively, having an American co-author (co-authors USA) is less important than having a Mexican SNI Candidate co-author in terms of the observed effects on the researcher's gatekeeping score.

Finally, to better understand the different components that drive our results, we run two separate treatment effect endogenous models, which look at the gatekeeping index's two components separately. The results are presented in Table 5.12. The bonding component results are presented in Model 5, while those of the bridging component are shown in Model 6. Concerning our variable of interest, the results show that in absolute terms, having a foreign degree brings no significant increase to the bonding component, while is significantly associated with a strong increase in the bridging component of the index. 
Table 5.12 Impact on others, Average Treatment Effect of Average Reach, and External Weight. Regressions with endogenous treatment effects on the separate components of the gatekeeping index.

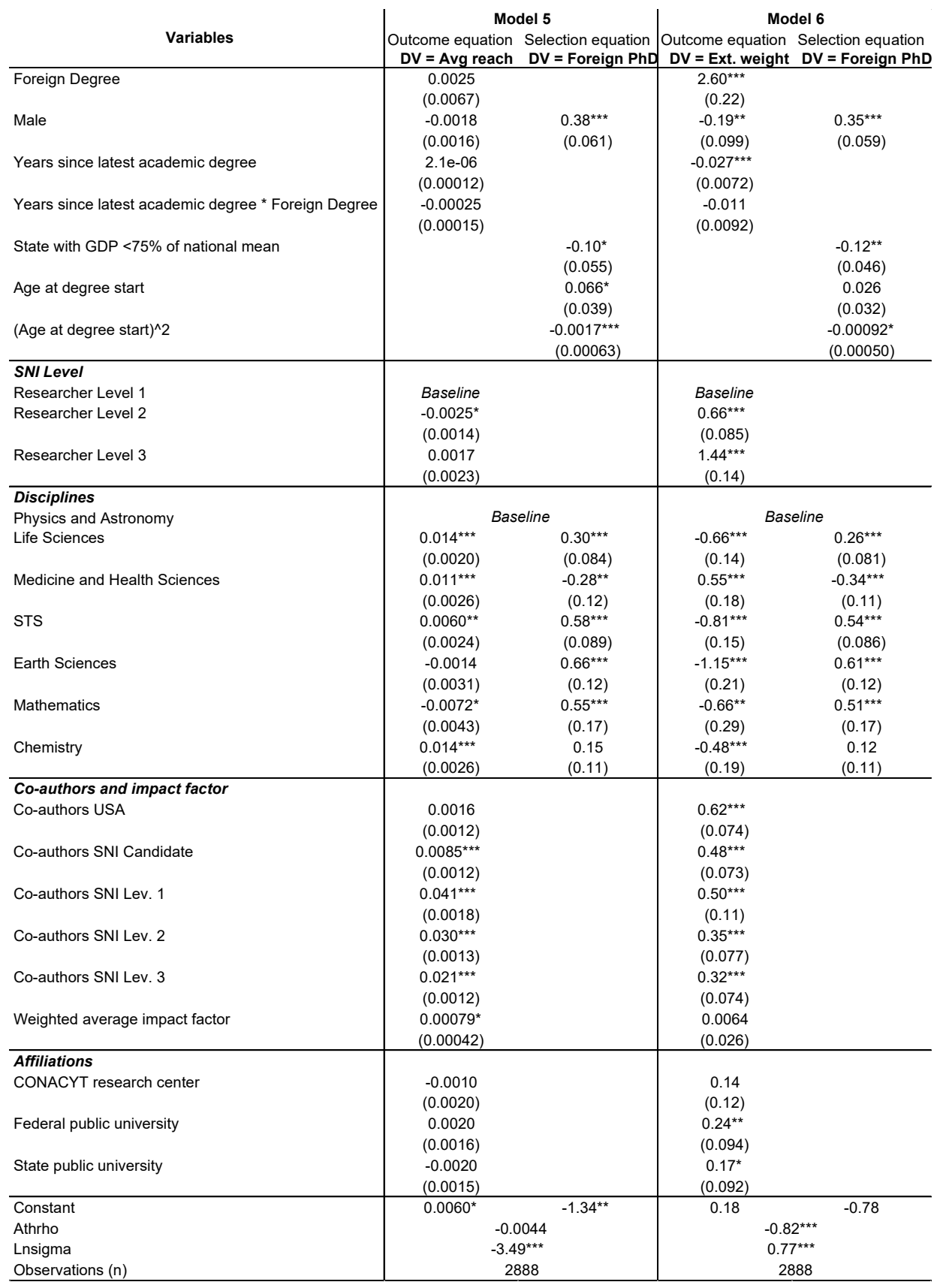

Standard errors in parentheses. Significance values: $* * * p<0.01, * * p<0.05, * p<0.1$. 


\subsection{Discussion and Conclusions}

Access to foreign knowledge is often a controversial challenge in Middle-Income countries, especially considering that public funds to research are very limited in these countries. Governments often struggle between investing funds in local universities and their indigenous science systems or investing these funds supporting individual researchers to study abroad and gain from social and human capital in internationally renowned institutions.

To contribute to the debate on the role of internationally mobile scientists on knowledge transfer and technological upgrading in developing countries, in this Chapter, we looked at the collaboration patterns of Mexican researchers who obtained higher education outside Mexico and compared them to the patterns of their colleagues who received their education from a Mexican institution. Using data from the National Council for Science and Technology (CONACYT) and the ISI Web of Science database, this Chapter investigates scientific collaborations of researchers that are members of the Mexican National System of Researchers (SNI). It analyses whether researchers with a foreign academic degree accelerate introducing external knowledge into the Mexican scientific community and thus contribute to upgrading the local science system.

To achieve international standing and become competitive in the academic world, researchers need to be part of the international research community. A way to do this is to embed themselves in international collaborative research networks. To quantify the extent to which each researcher can tap into global knowledge and facilitate its transmission locally, we compute a "gatekeeping" index which measures both the researcher's access to outside knowledge (bridging-component) and his/her distance to other Mexican researchers (bonding-component) in the network of co-authorships.

Our results suggest that foreign-educated researchers - by having more global contacts with international scientists than locally-educated ones, while not being either less connected locally - can represent important conduits of knowledge for the Mexican scientific system.

We find that training abroad increases researchers' international exposure and their connectivity with foreign networks without significantly reducing their connections to the Mexican research community compared to researchers that received training in Mexico. However, this international exposure comes at a cost. After controlling for possible endogenous sample selection, our empirical models indicate that studying abroad reduces the probability that the researchers reach higher seniority levels in the Mexican academic system. These researchers are less likely to be promoted throughout their academic lives.

Contrasting with this loss for the individual, our findings suggest that researchers who study abroad and bring back their knowledge, connections, and social capital to the national research 
system, benefit the system overall. We find that obtaining foreign education gives Mexican researchers a better position to tap into global knowledge and facilitate its transmission into Mexican science networks. By being better connected globally while maintaining local connections, foreigneducated researchers in Mexico are ideally placed to contribute to local upgrading and plug other local researchers into wider global scientific communities and knowledge pools.

These findings have several implications from the public policy viewpoint.

The most important implication is that public policies focusing on sending students abroad generate system-wide benefits. For example, the CONACYT scholarships program has benefited thousands of Mexican students since its start in 1971, giving financial support for postgraduate studies in Mexico and abroad. Luchilo (2009) showed that $25.5 \%$ of all postgraduate students relied on scholarships to pursue their studies in 2007. Those students that received scholarships showed employability rates of $80.8 \%$ on average. $87.6 \%$ and $91.8 \%$ of all master's degree and PhD students respectively trained abroad were employed after receiving their training. This compares to $77 \%$ and 87.5\% of master's degree and PhD students, respectively, of those that received training in Mexico. Moreover, out of all SNI members in 2007, 52.4\% received a CONACYT scholarship. Those who received a scholarship represented the largest share of SNI members at Candidate (79.2\% of total) and Level 1 (58.8\%) members (Luchilo, 2009). Suggesting that access to a scholarship has important effects on the early career of the researchers.

Access to funds for pursuing postgraduate studies is of particular importance in emerging and developing countries. Lack of financial resources results in the under-representation of researchers from low-income backgrounds in the academic systems of MICs. For Mexico's case, and based on our working sample, $40.3 \%$ or 1181 researchers are from wealthy Mexican states (or those states that have an average GDP per capita higher than $200 \%$ of the national average). These researchers are from only 4 states: Campeche, Nuevo León, Quintana Roo, and Distrito Federal (or D.F., the Mexican capital). Even among these 'wealthy' researchers, 92.1\% are from the D.F. From those that were born in the D.F., $37.3 \%$ studied abroad.

Our results also show that those researchers that are born in a Mexican state with a GDP per capita $75 \%$ lower than the national average, or 'poor states' are less likely to study abroad. About $34.6 \%$ of these researchers in our working sample had a foreign degree, compared to $37.7 \%$ for all 
other researchers. Researchers from 'non-wealthy' states come from 13 different states ${ }^{70}$, with the largest shares of them being born in Veracruz (17.2\%), Puebla (16.8\%), and Michoacán (14.5\%).

Wealth is clearly a determinant for access to education, and more so for access to foreign education. Given that we do not have access to data on the availability of funds and financing at the researcher level, we have used the relative wealth of the Mexican state where the researchers were born as a proxy to understand the access to funds (or the impact of wealth) for studying abroad. There are practically only two ways to finance a stay abroad: self-financing (including private loans) and external funding (be it from a scholarship program, private funder, etc.). In 2007, $73 \%$ of Mexican students self-financed their postgraduate studies, both nationally and abroad. The share of students self-financed was higher in the Mexican capital D.F., equalling 82\% (Luchilo, 2009).

Our impact-on-self model shows that studying abroad comes at an individual cost for the researchers, resulting in lower probabilities of promotion in the academic system. Ideally, our model would include variables that account for the time devoted to research and teaching, but given the lack of these data, we can only speculate on the reasons for this negative impact on self.

There might be several reasons behind this finding.

Foreign-trained researchers might face more difficulties to (re)integrate into the Mexican research system and re-build the social capital and connections lost during the time spent abroad. They are likely to lose on social capital, have a poorer understanding of how the system works, and experience longer adaptation periods to the local system, resulting in lower research productivity.

A second possible explanation is brain drain. Our study sample does not include those Mexican researchers who did not return to Mexico after receiving their training. One could reasonably expect that these researchers are better connected internationally than those that went back. One could also expect that they are also the most competitive and productive researchers, as they managed to find academic work abroad. Official sources have calculated brain drain to involve $5 \%$ of the students granted postgraduate studies abroad (CONACYT, 2000). However, many have argued that this estimate is low, given that it is only based on a sample of researchers that received funding from the CONACYT's scholarships program, and thus excludes all free movers who have used alternative mobility channels to study abroad, and all other economic and professional sectors beyond the academic one (Aupetit, 2015). Others have estimated brain drain to represent up to $80 \%$ of all Mexican researchers that studied abroad (OEI, 2013).

\footnotetext{
${ }^{70}$ Chiapas, Guanajuato, Guerrero, Hidalgo, Michoacán, Nayarit, Oaxaca, Puebla, San Luis Potosí, Tabasco, Tlaxcala, Veracruz and Zacatecas.
} 
Among the main reasons explaining academic brain drain in Mexico, there is the lack of proper research infrastructures and resources, non-competitive salaries in academia when compared to salaries abroad (Velasco, 2014), and the lack of academic positions fitting the researchers' acquired skills and training (OEI, 2013).

Compared to the mature CONACYT scholarship program or the SNI, policies to (re-) integrate Mexican foreign-trained researchers into the Mexican higher education system are still rather weak and poorly funded. In the 1990s, the Mexican federal government had a program offering favorable conditions for the return/entry to Mexico for young scientists and/or established scientists. This program was the result of a 50\% co-investment arrangement with the World Bank. Aupetit (2006) argues that although there is evidence of an increased number of repatriations in the early 1990s attributable to the program, there is no record on the trajectory of these repatriates to-date. It is thus impossible to know if Mexico was a transition country for these academics or if these repatriations' long-term benefits can be accounted for.

A similar program, called the Programme for Retention and Return, has been sponsored by CONACYT since 2013. In 2014, the program financed the repatriation and retention of 147 researchers, out of which 48 (32.6\% of total) were repatriations (CONACYT, 2015). These levels are low, considering that estimates of the number of Mexicans with postgraduate degrees residing only in the United States in 2012 amounted to 152,851 (González Rodríguez, 2015).

Further attention should be paid to this type of policy. Our results suggest large benefits to the Mexican academic system from reintegration and repatriation of researchers. However, repatriation programs must face a lack of jobs for qualified researchers. Mexican policymakers' main challenge is to create the appropriate conditions, or absorption capacity, in Mexico to welcome its repatriates.

Also, some Mexican researchers who study abroad will choose to remain abroad for professional or personal reasons. Out of our initial population of 5,961 researchers, 80 of them, or $1.84 \%$, had a foreign work affiliation in 2013. Interestingly, of those 80,74 researchers have Mexican academic degrees (i.e., they did not study abroad). These researchers with foreign affiliations are on average less productive than those with a Mexican affiliation when the absolute number of papers in a 5 -year period is considered (5.11 papers vs. 8.61 papers). However, they publish their research in journals with a higher impact factor than those working in Mexico (3.36 weighted average impact factor for those working abroad vs. 2.27). Also, researchers who have a foreign degree and work abroad have particularly lower gatekeeping indexes. This finding is more compatible with brain drain. 
Our study excludes researchers that work abroad as our main aim is to understand how foreign education influences the Mexican academic system. More research is needed to understand the role and contribution of these researchers to Mexican academic networks.

How to better connect researchers who stay abroad to the Mexican academic system is another topic that requires more research and policy attention. These researchers could also be beneficiaries and contributors to public policies aiming to enhance international knowledge spillovers. Often referred to as the 'diaspora option' (as opposed to the 'return option'), diaspora networks' objective is to foster the development of their members' country of origin by utilizing the skills of the expatriates (Meyer et al., 2001). The objectives can be diverse: from technology transfer, exchange of students and joint research projects, to access to data and training. The diaspora option has much more affinity with the network's approach used in our paper. The approach uses a connectivist view of embedded knowledge and the use of human, material, and cognitive resources available from the network. Diaspora academic networks have successfully existed in other Latin American countries, such as Argentina, Uruguay, Peru, and Venezuela (Aupetit, 2006).

Another interesting aspect of our results regards gender differences in the impact on self and the impact on others models. The impact on self-model shows that, relative to female researchers, men have higher probabilities of having a foreign degree and higher probabilities of reaching the top SNI levels. In contrast, being male has a significant negative effect on the gatekeeping index. Thus, male researchers' impact from access to foreign knowledge is positive with regards to self but negative with regards to the academic system. This finding requires more in-depth research. However, research on gender productivity gaps in Mexico looking at women's status in public research centers and public universities (and Chapter 3), showed that women are $35 \%$ less likely to be promoted than men in research centers and 22\% less likely to be promoted than men in universities (Rivera León et al., 2017).

Our results are also interesting from the point of view of the quality of the research produced by researchers trained abroad and in Mexico. Descriptive statistics show that researchers with a Mexican degree always publish in higher IF journals than those with a foreign degree, even if the differences are not large. Our econometric models show that the quality of research is a significant and positive predictor of the likelihood of being in a higher SNI level, and this becomes more important among higher levels of seniority. We also find that the quality of research has no significant effect on higher gatekeeping index scores.

Indeed, the quality of the training institution is a strong determinant of the effects that foreign training has on the individual. Recent research (Müller et al., 2018) underlines the importance of the quality of the foreign institution where the researchers receive the training, providing evidence that 
"foreign" is not necessarily "better" in the case of MICs. Using data for South African researchers within an indigenous science system like the Mexican, the authors found that PhDs trained in top South African universities produce a similar quantity and quality research output to those trained in leading universities in the developed world. The issue of the quality of the foreign training of SNI researchers clearly requires more in-depth investigation.

Following this last argument, understanding the role of the local academic and research system in the upgrading of developing countries is important. Understanding how many financial resources should be allocated for sending students abroad versus investing those same resources in improving the local academic institutions' quality becomes even more relevant. There is no simple answer to this.

Research in the innovation literature has found that short stays such as fairs, exhibitions, conventions, congresses, and conferences often serve as hotspots for intense knowledge exchange that can also contribute to building strong social networks and idea generation (Maskell et al., 2006) that are similar to those found in more permanent settings. Transferable to the research policy domain, one could argue that short academic stays or temporal academic visits or conferences could also extend researchers' academic networks and make them benefit from foreign knowledge. This alternative has the advantage of being comparatively less expensive and would allow for a larger number of beneficiaries. 



\section{Chapter 6. Conclusions}

Through a quantitative econometric approach anchored in the economics of science literature and making use of social network theory, this thesis investigates the role of scientists and scientific communities in the process of knowledge creation by looking at scientific productivity, its determinants and effects at individual and collective levels, as well at the macro level.

We introduced this thesis by asking, what are the determinants of knowledge creation in the context of Middle-Income Countries?

We investigate the role and effects of different determinants on scientific productivity: cognitive proximity - notably gender and ethnicity, status homophily, organizational proximity, social and community structure, and access to foreign knowledge and international collaboration networks. We use four empirical chapters to understand the role and effect of these determinants on scientific productivity in-depth. For doing so, we use two-novel datasets of researchers of the National Research Foundation (NRF) of South Africa and the National System of Researchers (SNI) of Mexico and their scientific production.

The results of the empirical chapters point to a complex picture of determinants in the context of MICs: one where personal and cognitive characteristics, organizational and social structures, and collaboration practices, all interact and affect the productivity of researchers.

Chapter 2 studied the different factors associated with research collaboration for the first time (tie formation) and subsequent collaborations (tie persistence). We found that different factors are associated with each type of collaboration. Collaborations happen for the first time among researchers that are well connected and close to each other, have high cognitive and organizational proximity, and are part of the same social communities. In contrast, little seems to matter apart from social structure and organizational proximity to make a collaboration persist over time. Concerning cognitive proximity, we also found that researchers are more likely to collaborate for the first time with others of the same ethnicity, and they are more likely to make the collaboration persist over time with others of the same gender. 
Chapters 3 and 4 provide empirical evidence of gender role as a determinant of scientific productivity. Both Chapters show the magnitude of the gender gap in scientific publication productivity and shed light on the reasons for and consequences of existing inequalities in scientific performance at the individual and aggregate academic system levels. We showed that collaboration characteristics, probabilities of promotion, selectivity, and initial productivity account for differences in scientific productivity. Other factors, such as the quality of the research and institutional affiliation (Chapter 3), and ethnicity (Chapter 4), also explain the different magnitudes of gender productivity gaps.

To our initial surprise, the results of both empirical applications in Mexico and South Africa showed that there are almost no or no gender publication productivity gaps in both countries. In other words, women are marginally less productive than men or as productive as men, particularly when the research output is weighted by the quality of the outputs (Chapter 3). Moreover, once we control for other factors, notably promotion, we find that the gender productivity gap favors women. We showed that being female has a positive and significant effect on an individual's productivity, regardless of their institutional affiliation (Chapter 3) and ethnicity (Chapter 4). We also showed that significant individual and system-wide productivity increases for both females and males (but notably females) could be achieved by controlling for selectivity and promotion, and eliminating promotion biases would result in the largest increase to aggregate productivity.

Moreover, we showed that women publish, on average, in journals with higher impact factors than men do (Chapter 3). However, -before controlling for selectivity and promotion, gender productivity gaps in favor of men appear to increase as the impact factor of the journal of publication increases but varying on institutional settings.

Chapter 4 expands the gender productivity gaps model to the South African context, resulting in a gender-ethnicity productivity gaps model that accounts for the complexities that these determinants alone and together have on scientific productivity. Our findings suggest the existence of a race productivity gap. We show that ethnicity plays a significant role in researchers' overall productivity and that ethnicity has more explanatory power than gender for understanding productivity gaps. Women are slightly more productive than men among white and non-white researchers, with white researchers always more productive than non-white. Moreover, ethnicity and age -rather than gender, also explain the largest differences in the frequency of non-publishing years among researchers. The results show that female researchers have fewer chances than men to be promoted in their academic careers - even when they are equally or even more productive than their male peers, and they are under-represented in the highest levels of seniority. 
The findings of both gender chapters (Chapters 3 and 4) provide a complex picture of external barriers that influence women's science performance. A picture where women face more difficulties in their academic careers and are not recognized and rewarded equally as men. This has direct and indirect effects on their productivity. This picture characterizes well the deficit model of Sonnert and Holton (1995) for explaining gender productivity gaps in science.

In Chapter 5, we analyzed the effect of access to foreign/international knowledge through education and training on scientific productivity. Firstly, we looked at how foreign training affects the career of the researcher itself (impact-on-self). Secondly, we looked at the 'outward' effects of foreign training by analyzing how it influences the researchers' position in international collaboration networks and facilitates the diffusion of knowledge nationally and internationally (impact-on-others). We find that foreign-educated researchers play an important role as conduits of knowledge to the scientific community at large and have a central role in the domestic upgrading of their academic fields. They are also better connected to international research networks. However, we also showed that the degree's origin becomes irrelevant at higher levels of seniority as locally-trained researchers are equally well connected internationally, compared to those who received their training abroad. Moreover, this increased connectedness comes with a cost. We find that foreign-educated researchers have fewer probabilities of promotion to higher academic ranks relative to their nationally-trained peers when controlling for endogenous sample selection.

Two methodological contributions of this thesis deserve a highlight.

First, the results of Chapter 2 and the use of community detection algorithms in the methodological framework -and going beyond the more traditional network metrics, put upfront that a measure of social capital is needed to have a complete picture of the determinants of scientific productivity. To investigate the meso-level effects of social structure on scientific collaboration, the results argue for using the network approach in understanding the embedded traits of social capital in the rational behavior of researchers and the importance of these as determinants of scientific productivity. We believe that integrating the network approach to more empirical studies would benefit and enrich the study of the economics of science.

Second, Chapters 3 and 4 propose a novel measurement of gender parity impacts: an econometric framework to measure the macro-effects of reducing gender productivity gaps in science through policy scenarios to assess the magnitude of the potential impacts. This methodology is novel and expands the micro-effects model of Mairesse and Pezzoni (2015). This contribution is likely to resonate among policymakers concerned in improving national research performance as a decision- 
making tool. It provides a concise and concrete measurement of the costs and benefits of reducing or eliminating gender productivity gaps.

The limitations of the thesis are three-fold.

First, although the empirical chapters of this thesis contribute to a better understanding of the determinants of scientific productivity in MICs, one must treat their generalizability with caution. For instance, we discussed in Chapter 4 that our findings on gender productivity gaps for South Africa differ from those of Prozesky (2006a, 2008a) and that the differences are explained largely by the research design (study sample, the period of analysis, and methodology). Similarly, the findings of Chapter 3 are not fully in line with those of Gonzalez-Brambila and Veloso (2007) with regards to the existence of gender productivity gaps in Mexico.

It is clear that as the economics of science literature expands into the context of MICs, comparative studies will become more important to derive broader conclusions from a set of countries and empirical applications. These comparisons are necessary by comparing developing countries with each other and comparing developing countries with developed countries. Both types of comparisons would enrich the economics of science literature and provide different but complementary sets of policy implications and applications. The research of Mairesse et al. (2019) is already moving in this direction, both in the context of developed and developing countries.

Second, the methodology used in Chapter 2 could be further improved in order to establish causation from our results fully. One particular issue concerns the 'de-trending' of the variables we use. Due to the panel data's construction, each dyad in the sample is observed to have a sequence of failures ended by a success. The fact that successes are by construction observed later than failures creates a correlation with any variable having a time trend. Moreover, our research collaboration network is growing over time, which will result in a time trend of all network measures. An alternative to solve this issue is to de-trend all the dyadic measures, and estimate a model of the regressor including a dyad-specific intercept and a linear time trend, and to include into the panel regression the difference between observed and the expected value of the regressor, i.e., the residual of the regression, instead of the explanatory variable itself. This correction would bring further robustness to our methodology. For now, and given this limitation, the results presented in Chapter 2 help establishing correlations at the least.

Third, the proposed macro-estimations of gender productivity gaps of Chapters 3 and 4 have an important methodological caveat. The computed estimates of effects make strong assumptions about how the variables interact. Thus, the parity impacts models' results should not be treated as 
predictions but rather as indications of the magnitude and direction of such effects. We believe, nonetheless, that these indications could be used as powerful policymaking tools.

The thesis leads to several avenues for further research.

The discussion of Chapter 2 hints at the idea of further expanding the econometric models for the formation and persistence of ties by sorting out two different types of factors affecting scientific productivity: the unobserved characteristics of agents' effect vs. the social interaction effect, as possible. This would require estimating a more complex model that accounts for measurement uncertainty and further characterization of social communities. The expansion of the models presented in this thesis would also further increase their explanatory power.

The econometric models of Chapters 3 and 4 - the gender chapters, could be expanded by including additional explanatory factors of gender productivity gaps. Motherhood and family characteristics, such as the number and age of children, are the most obvious ones that could further expand our models. These factors can be technically measured but would require extensive primary data collection. For South Africa, such a study would complement the qualitative study of Prozesky (2008a), focusing on the effects of motherhood on South African researchers' scientific productivity and career development.

The findings of Chapter 4 open the door to expanding a whole new strand of research: that of the race-gender parity in science. Women are part of an academic landscape that is layered and shaped by gender, class, and race. Black women often face the combined effect of race and gender inequalities and discrimination. Most of the existing literature, limited in the context of MICs, look at the effects on research productivity of gender and race separately. It is clear, in particular in the aftermath of the "Black Lives Matter" movement that has brought mainstream attention to the existing racial and ethnic discrimination and disparities society-wide and worldwide, that more research is needed to unveil the effects of the interactions of gender and race on science systems. Chapter 4 helps in unveiling these complexities in understanding and measurement. The macroscenarios on gender-parity could also be extended to account for the interactions of gender and race. Understanding the macro-effects of eliminating race gaps would also enrich further the analysis and results presented in this thesis.

Chapter 4, the South African gender chapter, could also benefit from expanding the definition of scientific productivity by including a measurement of scientific quality and impact. Although one might argue that research quality is already endogenous to the proposed econometric model, given how the rating system of the NRF works, an explicit measurement of quality would increase the 
robustness of the results. This expansion would also allow for more appropriate comparisons of the empirical applications of Mexico and South Africa of Chapters 3 and 4.

Finally, the impact-on-self model of Chapter 5 could be further enriched by adding a measurement of the quality of the researchers' foreign training. It is clear that the quality of the training is likely to be influential in the researcher's career path and that more research is needed to understand this influence. Moreover, Chapter 5 also brings up the challenges that MICs face concerning brain-drain. In an ideal scenario with complete data, one could further research the contributions and impact-on-others that these researchers have on the overall productivity and knowledge transfer of national research systems in MICs.

Overall, the research presented in this thesis provides tools for informing policy discussions on how best to implement science policies in MICs. It also informs on the formulation of more evidencebased policies affecting the funding and conduct of scientific research in MICs.

In Chapter 2, we showed that researchers' cognitive preferences with regards to the choice of collaboration partners adapt over time and seem to favor the homophily principle, particularly concerning personal characteristics, such as gender and race. This finding points to the risk of segregation of 'minorities' in academic systems. From a research policy perspective, this also signals the need to promote cross-race and cross-gender contacts and diversity in research networks.

The most important policy implication of the gender chapters ( 3 and 4 ) concerns the promotion of women to higher ranks in academia. Our results suggest that policy should focus on how to enable equal opportunities for promotion for women. Gender equality in promotion depends greatly on the working environment and can be undoubtedly encouraged through incentives, including support grants exclusive to females to alleviate their under-representation, promotion policies, and other career development opportunities.

Chapter 5 provides empirical evidence that researchers that receive their training abroad generate system-wide benefits for their home countries in the form of access to international research networks and act as gatekeepers in transferring this knowledge to their local networks. This main finding puts in evidence the importance of promoting access to foreign knowledge to researchers in MICs. However, it also highlights the main challenge of promoting this access: selection. Wealth is clearly a determinant for access to education, and more so for access to foreign education. We showed that researchers with access to foreign education are mostly young, male, and from large (capital) cities. This has profound implications on how to enable more opportunities to other strata of the academic communities in MICs in accessing foreign education, particularly women (given our findings of Chapters 3 and 4). It also underlines the importance of promoting policies that support researchers' 
integration in MICs to foreign education, such as graduate scholarship programs. These programs are increasingly common in MICs but often struggle with limited public funds and face the challenge of re-integrating the researchers back to their home countries in the face of competing brain-drain.

Finally, our results suggest large benefits to the academic system from the reintegration and repatriation of researchers. The reintegration of researchers to their home countries is an issue that deserves policy attention. This issue also brings forward the main challenges that academic systems in MICs face to successfully re-integrate these researchers back to their home countries: the lack of proper research infrastructures and resources, the lack or limited competitive salaries to attract the researchers back, and the lack of demand for the specific skillsets obtained abroad in the labor market for researchers. These are by no means issues easy to solve. The main challenge for policymakers remains creating the appropriate conditions, or absorption capacity, to welcome their repatriates back.

As a complement to repatriation policies, policies aiming at enhancing international knowledge spillovers and the promotion of diaspora academic networks could also work in better utilizing and transferring the skills and benefits of foreign training. 



\section{References}

ABRAMOVITZ, M. 1986. Catching Up, Forging Ahead, and Falling Behind. The Journal of Economic History, 46, 385-406.

AEA. 2019. How can economics solve its gender problem? [Online]. American Economics Assocation. Available: https://www.aeaweb.org/webcasts/2019/how-can-economics-solve-gender-problem [Accessed 27 January 2019 2019].

AFETI, G., NG'ETHE, N. \& SUBOTZKY, G. 2008. Differentiation and Articulation in Tertiary Education Systems.

AGRAWAL, A., KAPUR, D., MCHALE, J. \& OETTL, A. 2011. Brain drain or brain bank? The impact of skilled emigration on poor-country innovation. Journal of Urban Economics, 69, 43-55.

ALLISON, P. D. 1982. Discrete-Time Methods for the Analysis of Event Histories. Sociological Methodology, 13, 61-98.

ARENSBERGEN, P. V., WEIJDEN, I. V. D. \& BESSELAAR, P. V. D. 2012. Gender differences in scientific productivity: a persisting phenomenon? Scientometrics, 93, 857-868 p.p. .

ARTHUR, W. B. 1990. Positive Feedbacks in the Economy. Scientific American, 262, 92-99.

AUPETIT, S. D. 2006. The brain drain in Mexico-a subject for research...or agenda? Globalisation, Societies and Education, 4, 103-120.

AUPETIT, S. D. 2015. Mexico's Brain Drain. International Higher Education, 0.

BAGUES, M., SYLOS-LABINI, M. \& ZINOVYEVA, N. 2017. Does the Gender Composition of Scientific Committees Matter?+. American Economic Review, 107, 1207-1238.

BAKER, J. G. \& FINN, M. G. 2003. Stay rates of foreign national doctoral students in the U.S. Economic Programs. (March 19, 2003). Available at SSRN: https://ssrn.com/abstract $=398640$

BALDASSARI, D. \& DIANI, M. 2007. The integrative power of civic networks. American Journal of Sociology, 113, 735-780 p.p.

BARNARD, H., COWAN, R., DE ARROYABE ARRANZ, M. F. \& MÜLLER, M. 2015. The Role of Global Connectedness in the Development of Indigenous Science in Middle-Income Countries. The Handbook of Global Science, Technology, and Innovation. Wiley Online Books.

BARNARD, H., COWAN, R. \& MÜLLER, M. 2012. Global excellence at the expense of local diffusion, or a bridge between two worlds? Research in science and technology in the developing world. Research Policy, 41, 756-769.

BARNARD, H., COWAN, R. \& MÜLLER, M. 2016. On the value of foreign PhDs in the developing world: Training versus selection effects. UNU-MERIT Working Paper Series, No. 2016-006.

BARUFFALDI, S. H. \& LANDONI, P. 2012. Return mobility and scientific productivity of researchers working abroad: The role of home country linkages. Research Policy, 41, 1655-1665.

BATHELT, H., MALMBERG, A. \& MASKELL, P. 2004. Clusters and knowledge: local buzz, global pipelines and the process of knowledge creation. Progress in Human Geography, 28, 31-56.

BELL, M. \& PAVITT, K. 1993. Technological Accumulation and Industrial Growth: Contrasts Between Developed and Developing Countries. Industrial and Corporate Change, 2, 157-210.

BELLAS, M. L. \& TOUTKOUSHIAN, R. K. 1999. Faculty time allocations and resarch productivity: Gender, race and family effects. The Review of Higher Education, 22, 367-390. 
BELLOTTI, E., KRONEGGER, L. \& GUADALUPI, L. 2016. The evolution of research collaboration within and across disciplines in Italian Academia. Scientometrics, 1-29.

BOSCHINI, A. \& SJÖGREN, A. 2007. Is Team Formation Gender Neutral? Evidence from Coauthorship Patterns. Journal of Labor Economics, 25, 325-365.

BOSCHMA, R. 2005. Proximity and Innovation: A Critical Assessment. Regional Studies, 39, 61-74.

BOZEMAN, B., GAUGHAN, M., YOUTIE, J., SLADE, C. \& RIMES, H. 2015. Research collaboration experiences, good and bad: Dispatches from the front lines.

BRASS, D. J. 1985. MEN'S AND WOMEN'S NETWORKS: A STUDY OF INTERACTION PATTERNS AND INFLUENCE IN AN ORGANIZATION. Academy of Management Journal, 28, 327-343.

BRESCHI, S. \& LISSONI, F. 2009. Mobility of skilled workers and co-invention networks: an anatomy of localized knowledge flows. Journal of Economic Geography, 9, 439-468.

BROUNS, M. 2000. The gendered nature of assessment procedures in scientific research funding: the dutch case. Higher Education in Europe, 25, 193-201.

BROWN, C. C. 1975. On the Use of Indicator Variables for Studying the Time-Dependence of Parameters in a Response-Time Model. Biometrics, 31, 863-872.

BRUNN, S. D. \& O'LEAR, S. R. 1999. Research and communication in the "invisible college" of the Human Dimensions of Global Change. Global Environmental Change, 9, 285-301.

BURLAMAQUI, L. 2020. Schumpeter, the entrepreneurial state and China. UCL Institute for Innovation and Public Purpose, Working Paper Series (IIPP WP 2020-15).

BUTLER-ADAM, J. 2015. Africa needs more women hooked on science [Online]. Available: https://mg.co.za/article/2015-06-04-africa-needs-to-get-more-women-hooked-on-science [Accessed 18 August 2018 2018].

CABRERO MENDOZA, E. 2014. Main achievements and challenges of Mexico's National Researcher's System 30 years after its creation. In: (CONACYT), C. N. D. C. Y. T. (ed.).

CALLARD, F. \& FITZGERALD, D. 2015. Meeting People Is Easy: The Pragmatics of Interdisciplinary Collaboration. In: CALLARD, F. \& FITZGERALD, D. (eds.) Rethinking Interdisciplinarity across the Social Sciences and Neurosciences. London: Palgrave Macmillan UK.

CANTNER, U. \& RAKE, B. 2014. International research networks in pharmaceuticals: Structure and dynamics. Research Policy, 43, 333-348.

CARAYOL, N. \& MATT, M. 2006. Individual and collective determinants of academic scientists' productivity. Information Economics and Policy, 18, 55-72.

CASSI, L. \& PLUNKET, A. 2015. Research Collaboration in Co-inventor Networks: Combining Closure, Bridging and Proximities. Regional Studies, 49, 936--954.

CASTILLO, R., GRAZZI, M. \& TACSIR, E. 2014. Women in Science and Technology. What does the literature say? Inter-American Development Bank, Institutions for Development, Technical Note No. IDB-TN-637.

CLARIVATE ANALYTICS 2018. Web of Science Database.

COE, D. T. \& HELPMAN, E. 1995. International R\&D spillovers. European Economic Review, 39, 859887.

COHEN, W. M. \& LEVINTHAL, D. A. 1990. Absorptive Capacity: A New Perspective on Learning and Innovation. Administrative Science Quarterly, 35, 128-152. 
COLE, J. R. \& ZUCKERMAN, H. 1984. The productivity puzzle: Persistence and change in patterns of publication of men and women scientists. In: MAEHR, M. L. \& STEINKAMP, M. W. (eds.) Advances in motivation and achievements. Greenwich, CT: JAJ Press.

COLEMAN, J. C. 1974. Power and the Structure of Society, New York, Norton.

COLEMAN, J. S. 1988. Social Capital in the Creation of Human Capital. American Journal of Sociology, 94, S95-S120.

CONACYT 2000. Treinta años del Programa de becas crédito del Conacyt: evolución, resultados e impacto. Ciencia y Desarrollo. Serie Documentos (4).

CONACYT 2015. Informe General del Estado de la Ciencia, la Tecnología y la Innovación. http://www.siicyt.gob.mx/index.php/transparencia/informes-conacyt/informe-general-del-estadode-la-ciencia-tecnologia-e-innovacion/informe-general-2014/1572-informe-general-2014/file: Consejo Nacional de Ciencia y Tecnología.

CREW, B. 2019. The top 10 countries in research collaboration [Online]. Available: https://www.natureindex.com/news-blog/data-visualization-top-ten-countries-researchcollaboration [Accessed].

DAHLANDER, L. \& MCFARLAND, D. A. 2013. Ties that last: Tie formation and persistence in research collaborations over time. Administrative Science Quarterly, 58, 69-110.

DEFAZIO, D., LOCKETT, A. \& WRIGHT, M. 2009. Funding incentives, collaborative dynamics and scientific productivity: Evidence from the EU framework program. Research Policy, 38, 293-305.

DHET 2010. Report on the Stakeholder Summit on Higher Education Trransformation. Called by the Minister of Higher Education and Training, Dr. Blade Nzimande. Department of Higher Education and Training, Republic of South Africa.

ELSEVIER 2017. Gender in the Global Research Landscape. https://www.elsevier.com/ data/assets/pdf file/0008/265661/ElsevierGenderReport final forweb.pdf.

EVANS, T. S., LAMBIOTTE, R. \& PANZARASA, P. 2011. Community structure and patterns of scientific collaboration in Business and Management. Scientometrics, 89, 381-396.

FAFCHAMPS, M., VAN DER LEIJ, M. J. \& GOYAL, S. 2010. Matching and Network Effects. Journal of the European Economic Association, 8, 203--231.

FAGERBERG, J. 1987. A technology gap approach to why growth rates differ. Research Policy, 16, 8799.

FAGERBERG, J., VERSPAGEN, B. \& SRHOLEC, M. 2010. Innovation and Economic Development.

FCCYT 2011. Ranking de Producción Científica Mexicana: Ranking 2011. http://www.foroconsultivo.org.mx/libros editados/ranking por institucion 2011.pdf: Foro Consultivo Científico y Tecnológico, AC.

FELD, S. L. 1980. The Focused Organization of Social Ties. American journal of sociology, 86, 1015.

FORTUNATO, S. 2010. Community detection in graphs. Complex Networks and Systems Lagrange Laboratory.

FOX, M. F. 1981. Sex, Salary, and Achievement: Reward-Dualism in Academia. Sociology of Education, $54,71$.

FOX, M. F. \& FAVER, C. A. 1985. Men, women, and publication productivity: Patterns among social work academics. Sociology Quarterly, 26, 537-549 p.p. . 
FU, X., PIETROBELLI, C. \& SOETE, L. 2011. The Role of Foreign Technology and Indigenous Innovation in the Emerging Economies: Technological Change and Catching-up. World Development, 39, 12041212.

GIBSON, J. \& MCKENZIE, D. 2014. Scientific mobility and knowledge networks in high emigration countries: Evidence from the Pacific. Research Policy, 43, 1486-1495.

GINTHER, D. K. \& KAHN, S. 2004. Women in Economics: Moving Up or Falling Off the Academic Career Ladder? Journal of Economic Perspectives, 18, 193-214.

GOLDIN, C. 2016. Human Capital. Handbook of Cliometrics. Heidelberg, Germany: Springer Verlag.

GONZÁLEZ RODRíGUEZ, J. D. J. 2015. Fuga de cerebros. Centro de Estudios Sociales y de Opinion Pública.

GONZALEZ-BRAMBILA, C. \& VELOSO, F. M. 2007. The determinants of research output and impact: A study of Mexican researchers. Research Policy, 36, 1035-1051.

GORDON, M. D. 1980. A critical reassessment of inferred relations between multiple authorship, scientific collaboration, the production of papers and their acceptance for publication. Scientometrics, 2, 193-201.

GRANOVETTER, M. 1985. Economic Action and Social Structure: The Problem of Embeddedness. American Journal of Sociology, 91, 481-510.

GRIFFITH, B. C. \& MULLINS, N. C. 1972. Coherent Social Groups in Scientific Change. Science, 177, 959.

GUTIÉRREZ, D. E. A. 2011. Eye on Mexico: Public support for science is high, but transition to a research-based economy remains a challenge. . Research and Public Opinion, 1.

HARRIS, T. M. 2007. Black feminist thought and cultural contracts: Understanding the intersection and negotiation of racial, gendered, and professional identities in the academy. New Directions for Teaching and Learning, 2007, 55-64.

HOEKMAN, J., FRENKEN, K. \& VAN OORT, F. 2009. The geography of collaborative knowledge production in Europe. The Annals of Regional Science, 43, 721-738.

HOISL, K. \& MARIANI, M. 2012. The gender gap in inventive jobs - could women (inventors) ask for more? New Frontiers in the Economics and Management of Innovation. Bocconi University.

HOISL, K. \& MARIANI, M. 2017. It's a Man's Job: Income and the Gender Gap in Industrial Research. Management Science [Online], 63.

HOLLAND, P. W. 1986. Statistics and Causal Inference. Journal of the American Statistical Association, $81,945-960$.

HSRC 2017. South African National Survey of Research and Experimental Development. Statistical Report 2015/16. Human Sciences Research Council.

HU, Z., CHEN, C. \& LIU, Z. 2014. How are collaboration and productivity correlated at various career stages of scientists? Scientometrics, 101, 1553-1564.

IBARRA, H. 1993. Personal Networks of Women and Minorities in Management: A Conceptual Framework. ACADEMY OF MANAGEMENT REVIEW, 18, 56.

IGLIČ, H., DOREIAN, P., KRONEGGER, L. \& FERLIGOJ, A. 2017. With whom do researchers collaborate and why? Scientometrics, 112, 153-174.

JACOB, J. \& SASSO, S. 2015. Foreign direct investment and technology spillovers in low and middleincome countries: A comparative cross-sectoral analysis. UNU-MERIT Working Papers 035. 
JACOBS, D. \& INGWERSEN, P. 2000. A Bibliometric Study of the Publication Patterns in the Sciences of South African Scholars 1981-96. Scientometrics : An International Journal for all Quantitative Aspects of the Science of Science, Communication in Science and Science Policy, 47, 75-93.

JONKERS, K. \& CRUZ-CASTRO, L. 2013. Research upon return: The effect of international mobility on scientific ties, production and impact. Research Policy, 42, 1366-1377.

JONKERS, K. \& TIJSSEN, R. 2008. Chinese researchers returning home: Impacts of international mobility on research collaboration and scientific productivity. Scientometrics, 77, 309-333.

JOUBERT, M. \& GUENTHER, L. 2017. In the footsteps of Einstein, Sagan and Barnard: Identifying South Africa's most visible scientists. South African Journal of Science, 113.

KATZ, J. S. \& MARTIN, B. R. 1997. What is research collaboration? Research Policy, 26, 1-18.

KEYNES, S. 2017. Inefficient equilibrium. Women and economics: the profession's problem with women could be a problem with economics itself. . The Economist.

KEYNES, S. 2019. Study thyself. How economics is trying to fix its gender problem. The Economist, January 10th 2019.

KOSSINETS, G. \& WATTS, D. J. 2009. Origins of Homophily in an Evolving Social Network. American Journal of Sociology, 115, 405-450.

KOZMA, C. \& CALERO-MEDINA, C. 2019. The role of South African researchers in intercontinental collaboration. Scientometrics, 121, 1293-1321.

KRACKHARDT, D. 1988. Predicting with networks: Nonparametric multiple regression analysis of dyadic data. Social Networks, 10, 359-381.

KRAPF, M. 2015. Age and complementarity in scientific collaboration. Empirical Economics, 49, 751781.

KRIGE, S. 2007. An historical review and analysis of the NRF rating system.

LAMBIOTTE, R. \& PANZARASA, P. 2009. Communities, knowledge creation and information diffusion. Journal of Informetrics, 3.

LANCICHINETTI, A., RADICCHI, F., RAMASCO, J. J. \& FORTUNATO, S. 2011. Finding Statistically Significant Communities in Networks. PLOS ONE, 6, e18961.

LAWSON, C., GEUNA, A. \& FINARDI, U. 2017. The Funding-Productivity Nexus in Science: Family and other sources of endogeneity.

LAZEGA, E. 2001. The collegial phenomenon : the social mechanisms of cooperation among peers in a corporate law partnership, Oxford ;, Oxford University Press.

LAZEGA, E., KRAATZ, M. S. \& SHAH, N. 2003. BOOK REVIEWS - The Collegial Phenomenon: The Social Mechanisms of Cooperation among Peers in a Corporate Law Partnership. Administrative science quarterly., 48, 525.

LEE, S. \& BOZEMAN, B. 2005. The Impact of Research Collaboration on Scientific Productivity. Social Studies of Science, 35, 673-702.

LEVI-MARTIN, J. \& YEUNG, K. T. 2006. Persistence of close personal ties over a 12-year period. Social Networks, 28, 331-362 p.p.

LEVIN, S. G. \& STEPHAN, P. E. 1998. Gender Differences in the Rewards to Publishing in Academe: Science in the 1970s. Sex Roles : A Journal of Research, 38, 1049-1064. 
LISSONI, F., MAIRESSE, J., MONTOBBIO, F. \& PEZZONI, M. 2011. Scientific productivity and academic promotion: a study on French and Italian physicists. Industrial and Corporate Change, 20, 253-294.

LLOYD-JONES, B. 2009. Implications of Race and Gender in Higher Education Administration: An African American Woman's Perspective. Advances in Developing Human Resources, 11, 606-618.

LONG, J. S., ALLISON, P. D. \& MCGINNIS, R. 1993. Rank Advancement in Academic Careers: Sex Differences and the Effects of Productivity. American Sociological Review, 58, 703.

LUCHILO, L. 2009. Los impactos del programa de becase del CONACYT mexicano: un análisis sobre la trayectoria ocupacional de los ex becarios 1997-2006. Revista Iberoamericana de ciencia tecnología y sociedad, 5, 175-205.

LUNA-MORALES, M. E. 2012. La colaboración científica y la internacionalización de la ciencia mexicana de 1980 a 2004. Investigación bibliotecológica, 26, 103-129.

LUNDVALL, B.-Å. 2010. National Systems of Innovation: Toward a Theory of Innovation and Interactive Learning, Anthem Press.

MADDALA, G. S. 1983. Limited-Dependent and Qualitative Variables in Econometrics, Cambridge, Cambridge University Press.

MAIRESSE, J. \& PEZZONI, M. 2015. Does Gender Affect Scientific Productivity? A Critical Review of the Empirical Evidence and a Panel Data Econometric Analysis for French Physicists. Revue économique, 66, 65-113.

MAIRESSE, J., RIVERA LEÓN, L., COWAN, R. \& PEZZONI, M. 2019. Determinants of the publication productivity gender gap in scientific research: micro-level assessment, macro-level implications and policy scenarios. Comparing the evidence for Mexico, South Africa and France. . 11th MEIDE Conference: Model-based Evidence on Innovation and Development. Abidjan - Cote d'Ivoire.

MALI, F., KRONEGgER, L., DOREIAN, P. \& FERLIGOJ, A. 2012. Dynamic Scientific Co-Authorship Networks. In: SCHARNHORST, A., BÖRNER, K. \& VAN DEN BESSELAAR, P. (eds.) Models of Science Dynamics: Encounters Between Complexity Theory and Information Sciences. Berlin, Heidelberg: Springer Berlin Heidelberg.

MARIN, A. \& BELL, M. 2006. Technology spillovers from Foreign Direct Investment (FDI): the active role of MNC subsidiaries in Argentina in the 1990s. The Journal of Development Studies, 42, 678-697.

MARMOLEJO-LEYVA, R., PEREZ-ANGON, M. A. \& RUSSELL, J. M. 2015. Mobility and International Collaboration: Case of the Mexican Scientific Diaspora. PLOS ONE, 10, e0126720.

MASKELL, P., BATHELT, H. \& MALMBERG, A. 2006. Building global knowledge pipelines: The role of temporary clusters. European Planning Studies, 14, 997-1013.

MAÜRTIN-CAIRNCROSS, A. 2003. Creating 'space' for publication: challenges faced by women academic staff at historically black South African universities. . Doctor of Philosophy, University of the Western Cape.

MAZZUCATO, M. 2018. Mission-oriented innovation policies: challenges and opportunities. Industrial and Corporate Change, 27, 803-815.

MCNERNEY, J., FATH, B. D. \& SILVERBERG, G. 2013. Network structure of inter-industry flows. Physica A: Statistical Mechanics and its Applications, 392, 6427-6441.

MCPHERSON, J. M. \& SMITH-LOVIN, L. 1987. Homophily in Voluntary Organizations: Status Distance and the Composition of Face-to-Face Groups. American Sociological Review, 52, 370-379. 
MCPHERSON, M., SMITH-LOVIN, L. \& COOK, J. M. 2001. Birds of a Feather: Homophily in Social Networks. Annual Review of Sociology, 27, 415-444.

MEHRA, A., KILDUFF, M. \& BRASS, D. J. 1998. AT THE MARGINS: A DISTINCTIVENESS APPROACH TO THE SOCIAL IDENTITY AND SOCIAL NETWORKS OF UNDERREPRESENTED GROUPS. Academy of Management Journal, 41, 441-452.

MEYER, J.-B. 2001. Network Approach versus Brain Drain: Lessons from the Diaspora. International Migration, 39, 91-110.

MEYER, J.-B., KAPLAN, D. \& CHARUM, J. 2001. Scientific Nomadism and the New Geopolitics of Knowledge. International Social Science Journal, 53, 309-321.

MINDELI, L. E. \& MARKUSOVA, V. A. 2015. Bibliometric studies of scientific collaboration: International trends. Automatic Documentation and Mathematical Linguistics, 49, 59-64.

MOEN, J. 2005. Is Mobility of Technical Personnel a Source of R\&D Spillovers? Journal of Labor Economics, 23, 81-114.

MULKAY, M. J., GILBERT, G. N. \& WOOLGAR, S. 1975. Problem Areas and Research Networks in Science. Sociology, 9, 187-203.

MÜLLER, M., COWAN, R. \& BARNARD, H. 2018. On the value of foreign PhDs in the developing world: Training versus selection effects in the case of South Africa. Research Policy, 47, 886-900.

MURAKAMI, Y. 2014. Influences of return migration on international collaborative research networks: cases of Japanese scientists returning from the US. The Journal of Technology Transfer, 39, 616-634.

NATIONAL SCIENCE FOUNDATION 2014. Science and Engineering Indicators 2014. Arlingtom VA: National Science Board (NSB 14-01).

NCHE 1997. Education White Paper 3 - A programme for Higher Education Transformation. In: EDUCATION, N. C. O. H. (ed.). South Africa.

NELSON, R. R. 1993. National Innovation Systems: A Comparative Analysis, Available at SSRN: https://ssrn.com/abstract=1496195.

NRF 2005a. Definition of NRF Rating Categories. National Research Foundation, Research and Innovation Support and Advancement (RISA).

NRF 2005b. Facts and Figures 2005: The NRF Evaluating and Rating System. In: FOUNDATION, N. R. (ed.). Pretoria.

NRF 2014. Definition of NRF Rating Categories. National Research Foundation, Research and Innovation Support and Advancement (RISA).

OECD 2009. OECD Reviews of Innovation Policy: Mexico. Paris.

OECD 2014a. Education Policy Outlook, OECD Publishing.

OECD 2014b. International Migration Outlook 2014. OECD Publishing, Paris.

OECD 2014c. OECD Science, Technology and Industry Outlook 2014. OECD Publishing.

OECD 2015. OECD Economic Surveys: Mexico.

OECD 2017. OECD Economic Surveys: Mexico 2017. In: PUBLISHING, O. (ed.). http://www.oecd.org/eco/surveys/economic-survey-mexico.htm.

OEI. 2013. 80 por ciento de investigadores no regresan a México [Online]. Available: https://www.oei.es/historico/divulgacioncientifica/?80-por-ciento-de-investigadores-no [Accessed]. 
PADILLA-GONZALEZ, L., METCALFE, A. S., GALAZ-FONTES, J. F., FISHER, D. \& SNEE, I. 2011. Gender Gaps in North American Research Productivity: Examining Faculty Publication Rates in Mexico, Canada, and the U.S. Compare: A Journal of Comparative and International Education, 41, 649-668.

PAISLEY, W. Information needs and uses. 1968.

PATIÑO BARBA, L. \& TAGÜEÑA PARGA, J. 2014. STEM: Gender perspective in Mexico. Presentation to the Science Centre World Summit 2014.

PEZZONI, M., STERZI, V. \& LISSONI, F. 2012. Career progress in centralized academic systems: Social capital and institutions in France and Italy. Research Policy, 41, 704-719.

PIENAAR, M., BLANKLEY, W., SCHIRGE, G. U. \& VON GRUENEWALDT, G. 2000. The South African system of evaluating and rating individual researchers: its merits, shortcomings, impact and future. Research Evaluation, 9, 27-36.

PIETROBELLI, C. \& RABELLOTTI, R. 2011. Global Value Chains Meet Innovation Systems: Are There Learning Opportunities for Developing Countries? World Development, 39, 1261-1269.

POURIS, A. 2007. The National Research Foundation's rating system: why scientists let their ratings lapse. South African Journal of Science, 103, 439-441.

POURIS, A. \& HO, Y.-S. 2014. Research emphasis and collaboration in Africa. Scientometrics, 98, 21692184.

PRICE, D. J. 1963. DE S.(1986). Little science, big science-and beyond. New York: Columbia University Press.

PROZESKY, H. 2006a. Gender differences in the journal publication productivity of South African academic authors. South African Review of Sociology, 37, 87-112.

PROZESKY, H. 2006b. Gender differences in the publication productivity of South African scientists. Doctor of Philosphy, Stellenbosch University.

PROZESKY, H. 2008a. A Career-History Analysis of Gender Differences in Publication Productivity among South African Academics. Science \& Technology Studies, 28.

PROZESKY, H. 2008b. A career-history analysis of gender differences in publication productivity among South African academics. Science \& Technology Studies [Online], 21.

PROZESKY, H. \& BOSHOFF, N. 2012. Bibliometrics as a tool for measuring gender-specific research performance: an example from South African invasion ecology. Scientometrics, 90, 383-406.

RABE, M. \& RUGUNANAN, P. 2012. Exploring Gender and Race amongst Female Sociologists Exiting Academia in South Africa. Gender and Education, 24, 553-566.

RAMOHAI, J. 2014. 'Marginalised Access' in South African Higher Education: Black Women Academics Speak! Mediterranean Journal of Social Sciences; Vol 5, No 20 (2014): September 2014.

REAGANS, R. 2010. Close Encounters: Analyzing How Social Similarity and Propinquity Contribute to Strong Network Connections. Organization Science, 22, 835-849.

REGETS, M. C. 2007. Research issues in the international migration of highly skilled workers: a perspective with data from the United States. National Science Foundation.

RICKER, M., HERNÁNDEZ, H. M. \& DALY, D. C. 2010. Contrasting Views on Mexico's National System of Researchers. Revista Interciencia, 35.

RICYT 2014. Indicadores de Insumo 2014. Buenos Aires, Argentina: Red Iberoamericana de Indicadores de Ciencia y Tecnología. 
RIVERA LEÓN, L., COWAN, R. \& MÜLLER, M. Formation and persistence of research communities in Middle Income Countries: The case of South Africa. 2015. https://www.semanticscholar.org/paper/Formation-and-persistence-of-research-communitiesLe\%C3\%B3n-Cowan/ccf42fb054bcdbee5bdad9aeeae626977a390faf - related-papers.

RIVERA LEÓN, L., MAIRESSE, J. \& COWAN, R. 2016. An econometric investigation of the productivity gender gap in Mexican research, and a simulation study of the effects on scientific performance of policy scenarios to promote gender equality. UNU-MERIT Working Paper Series, 2016-072.

RIVERA LEÓN, L., MAIRESSE, J. \& COWAN, R. 2017. Gender Gaps and Scientific Productivity in MiddleIncome Countries. Inter-American Development Bank Working Paper Series, IDB-WP-800.

ROMER, P. M. 1986. Increasing Returns and Long-Run Growth. Journal of Political Economy, 94, 10021037.

ROMER, P. M. 1987. Growth Based on Increasing Returns Due to Specialization. American Economic Review, 77, 56.

ROMER, P. M. 1994. The Origins of Endogenous Growth. Journal of Economic Perspectives, 8, 3-22.

ROODMAN, D. 2011. Fitting Fully Observed Recursive Mixed-process Models with $\mathrm{cmp}$. The Stata Journal, 11, 159-206.

RSA 1998. National Research Foundation Act, Act 23 of 1998. In: AFRICA, R. O. S. (ed.) 397. Cape Town: Government Gazette.

SARSONS, H. 2017. Gender Differences in Recognition for Group Work. Working Paper, Harvard University.

SASSO, S. \& RIVERA LEÓN, L. 2018. Scientific mobility as a bridge between two worlds. Analyzing the impact of foreign-educated researchers in academic upgrading in Mexico. . Talent on the Move. Essays on human capital, graduate mobility and economic development. . Maastricht: Universitaire Pers Maastricht.

SAX, L. J., HAGEDORN, L. S., ARREDONDO, M. \& III, F. A. D. 2002. Faculty Research Productivity: exploring the Role of Gender and Family-Related Factors. Research in Higher Education, 43, 423-446.

SCELLATO, G., FRANZONI, C. \& STEPHAN, P. 2015. Migrant scientists and international networks. Research Policy, 44, 108-120.

SEABRIGHT, M., LEVINTHAL, D. \& FICHMAN, M. 1992. Role of individual attachments in the dissolution of inter-organisational relationships. Academy of Management Journal, 35, 122-160 p.p. .

SIR 2013. Iberoamerican Ranking SIR 2013. Scimargo Institutions Ranking. Scimargo Research Group. SMITH, A. 1776. An Inquiry into the Nature and Causes of the Wealth of Nations, London, Methuen \& Co.

SNIJDERS, T. A. B. 2001. The statistical evaluation of social network dynamics. Sociological Methodology, 31, 361-395 p.p. .

SOLOW, R. M. 1957. Technical Change and the Aggregate Production Function. The Review of Economics and Statistics, 39, 312-320.

SONNERT, G. 1999. Women in Science and Engineering: Advances, Challenges, and Solutions. Annals of the New York Academy of Sciences, 869, 34-57.

SONNERT, G. \& HOLTON, G. J. 1995. Who succeeds in science? : the gender dimension. New Brunswick, N.J.: Rutgers University Press. 
SOORYAMOORTHY, R. 2014. Publication productivity and collaboration of researchers in South Africa: new empirical evidence. Scientometrics, 98, 531-545.

STEPHAN, P. E. 1996. The economics of science. Journal of Economic Literature, 34, 1199.

SUBOTZKY, G. 2001. Addressing Equity and Excellence in Relation to Employment: What Prospects for Transformative Change in South Africa? Equity \& Excellence in Education, 34, 56-69.

THÉVENON, O., ALI, N., ADEMA, W. \& SALVI DEL PERO, A. 2012. Effects of Reducing Gender Gaps in Education and Labour Force Participation on Economic Growth in the OECD. OECD Social, Employment and Migration Working Papers, No. 138. OECD Publshing.

THORN, K. \& HOLM-NIELSEN, L. B. 2008. International Mobility of Researchers and Scientists: Policy Options for turning a drain into a gain. In: SOLIMANO, A. (ed.) The International Mobility of Talent: Types, Causes, and Development Impact.

TIMMERS, T. M., WILLEMSEN, T. M. \& TIJDENS, K. G. 2010. Gender diversity policies in unversities: A multi-perspective framework of policy measures. Higher Education, 59, 719-735.

TRIPPL, M. \& MAIER, G. 2011. Knowledge Spillover Agents and Regional Development. In: NIJKAMP, P. \& SIEDSCHLAG, I. (eds.) Innovation, Growth and Competitiveness: Dynamic Regions in the Knowledge-Based World Economy. Berlin, Heidelberg: Springer Berlin Heidelberg.

UAM-BUAP 2009. Encuesta. In: CAMPOS, G. R. (ed.) Informe final del proyecto "El mercado de trabajo de los investigadores en el centro de México". México: UAM-BUAP-CONACYT.

UCAK, A. 2015. Adam Smith: The Inspirer of Modern Growth Theories. Procedia-Social and Behavioral Sciences, 195, 663-672.

UNESCO 2015. UNESCO Science Report: towards 2030. United Nations Educational, Scientific and Cultural Organization.

VAN DER LEIJ, M. 2006. The Economics of Networks: theory and empirics. Thela Thesis, Amsterdam.

VOELKER, T. A., MCDOWELL, W. C. \& HARRIS, M. L. 2013. Collaborative Preference: The Role of Homophily, Multiplexity, and Advantageous Network Position across Small and Medium-Sized Organizations. Administrative Issues Journal: Education, Practice, and Research, 3.

WAGNER, C. S. \& LEYDESDORFF, L. 2005. Network structure, self-organization, and the growth of international collaboration in science. Research Policy, 34, 1608-1618.

WAGNER, C. S., WHETSELL, T. \& MUKHERJEE, S. 2019. Novel findings rare from international collaborations [Online]. Available: https://www.natureindex.com/news-blog/novel-findings-rarefrom-international-collaborations [Accessed 18 August 2020 2020].

WALKER, M. 1998. Academic Identities: women on a South African landscape. British Journal of Sociology of Education, 19, 335-354.

WARD, M. D. \& AHLQUIST, J. S. 2018. Maximum Likelihood for Social Science: Strategies for Analysis, Cambridge, Cambridge University Press.

WELLMAN, B., WONG, R. Y., TINDALL, D. \& NAZER, N. 1997. A decade of network change: turnover, persistence and stability in personal communities. Social Networks, 19, 27-50 p.p. .

WILLIAMS, T. \& ALUJA, M. 2010. Contrasting Views on Mexico's National System of Researchers. Revista Interciencia, 35.

WINGFIELD, B. \& VAUGHAN, K. 2017. Money woes force South Africa to revisit how it rewards researchers. The Conversation. 
WOOLDRIDGE, J. M. 2002. Econometric analysis of cross section and panel data, Cambridge, Mass, MIT Press.

WUCHTY, S., JONES, B. F. \& UZZI, B. 2007. The Increasing Dominance of Teams in Production of Knowledge. Science, 316, 1036-1039.

YNALVEZ, M. A. \& SHRUM, W. M. 2009. International Graduate Science Training and Scientific Collaboration. International Sociology, 24, 870-901.

YOUTIE, J. \& BOZEMAN, B. 2014. Social dynamics of research collaboration: norms, practices, and ethical issues in determining co-authorship rights. Scientometrics, 101, 953-962.

ZACHARY, W. W. 1977. An Information Flow Model for Conflict and Fission in Small Groups. Journal of Anthropological Research, 33, 452-473.

ZUCKER, L. G., DARBY, M. R. \& ARMSTRONG, J. 1998. GEOGRAPHICALLY LOCALIZED KNOWLEDGE: SPILLOVERS OR MARKETS? Economic Inquiry, 36, 65--86.

ZUCKERMAN, H. \& COLE, J. R. 1992. The outer circle : women in the scientific community, New Haven, Yale University Press. 



\section{Appendix to Chapter 3}

Table A3. 1 SNI's Managing Authorities, Composition, and Main Responsibilities

\begin{tabular}{|c|c|c|}
\hline Authority & Composition & Main responsibilities \\
\hline $\begin{array}{l}\text { Approval Council } \\
\text { (Consejo de } \\
\text { Aprobación) }\end{array}$ & $\begin{array}{l}\text { CONACYT's Director-General } \\
\text { Director of Scientific and Academic } \\
\text { Development, CONACYT } \\
\text { Director of Technology Development and } \\
\text { Innovation in Businesses, CONACYT } \\
\text { Director of Groups and Research } \\
\text { Centers, CONACYT } \\
\text { Director of Training and development of } \\
\text { researchers, CONACYT } \\
\text { Director of the SNI } \\
\text { Undersecretary of Higher Education, } \\
\text { Ministry of Education } \\
\text { Head of Planning and Evaluation of } \\
\text { Education Policies, Ministry of Education } \\
\text { General Coordinator of the Advisory } \\
\text { Forum for Science and Technology }\end{array}$ & $\begin{array}{l}\text { Designate (yearly) the members of the } \\
\text { Dictating Commissions, and the Honor } \\
\text { Meeting Group, based on the proposals } \\
\text { presented by the Executive Secretary } \\
\text { Approve the yearly 'Open Calls' } \\
\text { Approve the evaluation criteria by scientific } \\
\text { discipline presented by the Dictating } \\
\text { Commissions } \\
\text { Decide on the research distinctions based } \\
\text { on the proposals presented by the Dictating } \\
\text { Commissions and the Reviser Commissions. }\end{array}$ \\
\hline $\begin{array}{l}\text { Consulting } \\
\text { Committee } \\
\text { (Comité Consultivo) }\end{array}$ & $\begin{array}{l}\text { Director of the SNI } \\
\text { Presidents of the different Dictating } \\
\text { Committees } \\
\text { President of the Committee }\end{array}$ & $\begin{array}{l}\text { Propose the formulation and application of } \\
\text { SNI policies in support of the development } \\
\text { of science, technology, and innovation } \\
\text { Provide expert inputs about the regulations, } \\
\text { organizations, and functioning of the SNI }\end{array}$ \\
\hline $\begin{array}{l}\text { Scientific } \\
\text { Committees } \\
\text { (Comisiones } \\
\text { Dictaminadoras) }\end{array}$ & $\begin{array}{l}\text { There is a Scientific Committee for each } \\
\text { of the SNI's scientific areas ( } 7 \text { in total) }\end{array}$ & $\begin{array}{l}\text { Evaluate the academic quality, } \\
\text { transcendence, and impact of scientific and } \\
\text { technology research outputs }\end{array}$ \\
\hline $\begin{array}{l}\text { Appeals Committee } \\
\text { (Comisiones } \\
\text { Revisoras) }\end{array}$ & $\begin{array}{l}\text { There is an Appeals Committee for each } \\
\text { of the scientific disciplines represented } \\
\text { by the Dictating Committees. }\end{array}$ & $\begin{array}{l}\text { Resolve and reconsider claims made by } \\
\text { researchers relative to their entry and re- } \\
\text { entry to the SNI }\end{array}$ \\
\hline $\begin{array}{l}\text { Honor Meeting } \\
\text { Group } \\
\text { (Junta de Honor) }\end{array}$ & $\begin{array}{l}\text { Five members of the SNI (Level III) } \\
\text { Director of the SNI }\end{array}$ & $\begin{array}{l}\text { Analyze special cases of professional ethics } \\
\text { faults committed by members of the SNI }\end{array}$ \\
\hline Executive Secretary & $\begin{array}{l}\text { Director of Scientific and Academic } \\
\text { Development, CONACYT }\end{array}$ & $\begin{array}{l}\text { Formulate the proposals of the Dictating } \\
\text { Commissions after consulting with the } \\
\text { Advisory Forum for Science and Technology } \\
\text { Present for consideration and approval the } \\
\text { evaluation criterion and processes of the } \\
\text { SNI } \\
\text { Designate the Presidents of the Dictating } \\
\text { Commissions and the members of the } \\
\text { Reviser Commissions } \\
\text { Subscribe the distinctions and agreements } \\
\text { of approved researchers as members of the } \\
\text { SNI }\end{array}$ \\
\hline Director of the SNI & $\begin{array}{l}\text { Director of the SNI, elected by } \\
\text { Government Board of the CONACYT, } \\
\text { following the proposal of the Director- } \\
\text { General }\end{array}$ & $\begin{array}{l}\text { Elaborate (in coordination with the } \\
\text { Consulting Committee) projects of norms } \\
\text { and regulations for the functioning of the } \\
\text { SNI } \\
\text { Formulate the yearly Open Calls }\end{array}$ \\
\hline
\end{tabular}




\begin{tabular}{|l|l|l|}
\hline Authority & Composition & Main responsibilities \\
\hline & & $\begin{array}{l}\text { Receive the applications of researchers for } \\
\text { membership to the SNI } \\
\text { Supervise the evaluation mechanisms of the } \\
\text { SNI }\end{array}$ \\
\hline
\end{tabular}

Table A3. 2 Definitions of SNI Levels

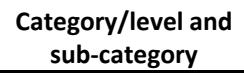

\begin{tabular}{|c|c|}
\hline sub-category & Miain requirements for granting \\
\hline \multirow[b]{2}{*}{ Candidate } & PhD level \\
\hline & Had passed less than 15 years after obtaining a Bachelor's degree \\
\hline \multirow{8}{*}{$\begin{array}{l}\text { National } \\
\text { Researcher }\end{array}$} & PhD level \\
\hline & Had produced original and high-quality scientific and technology research \\
\hline & Had participated in activities of dissemination of science and technology \\
\hline & All requirements of Level 1 \\
\hline & $\begin{array}{l}\text { Had undertaken, individually or in a group, original research where a new research } \\
\text { line or agenda is achieved }\end{array}$ \\
\hline & Had supervised graduate students and trained highly qualified human resources \\
\hline & All requirements for Level 2 \\
\hline & $\begin{array}{l}\text { Had developed research that represents a transcendental scientific contribution for } \\
\text { the generation and application of knowledge }\end{array}$ \\
\hline \multirow[t]{2}{*}{3} & Had become a leader in the scientific and technology community in Mexico \\
\hline & $\begin{array}{l}\text { Been recognized at national and international level for their scientific and technology } \\
\text { activity, and had realized a remarkable achievement in the training of highly qualified } \\
\text { human resources }\end{array}$ \\
\hline \multirow{4}{*}{$\begin{array}{l}\text { Recognized National } \\
\text { Researcher (Emeritus) }\end{array}$} & Being at least 65 years old at the moment of application \\
\hline & $\begin{array}{l}\text { Had received the distinction of National Researcher Level III for at least } 15 \\
\text { consecutive years }\end{array}$ \\
\hline & $\begin{array}{l}\text { Demonstrate an exceptional career in Mexico through a fundamental contribution to } \\
\text { the generation of scientific knowledge, and the training of new generations of } \\
\text { researchers, through leadership and international recognition. }\end{array}$ \\
\hline & Been recommended by at least 9 members of the relevant Dictating Commission \\
\hline
\end{tabular}

Table A3. 3 List of Mexican Public Universities Covered in the Analysis

\begin{tabular}{ll} 
No. & \multicolumn{1}{c}{ Name } \\
\hline 1 & Benemerita Universidad Autonoma de Puebla \\
2 & Instituto Politecnico Nacional \\
3 & Instituto Tecnologico de Sonora \\
4 & Universidad Autonoma Agraria Antonio Narro \\
5 & Universidad Autonoma Benito Juarez de Oaxaca \\
6 & Universidad Autonoma Chapingo \\
7 & Universidad Autonoma de Aguascalientes \\
8 & Universidad Autonoma de Baja California \\
9 & Universidad Autonoma de Baja California Sur \\
10 & Universidad Autonoma de Campeche
\end{tabular}


No.

Name

\begin{tabular}{|c|c|}
\hline 11 & Universidad Autonoma de Chiapas \\
\hline 12 & Universidad Autonoma de Chihuahua \\
\hline 13 & Universidad Autonoma de Ciudad Juarez \\
\hline 14 & Universidad Autonoma de Coahuila \\
\hline 15 & Universidad Autonoma de Guadalajara \\
\hline 16 & Universidad Autonoma de Guerrero \\
\hline 17 & Universidad Autonoma de La Ciudad de Mexico \\
\hline 18 & Universidad Autonoma de Nayarit \\
\hline 19 & Universidad Autonoma de Nuevo Leon \\
\hline 20 & Universidad Autonoma de Queretaro \\
\hline 21 & Universidad Autonoma de San Luis Potosi \\
\hline 22 & Universidad Autonoma de Sinaloa \\
\hline 23 & Universidad Autonoma de Tamaulipas \\
\hline 24 & Universidad Autonoma de Tlaxcala \\
\hline 25 & Universidad Autonoma de Yucatan \\
\hline 26 & Universidad Autonoma de Zacatecas \\
\hline 27 & Universidad Autonoma del Carmen \\
\hline 28 & Universidad Autonoma del Estado de Hidalgo \\
\hline 29 & Universidad Autonoma del Estado de Mexico \\
\hline 30 & Universidad Autonoma del Estado de Morelos \\
\hline 31 & Universidad Autonoma Metropolitana \\
\hline 32 & Universidad de Colima \\
\hline 33 & Universidad de Guadalajara \\
\hline 34 & Universidad de Guanajuato \\
\hline 35 & Universidad de Quintana Roo \\
\hline 36 & Universidad de Sonora \\
\hline 37 & Universidad Del Ejercito Y Fuerza Aerea \\
\hline 38 & Universidad Juarez Autonoma de Tabasco \\
\hline 39 & Universidad Juarez del Estado de Durango \\
\hline 40 & Universidad Michoacana de San Nicolas de Hidalgo \\
\hline 41 & Universidad Nacional Autonoma de Mexico \\
\hline 42 & Universidad Veracruzana \\
\hline
\end{tabular}

\section{Table A3. 4 List of Mexican Public Research Centers Covered in the Analysis}

No. Name

1 Centro de Innovación Aplicada en Tecnologías Competitivas, A.C.

2 Centro de Investigación Científica de Yucatán, A.C.

3 Centro de Investigación Científica y de Educación Superior de Ensenada

4 Centro de Investigación en Alimentación y Desarrollo, A.C. 


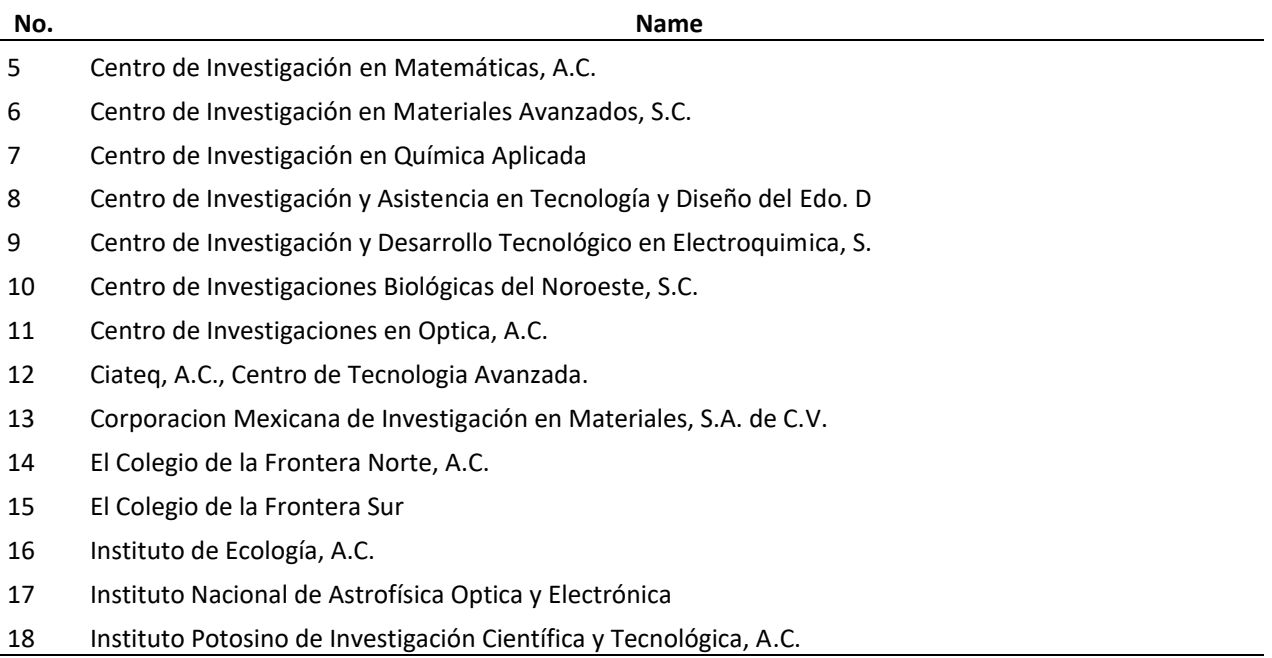

\section{A3.1. Building the Study Sample}

The study sample was limited to researchers with at least one WoS publication in the five years before the ranking acquired in 2013. This resulted in matching 5,896 researchers or 29.9 percent of all researchers affiliated with the SNI in 2013. We also only focused on researchers in the hard sciences, as our sample replicates the population of SNI researchers in 2013. Moreover, the hard sciences correspond to 97 percent of the matches obtained with WoS publication data, or 5,706 SNI researchers. ${ }^{71}$ We also decided to exclude those disciplines in which no female researchers were matched in our sample. This resulted in the exclusion of Logic and Electrical Engineering. Thus, the disciplines covered in our final sample are Mathematics, Astronomy and Astrophysics, Medicine and Human Pathology, Technology Sciences, Physics, Earth Sciences, Agronomy, Health Sciences, and Chemistry.

Finally, we decided to focus our analysis on researchers affiliated with a public university (at federal or state level) or a public research center, including the Ministry of Education research centers and the CONACYT research centers. We obtained matches for only 10 private universities, and the

\footnotetext{
${ }^{71}$ Details on the number of researchers in the SNI population in 2013 and the WoS matches obtained are presented in table 13 below in this Appendix. The number of matches in social science and humanities disciplines obtained correspond only to 3 percent of the population, compared to 41 percent in the hard sciences.
} 
observations represented only 1.4 percent of all ${ }^{72}$. These relatively low numbers led us to exclude all researchers that reported affiliation to a private university, private research center, private companies, and other organizations, including hospitals and government ministries. We also excluded from our sample all those SNI researchers affiliated with a foreign institution in 2013, as they were likely to be exposed to different institutional arrangements and to have work environments very different from those with a Mexican affiliation. Finally, we excluded those researchers on whom data on affiliation or personal characteristics were missing, as well as those whose SNI rankings had fallen in the period of analysis or who received a rank in less than three years from the first observed publication. Table 13 presents the SNI population in 2013 by discipline, as well as the study sample.

To ensure completeness concerning Mexican researchers' scientific production, and as a way of running a robustness check, we also looked at publications in the WoS SciELO Mexico. The WoS SciELO Citation Index includes critically important regional content with international impact, where only high-quality regional journals are included. Most of the Mexican publications in SciELO are in Spanish. SciELO Mexico has publications dating back to 1997 forward, mostly in the social sciences and the humanities. In the hard sciences, we identified 524 publications for the period 1997-2014. About 79 percent of the articles obtained are in Spanish and a large majority for 2010-2014. ${ }^{73}$ The matching of these records with SNI affiliations in 2013 resulted in a match of 99 publications by SNI researchers in our final sample. About 81.5 percent of the SciELO publications matched are by male authors, compared to 18.5 percent by female authors. We refer to SciELO data in some of the descriptive tables presented in the paper. However, since the number of SciELO publications is low, representing only 0.22 percent of WoS core publications, our main econometric analysis is based only on WoS core publications.

Table A3. 5 Study Sample of SNI Researchers

\footnotetext{
72 The classifications of private and public universities and public research centers were obtained from the Comparative Study of Mexican Universities (available at http://www.execum.unam.mx/).

${ }^{73}$ The hits in the social sciences, arts, and humanities (SSH) are much more numerous: 1334 in total, with 80 percent of the social sciences records, and 94 percent of records in Spanish. Forty-six percent of the affiliates are Mexican authors, and most of the co-authors are from other Latin countries, the largest being Argentina.
} 


\begin{tabular}{|c|c|c|c|c|c|c|c|}
\hline Discipline & 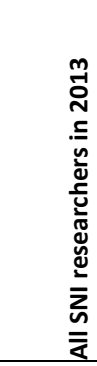 & 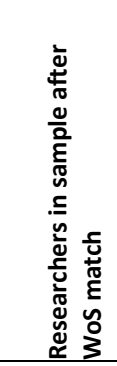 & 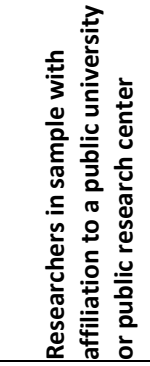 & 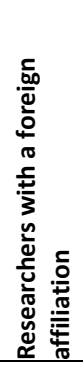 & 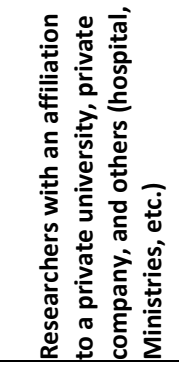 & 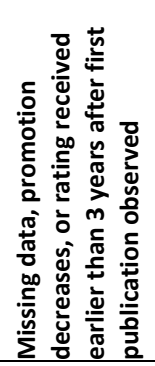 & 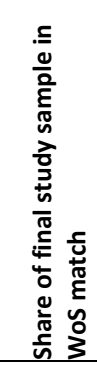 \\
\hline Life sciences & 3190 & 1317 & 690 & 34 & 323 & 270 & $52.4 \%$ \\
\hline Technological sciences & 2850 & 1228 & 440 & 7 & 362 & 419 & $35.8 \%$ \\
\hline Physics & 1685 & 601 & 326 & 10 & 119 & 146 & $54.2 \%$ \\
\hline Agronomy & 1601 & 822 & 300 & 3 & 254 & 265 & $36.5 \%$ \\
\hline Medicine and human pathology & 1477 & 687 & 206 & 7 & 387 & 87 & $30.0 \%$ \\
\hline Chemistry & 1085 & 464 & 233 & 11 & 99 & 121 & $50.2 \%$ \\
\hline Earth sciences & 842 & 313 & 183 & 2 & 41 & 87 & $58.5 \%$ \\
\hline Mathematics & 696 & 130 & 47 & 1 & 26 & 56 & $36.2 \%$ \\
\hline Astronomy and astrophysics & 203 & 45 & 25 & 1 & 4 & 15 & $55.6 \%$ \\
\hline Health sciences & 202 & 98 & 31 & 1 & 59 & 7 & $31.6 \%$ \\
\hline Total & 13831 & 5705 & 2481 & 77 & 1674 & 1473 & $43.5 \%$ \\
\hline
\end{tabular}

Table A3. 6 Population of SNI Researchers in $\mathbf{2 0 1 3}$ by Discipline and Corresponding Sample Obtained through Publication Matching with Web of Science (WoS) Data

\begin{tabular}{|c|c|c|c|c|c|}
\hline Discipline & $\begin{array}{c}\text { All SNI } \\
\text { researchers in } \\
2013 \\
\end{array}$ & $\begin{array}{c}\text { Researchers } \\
\text { in sample }\end{array}$ & $\begin{array}{l}\text { Share of } \\
\text { all SNI }\end{array}$ & $\begin{array}{c}\text { Share of } \\
\text { sample }\end{array}$ & $\begin{array}{c}\text { Sample/SNI } \\
\text { population }\end{array}$ \\
\hline Life sciences & 3190 & 1317 & $16 \%$ & $22 \%$ & $41 \%$ \\
\hline Technological sciences & 2850 & 1228 & $14 \%$ & $21 \%$ & $43 \%$ \\
\hline Physics & 1685 & 601 & $9 \%$ & $10 \%$ & $36 \%$ \\
\hline Agronomy & 1601 & 822 & $8 \%$ & $14 \%$ & $51 \%$ \\
\hline Medicine & 1477 & 687 & $7 \%$ & $12 \%$ & $47 \%$ \\
\hline Chemistry & 1085 & 464 & $6 \%$ & $8 \%$ & $43 \%$ \\
\hline Economics & 888 & 44 & $5 \%$ & $1 \%$ & $5 \%$ \\
\hline Sociology & 856 & 24 & $4 \%$ & $0 \%$ & $3 \%$ \\
\hline Earth sciences & 842 & 313 & $4 \%$ & $5 \%$ & $37 \%$ \\
\hline History & 730 & 10 & $4 \%$ & $0 \%$ & $1 \%$ \\
\hline Mathematics & 696 & 130 & $4 \%$ & $2 \%$ & $19 \%$ \\
\hline Arts and literature & 506 & 4 & $3 \%$ & $0 \%$ & $1 \%$ \\
\hline Anthropology & 498 & 9 & $3 \%$ & $0 \%$ & $2 \%$ \\
\hline Political science & 487 & 4 & $2 \%$ & $0 \%$ & $1 \%$ \\
\hline Law & 436 & 3 & $2 \%$ & $0 \%$ & $1 \%$ \\
\hline Psychology & 413 & 53 & $2 \%$ & $1 \%$ & $13 \%$ \\
\hline
\end{tabular}




\begin{tabular}{lrrrrr} 
& $\begin{array}{c}\text { All SNI } \\
\text { researchers in } \\
\text { Discipline }\end{array}$ & $\begin{array}{c}\text { Researchers } \\
\text { in sample }\end{array}$ & $\begin{array}{c}\text { Share of } \\
\text { all SNI }\end{array}$ & $\begin{array}{c}\text { Share of } \\
\text { sample }\end{array}$ & $\begin{array}{c}\text { Sample/SNI } \\
\text { population }\end{array}$ \\
\hline Pedagogy & 315 & 6 & $2 \%$ & $0 \%$ & $2 \%$ \\
Philosophy & 225 & 2 & $1 \%$ & $0 \%$ & $1 \%$ \\
Astronomy & 203 & 45 & $1 \%$ & $1 \%$ & $22 \%$ \\
Health sciences & 202 & 98 & $1 \%$ & $2 \%$ & $49 \%$ \\
Geography & 182 & 13 & $1 \%$ & $0 \%$ & $7 \%$ \\
Linguistics & 171 & 5 & $1 \%$ & $0 \%$ & $3 \%$ \\
Demography & 78 & 0 & $0 \%$ & $0 \%$ & $0 \%$ \\
Prospective studies & 53 & 11 & $0 \%$ & $0 \%$ & $21 \%$ \\
Ethics & 19 & 0 & $0 \%$ & $0 \%$ & $0 \%$ \\
Logic & 12 & 2 & $0 \%$ & $0 \%$ & $17 \%$ \\
Labor studies & 1 & 0 & $0 \%$ & $0 \%$ & $0 \%$ \\
Electrical Engineering & 1 & 1 & $0 \%$ & $0 \%$ & $100 \%$ \\
\hline & 19702 & 5896 & $100 \%$ & $100 \%$ & $30 \%$
\end{tabular}

\section{A3.2. Detailed Analysis of the Contribution of the Selectivity and Endogeneity Correction in Accounting for the Gender Productivity Gap}

Table A3. 7 Productivity Equation for SNI Researchers in Public Universities, without and with Corrections

\begin{tabular}{|c|c|c|c|c|}
\hline Productivity: (log) Prod & $\begin{array}{c}\text { No } \\
\text { Corrections }\end{array}$ & $\begin{array}{c}\text { Endogeneity } \\
\text { correction }\end{array}$ & $\begin{array}{l}\text { Selectivity } \\
\text { correction }\end{array}$ & $\begin{array}{c}\text { Endogeneity + } \\
\text { selectivity } \\
\text { corrections }\end{array}$ \\
\hline \multicolumn{5}{|l|}{ Age and gender } \\
\hline Woman $(=1)$ & -0.0046 & $0.025^{* *}$ & $0.064^{* * *}$ & $0.083^{* * *}$ \\
\hline$($ Age-40)/10 & 0.0089 & $-0.054 * * *$ & $-0.040 * * *$ & $-0.093 * * *$ \\
\hline$((\text { Age }-40) / 10)^{\wedge} 2$ & $-0.0075^{*}$ & 0.0049 & $0.014 * * *$ & $0.023 * * *$ \\
\hline$($ Age-40)/10 * Woman & 0.015 & $0.036^{* * *}$ & -0.012 & 0.0085 \\
\hline$((\text { Age- } 40) / 10)^{\wedge} 2 *$ Woman & -0.010 & $-0.022 * * *$ & -0.016 & $-0.026 * *$ \\
\hline \multicolumn{5}{|l|}{ Initial productivity } \\
\hline $\log ($ first Article) & $0.065^{* * *}$ & $0.042 * * *$ & 0.019 & 0.0031 \\
\hline log(average first Impact Factor) & $0.13^{* * *}$ & $0.12 * * *$ & $0.19 * * *$ & $0.19 * * *$ \\
\hline \multicolumn{5}{|l|}{ Promotion and non-publishing spells } \\
\hline Prob(promotion) & $0.12 * * *$ & $1.21 * * *$ & $0.095 * * *$ & $1.04 * * *$ \\
\hline Prob(non-publishing spells: lambda) & & & $-0.13 * * *$ & 0.032 \\
\hline \multicolumn{5}{|l|}{ Collaboration } \\
\hline $\log$ (No. of authors harmonic average) in t-1 & $0.13^{* * *}$ & $0.14^{* * *}$ & $0.16^{* * *}$ & $0.16^{* * *}$ \\
\hline log(articles SNI coauthors) in t-1 & 0.020 & 0.014 & -0.013 & -0.017 \\
\hline
\end{tabular}




\begin{tabular}{l|llll}
\multicolumn{1}{c|}{ Productivity: (log) Prod } & \multicolumn{1}{c}{$\begin{array}{c}\text { No } \\
\text { Corrections }\end{array}$} & $\begin{array}{c}\text { Endogeneity } \\
\text { correction }\end{array}$ & $\begin{array}{c}\text { Selectivity } \\
\text { correction }\end{array}$ & $\begin{array}{c}\text { Endogeneity + } \\
\text { selectivity } \\
\text { corrections }\end{array}$ \\
\hline $\log ($ Impact Factor SNI co-authors) in t-1 & $0.24^{* * *}$ & $0.23^{* * *}$ & $0.29^{* * *}$ & $0.28^{* * *}$ \\
$\log (\mathrm{SNI}$ coauthors' coauthors) in t-1 & $-0.056^{* *}$ & $-0.045^{*}$ & $-0.069^{* *}$ & $-0.061^{* *}$ \\
SNI coauthor no publications in t-1 & $0.18^{* * *}$ & $0.17^{* * *}$ & 0.070 & 0.071 \\
No publication in t-1 & 0.037 & $0.065^{* *}$ & $0.25^{* * *}$ & $0.23^{* * *}$ \\
\hline Seniority of co-authors & & & & \\
SNI co-author Candidate in t-1 & 0.00091 & -0.020 & -0.0090 & -0.024 \\
SNI co-author Level 1 in t-1 & -0.032 & $-0.043^{* *}$ & $-0.045^{*}$ & $-0.054^{* *}$ \\
SNI co-author Level 2 in t-1 & 0.013 & 0.0033 & 0.0097 & 0.00020 \\
SNI co-author Level 3 in t-1 & 0.016 & 0.0096 & 0.027 & 0.020 \\
\hline Gender and affiliations of co-authors & & & & \\
Foreign co-author in t-1 & $0.072^{* * *}$ & 0.020 & $0.065^{* * *}$ & 0.021 \\
Coll. University - PRC in t-1 & $-0.055^{*}$ & -0.046 & $-0.065^{*}$ & -0.054 \\
Female university & $0.041^{* *}$ & $0.032^{*}$ & -0.0024 & -0.0046 \\
Male university & 0.011 & -0.031 & -0.0014 & -0.036 \\
Female PRC & 0.017 & 0.0028 & -0.0065 & -0.020 \\
Male PRC & $0.040^{* *}$ & 0.021 & 0.019 & 0.0045 \\
\hline Time dummies & yes & yes & yes & yes \\
Discipline dummies & yes & yes & yes & yes \\
Constant & $0.35^{* * *}$ & $0.27^{* * *}$ & $0.29 * * *$ & $0.21^{* * *}$ \\
Observations & 24,914 & 24,914 & 24,914 & 24,914 \\
Observations npub ! 0 & & & 16,387 & 16,387 \\
Pseudo R2 & 0.122 & 0.134 & 0.180 & 0.189 \\
\hline Sgnificance & & & &
\end{tabular}

Significance: ${ }^{* * *} p<0.01,{ }^{* *} p<0.05,{ }^{*} p<0.1$

Table A3. 8 Productivity Equation for SNI Researchers in Public Research Centers, without and with Corrections

\begin{tabular}{|c|c|c|c|c|}
\hline Productivity: (log) Prod & $\begin{array}{c}\text { No } \\
\text { Corrections }\end{array}$ & $\begin{array}{c}\text { Endogeneity } \\
\text { correction }\end{array}$ & $\begin{array}{l}\text { Selectivity } \\
\text { correction }\end{array}$ & $\begin{array}{c}\text { Endogeneity + } \\
\text { selectivity } \\
\text { corrections }\end{array}$ \\
\hline \multicolumn{5}{|l|}{ Age and gender } \\
\hline Woman (=1) & -0.010 & 0.013 & 0.012 & 0.024 \\
\hline$($ Age-40)/10 & -0.0081 & $-0.051 * * *$ & $-0.098 * * *$ & $-0.12 * * *$ \\
\hline$\left((\text { Age-40)/10 })^{\wedge} 2\right.$ & 0.00066 & 0.014 & $0.030 * *$ & $0.038 * * *$ \\
\hline (Age-40)/10 * Woman & 0.0012 & 0.034 & -0.025 & 0.0015 \\
\hline$\left((\text { Age-40)/10 })^{\wedge} 2 *\right.$ Woman & 0.0052 & -0.0046 & 0.032 & 0.025 \\
\hline \multicolumn{5}{|l|}{ Initial productivity } \\
\hline $\log ($ first Article) & 0.0081 & 0.0092 & -0.019 & -0.017 \\
\hline log(average first Impact Factor) & $0.10^{* * *}$ & $0.098 * * *$ & $0.14^{* * *}$ & $0.14^{* * *}$ \\
\hline
\end{tabular}




\begin{tabular}{|c|c|c|c|c|}
\hline Productivity: (log) Prod & $\begin{array}{c}\text { No } \\
\text { Corrections }\end{array}$ & $\begin{array}{c}\text { Endogeneity } \\
\text { correction }\end{array}$ & $\begin{array}{l}\text { Selectivity } \\
\text { correction }\end{array}$ & $\begin{array}{c}\text { Endogeneity + } \\
\text { selectivity } \\
\text { corrections }\end{array}$ \\
\hline Prob(promotion) & $0.12 * * *$ & $0.51 * * *$ & $0.100 * * *$ & $0.35 * * *$ \\
\hline Prob(non-publishing spells: lambda) & & & -0.14 & -0.064 \\
\hline \multicolumn{5}{|l|}{ Collaboration } \\
\hline $\log ($ No. of authors harmonic average) in $\mathrm{t}-1$ & $0.13^{* * *}$ & $0.13^{* * *}$ & $0.14^{* * *}$ & $0.15^{* * *}$ \\
\hline $\log ($ articles SNI coauthors) in t-1 & $0.061^{*}$ & 0.053 & 0.041 & 0.034 \\
\hline $\log ($ Impact Factor SNI co-authors) in t-1 & $0.17^{* * *}$ & $0.15^{* * *}$ & $0.18^{* * *}$ & $0.17^{* * *}$ \\
\hline $\log (\mathrm{SNI}$ coauthors' coauthors) in t-1 & $-0.095^{*}$ & -0.083 & $-0.14 * *$ & $-0.13^{* *}$ \\
\hline SNI coauthor No publications in t-1 & 0.10 & 0.12 & -0.035 & -0.021 \\
\hline No publication in $\mathrm{t}-1$ & 0.048 & 0.066 & $0.18^{* * *}$ & $0.18^{* * *}$ \\
\hline \multicolumn{5}{|l|}{ Seniority of co-authors } \\
\hline SNI co-author Candidate in t-1 & 0.036 & 0.028 & 0.026 & 0.022 \\
\hline SNI co-author Level 1 in t-1 & $0.082^{*}$ & $0.074 *$ & 0.035 & 0.032 \\
\hline SNI co-author Level 2 in $\mathrm{t}-1$ & -0.012 & -0.011 & 0.0053 & 0.0051 \\
\hline SNI co-author Level 3 in t-1 & -0.034 & -0.026 & -0.040 & -0.034 \\
\hline \multicolumn{5}{|l|}{ Gender and affiliations of co-authors } \\
\hline Foreign co-author in $\mathrm{t}-1$ & $0.084^{* *}$ & $0.077^{* *}$ & $0.077^{*}$ & $0.076^{*}$ \\
\hline Coll. University - PRC in t-1 & 0.037 & 0.048 & 0.033 & 0.041 \\
\hline Female university & 0.0023 & -0.016 & 0.029 & 0.012 \\
\hline Male university & -0.056 & $-0.080 * *$ & -0.033 & -0.045 \\
\hline Female PRC & 0.054 & 0.055 & 0.049 & 0.052 \\
\hline Male PRC & 0.018 & -0.0098 & -0.011 & -0.027 \\
\hline Time dummies & yes & yes & yes & yes \\
\hline Discipline dummies & yes & yes & yes & yes \\
\hline Constant & $0.38 * * *$ & $0.34 * * *$ & $0.45^{* * *}$ & $0.42 * * *$ \\
\hline Observations & 4,620 & 4,620 & 4,620 & 4,620 \\
\hline Observations npub $!=0$ & & & 3,083 & 3,083 \\
\hline Pseudo R2 & 0.133 & 0.138 & 0.165 & 0.167 \\
\hline
\end{tabular}

Significance: ${ }^{* * *} p<0.01,{ }^{* *} p<0.05,{ }^{*} p<0.1$ 



\section{Impact}

Following article 22.5 of the Regulations for obtaining the doctoral degree at Maastricht University, adopted by a decision of the Board of Deans on 13 May 2020, this section discusses this doctoral thesis's scientific and social impact. The impact is discussed in three ways: by presenting first its scientific and social relevance, by explaining the target group to whom the research results are relevant, and by discussing the activities that the research has triggered.

Scientific and social relevance. The main objective of this research is to understand the role of scientists and scientific communities in the process of knowledge creation by looking at scientific productivity, its determinants and effects at the individual level, and the macro level, in the context of Middle-Income Countries (MICs). The thesis results point to a complex picture of determinants for MICs, one where researchers' productivity is influenced by personal characteristics - notably gender and ethnicity, organizational and social structures, scientific collaboration practices, access to foreign knowledge, and international collaboration networks, and their interactions.

The thesis contributes with several key novel scientific and policy insights and methods. It also provides tools for informing policy discussions in the science-policy field in MICs.

Chapter 2 argues for the integration of the network approach to more empirical studies in the economics of science. The Chapter shows that social structure affects scientific collaboration through the use of community detection algorithms in the methodological framework. A measure of social capital is needed in econometric models to have a complete picture of scientific productivity determinants.

Chapters 3 and 4 propose a novel measurement of gender parity impacts. One that is likely to resonate among policymakers concerned in improving national research performance, as it provides a concise and concrete measurement of the costs and benefits of reducing or eliminating gender productivity gaps in science. 
The findings of Chapters 2, 3, and 4 point to the risk of segregation of 'minorities' in academic systems. From a research policy perspective, this also signals the need to promote cross-race and cross-gender contacts and diversity in research networks.

The results of the gender chapters 3 and 4 suggest that policy should focus on how to enable equal opportunities for the promotion of women in science and that priority should be given to achieving gender equality in promotion, particularly for black female academics (Chapter 4).

Chapter 5 shows that researchers in MICs that receive their training abroad -often in developed countries with advanced science systems, generate system-wide benefits for their home countries in the form of access to international research networks and act as gatekeepers in transferring this knowledge to their local networks. The results also suggest that policy priority should be given to creating the appropriate conditions to successfully reintegrate researchers back to their home countries, especially given the financial and structural challenges that academic systems in MICs face.

Target group. This thesis has two main target groups. First, academics in the fields of the economics of science, gender economics, and economics of networks will benefit from the methodological contributions and empirical evidence. Second, policymakers in the field of science and research policy will benefit from the policy implications and the social relevance of the research.

More specifically, the empirical chapters also contribute to a better understanding of the functioning and impact of the rating system of researchers of the National Research Foundation (NRF) of South Africa and the National System of Researchers (SNI) of Mexico. As such, policymakers in charge of the management of both programs will find the results relevant for their work, as these suggest further avenues for improvement of both programs and discuss their broader relevance for the academic upgrading and enhancement of scientific productivity of South Africa and Mexico, as well as their impact.

Moreover, the research of Chapter 3, focusing on the micro and macro effects of gender publication productivity gaps in Mexico, was part of the research project "Science, Technology and Innovation Gender Gaps and their Economic Costs in Latin America and the Caribbean", led by the Competitiveness and Innovation Division of the Inter-American Development Bank (IDB) between 2015-2018, and financed by the IDB Gender and Diversity Fund. The results of this research served as input to policy practitioners in the IDB to better understand and measure gender gaps in Science Technology and Innovation (STI) in Latin America and the Caribbean (LAC). The research project 
concluded how important it is to integrate the gender dimension in developing and monitoring better public policies in STI in the LAC region.

Activities. The research in this thesis has been highly disseminated in several academic conferences. As such, it benefited from the discussions, comments, and inputs of several scholars and practitioners in STI policy studies.

Preliminary versions of the chapters were presented at the XXXV Sunbelt Conference of the International Network for Social Network Analysis in June 2015 in Brighton, United Kingdom; at the HDCA Conference on Capabilities on the Move in Washington, D.C. (USA) in September 2015; at the Atlanta Conference on Science and Innovation Policy in September 2015 at the Georgia Institute of Technology (USA); at the $9^{\text {th }}$ Model-based Evidence on Innovation and Development (MEIDE) Conference in Moscow, Russia in June 2016; and the 2016 OECD Blue Sky Forum on Science and Innovation Indicators in Ghent, Belgium.

Chapters 2 and 4 presenting South Africa's results benefited from first-hand extensive discussions and comments at the Workshop on Academic Science in South Africa, in Stellenbosch, in 2016. The workshop aimed to understand how research takes place in South African universities and what could be done to improve their scientific and societal performance. The workshop brought together a small group of European and South African scholars working towards understanding the dynamics of academic science in South Africa. It was co-organized and sponsored by the Centre for Research on Evaluation, Science and Technology (CREST), the Stellenbosch Institute for Advanced Study (STIAS), and the Institut Universitaire de France.

A previous version of Chapter 2 was published as a Conference Paper and presented at the European Meeting on Applied Evolutionary Economics (EMAEE) Conference 2015, held in Maastricht, the Netherlands, with the title "Formation and persistence of research communities in Middle-Income Countries: the case of South Africa".

A previous version of Chapter 3 was published as UNU-MERIT Working Paper No. 2016-072, titled "An econometric investigation of the productivity gender gap in Mexican research, and a simulation study of the effects on scientific performance of policy scenarios to promote gender equality". It was also published as an IDB Working Paper in 2017 under the title "Gender Gaps and Scientific Productivity in Middle-Income Countries: Evidence from Mexico".

The research of Chapters 3 and 4 motivated the comparative analysis of gender productivity gaps in France, South Africa, and Mexico, under the leadership of Prof. Dr. Jacques Mairesse. Some 
preliminary findings of this comparative research were presented at the $11^{\text {th }}$ MEIDE Conference in Abidjan, Cote d'Ivoire in 2019, with the title "Determinants of the publication productivity gender gap in scientific research: micro-level assessment, macro-level implications, and policy scenarios. Comparing the evidence for Mexico, South Africa and France". The plan is to continue expanding this line of research in the upcoming years.

The gender-ethnicity empirical chapters' results continue to attract broader attention, with media appearances in the newspaper The Conversation of the United Kingdom and in the IDB's blog "Puntos sobre la i" discussing innovation policy priorities for Latin America and the Caribbean. 


\section{About the Author}

Lorena Rivera León has worked as a researcher, policy analyst, and consultant in the field of research and innovation for over 14 years, including for various services of the European Commission, UNESCO, the OECD, and the Inter-American Development Bank. Her research focuses on the study of the economics of science in middle-income countries (MICs), and she is particularly interested in understanding the determinants of gender productivity gaps in science and measuring the impact of such gaps.

Since June 2017, she is an Economist at the World Intellectual Property Organization (WIPO), Department for Economics and Data Analytics, Composite Indicators Research Section. At WIPO, she acts as the Lead Researcher of the Global Innovation Index. She provides ad hoc technical advice to countries on innovation policy and performance and innovation metrics. Before joining WIPO, Lorena specialized and focused her interest in the intersection of regional policy, industrial policy, and enterprise and cluster policy at the EU level. Lorena worked for EU regions in several ways, through impact assessments and evaluations and providing policy intelligence and technical assistance for specific sectors.

In the field of innovation metrics, she has worked in the design and development of various innovation and entrepreneurship scoreboards at the European level, including the Regional Innovation Scoreboard of the EU and the Regional Ecosystems Scoreboard of the European Cluster Observatory.

She received her MA jointly from the Department of Economics, University of British Columbia, Canada, and the Université Pierre-Mendès-France. 



\section{UNU-MERIT/MGSoG Dissertation Series}

2021

\section{Lorena Rivera León}

Unveiling the Determinants of

Scientific Productivity in Middle-

Income Countries:

An Economics of Science Perspective

UNU-MERIT/MGSoG Dissertation

Series № 256

\section{Racky Balde}

Essays on Informal versus formal

Economy Choices

UNU-MERIT/MGSoG Dissertation

Series № 255

\section{Caio Torres Mazzi}

Learning, Capabilities and Governance in Global Value Chains

UNU-MERIT/MGSoG Dissertation

Series № 254

\section{Giulia Rossello}

Social Transformations and Labour

Market Entry

An Investigation into University

Systems in Emerging Economies

UNU-MERIT/MGSoG Dissertation

Series № 253
2020

Rose Camille Vincent

Essays in Public Economics

Multi-Layer Tax Structure and

Implications

UNU-MERIT/MGSoG Dissertation

Series № 252

Emmanuel Mensah

Structural change in developing countries: patterns, causes, and consequences

UNU-MERIT/MGSoG Dissertation

Series № 251

\section{Ornsaran Manuamorn}

Governance of International

Adaptation Finance for Local Climate

Change Adaptation: An Analysis of

Adaptation Fund Projects

UNU-MERIT/MGSoG Dissertation

Series № 250

\section{Gillian McFarland}

Doing policy in Further Education

An exploration of the enactment of the GCSE resits policy in Further

Education colleges in England

UNU-MERIT/MGSoG Dissertation

Series № 249 


\section{Omar Rodriguez Torres}

Essays on Entrepreneurship in

Colombia

UNU-MERIT/MGSoG Dissertation

Series № 248

\section{Elaine Lebon-McGregor}

International Organizations and

Global Migration Governance

UNU-MERIT/MGSoG Dissertation

Series № 247

Janyl Moldalieva

Playing the 'Game'of Transparency

and Accountability in Kyrgyzstan's

Resource Governance

UNU-MERIT/MGSoG Dissertation

Series № 246

Kaleab Kebede Haile

Essays on Rural Household Decision-

Making under Climate Risk

UNU-MERIT/MGSoG Dissertation

Series № 245

\section{Nora Jasmin Ragab}

Diaspora Mobilisation in a Conflict

Setting

UNU-MERIT/MGSoG Dissertation

Series № 244

\section{Mary Kaltenberg}

From Micro to Macro: Essays on

Technological Change and Income

Divergence

UNU-MERIT/MGSoG Dissertation

Series № 243

\section{Ayla E. Bonfiglio}

Student migrant, refugee or both?

Exploring Refugee Agency and

Mobility through Tertiary Education

in Kenya, South Africa and Uganda

UNU-MERIT/MGSoG Dissertation

Series № 242

\section{Danilo Sartorello Spinola}

Cycles, Economic Structures and

External Constraints.

A Structuralist study on the causes of economic volatility in Latin America

UNU-MERIT/MGSoG Dissertation

Series № 241

\section{9}

\section{Jemal Adem}

Livelihood Vulnerability to Shocks,

Behaviour and Investment in

Education: Essays in Behavioural

Development Economics

UNU-MERIT/MGSoG Dissertation

Series № 240

\section{Davina Osei}

Corrupt or corrupted networks?

An empirical enquiry

UNU-MERIT/MGSoG Dissertation

Series № 239

\section{Patima Chongcharoentanawat}

Beyond Static Inequality

Public policies and economic mobility in Thailand

UNU-MERIT/MGSoG Dissertation Series № 238 


\section{Charlotte Guillard}

Rethinking economic growth

and structural change.

The role of boundaries and linkages

between industries

UNU-MERIT/MGSoG Dissertation

Series № 237

\section{Nicolas Echarti}

Employment Effects or Vocational

Rehabilitation in Germany:

A quantitative analysis

UNU-MERIT/MGSoG Dissertation

Series № 236

\section{Shellie E. Solomon}

Neighborhoods Matter:

Crime, collective efficacy and

foreclosures in Miami

UNU-MERIT/MGSoG Dissertation

Series № 235

\section{Michał Kazimierczak}

Regional Innovation and

Entrepreneurship

Patents, trade marks, entry and

entrants' growth in European

manufacturing industries

UNU-MERIT/MGSoG Dissertation

Series № 234

\section{Fernanda Soares}

The Influence of Within School and Across Schools' Collaborative Practices on Student Learning and Teaching

Outcomes in West Africa

UNU-MERIT/MGSoG Dissertation

Series № 233

\section{Mira Bierbaum}

New Mindsets to Innovate Activation UNU-MERIT/MGSoG Dissertation

Series № 232

\section{Norman Dytianquin}

Technology in the Asian Miracle and Crisis Debates: Applications of and Insights from the Field of Influence Approach to Input-Output Analysis UNU-MERIT/MGSoG Dissertation Series № 231

\section{Nga Le}

The implications of health insurance for the labour market and patient satisfaction with medical care in Vietnam

UNU-MERIT/MGSoG Dissertation Series № 230

\section{Jinhyuck Park}

Intellectual Property right protection and cross-border RED investments by multinational enterprises

UNU-MERIT/MGSoG Dissertation Series № 229

\section{Richard de Groot}

Show me the Money:

Essays on the Impact of Cash Transfers on Child Nutrition and the Role of Intra-Household Dynamics UNU-MERIT/MGSoG Dissertation Series № 228 


\section{Catie Lott}

Diamonds are a Women's Best Friend

Broadening Measures of Women's

Access to Formal Political Decision-

Making

UNU-MERIT/MGSoG Dissertation

Series № 227

\section{Ana Cristina Calderon Ramirez}

Public Management Reforms

Three stories about public procurement agencification in Latin America

UNU-MERIT/MGSoG Dissertation

Series № 226

\section{Camilo Nicanor Carrillo Purin}

Teachers' in-service training and student achievement:

The effect of in-service training of

Peruvian teachers on student

achievement

UNU-MERIT/MGSoG Dissertation

Series № 225

\section{Hugo Confraria}

Developing scientific capacity in the

Global South

UNU-MERIT/MGSoG Dissertation

Series № 224

\section{Alison Cathles}

Educational Pathways and Skills:

Past, Present, and Future

UNU-MERIT/MGSoG Dissertation

Series № 223

\section{Ibrahima Sory Kaba}

Aggregate Fluctuations and

Development: Essays on

Macroeconomic Volatility and

Economic Growth

UNU-MERIT/MGSoG Dissertation

Series № 222

\section{Charlotte Keijser}

Firm Participation, Learning and

Innovation in Heterogenous Value

Chains of IT-enabled Services

UNU-MERIT/MGSoG Dissertation

Series № 221

\section{Salih Çevikarslan}

Innovation Strategies and Their

Implications for Technological Change and Market Outcomes:

An Evolutionary Multi-Agent Based

Modelling Approach

UNU-MERIT/MGSoG Dissertation

Series № 220

\section{Wondimagegn Mesfin Tesfaye}

Essays on the Impacts of Climate-

Smart Agricultural Innovations on

Household Welfare

UNU-MERIT/MGSoG Dissertation

Series № 219

\section{Tatevik Poghosyan}

How Board Networks Affect Firm Performance and Innovation Incentives in Transition Economies: The Case of Armenia

UNU-MERIT/MGSoG Dissertation Series № 218 


\section{Arip Muttaqien}

Essays on Inequality and Polarization: Empirical Studies in Developing Asia UNU-MERIT/MGSoG Dissertation Series № 217

2018

\section{Katrin Marchand}

Essays on Forced Migration and

Labour Market Participation in

Developing Countries

UNU-MERIT/MGSoG Dissertation

Series № 216

\section{Ortrun Merkle}

The Myth of Gender Neutral Power:

Corruption and Gender Norms

UNU-MERIT/MGSoG Dissertation

Series № 215

\section{Biljana Meshkovska}

Life after Trafficking:

(re)integration processes of women that have been trafficked for the purpose of sexual exploitation in Europe

UNU-MERIT/MGSoG Dissertation

Series № 214

\section{Vincenzo Vinci}

The Relevance of Institutions and

People's Preferences for Social

Protection

UNU-MERIT/MGSoG Dissertation

Series № 213

\section{Silke Heuser}

The Effectiveness of Environmental Policies on Reducing Deforestation in the Brazilian Amazon

UNU-MERIT/MGSoG Dissertation Series № 212

\section{Jennifer Waidler}

Social Assistance and Remittances and Their Role in the Fight Against Poverty UNU-MERIT/MGSoG Dissertation Series № 211

\section{Choolwe Muzyamba}

The role of community mobilization in the promotion of maternal health of women living with HIV in Zambia UNU-MERIT/MGSoG Dissertation Series № 210

\section{Juan Carlos A. Castillo Sánchez} Assessing the Role of the Export Sector in Mexican Economic

Development,1965-2014

UNU-MERIT/MGSoG Dissertation Series № 209

\section{Tareq Abuelhaj}

Food Security Policy Impact Analysis: The Econometrics of Cash and Food Assistance Cost Effectiveness UNU-MERIT/MGSoG Dissertation Series № 208

\section{Marta Férnandez de Arroyabe} Arranz

Essays on MEAS and Innovation UNU-MERIT/MGSoG Dissertation Series № 207 


\section{Clotilde Mahé}

Essays on Migration and Occupational

Choice

UNU-MERIT/MGSoG Dissertation

Series № 206

\section{Simone Sasso}

Talent on the move. Essays on Human Capital, Graduate Mobility and

Economic Development

UNU-MERIT/MGSoG Dissertation

Series № 205

Khaled Walid Rajab

Strategic Planning under Fragility

UNU-MERIT/MGSoG Dissertation

Series № 204

\section{Mutinta Hambayi Nseluke}

A Tall Order: Improving Child Linear

Growth

UNU-MERIT/MGSoG Dissertation

Series № 203

\section{Elvis Korku Avenyo}

Innovations and Firm Performance

in sub-Saharan Africa: Empirical

Analyses

UNU-MERIT/MGSoG Dissertation

Series № 202

\section{Ni Zhen}

Employment Dynamics, Firm

Performance and Innovation

Persistence in the Context of

Differentiated Innovation Types:

Evidence from Luxembourg

UNU-MERIT/MGSoG Dissertation

Series № 201

\section{Caroline Wehner}

Too Scared to Achieve: The Relation

Between Neuroticism,

Conscientiousness

and Socioeconomic Outcomes

UNU-MERIT/MGSoG Dissertation

Series № 200

\section{Stefania Innocenti}

On Institutional Persistence

UNU-MERIT/MGSoG Dissertation

Series № 199

\section{Hassen Abda Wako}

Economic Globalization, Institutions

and Development: Essays on Aid, Foreign Direct Investment and Trade UNU-MERIT/MGSoG Dissertation Series № 198

\section{7}

\section{Hans-Erik Edsand}

Winds of Change

UNU-MERIT/MGSoG Dissertation

Series № 197

\section{Ana Patricia Silva Vara}

Redressing the Gender Gap

UNU-MERIT/MGSoG Dissertation

Series № 196

\section{Andrés Iván Mideros Mora}

Essays on the Economic Effects of Noncontributory Social Protection UNU-MERIT/MGSoG Dissertation Series № 195 


\section{Tobias Broich}

New Actors in the Global Economy UNU-MERIT/MGSoG Dissertation

Series № 194

\section{Bernard Nikaj}

From No-government to E-government UNU-MERIT/MGSoG Dissertation

Series № 193

\author{
Ali Safarnejad \\ Prioritizing the HIV Response \\ UNU-MERIT/MGSoG Dissertation \\ Series № 192

\section{Clovis Freire} \\ Diversification and Structural \\ Economic Dynamics \\ UNU-MERIT/MGSoG Dissertation \\ Series № 191

\section{Michael Verba} \\ Innovation and Knowledge Dynamics: \\ Essays on the Knowledge Economy \\ UNU-MERIT/MGSoG Dissertation \\ Series № 190
}

\section{Pui Hang Wong}

The Hearts and Minds in Conflict and Peace: The Economics of

Counterinsurgency and the Psychology of Reconstruction

UNU-MERIT/MGSoG Dissertation

Series № 189

\section{Brenda Yamba}

Schooling Despite All Odds: Evidence from Lesotho on Female Child Carers who Stayed in School

UNU-MERIT/MGSoG Dissertation Series № 188

\section{Sheng Zhong}

Moving towards An Energy Efficient

Future: Essays on Energy Efficiency,

Technology and Development

UNU-MERIT/MGSoG Dissertation

Series № 187

\section{Julieta Marotta}

Access to Justice and Legal

Empowerment of Victims of Domestic

Violence through Legal Organizations in the City of Buenos Aires: A

Qualitative Empirical Legal Study

UNU-MERIT/MGSoG Dissertation

Series, № 186

\section{Andrea Franco-Correa}

On the Measurement of

Multidimensional Poverty as a Policy Tool: Empirical Applications to Chile, Colombia, Ecuador and Peru UNU-MERIT/MGSoG Dissertation Series, № 185

\section{6}

\section{Yesuf Awel}

Insurance for Growth: Empirical Essays on Insurance Demand and Impacts in Africa UNU-MERIT Dissertation Series, № 108

\section{Tigist Mekonnen Melesse}

Grow More Food using Fewer

Resources: Agricultural Technology

Adoption and Innovation Practices for Inclusive and Sustainable

Development

UNU-MERIT Dissertation Series, № 107 


\section{Eleni Yitbarek \\ Getting Ahead or left Behind? Essays on Poverty Dynamics and Social \\ Mobility in Africa \\ UNU-MERIT Dissertation Series, № 106}

\section{Thuy Dieu Nguyen}

Firm-Level Theory and Evidence of

Corruption

UNU-MERIT Dissertation Series, № 105

\section{Raquel Tsukada Lehman}

Essays on Household Production with Labor-Saving Technology

UNU-MERIT Dissertation Series, № 104

\section{Eva Barteková}

Multi-Problem Challenges for a Renewable Future: Empirical Studies on Competitive Disadvantages from Electricity Price Differentials and Mineral Supply Risk in an Open Economy

UNU-MERIT Dissertation Series, № 103

\section{Jocelyn Olivari}

Entrepreneurial Traits and Innovation: Evidence from Chile

UNU-MERIT Dissertation Series, № 102

\section{Muhammad Shafique}

Essays on the role of knowledge, RED, and Technology-based Firms in the Evolution of Socio-techno-economic System

UNU-MERIT Dissertation Series, № 101

\section{Serdar Türkeli}

Governance of Innovation Policy:

Empirical Studies on Applied Political Economy by Multi-Methods Analysis UNU-MERIT Dissertation Series, № 100

\section{Ayokunu Adedokun}

Pathways to Sustainable Peace building in Divided Societies: Lessons and Experiences from Mozambique MGSoG Dissertation Series, № 75

\section{Luiz Rothier Bautzer}

Organizing Concurrent Engineering through ICT Platforms

Blueprinting Product Lifecycle

Management Platforms across

Disciplinary Agencies

MGSoG Dissertation Series, № 74

\section{Natalia Popova}

Migration in the Periphery of the European Union:

Determinants of Successful and Sustainable Labour Market Integration of Return Migrants in Albania, Egypt, Moldova and Tunisia MGSoG Dissertations Series, № 73 


\section{Richard A. Martina}

Uncertainty and Resource Constraint in the Small Island Developing States: Essays in Entrepreneurial Cognition MGSoG Dissertations Series, № 72

\section{Cécile Cherrier}

The Expansion of Basic Social

Protection in Low-income Countries: An Analysis of Foreign Aid Actors'

Role in the Emergence of Social

Transfers in Sub-Saharan Africa

MGSoG Dissertations series, № 71

\section{Paul Caldron}

The Tacit Bargain in Short-Term Medical Missions: Why U.S. physicians go and what it costs MGSoG Dissertation Series, № 70

\section{Mahmut Kobal}

Customs \& Excellence: A Comparative Approach on Administrative and Regulatory Compliance Perspectives of the EU-Turkey Customs Union MGSoG Dissertation Series, № 69

\section{Craig Loschmann}

Essays on Conflict-related Migration and Development in the Case of Afghanistan

MGSoG Dissertations Series, № 68

\section{Andrea Milan}

Rural Livelihoods, Location and Vulnerable Environments: Approaches to Migration in Mountain areas of Latin America MGSoG Dissertation Series, № 67

\section{Farida Lada}

On Guarding the Welfare of Clinical

Trial Subjects While Promoting Novel Drug Innovation

A Game Theoretical Approach

MGSoG Dissertation Series, № 66

\section{5}

\section{Hibret Belete Maemir}

Dissecting Aggregate Productivity: International Integration and Growth with Heterogeneous Firms

UNU-MERIT Dissertation Series, № 96

\section{Giorgio Triulzi}

Looking for the Right Path: Technology Dynamics, Inventive Strategies and Catching-up in the Semiconductor Industry

UNU-MERIT Dissertation Series, № 95

\section{Abdul Baseer Qazi \\ Knowledge flows and networks in the ICT sector: The case of Pakistan \\ UNU-MERIT Dissertation Series, № 94}

\section{Ajay Thutupalli}

Technology Paradigm Shifts in Agriculture: Drivers of Sustainability and Catch up UNU-MERIT Dissertation Series, № 93 


\section{Eduardo Urias}

Improving access to HIVIAIDS

treatment in Brazil: When are

Compulsory Licenses effective in Price

Negotiations?

UNU-MERIT Dissertation Series,

№ 92

\section{Francesca Guadagno \\ Why have so few Countries \\ Industrialised? \\ UNU-MERIT Dissertation Series, \\ № 91}

\section{Daniel Opolot}

The Evolution of Beliefs and Strategic

Behaviour

UNU-MERIT Dissertation Series,

№ 90

\begin{abstract}
Alejandro Lavopa
Structural Transformation and

Economic Development: Can

Development Traps be Avoided

UNU-MERIT Dissertation Series, № 89
\end{abstract}

\section{Jinjin Zhao}

Urban water management reform: The

Case of China

UNU-MERIT Dissertation Series, № 88

\section{Simona Vezzoli}

Borders, Independence and Post-

colonial Ties: the Role of the State in

Caribbean Migration

MGSoG Dissertation Series, № 65

\section{Silvia Consuelo Gómez Soler}

Civil Conflict and Education: How

Does Exposure to Civil Conflict Affect

Human Capital Accumulation?

Evidence from Standardized Exit

Exams in Colombia

MGSoG Dissertation Series, № 64

\section{Paula Nagler}

Occupational Choice in the Developing

World

MGSoG Dissertation Series, № 63

\section{Jasmin Kientzel}

Determinants of Professional

Commitment to Environmental

Sustainability

MGSoG Dissertation Series, № 62

\section{Mehmet Güney Celbiş}

Regional Policies: Convergence, Trade, and the Allocation of Public Capital MGSoG Dissertation Series, № 61

\section{Florian Henning}

Living Up to Standard:

Interoperability Governance and

Standards Adoption in Government

Information Networks

MGSoG Dissertation Series, № 60

\section{Niels P. Groen}

The Never-Ending Project

Understanding E-Government Project

Escalation

MGSoG Dissertation Series, № 59

\section{Derek Copp}

Teacher-Based Reactivity to Provincial Large-scale Assessment in Canada MGSoG Dissertation Series, № 58 


\section{Michaella Vanore}

Family-Member Migration and the

Psychosocial Health Outcomes of

Children in Moldova and Georgia

MGSoG Dissertation Series, № 57

\section{Sonja Fransen}

The Economic and Social Effects of

Remittances and Return Migration in

Conflict-Affected Areas: The Case of

Burundi

MGSoG Dissertation Series, № 56

\section{Ibrahim Khalil Conteh}

The Impact of Floods on Primary

School Education in Zambia

MGSoG Dissertation Series, № 55

\section{Richard Bluhm}

Growth Dynamics and Development

Essays in Applied Econometrics and

Political Economy

MGSoG Dissertation Series, № 54

\section{Nevena P. Zhelyazkova}

Work-Family Reconciliation and Use of Parental Leave in Luxembourg:

Empirical Analysis of Administrative Records

MGSoG Dissertation Series, № 53

\section{4}

\section{Dirk Crass}

The Impact of Brands on Innovation and Firm Performance: Empirical Evidence from Germany

UNU-MERIT Dissertation Series, № 87

\section{Samyukta Bhupatiraju}

The Geographic Dimensions of Growth and Development

UNU-MERIT Dissertation Series, № 86

\section{François Lafond}

The Evolution of Knowledge Systems UNU-MERIT Dissertation Series, № 85

\section{Annalisa Primi}

Promoting Innovation in Latin America: What Countries Have Learned (and What They Have Not) in Designing and Implementing Innovation and Intellectual Property Policies

UNU-MERIT Dissertation Series, № 84

\section{Fatoumata Lamarana Diallo}

Evaluation of Meal and Deworming Programs for Primary Schools in Rural Senegal

UNU-MERIT Dissertation Series, № 83

\section{Sachin Kumar Badkas}

Metachoice and Metadata: Innovating with Environmental Policy Analysis in Europe

MGSoG Dissertation Series, № 52

\section{Irina S. Burlacu}

An Evaluation of Tax-Benefit Systems Impact on the Welfare of Frontier Worker:

The Case of Luxembourg and Belgium MGSoG Dissertation Series, № 51 


\section{Özge Bilgili}

Simultaneity in Transnational

Migration Research: Links Between

Migrants' Host and Home Country

Orientation

MGSoG Dissertation Series, № 50

Yulia Privalova Krieger

Reshaping the Big Agenda:

Transnational Politics and Domestic

Resistance Financial crisis and social protection reform in Bosnia and Herzegovina

MGSoG Dissertation Series, № 49

\section{Marieke van Houte}

Moving Back or Moving Forward?

Return migration after Conflict

MGSoG Dissertation Series, № 48

\section{Oxana Slobozhan}

Global Governance in the Management of Natural Resources: The Case of the Extractive Industries Transparency Initiative (EITI)

MGSoG Dissertation Series, № 47

\section{Luis Bernardo Mejia Guinand}

The Changing Role of the Central

Planning Offices in Latin America: A

Comparative Historical Analysis

Perspective (1950-2013)

MGSoG Dissertation Series, № 46

\section{Cheng Boon Ong}

Ethnic Segregation in Housing,

Schools and Neighbourhoods in the

Netherlands

MGSoG Dissertation Series, № 45

\section{Luciana V. Cingolani}

Bureaucracies for Development:

Oxymoron or Reality? Studies on State

Capacity in Challenging Governance

Contexts

MGSoG Dissertation Series, № 44

\section{Carlos Cadena Gaitán}

Green Politics in Latin American

Cities - Sustainable Transport Agendas

MGSoG Dissertation Series, № 43

\section{Katie Kuschminder}

Female Return Migration and

Reintegration Strategies in Ethiopia

MGSoG Dissertation Series, № 42

\section{Metka Hercog}

Highly-Skilled Migration and New

Destination Countries

MGSoG Dissertation Series, № 41

\section{Margaret Agaba Rugadya}

Can Remittances Influence the Tenure and Quality of Housing in Uganda?

MGSoG Dissertation Series, № 40

\section{Ilire Agimi}

New Governance Under Limited

Statehood: The Case of Local

Government Reform in Kosovo

MGSoG Dissertation Series, № 39

2013

\section{Anant Kamath}

Information Sharing through Informal Interaction in Low-Tech Clusters UNU-MERIT Dissertation Series, № 82 


\section{Flavia Pereira de Carvalho}

What we talk about when we talk about

Brazilian Multinationals: An

Investigation on Brazilian FDI,

Economic Structure, Innovation and

the Relationship between them

UNU-MERIT Dissertation Series,

№ 81

\section{Jun Hou}

Complementarity in Innovation and

Development: A Cross-country

Comparison

UNU-MERIT Dissertation Series, № 80

\section{Rufin Baghana}

Impacts of Government Incentives to RED, Innovation and Productivity:

A Microeconometric Analysis of the

Québec Case

UNU-MERIT Dissertation Series, № 79

\section{Lilia I. Stubrin}

High-Tech Activities in Emerging

Countries: A Network perspective on

the Argentinean Biotech Activity

UNU-MERIT/MGSoG Dissertation

Series, № 78

\section{Kristine Farla}

Empirical Studies on Institutions, Policies and Economic Development MGSoG Dissertation Series, № 38

\section{Marina Petrovic}

Social Assistance and Activation in the Pursuit of Happiness: Shedding New Light on Old Policy Solutions to Social Exclusion

MGSoG Dissertation Series, № 37

\section{Laura Torvinen}

Assessing Governance Assessments:

The Case of Mozambique: Governance Assessments in the Context of Aid Effectiveness Discourse MGSoG Dissertation Series, № 36

\section{Biniam Egu Bedasso}

Institutional Change in the Long Shadow of Elite: Essays on Institutions, Human Capital and Ethnicity in Developing Countries MGSoG Dissertation Series, № 35

\section{Sepideh Yousefzadeh Faal} Deghati

Childhoods Embargoed: Constructing and Reconstructing Multidimensional Child Poverty in Iran 1984-2009 MGSoG Dissertation Series, № 34

\section{Robert Bauchmüller}

Investing in Early Childhood Care and Education: The Impact of Quality on Inequality

MGSoG Dissertation Series, № 33

\section{Martin Rehm}

Unified Yet Separated: Empirical Study on the Impact of Hierarchical Positions within Communities of Learning

MGSoG Dissertation Series, № 32 
2012

\author{
Abdul Waheed \\ Innovation Determinants and \\ Innovation as a Determinant: Evidence \\ from Developing Countries \\ UNU-MERIT Dissertation Series, \\ № 77
}

\section{Bilal Mirza}

Energy Poverty and Rural Energy

Markets in Pakistan

UNU-MERIT Dissertation Series,

№ 76

\section{Benjamin Engelstätter \\ Enterprise Software and Video Games: \\ An Empirical Analysis \\ UNU-MERIT Dissertation Series, \\ № 75}

\section{Fulvia Farinelli}

Natural Resources, Innovation and

Export Growth: The Wine Industry in

Chili and Argentina

UNU-MERIT Dissertation Series

\section{Rodolfo Lauterbach}

Innovation in Manufacturing: From

Product Variety and Labor

Productivity Growth to Economic

Development in Chile

UNU-MERIT Dissertation Series

\section{Kirsten Wiebe}

Quantitative Assessment of

Sustainable Development and Growth in Sub-Saharan Africa

UNU-MERIT Dissertation Series, № 74

\section{Julio Miguel Rosa}

Organizational Strategies, Firms'

Performance and Spatial Spillovers:

The Canadian Case in Research and

Development.

UNU-MERIT Dissertation Series,

№ 73

Johannes Wilhelmus Marie Boels Joseph Schumpeter, Honderd Jaar

Economische Ontwikkeling: Een

Historisch-theoretische Beschouwing.

UNU-MERIT Dissertation Series

\section{Dorcas Mbuvi}

Utility Reforms and Performance of the

Urban Water Sector in Africa

MGSoG Dissertation Series, № 31

\section{Lina Salanauskaite}

Distributional Impacts of Public

Policies: Essays in Ex-Ante and Ex-

Post Evaluation

MGSoG Dissertation Series, № 30

\section{Esther Schüring}

To Condition or not - is that the

Question?

An Analysis of the Effectiveness of ExAnte and Ex-Post Conditionality in

Social Cash Transfer Programs

MGSoG Dissertation Series, № 29

\section{Joe Abah}

Strong Organisations in Weak States: Atypical Public Sector Performance in Dysfunctional Environments MGSoG Dissertation Series, № 28 


\section{Zina Samih Nimeh}

Social Citizenship Rights: Inequality and Exclusion

MGSoG Dissertation Series, № 27

2011

\section{Daniel Vertesy}

Interrupted Innovation: Emerging

Economies in the Structure of the

Global Aerospace Industry

UNU-MERIT Dissertation Series, № 72

\section{Tina Saebi}

Successfully Managing Alliance

Portfolios: An Alliance Capability

View

UNU-MERIT Dissertation Series, № 71

\section{Nora Engel}

Tuberculosis in India: A Case of

Innovation and Control

UNU-MERIT/MGSoG Dissertation

Series, № 70

\section{Evans Mupela}

Connectivity and growth in Sub-

Saharan Africa: The Role of

Communication Satellites

UNU-MERIT Dissertation Series,

№ 69

\section{Nantawan Kwanjai}

Cross Cultural Intelligence amid Intricate Cultural Webs: A Tale of the

UnDutchables in the Land of 1002

Smiles

UNU-MERIT Dissertation Series, № 68

\section{Lina Sonne}

Innovation in Finance to Finance

Innovation: Supporting Pro-poor

Entrepreneur-based Innovation

UNU-MERIT Dissertation Series,

№ 67

\section{Lenka Eisenhamerová}

Legitimacy of 'Humanitarian Military

Intervention'

MGSoG Dissertation Series, № 26

\section{Sonila Tomini}

Informal Payments for Health Care

Services in Albania

MGSoG Dissertation Series, № 25

\section{Jinjing Li}

Dynamic Microsimulation in Public Policy Evaluation

MGSoG Dissertation Series, № 24

Aziz Atamanov

Rural Nonfarm Employment and International Migration as

Alternatives to Agricultural

Employment: The Case of Kyrgyzstan

MGSoG Dissertation Series, № 23

\section{Frieda Vandeninden}

Poverty Alleviation: Aid and Social Pensions

MGSoG Dissertation Series, № 22

\section{Juliana Nyasha Tirivayi}

The Welfare Effects of Integrating

AIDS Treatment with Food Transfers:

Evidence from Zambia

MGSoG Dissertation Series, № 21 


\section{Agnieska Ewa Sowa}

Who's Left Behind? Social Dimensions of Health Transition and Utilization of Medical Care in Poland

MGSoG Dissertation Series, № 20

\section{Emmanaouil Sfakianakis}

The Role of Private Actors in the

Provision of Public Goods with

Applications to Infrastructure and

Financial Stability

MGSoG Dissertation Series, № 19

\section{Siu Hing Lo}

White Collars Green Sleeves: An Inter-

organizational Comparison of

Determinants of Energy-Related

Behaviors among Office Workers

MGSoG Dissertation Series, № 18

\section{Treena $\mathbf{W u}$}

Constraints to Human Capital

Investment in Developing Countries:

Using the Asian Financial Crisis in

Indonesia as a Natural Experiment

MGSoG Dissertation Series, № 17

\section{Henry Espinoza Peña}

Impact Evaluation of a Job-Training

Programme for Disadvantaged Youths:

The Case of Projoven

MGSoG Dissertation Series, № 16
2010

\section{Fernando Santiago}

Human Resources Management

Practices and Learning for Innovation in Developing Countries:

Pharmaceutical Firms in Mexico

UNU-MERIT Dissertation Series,

№ 66

\section{Zakaria Babutsidze}

Essays on Economies with

Heterogeneous Interacting Consumers

UNU-MERIT Dissertation Series,

№ 65

\section{Bertha Vallejo}

Learning and Innovation Under

Changing Market Conditions: The

Auto Parts Industry in Mexico

UNU-MERIT Dissertation Series,

№ 64

\section{Donatus Ayitey}

Technical Change, Competitiveness

and Poverty Reduction: A Study of the

Ghanaian Apparel Industry

UNU-MERIT Dissertation Series,

№ 63

\section{Sergey Filippov}

Multinational Subsidiary Evolution:

Corporate Change in New EU Member

States

UNU-MERIT Dissertation Series, № 62 


\section{Asel Doranova}

Technology Transfer and Learning under the Kyoto Regime: Exploring the Technological Impact of CDM Projects in Developing Countries

UNU-MERIT Dissertation Series, № 61

\section{Florian Tomini}

Between Family and Friend:

Understanding the Interdependency of

Private Transfers

MGSoG Dissertation Series, № 15

\section{Michał Polalowski}

The Institutional Transformation of Social Policy in East Central Europe: Poland and Hungary in Comparative and Historical Perspective

MGSoG Dissertation Series, № 14

\section{Maha Ahmed}

Defining, Measuring and Addressing Vulnerability: The Case of Post

Conflict Environments

MGSoG Dissertation Series, № 13

\section{Pascal Beckers}

Local Space and Economic Success:

The Role of Spatial Segregation of Migrants in the Netherlands

MGSoG Dissertation Series, № 12

\section{Victor Cebotari}

Conflicting Demands in Ethnically

Diverse Societies: Ethno political

Contention and Identity Values in Europe

MGSoG Dissertation Series, № 11

\section{Dennis Gyllensporre}

Competing and Complementary

Perspectives on the EU as a Crisis

Management Actor:

An Examination of the Common

Security and Defence Policy through the Lenses of Idealism and Realism

MGSoG Dissertation Series, № 10

\section{Judit Vall Castello}

Business Cycle and Policy Effects on Labour Market Transitions of Older and Disabled Workers in Spain

MGSoG Dissertation Series, № 9

\section{Keetie Roelen}

False Positives or Hidden Dimensions:

The Definition and Measurement of

Child Poverty

MGSoG Dissertation Series, № 8

\section{Denisa Maria Sologon}

Earning Dynamics in Europe

MGSoG Dissertation Series, № 7

\section{Melissa Siegel}

Money and Mobility: Migration and Remittances

MGSoG Dissertation Series, № 6

\section{Jessica S. Hagen-Zanker}

Modest Expectations: Causes and

Effects of Migration on Migrant

Households inSource Countries

MGSoG Dissertation Series, № 5 
Mirtha R. Muniz Castillo

\section{Alexis Habiyaremye}

From Primary Commodity Dependence to Diversification and Growth:

Absorptive Capacity and Technological Catch Up in Botswana and Mauritius. UNU-MERIT Dissertation Series, № 60

\section{Yoseph Getachew}

The Role of Public Capital in Economic Development

UNU-MERIT Dissertation Series, № 59

\section{Sandra Leitner}

Embodied Technological Change and Patterns of Investment in Austrian Manufacturing

UNU-MERIT Dissertation Series, № 58

\section{Semih Akçomak}

The Impact of Social Capital on

Economic and Social Outcomes

UNU-MERIT Dissertation Series, № 57

\section{Abraham Garcia}

The Role of Demand in Technical

Change

UNU-MERIT Dissertation Series, № 56

\section{Saurabh Arora}

Coherence in Socio-technical Systems:

A Network Perspective on the Innovation Process

UNU-MERIT Dissertation Series, № 55
Human Development and Autonomy in Project Aid: Experiences from four bilateral projects in Nicaragua and $\mathrm{El}$ Salvador

MGSoG Dissertation Series, № 4

Christiane Arndt

Governance Indicators

MGSoG Dissertation Series, № 3

\section{Britta Augsburg}

Microfinance: Greater Good or Lesser Evil?

MGSoG Dissertation Series, № 2

2008

\section{Rutger Daems}

Medicines for the Developing World UNU-MERIT Dissertation Series, № 54

\section{Johannes Hanel}

Assessing Induced Technology:

Sombart's Understanding of Technical

Change in the History of Economics UNU-MERIT Dissertation Series, № 53

\section{Rifka Weehuizen}

Mental Capital: the Economic Significance of Mental Health UNU-MERIT Dissertation Series, № 52 


\section{Danielle Cloodt}

The Relationship between RED

Partnership Formation, Social

Embeddedness and Innovative

Performance

UNU-MERIT Dissertation Series,

№ 51

\section{Sabine Fuss}

Sustainable Energy Development under Uncertainty

UNU-MERIT Dissertation Series, № 50

\section{Geranda Notten}

Measuring and Managing Poverty

Risks

MGSoG Dissertation Series, № 1

2007

\section{Tobias Kronenberg}

Reconciling Environmental

Conservation with Economic

Prosperity: The Feasibility of Double

Dividends in the Short and Long Run

UNU-MERIT Dissertation Series,

№ 49

\section{Viktoria Kravtsova}

Assessing the Impact of Foreign Direct Investment in Transition Economies UNU-MERIT Dissertation Series, № 48

\section{Suhail Sultan}

The Competitive Advantage of Small and Medium Sized Enterprises: The Case of Jordan's Natural Stone Industry

UNU-MERIT Dissertation Series, № 47

2006

\section{Bulat Sanditov}

Essays on Social Learning and Imitation

UNU-MERIT Dissertation Series, № 46

\section{Mamata Parhi}

Dynamics of New Technology Diffusion: A Study of the Indian Automotive Industry UNU-MERIT Dissertation Series, № 45

\section{Andreas Reinstaller}

Social Structures and the Innovation Process: Their Role in the Demand of Firms and Consumers

UNU-MERIT Dissertation Series, № 44

\section{Rose Kiggundu}

Innovation systems and Development: The Journey of a Beleaguered Nile Perch Fishery in Uganda UNU-MERIT Dissertation Series, № 43 


\section{Thomas Pogue}

The Evolution of Research

Collaboration in South African Gold

Mining: 1886-1933

UNU-MERIT Dissertation Series,

№ 42

\section{Geoffrey Gachino}

Foreign Direct Investment, Spillovers

and Innovation: The Case of Kenyan

Manufacturing Industry

UNU-MERIT Dissertation Series,

№ 41

\section{Önder Nomaler}

Technological Change, International

Trade and Growth: An Evolutionary,

Multi-Agents-Based Modeling

Approach

UNU-MERIT Dissertation Series,

№ 40

2005

Samia Satti Osman Mohamed-

Nour

Change and Skill Development in the Arab Gulf Countries

UNU-MERIT Dissertation Series, № 39

\section{Elad Harison}

Intellectual Property Rights:

Economics and Policy Analysis

UNU-MERIT Dissertation Series, № 38

\section{Daniel Dalohoun}

Learning to innovate: agricultural innovation and entrepreneurship: the case of Songhaï farmers in Benin UNU-MERIT Dissertation Series, № 37

\section{Müge Ozman}

Networks, Organizations and

Knowledge

UNU-MERIT Dissertation Series, № 36

\section{Bas Straathof}

Product Variety and Economic

Growth: The Counteracting Effects of

Scale and Idiosyncrasy

UNU-MERIT Dissertation Series, № 35

\section{Wilfred Schoenmakers}

Knowledge Flows between

Multinational Companies: A Patent

Data Analysis

UNU-MERIT Dissertation Series, № 34

\section{Myriam Cloodt}

Mergers and Acquisitions ( $M$ and As) in High-Tech Industries: Measuring the Post-M and A Innovative Performance of Companies UNU-MERIT Dissertation Series, № 33 


\section{Viki Sonntag}

Speed, Scale and Sustainability

\section{Paola Criscuolo}

$R \mathcal{E D}$ Internationalisation and

UNU-MERIT Dissertation Series,

№ 27

Knowledge Transfer: Impact on MNEs

and their Home Countries

Masaru Yarime

UNU-MERIT Dissertation Series,

№ 32

From End-of-Pipe Technology to Clean

Technology

UNU-MERIT Dissertation Series,

Maarten Verkerk

Trust and Power on the Shop Floor

UNU-MERIT Dissertation Series,

№ 31

Gottfried Leibbrandt

Adoption, Harmonization and

Succession of Network Technologies

across Countries

№ 26

Stéphane Malo

The Combinatorial Chemistry

Revolution: Sustaining a Superior

Performance Position through

Technological Learning

UNU-MERIT Dissertation Series,

№ 25

UNU-MERIT Dissertation Series,

№ 30

2002

\section{Mark Sanders}

Skill Biased Technical change: Its

Origins, the Interaction with the

Labour Market and Policy Implications

UNU-MERIT Dissertation Series,

№ 29

2003

Annelies Hogenbirk

Determinants of Inward Foreign

Direct Investment: the Case of the

Netherlands

UNU-MERIT Dissertation Series, № 24

\section{Bastiaan Johan terWeel}

The Computerization of the Labour Market

UNU-MERIT Dissertation Series

Inter-firm Cooperation in High-tech

Industries: a Study of RED

Partnerships in Pharmaceutical

Biotechnology

UNU-MERIT Dissertation Series,

№ 28 


\section{Marjolein Caniëls}

John Adeoti

Technology Investment in Pollution Control in Sub-Saharan Africa: The Case of the Nigerian Manufacturing Industry

UNU-MERIT Dissertation Series, № 23

\section{Edward Huizenga}

Innovation Management: How

Frontrunners Stay Ahead: An

Empirical Study on Key Success

Factors in the ICT sector

UNU-MERIT Dissertation Series,

№ 22

2000

\section{Machiel van Dijk}

Technological Change and the

Dynamics of Industries: Theoretical Issues and Empirical evidence from Dutch Manufacturing

UNU-MERIT Dissertation Series, № 21

1999

\section{Jan Cobbenhagen}

Managing Innovation at the Company Level: A Study on Non-Sector-Specific Success Factors

UNU-MERIT Dissertation Series, № 20
Regional Growth Differentials: The Impact of Locally Bounded Knowledge Spillovers

UNU-MERIT Dissertation Series, № 19

1998

\section{Aldo Geuna}

Resource Allocation and Knowledge production: Studies in the Economics of University Research

UNU-MERIT Dissertation Series, № 18

1996

\section{Reinoud Joosten}

Dynamics, Equilibria, and Values UNU-MERIT Dissertation Series, № 17

\section{Hugo Kruiniger}

Investment, $R \mathcal{E} D$, and the Financing Decisions of the Firm

UNU-MERIT Dissertation Series, № 16

\section{5}

\section{Hans van Meijl}

Endogenous Technological Change:

The Case of Information Technology, Theoretical Considerations and Empirical Results

UNU-MERIT Dissertation Series, № 15 


\section{René Kemp}

Environmental Policy and Technical

Change: A Comparison of the

Technological Impact of Policy

Instruments

UNU-MERIT Dissertation Series,

№ 14

\section{Rohini Acharya}

The Impact of New Technologies on Economic Growth and Trade: A Case Study of Biotechnology

UNU-MERIT Dissertation Series, № 13

\section{Geert Duysters}

The Evolution of Complex Industrial Systems: The Dynamics of Major IT Sectors

UNU-MERIT Dissertation Series, № 12

\section{Marjan Groen}

Technology, Work and Organisation: A Study of the Nursing Process in Intensive Care Units

UNU-MERIT Dissertation Series, № 11

1994

\section{Huub Meijers}

On the Diffusion of Technologies in a Vintage Framework: Theoretical Considerations and Empirical Results UNU-MERIT Dissertation Series, № 10

\section{Theon van Dijk}

The Limits of Patent Protection: Essays on the Economics of Intellectual

Property Rights

UNU-MERIT Dissertation Series, № 9

\section{Hans Voordijk}

Naar Integrale Logistiek in

Bedrijfsketens: Ontwikkelingen in de Bouw

UNU-MERIT Dissertation Series, № 8

1993

\section{Paul Diederen}

Technological Progress in Enterprises and Diffusion of Innovation:

Theoretical Reflections and Empirical Evidence

UNU-MERIT Dissertation Series, № 7

\section{Ben Dankbaar}

Economic Crisis and Institutional Change: The Crisis of Fordism from the Perspective of the Automobile Industry UNU-MERIT Dissertation Series, № 6

\section{Hanno Roberts}

Accountability and Responsibility: The Influence of Organisation Design on Management Accounting UNU-MERIT Dissertation Series, № 5 
1992

\section{Bart Verspagen}

Uneven Growth between

Interdependent Economies: An

Evolutionary View on Technology

Gaps, Trade and Growth

UNU-MERIT Dissertation Series,

№ 4

\section{Sjoerd Romme}

A Self-organization Perspective on

Strategy Formation

UNU-MERIT Dissertation Series,

№ 3

1989

John Spangenberg

Economies of Scale, and Atmosphere in

Research Organisations

UNU-MERIT Dissertation Series,

№ 2

1988

\section{John Hagedoorn}

Evolutionary and Heterodox

Innovation Analysis: A Study of

Industrial and Technological

Development in Process Control and

Information Technology

UNU-MERIT Dissertation Series,

№ 1 